$$
\text { , }
$$ 


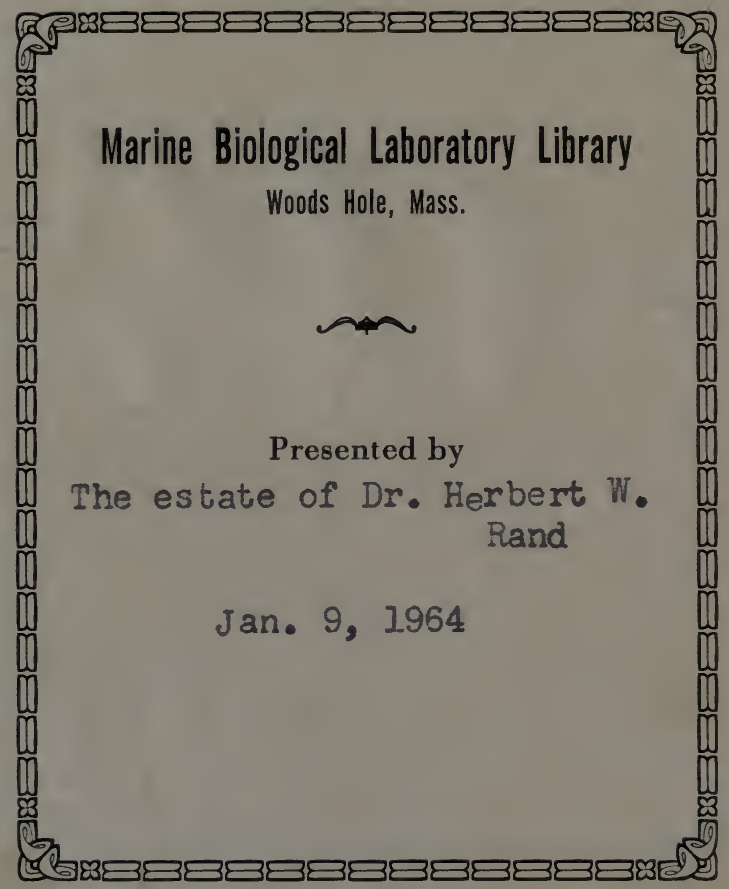


Terbur cakand zency. 1916. 


$$
\text { enthos an }
$$


THE MACMILLAN COMPANY NEW YORK - BOSTON - CHICAGO - DALLAS ATLANTA - SAN FRANCISCO

MACMILLAN \& CO., Limited LONDON · BOMBAY - CALCUTTA MELBOURNE

THE MACMILLAN CO. OF CANADA, LtD. TORONTO 


\section{MORPHOLOGY}

OF INVERTEBRATE TYPES

BY

ALEXANDER PETRUNKEVITCH, PH.D.

ASSISTANT PROFESSOR OF ZOÖLOGY IN THE SHEFFIELD SCIENTIFIC SCHOOL OF YAIE UNIVERSITY

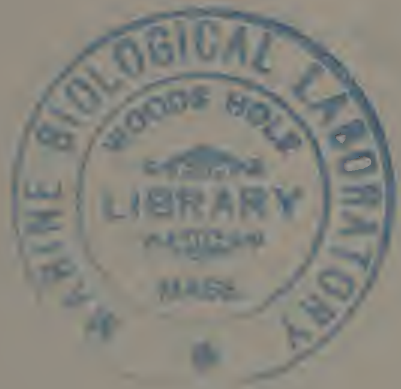

Nive Jark

THE MACMILLAN COMPANY

$$
\text { I9I6 }
$$

All rights reserved 


\section{COPYRIGHT, IgI6}

By THE MACMILLAN COMPANY By THE MACMILLAN COMPANY
Set up and electrotyped. Published July, Igr6. \\ (a)}

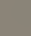




\section{PREFACE}

Owing to the rapid advance of Experimental Zoölogy, the older branches of morphological study such as Comparative Anatomy and Embryology, have been left in the background. In order to acquire familiarity with modern methods and problems, it became necessary to curtail the time allotted to Morphology. As a natural consequence the laboratory guides in general use in this country are more elementary than is desirable. The result has proved in many ways unsatisfactory. The student is left with only a superficial knowledge of the structure, life and development of those very animals which in his later studies he is going to use for experiments.

But the high tide in Experimental Zoölogy has been reached and passed. A general tendency to return to morphological studies is manifest in recent years in the great increase in the number of papers dwelling upon the anatomy of invertebrates. It seems, therefore, desirable to place in the hands of the student, a manual which will enable him to lay the foundation for a knowledge of invertebrate anatomy.

The usual method of teaching this subject consists in having the student dissect a series of types, but while doing this he is supposed to pay attention only to structures of a general character and to skip details. This method is open to grave criticism. Generalization should come as the result of extended observation. If we substitute generalization for observation, we do the student's work for him and defeat our own end. By this I do not mean to say that the student should be offered only a knowledge of minute facts and left to his own resources to sift the material and draw conclusions. On the contrary! The 
teacher should guide the student until the latter learns to distinguish important from trivial, generalized from specialized, and correlated from disconnected facts. Only in this way will the student learn scientific observation and inductive thought as opposed to mere statement of facts and random conclusions. But in order to accomplish this, the student should first of all learn to observe everything that can be observed from a thorough dissection with simple methods.

Accordingly the treatment of the subject of this manual differs somewhat from the usual. Each chapter consists of two parts: a monograph in which a description is given of the animal selected as representative of its class and instructions for the students to follow in dissection. The descriptions while short, are sufficiently detailed to include obvious structures of specific value. The monographs are based partly on work done by others, partly on my own dissections and investigations. To these latter are due some of the divergencies from generally accepted opinions as well as statements not to be found elsewhere in print. I have examined all important papers which have been published up to the present time and if I do not give any list of these it is: first, because the student has no need of them; second, because the teacher will know how to get at the sources; and, third, because a comprehensive list would make the book too long and in consequence, too expensive, while a partial list would be of no great value.

The instructions have been followed successfully by my students for two years, and have thus stood the test of the laboratory. The student is expected to read the descriptive part at home, the day before the exercise. The accompanying figures will help him to understand the subject. At the same time he will not be able to copy them in the laboratory instead of making original drawings from the specimen he dissects, for the simple reason that they either represent the structure of some other, though nearly related species, or are diagrammatic. Some of these figures are copies from other books; some are 
combination drawings or modified in one respect or another in accordance with my own ideas and dissections.

A few words of explanation are necessary in regard to the choice of material. I tried to use only American species but this proved difficult in the case of Trematodes and leeches. I have examined many species of Trematodes but none of them is comparable to the common, small, European liver fluke, Dicrocœlium lanceatum. This species does not occur in the Western Hemisphere, but it is a truly typical representative of its class and so common in Europe that it may be bought of foreign firms in unlimited quantities. The medicinal leech is for sale alive in this country and there is therefore no special advantage in giving preference to indigenous species which one would have to collect since they are not on the market. I tried also to avoid species which are usually studied in the Freshman year in the course in General Biology. Experience has shown me that the students resent repetition and surely there is no need for it. As long as the student is required to take General Biology or Elementary Zoölogy preparatory to Invertebrate Zoölogy, a diversity of material is of distinct advantage. An unfortunate exception had to be made in the case of the Earthworm, but I do not know of any convenient substitute. A concession to tradition had to be made in the case of the locust. In my opinion a roach is to be preferred, because it is easier to dissect and because it may be kept alive in winter; but private conversation with various colleagues has convinced me that it would not do to leave out the grasshopper. Some groups had to be omitted altogether on account of lack of space. If the book meets with favorable reception, new chapters may be added in a later edition.

The detailed descriptions in the manual of the anatomy of animals which the student is given to dissect, will relieve the teacher of the necessity of lecturing on this subject. His time may be better spent in giving a general account of the group to which each animal belongs and in treating broader aspects 
viii

\section{PREFACE}

of the problems involved in the study of Morphology. The whole aim of the teacher should be to attain a perfect balance between laboratory work and lectures, for the one teaches methods, the other, results.

Alexander Petrunkevitch.

New Haven, Conn.

May, I9i6. 


\section{TABLE OF CONTENTS}

PAGE

Preface . . . . . . . . .

Table of Magnifications .................. xi

LIST OF THINGS TO BE FURNISHED BY THE LABORATORY . . . . . . . xii

List of things to be furnished by the StUdent....... xiii

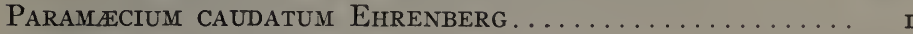

Grantia ciliata Fabricius. . . . . . . . . . . . . . . io

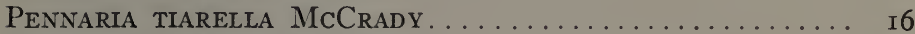

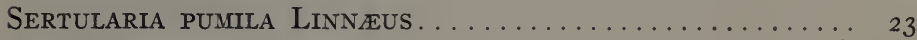

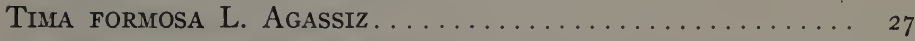

Gonionemus murbachil Mayer................ 33

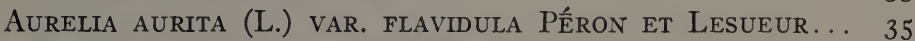

Metridium marginatum Milne-Edwards........... 45

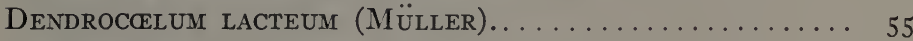

Dicroccelium lanceatum Stiles and Hassall ......... $6_{2}$

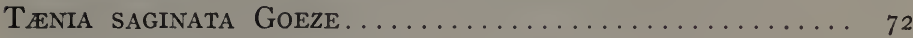

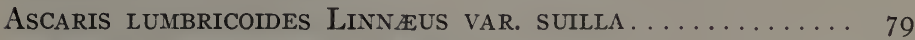

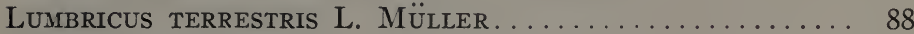

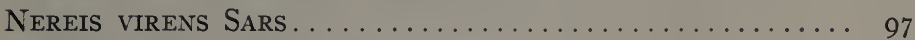

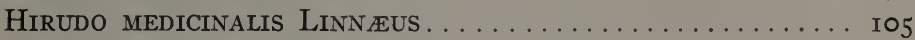

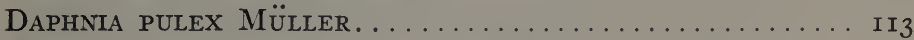

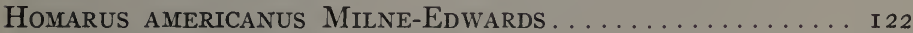

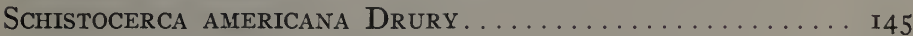

Agelena nevia Walckener................. I 58

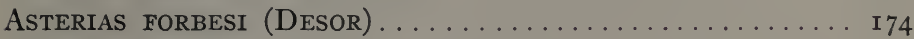

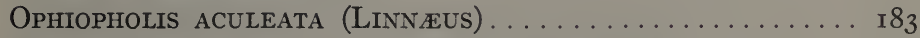

Pentacrinus asteria (CAPUtmedus $\approx$ ) (MUller) . . . . . . I 89

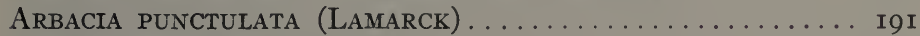

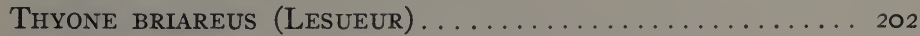

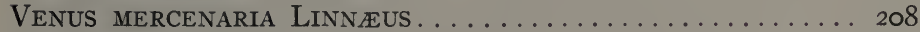

LimaX MaXimus Linneus..................... 220

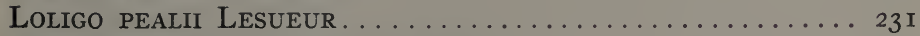

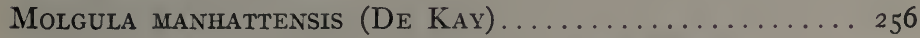

ix 



\title{
TABLE OF MAGNIFICATIONS
}

\author{
Bausch and Lomb Optical Co.
}

Objective

Eyepiece

Spencer Lens Co.

Objective

Eyepiece

I6 $\mathrm{mm} .(2 / 3)$

$8 \mathrm{~mm} \cdot(\mathrm{x} / 3)$

$4 \mathrm{~mm} .(\mathrm{x} / 6)$

$\begin{array}{rr}5 \times & \text { IO X } \\ 50 \times & \text { I00 X } \\ 100 X & 200 \times \\ 2 \text { I } 5 \times & 430 \times\end{array}$

\section{ERNST LEITZ}

Objective

Eyepiece

I6 $\mathrm{mm}$.

$8 \mathrm{~mm}$.

$4 \mathrm{~mm}$.

$\begin{array}{rr}4 \mathrm{X} & 8 \mathrm{x} \\ 50 \mathrm{x} & 75 \mathrm{x} \\ \mathrm{I} 25 \mathrm{X} & 210 \mathrm{x} \\ 2 \text { IO X } & 465 \mathrm{x}\end{array}$

$\begin{array}{lrr} & \text { I } & \text { IV } \\ 3(\text { I6.2 mm.) } & 5 \text { I X } & \text { IO3 } \\ 4 \text { (I0.0 mm.) } & 9 \text { I X } & \text { I82 } \\ 6 \text { (4.0 mm.) } & 240 \mathrm{x} & 460\end{array}$




\section{A LIST OF THINGS TO BE FURNISHED BY THE LABORATORY FOR EVERY STUDENT}

I. Microscope. Stand with rack and pinion, micrometer screw, mirror, substage with Abbe Condenser and Iris diaphragm, triple revolving nosepiece. Objectives $16 \mathrm{~mm}$. ( $2 / 3$ inch), $8 \mathrm{~mm}$. ( $\mathrm{x} / 3$ inch), and $4 \mathrm{~mm}$. ( $1 / 6$ inch); Huýghenian eyepieces of the magnifying power of 5 and ro $x$.

2. Dissecting microscope; stand and one lens of to diameter magnification.

3. Dissecting tray, round, about 6 or 7 inches in diameter.

4. Dissecting tray, rectangular, Io $\mathrm{x}$ I6 inches.

5. Syracuse dish.

6. Stender dish, $25 \mathrm{~mm}$. high, $50 \mathrm{~mm}$. in diameter.

7. Finger bowl.

8. Watch glass.

9. Two pipettes.

I0. One dozen pig's bristles.

II. Stiff, black horsehair (from horse's tail).

I2. Filter paper.

I3. Lens paper.

I4. Reagents: $10 \%$ ether in water; $20 \%$ solution of caustic potash; quince seed jelly; Methylgreen saturated in $\mathrm{r} \%$ acetic; hydrochloric acid.

I5. Prepared slides and specimens for dissection. 


\section{A LIST OF THINGS WHICH THE STUDENT HIMSELF SHOULD PROVIDE AND KEEP IN THE LABORA- TORY}

I. Loose leaf notebook $8 \times$ Io $\% / 2$ inches, with white drawing paper.

2. Ruler with inch-centimeter scale.

3. Divider.

4. Soft pencil.

5. Hard pencil.

6. Set of colored pencils.

7. Eraser.

8. Dissecting instruments: large scissors with one blunt end, fine scissors, two handles for needles, sewing needles, two forceps, spatula, tube for blowing into organs, razor.

9. One package of pins.

ro. Slides.

Ir. Cover glasses.

I2. A hard tooth brush.

13. A towel. 



\section{MORPHOLOGY OF INVERTEBRATE TYPES}





\section{MORPHOLOGY OF INVERTEBRATE TYPES}

\section{PARAMACIUM CAUDATUM Ehrenberg}

Material. Paramæcium caudatum may be obtained easily in immense quantities from hay infusions inoculated a few days before the exercise. Fixation, staining and washing may be accomplished without difficulty by the use of a centrifuge. The stained specimens are then transferred gradually into $95 \%$ alcohol, picked up with a fine pipette and squirted onto a slide covered with a thin layer of glycerine-albumen. The slide may be finished in the usual manner. Live Protozoa are found in any aquarium prepared for the purpose some two weeks in advance. It is advisable to use mud from the bottom of various pools and to put it into separate dishes. I have obtained excellent cultures of Amœba several times from infusions of horse manure.

Every student should receive a small aquarium with live Protozoa, a small flask with hay infusion containing Paramæcium, and prepared slides of Paramæcium stained in Iron Hæmatoxylin.

\section{Descriptive Part}

Paramæcium caudatum is one of the best known Protozoa and occurs all over the world in fresh water pools. It belongs to the Class Ciliata characterized by the presence of cilia which function as organs of locomotion. Compared with an Amœba, Paramæcium is a highly differentiated creature. Yet it has none of the organs characteristic of higher animals. Its 
body consists of a single cell which has therefore to perform within itself the various functions of life, such as nutrition, sensation and reproduction. Nature has assigned these functions to various parts of the cell, which may be compared with organs of multicellular animals. One must bear in mind, however, that no homology exists between cell-parts and organs, and that even the analogy is quite superficial. It is advisable, therefore, to use the term organellum in treating the structures of unicellular organisms and to speak of sensory, nutritive, protective, reproductive and other organella.

The body of Paramæcium is asymmetrical, i. e., it cannot be divided into two like parts. The anterior end is wider and more blunt than the posterior one. Paramæcium appears almost round in a cross-section, yet there is a distinct difference between two surfaces one of which may be regarded as dorsal and the other as ventral. The latter is characterized by the presence of a large depression or peristome which extends from the anterior end to somewhat beyond the middle of the body and is as wide as half the width of the animal. At the bottom of the peristome is the mouth or cytostome which leads into a short, curved cytopharynx with an undulating membrane. Halfway between the lower end of the latter and the posterior end of the body is a small opening functioning as an anus and called cytopyge. There are two pulsating vacuoles, one about onequarter of the entire length from the anterior end, the other about the same distance from the posterior end of the animal. In about the middle of the body is a large macronucleus and a small micromucleus.

Protoplasmic structures. The protoplasm of Paramæcium shows the characteristic differentiation into ectoplasm and endoplasm. The latter is devoid of particular structures. It has a finely granulated appearance and contains food-vacuoles with food in various stages of digestion, and the two nuclei. The ectoplasm, on the other hand, presents many structures and is subdivided into three layers: pellicula, alveolar layer and 


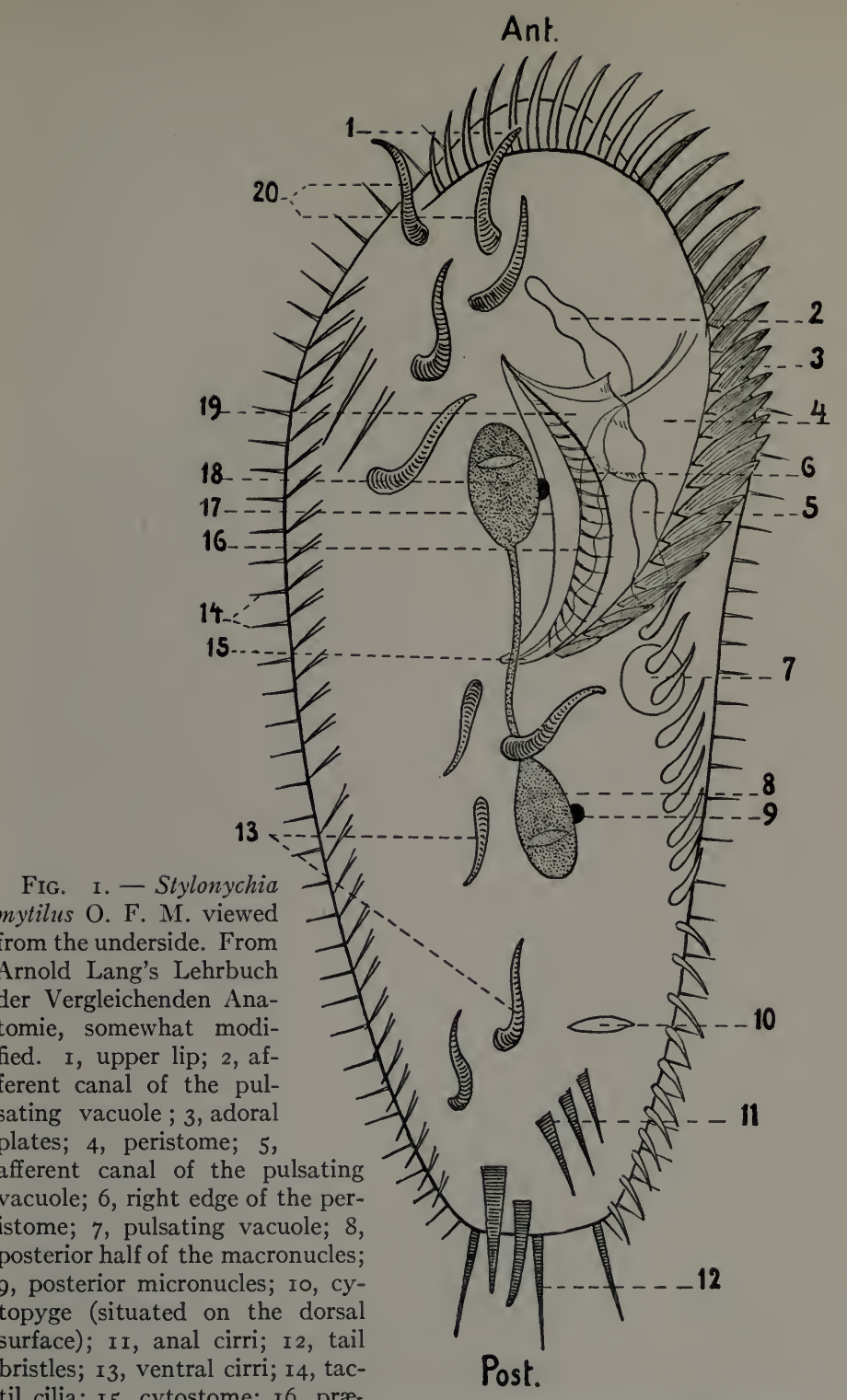

til cilia; I5, cytostome; I6, præ-

oral row of cilia; 17 , right wall of peristome; 18 , anterior half of macronucleus; 19 , undulating membrane; 20 , frontal cirri. 
cortical layer. The pellicula is a thin elastic membrane covering the entire body. It has a distinctly striated appearance due to the fact that the surface is divided into small hexagonal fields separated from each other by ridges. From the center of each field arises a long cilium. Under the base of the cilium is a motor center in the shape of a small grain from which a fibre runs toward the endoplasm. The rhythmic beating of the cilia produces a pressure on the water and propels the animal in a wide spiral course. At the posterior end of the body are several immobile cilia probably with tactile function. In the angles formed by the ridges of the pellicula as well as in the middle of some ridges are the insertion points of the trichocyst ends. The alveolar layer is situated immediately under the pellicula and consists of a single layer of alveoli with walls at right angles to the surface. The innermost layer of the ectoplasm is the cortical layer which contains the trichocysts and the pulsating vacuols. The trichocysts are protective organella. They are present in immense numbers and have the shape of small spindles with a thickened end directed toward the surface and a rod-like process inserted in the ridges of the pellicula, as described above. When the animal is irritated the trichocysts "explode" and appear as long and thin threads acting as harpoons. The Pulsating or contractile vacuoles are excretory organella. They consist of a central collecting vacuole and from seven to ten afferent vacuoles. The central vacuole is distended to its limit when the afferent vacuoles are contracted and is in systole when the afferent vacuoles are in diastole. The afferent vacuoles empty their content into the central vacuole which in its turn empties the fluid to the outside through a small excretory pore situated in the pellicula over the center of the vacuole.

We have seen already that the mouth or cytostome is situated at the bottom of the peristome and leads into a short, curved cytopharynx. The undulating membrane which is attached to the wall of the cytopharynx is in continuous motion, drawing food particles toward the posterior end of the cytopharynx where the 
latter ends in the endoplasm. A food vacuole is formed around the food thus drawn in. It detaches itself from the end of the cytopharynx and moves through the endoplasma first downward, then upward and again downward. During this cyclosis or travelling through the endoplasma the food particle is digested and at the end of the process the waste matter is emptied through the cytopyge.

Reproduction. Asexual reproduction is the usual method and consists in a transverse division. This is initiated by changes in the micronucleus which is essentially a reproductive organellum. It becomes elongated and its chromatic substance shows an arrangement similar to that in mitosis of cells in higher animals, yet without the presence of a centrosome. The cytostome, too, becomes elongated and compressed in the middle to the shape of a narrow slit. The cytopharynx produces posteriorly a new cytopharynx. Two new pulsating vacuols are formed so that each daughter individual will receive an old and a new vacuole. Next the macronucleus becomes also elongated. A constriction appears in the middle of the animal which at this stage of its life is almost twice as long as usual. Finally both nuclei divide in two, their division is followed by a division of the protoplasm and the two halves of the original Paramæcium become independent individuals. Each is provided with all necessary organella, assumes the shape of a normal Paramæcium and is soon ready to divide again. Such transverse division may go on for from 80 to Ioo generations, but sooner or later a reorganization of the nuclear apparatus has to take place in order that the race should not die out. This is accomplished by a process recently discovered by Woodruff. The micronucleus divides twice. Three of the four micronuclei thus formed disintegrate and are resorbed by the protoplasm. The fourth micronucleus alone persists. The macronucleus which is essentially a vegetative nucleus, breaks up and is also resorbed by the protoplasm. A new macronucleus is formed from the micronucleus in a way similar to that in conjugation. 
Sexual reproduction consists in conjugation. In this process the reorganization of the nuclear apparatus is combined with amphimixis. Two individuals approach each other and bring their ventral (oral) surfaces into close contact. The macronuclei remain for a while undisturbed, but later show signs of degeneration. After the separation of the conjugants they break up into small parts which are gradually resorbed by the protoplasm. The micronuclei, on the other hand, play the chief rôle in conjugation. They divide in both individuals twice in succession. Of the four micronuclei thus formed, three disintegrate and are resorbed by the protoplasm. The fourth micronucleus of each conjugant divides into a stationary or female nucleus and a migrating or male mucleus. The latter leaves the individual in which it was formed and enters the other conjugant. Here it fuses with the stationary nucleus forming a synkarion. When both individuals have exchanged their migrating nuclei and formed synkaria, conjugation is finished. The individuals separate, but their nuclear apparatus is not normal. Now the reconstruction of the macronucleus begins. The synkarion divides three times in succession giving rise to eight nuclei. Three of these nuclei disintegrate and are resorbed by the protoplasm, one assumes the shape and function of the micronucleus, while the remaining four grow and change eventually into macronuclei. The exconjugant is now ready for a new division. First the micronucleus divides in two; then two of the four future macronuclei pass to the one end, and two to the other end of the dividing Paramæcium. When the division is completed each daughter cell has one micronucleus and two macronuclei. Yet another division must take place. The micronucleus divides again while of the two macronuclei one passes to one end and the other to the other end of the animal. Thus the balance of nuclei is restored in the third generation and each individual is now in possession of a single micronucleus and a single macronucleus. 


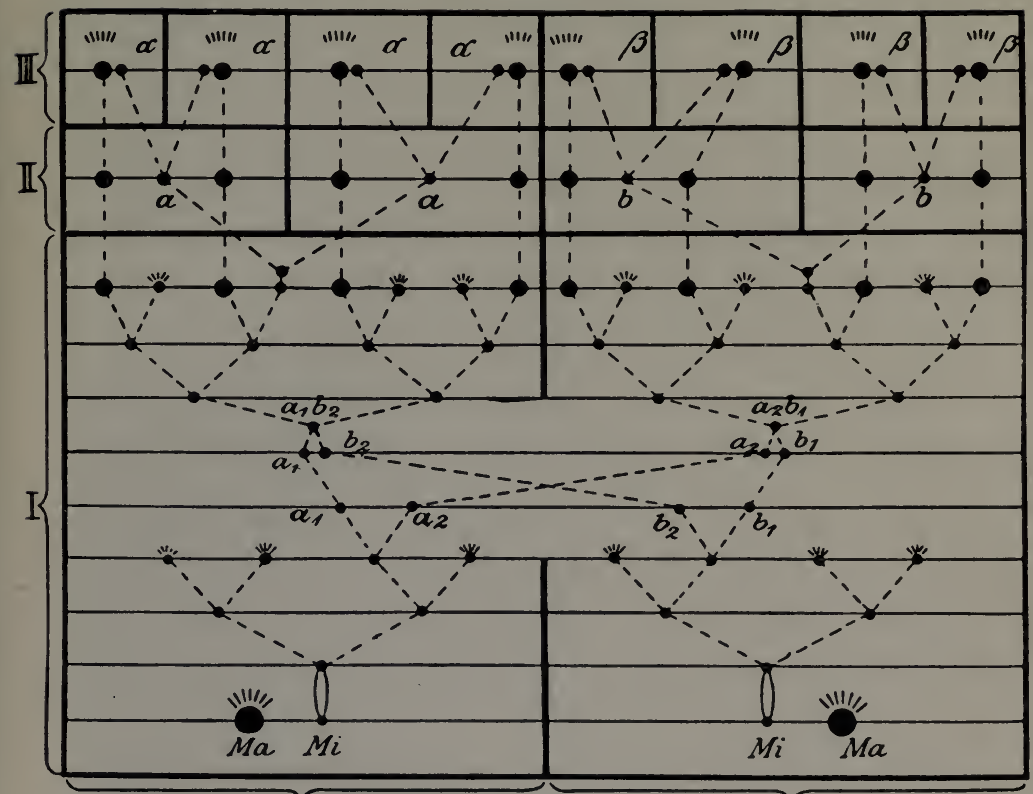

FIG. 2. - Diagram representing the various stages in the process of conjugation and of the following reconstruction of the macronucleus in Paramæcium. From Arnold Lang's Lehrbuch der Vergleichenden Anatomie. Ma, macronucleus of the conjugant; $M i$, micronucleus of the conjugant; $a^{1}, b^{1}$, stationary micronuclei; $a_{2}, b_{2}$, migrating micronuclei; $a_{1} b_{2}, a_{2} b_{1}$, synkarion; I, the two conjugants $A$ and $B$; II, the four individuals of the second generation produced by the transverse division of the exconjugants; III, the eight individuals of the third generation, each with a single macronucleus and micronucleus; the crown indicates the disintegration of the corresponding nucleus.

\section{Instructions}

I. Put a small drop of hay infusion containing live Paramæcia on a slide, add a small drop of quince seed jelly, cover with a cover glass and examine under low power (roo diameters). When the animals have quieted down examine a paramæcium under higher power (200 diameters) and make a drawing showing outline of body, peristome, cilia, pulsating vacuoles, food 
particles, macronucleus. Label anterior and posterior end, dorsal and ventral surface.

2. Find under low power a specimen in the process of division. Examine it at 200 diameters and make a drawing showing as many structures as are visible.

3. If possible, try to find a couple of Paramæcia in conjugation and make a drawing of them.

4. Take another drop of the same infusion, put a drop of the methylgreen solution in $\mathrm{I} \%$ acetic acid on a cover glass, turn the cover glass over, so that the drop will be suspended from the underside and allow the cover glass to drop suddenly on the drop of hay infusion from a height of about one inch. This will fix the animals and stain the nucleus after a while. Examine under high power (400 diameters) and make a drawing showing all structures brought out by the stain.

5. Examine the prepared slide under high power (400 diameters) and make a drawing showing trichocysts, macronucleus and, if visible, micronucleus.

6. Examine the prepared slide with Paramæcia in division under high power (400 diameters) and make a drawing of it.

7. Examine the prepared slide of Paramæcia in conjugation under high power (400 diameters) and make a drawing of it.

8. Additional exercise. Place a drop of water from the side of an aquarium on a slide, add a small drop of quince seed jelly, cover with a cover glass and examine under low power (roo diameters). Find as many species of Protozoa as possible, examine them one after the other under high power (400 diameters), identify them with the aid of a proper book and make drawings. Label Class and Order to which the species belongs.

9. Additional exercise. Take a drop of water from the bottom of the aquarium with some sediment and do as in the preceding exercise.

Io. Additional exercise. Cut off with fine scissors the head and the last abdominal segment of a mealworm (larva of a beetle, Tenebrio molitor). Take the end of the protruding alimentary 
canal firmly with a forceps and pull it out. Place it on a slide and squeeze out the contents. Remove the alimentary canal, cover the drop with a cover glass and examine under low power. Find two associated individuals of the mealworm gregarine and make a drawing of them. Label protomerite, deuteromerite with the nucleus, exoplasma and endoplasma.

I I. Additional exercise. Examine a prepared slide with a stained transverse section through an earthworm in the region of the sexual organs. Find as many stages of the gregarines as possible and make drawings of them. One may count on finding encysted individuals in stages of sporogony and spores of the second generation with eight sporozoits in each.

I2. Additional exercise. Examine a prepared slide with transverse sections through the alimentary canal of the centipede Lithobius and find as many stages of the coccidium as possible. Stages of schizogony, macrogametocytes and microgametocytes may be found in the intestinal endothelial cells, cysts in the lumen of the intestine. 


\section{GRANTIA CILIATA Fabricius}

Material. Grantia ciliata is very common on the Atlantic Coast. It is found in shallow water just below the low tide mark. Specimens intended for general study as well as for sections showing the arrangement of spicules, should be preserved in alcohol. Specimens intended for microscopic study must be preserved in a special manner. The best method is that of Minchin. It consists in preserving the specimens in the place where they are collected. The collector should take with him a I\% aqueous solution of osmic acid, distilled water and Ranvier's picrocarmin. As soon as the specimens have been brought to the surface they must be plunged into a mixture of equal parts of osmic acid and sea water. After five minutes the specimens must be washed in several changes of distilled water and allowed then to remain for two hours in picrocarmin. They are then ready to be washed again in distilled water and to be transferred into alcohol. Before imbedding the specimens must be decalcified by any one of the usual methods. The sections may be stained for five minutes in a solution composed of one part of $\mathrm{r} \%$ aqueous solution of nigrosin and nine parts of a saturated aqueous solution of picric acid. Every student should receive for study one alcoholic specimen and the following four prepared slides: a transverse section through an alcoholic specimen, not stained; spicules isolated by boiling in a solution of potassium hydrate; a transverse section through a decalcified specimen preserved by the method of Minchin; a tangential longitudinal section through a similar specimen.

\section{Descriptive Part}

Grantia ciliata is a common representative of the Phylum Porifera and belongs to the group of calcareous sponges. Unlike 
FIg. 3. - Transverse section through Sycon gelatinosum from Parker \& Haswell, Textbook of Zoölogy. IC, incurrent canal; $R$, radial tube (flagellated chamber); $s p$, triradiate spicules; $s p^{\prime}$, spicules of cortex; $d c$, cortex; $s p^{\prime \prime}$, triradial spicules of atrium; $e c$, ectoderm; $e n$, endoderm; $p m$, external incurrent pore; $p p$, prosopyle; $a p$, apopyle; $d i$, diaphragm; exc, excurrent passage; $P$. G., atrium; em, early embryo; $\mathrm{em}^{\prime}$, late embryo.

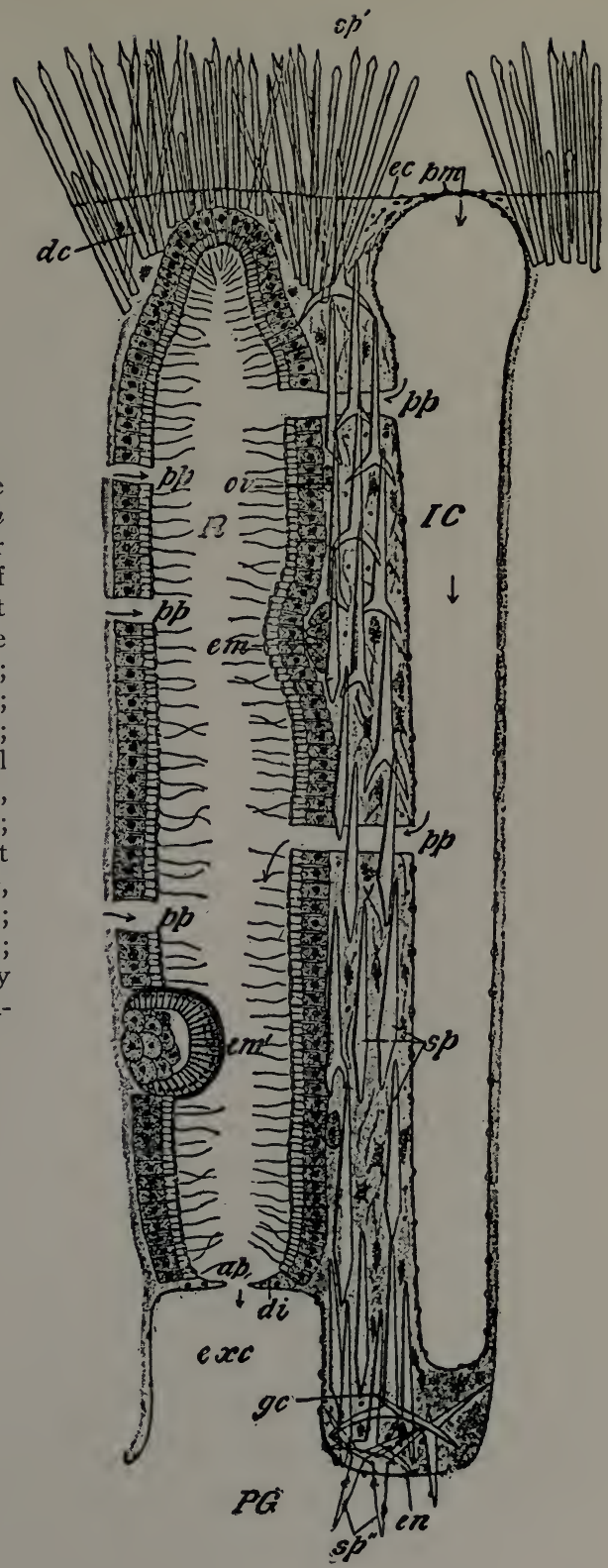


the majority of sponges it is not a colonial form, so that individuals produced by budding are connected with the mother individual only at the base. It is devoid of locomotion and remains throughout its life attached to the surface of the rock or pile on which it grows. A great number of calcareous spicules support the soft tissues and play the rôle of a primitive skeleton.

General anatomy. Grantia ciliata has more or less the shape of a hollow cylinder with a blind base. It is built on the principle of radial symmetry. The free end terminates in a wide opening or osculum surrounded by a crown of long oscular spicules. Smaller cortical spicules cover the whole surface of the sponge like bristles of a brush. More or less concealed by them are numerous small external pores which lead into the so-called incurrent canals. These canals are arranged radially to the longitudinal axis of the sponge. They end blindly and do not reach the central cavity. This cavity is called the atrium. The surface of the wall, which faces the atrium is also perforated by numerous, regularly arranged pores called apopyles. They lead into radial tubes, which are arranged similarly to the incurrent canals, i.e., radially to the longitudinal axis of the sponge. They too, end blindly, but at the end opposite to the blind end of the incurrent canals, under the so-called cortex or a layer of tissue underlying the external surface of the sponge. The incurrent canals communicate with the radial tubes by means of numerous pores or prosopyles. Water containing food in the shape of minute animal and plant life is drawn into the incurrent canals through the external pores by the motion of the flagella of the cells lining the radial tubes. From the incurrent canals it passes into the radial tubes through the prosopyles, from the radial tubes into the atrium through the apopyles and is finally thrown out of the body through the osculum. Thus the acts of respiration and nutrition are accomplished at the same time. Respiration and digestion take place in the radial tubes.

Miscroscopic anatomy. The walls of the sponge are composed of three distinct layers of cells: ectoderm, mesenchyme 
and endoderm. The mesenchyme is often called mesoderm, but since it has not the same origin as the mesoderm of higher animals, the term mesenchyme is preferable.

Ectoderm. The outside covering of the walls of the sponge and the lining of the incurrent canals is formed by a single layer of ectodermal cells. These cells are polygonal in shape, quite flat and belong to the type of pavemental epithelium. In the incurrent canals larger cells are found scattered irregularly among the common ectodermal cells. These larger cells are perforated and are therefore called porocytes. The pore of a porocyte is nothing but a prosopyle which has already been mentioned.

Endoderm. The lining of the atrium as well as of the radial tubes is formed by a single layer of endodermal cells. These belong to two different types. The cells lining the atrium look very much like the ectodermal cells and belong to the same type although they are of different origin. The cells lining the radial tubes are called collar cells or choanocytes. They are long, with a collar at their inner edge and a long flagellum protruding far into the hollow space of the tube. Owing to these cells the radial tubes have been also termed the "flagellated chambers."

Mesenchyme. The mesenchyme is a gelatinous substance or mesoglcea containing cells and spicules. It fills out the space between the incurrent canals and the radial tubes and forms the cortex under the ectodermal layer on the surface of the sponge. Some of the cells found in the mesoglœa look like common connective cells with several processes and are called collencytes. Others assume the shape of long spindles and, being contractile, function as muscles. Such cells are found surrounding the apopyles and the osculum where they form a real sphincter. Some cells have the ability of amœboid motion and are called amcbocytes. Still other cells are said to have nervous function. All these various types of cells are supposed to be modified collencytes. Another type of cells found in the mesoglœa are the more or less round scleroblasts or cells produc- 
ing spicules. The spicules in Grantia belong to two types. The oscular spicules and the spicules imbedded in the cortex have the shape of longer or shorter needles. Every needle is produced as a calcareous secretion of a single scleroblast. The spicules found in the mesoglœa between the radial tubes and the incurrent canals are composed of three radii. These triradial spicules are so situated in the wall of the sponge that one of the three rays coincides with a radius and points toward the surface of the sponge. Every triradial spicule is produced as a calcareous secretion of three scleroblasts.

Reproduction. Asexual reproduction consists in the formation of a bud near the base of the sponge. The bud grows and soon an osculum appears at its free end. In this way loosely connected colonies of several individuals may be formed. Sexual reproduction is preceded by the formation of eggs and sperm cells. Both are modified amœbocytes. In the case of the egg it is a considerably grown and rounded up amœbocyte. In the case of the sperm an amœbocyte is first transformed into a so-called spermatogonial cell from which a number of spermatozoa develop. The fertilized egg remains for a long time in the mesoglœa under the endoderm of the radial tubes. It develops gradually into a ciliated larva or amphiblastula and escapes by way of a radial tube and the osculum. The larva attaches itself with the blastopore end to a suitable surface. Later the osculum breaks through at the pole opposite to the blastopore.

\section{Instructions}

I. Place an alcoholic specimen in a shallow dish with water and examine under the dissecting microscope. Make a quarter page drawing showing general shape, oscular spicules, and cortical spicules covering the surface.

2. Cut the specimen longitudinally into two symmetric halves. Use for that purpose a razor. Again examine the specimen under dissecting microscope, but this time the cut 
surface. Make a half page drawing showing the osculum with its spicules, atrium, apopyles or pores in the wall of the atrium, and the radial tubes and incurrent canals in the cut surface of the wall.

3. Examine under low power ( 50 diameters) a prepared slide with a cross-section through Grantia showing the arrangement of spicules. Make a half page drawing showing four of the radial tubes indicated by the rows of spicules.

4. Examine under microscope (200 diameters) a prepared slide of isolated spicules. Make a drawing of a triradial spicule and of shorter and longer needle-like spicules.

5. Examine under low power (Ioo diameters) a stained crosssection. Make a half page drawing showing four radial tubes. Label external pore, incurrent canal, radial tube, and apopyle.

6. Examine the same section under high power (400 diameters). Find a place with an embryo. Make a drawing showing the three layers of cells; label choanocytes (collar cells), ectoderm, mesenchyme, and embryo. If possible, find and show on the drawing a prosopyle.

7. Examine under low power (200 diameters) a stained tangential section. Determine which rings represent the crosssections of radial tubes by the shape of the cells facing the center of the ring. In doing so, remember that the radial tubes are lined with endodermic choanocytes (collar cells), while the incurrent canals have flat ectodermal cells. Make a half page drawing showing several of the tubes and canals and label them.

8. Additional exercise. Boil an alcoholic specimen in a test tube containing a solution of potassium hydrate. When all the tissues are dissolved, allow the spicules to settle, carefully pour off the liquid and wash the spicules twice in clean water. Pick up a number of spicules by means of a pipette and transfer them on to a slide. Place them under the microscope and focus. Add now a small drop of a ro\% solution of hydrochloric acid and observe how the spicules dissolve with the formation of small gas bubbles, proving their calcareous nature. 


\section{PENNARIA TIARELLA McCrady}

Material. P. tiarella is very common along the Atlantic Coast. Medusæ may be preserved in either osmic acid or formalin. Polyp colonies may be preserved by any one of the various methods proposed for the fixation of cœlenterata. The student should receive a colony of polyps, a specimen of medusa, a ready made slide of a polyp, stained and somewhat compressed, and a cross-section through a polyp and one through the stem.

\section{Descriptive Part}

Pennaria tiarella is a typical representative of the class Hydrozoa and has a complete alternation of generations or metagenesis. The polyp is gymnoblastic, i.e., neither the polyps themselves, nor the medusa buds are protected by a covering of the so-called perisarc.

Hydrosome or polyp colony. The colony is attached to the surface on which it grows, by root-like processes-the hydrorhiza. From the hydrorhyza runs a more or less straight stem or hydrocaulus with many alternating side branches which in turn give rise to simple or slightly branched ramuli. The perisarc or the membrane covering of the colony forms ringlets on the stem beyond every branch and at the base of every ramulus and ends at the base of every polyp or hydranth. The original and therefore oldest hydranth of the colony is the one at the top of the main stem. The next oldest hydranth is at the end of the branch nearest to the hydrorhiza. The youngest hydranth of the main stem is always the one nearest the top

Fig. 4. - Obelia sp. from Parker \& Haswell's Textbook of Zoölogy. $A$, portion of a colony with certain parts shown in longitudinal section; $B$, medusa; $C$, the same with reversed umbrella; $D$, the same, oral aspect; $B d .1,2$, buds; bls, blastostyle; coe, coenosarc; ect, ectoderm; end, endoderm; 


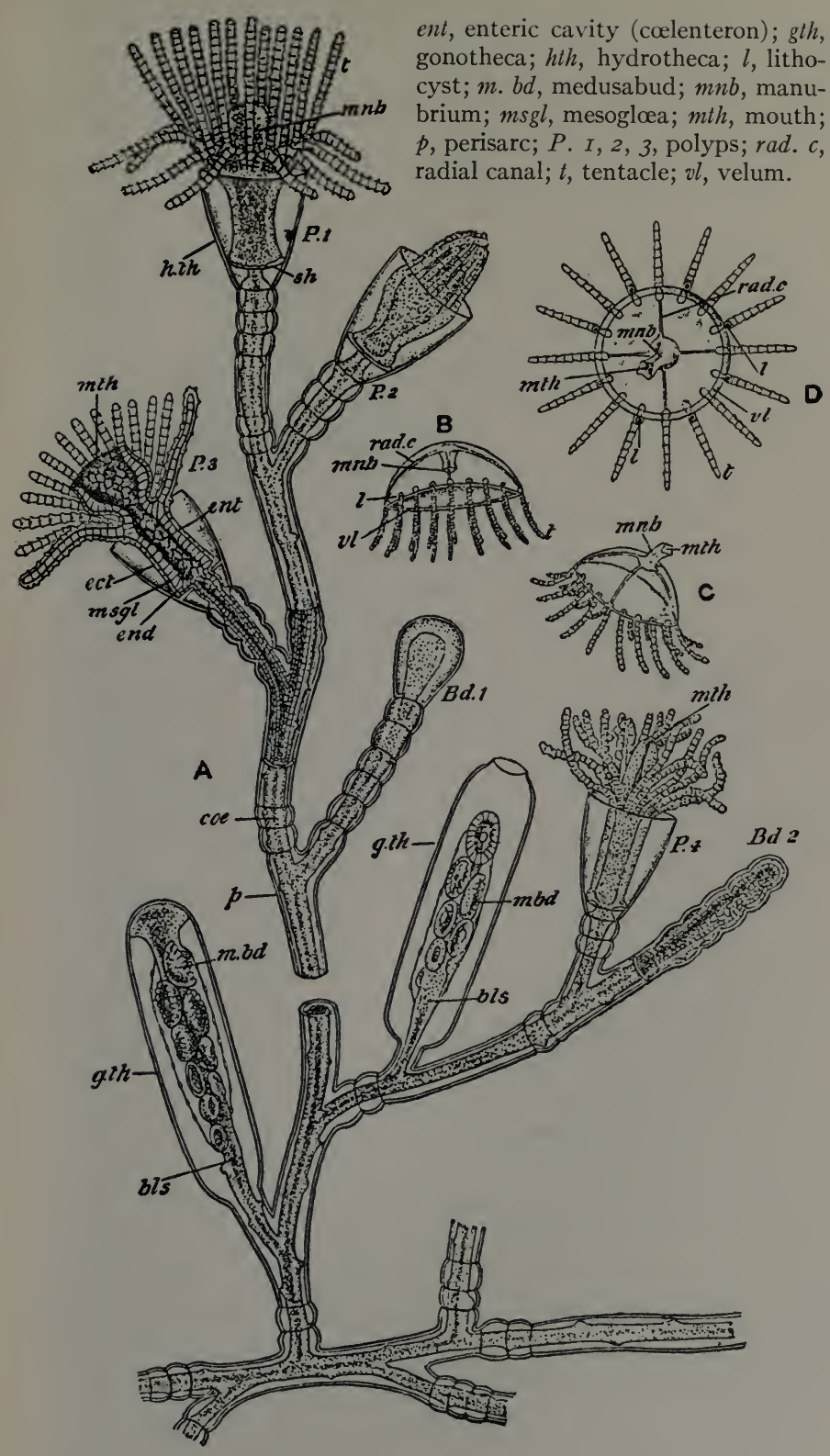


hydranth and the same is true for every branch. The reason for it lies in the monopodial method of branching. The original or founder-polyp becomes elongated at its base, producing the first or main stem. As the main stem grows in length the first bud appears near its base. This bud becomes the end polyp of the first or oldest branch. The main stem continues to grow and produces a second bud between the first branch and the top polyp, then a third bud and so on. The same process applies to the branches. The main stem with its root and branches is hollow and this cavity is naturally in direct continuation with the cavity of every hydranth. This cavity is the colenteron or gastro-vascular cavity. The hydranth consists of a short stem or peduncle and a flask-shaped head. The mouth is at the end of a conical hypostome. At the base of the hypostome are two or three verticels, each composed of from 5 to 7 short oral tentacles. These tentacles terminate in a knob of nematocysts. Near the base of the head is a circle of from I 2 to I6 long basal tentacles with nematocysts arranged in little groups along each tentacle. Each group of nematocysts appears as a little swelling of the tentacle. All tentacles are solid (not hollow). The medusa buds appear on the head, between the oral and basal tentacles. They become either free-swimming medusæ or remain rudimentary and sessile.

Microscopic structure. The walls of the hydrocaulus or stem, of the branches, and of the hydrorhyza are known under the name of cenosarc and are composed of three concentric layers. The outer layer secreting the perisarc is the ectoderm. It is composed of "indifferent" epithelial cells. Some of these cells in the hydrorhyza are modified into adhesive cells. The middle layer has the appearance of a thin membrane. It is a structureless, non-cellular mesoglcea. The inner layer is the endoderm and is composed of so-called circulatory endodermal cells. The walls of the hydranth are composed of the same three layers and here, too, the mesoglœa remains structureless. But the elements which enter into the formation of the ecto and endoderm are 


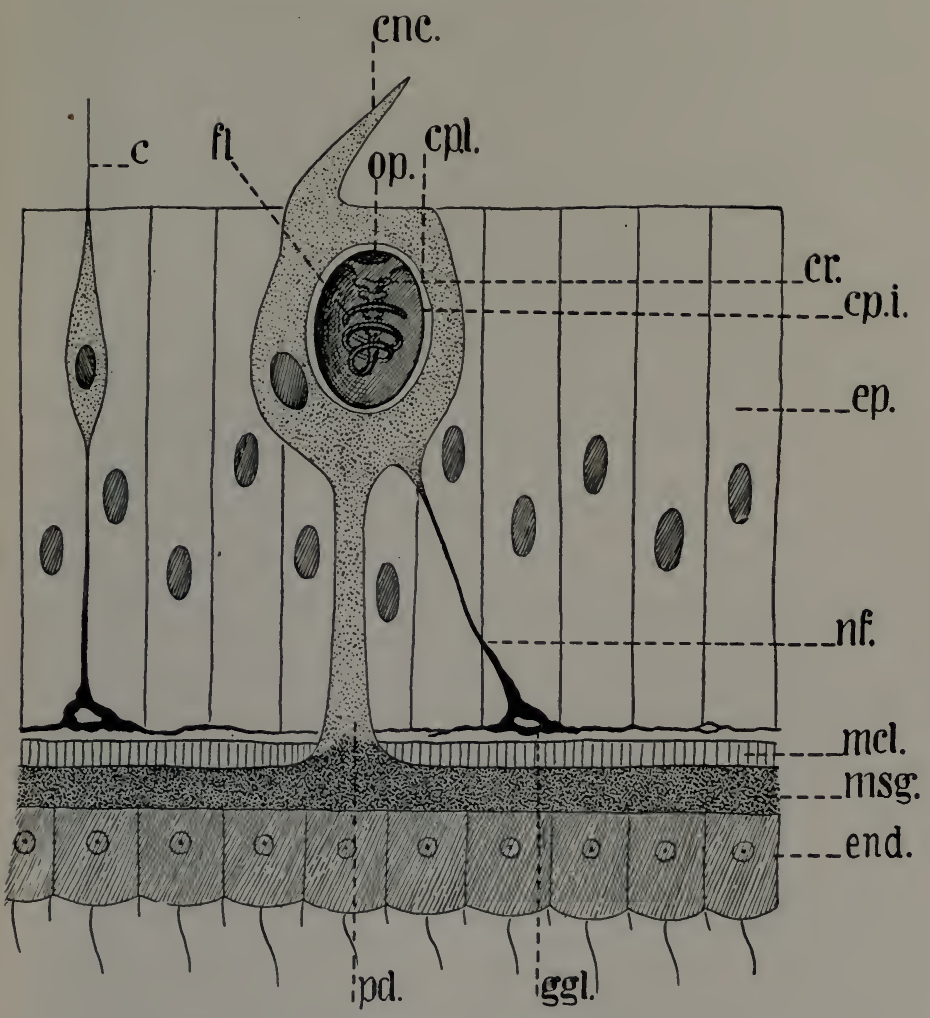

FIG. 5. - Schematic drawing of a section through the wall of a hydrozoön, after Dalage and Herouard, somewhat modified. $e p$, ectoderm; $m s g$, mesoglœa; end, endoderm; $g g l$, ganglionic cell; $m e l$, muscular fibres; $n f$, nerve fibre; $c$, palpocil; $c n c$, cnidocil; $p d$, peduncle; $c p l$, external layer of capsule; $c p i$, internal layer of capsule; $c r$, hooks; $f$, filament; $o p$, operculum.

different from those in the hydrocaulus. The ectoderm consists of an epithelial and a subepithelial layer. The epithelial layer is composed of indifferent and a few myo-epithelial cells, $i$. e., cells with a contractile process or muscular fibre at their base. All ectodermal muscular fibres belong to the longitudinal system of fibres. In the sub-epithelial layer are found among 
small so-called interstitial cells, genital cells and nerve cells. The endoderm consists of myo-epithelial flagellated cells and a few gland cells. The former are much larger than the corresponding ectodermal cells and each cell has a long flagellum on the surface facing the cavity of the polyp. Their contractile processes form the system of circular muscular fibres. The hypostome is different from the rest of the hydranth head in this respect that both circular and longitudinal muscle fibres are more numerous, that genital cells are absent and that among the cells of the ectoderm sensory cells are found. The structure of the tentacles is different in several respects. The tentacles are solid and the core of the tentacle is formed by a single row of large endodermal cells. They have the shape of short cylinders and their protoplasm is quite vacuolated. Circular muscle-fibres are absent. The epithelial layer of the ectoderm consists of myo-epithelial cells, sensory cells and nematocysts. The subepithelial layer contains interstitial cells, nerve cells and cnidoblasts or mothercells of the nematocysts. The nematocysts or nettlecells are arranged in batteries at the end of the oral tentacles and in the swellings of the basal tentacles. A nematocyst has the shape of an ellipsoid. It has an outer capsule with a short spine or cnidocil at the free end close to the apical opening of the capsule. This opening is closed by a plug. Inside the outer capsule is an inner capsule containing a spirally coiled up filament. The filament is a hollow tube and its wall is continuous with the wall of the inner capsule. When the cnidocil comes into contact with an object or when the polyp receives a chemical stimulus the nematocyst "explodes," $i$. e., the filament is suddenly everted through the apical opening. The nematocysts serve both as organs of defence and for the purpose of killing or stunning small animals which form the food of the polyp.

Medusome or free swimming medusa. This is the sexual stage in the life cycle of Pennaria tiarella and the sexes are separate. Both sexes look however alike but for a somewhat slenderer 
manubrium of the male. The medusa has the shape of an elongated bell or thimble. Its outer surface is called the exumbrella, the inner surface the subumbrella. The opening of the bell is partly closed by a circular velum. From the apex of the subumbrella the manubrium hangs down into the subumbrella cavity like the tongue of a bell. The mouth is at the free end of the manubrium. At the free edge of the bell are four equidistant knobs-rudimentary tentacles. Both exumbrella and subumbrella are covered with ectodermal cells. The manubrium is hollow and its cavity leads directly into a central cavity which is known under various names such as the central gastrovascular cavity or the stomach and which represents the central part of the colenteron. Radiating from the central cavity are four radial canals which run in the wall of the bell toward its edge where they open into a circular canal. Four gonads develop in the ectodermal layer of the manubrium at the time of maturity. The microscopic structure of the medusa of Pennaria tiarella is in its essential features the same as in Tima and will be considered in connection with that species.

\section{Instructions}

I. Place a complete colony of polyps, $i$. e., a hydrosome, in a shallow dish with water and examine it under the dissecting microscope. Make a half page drawing showing the hydrorhyza or root, the hydrocaulus or stem with its branches and their ramuli, and the hydranths or polyps. Label the founder polyp at the top of the stem and the end polyps of the branches in the sequence of their age as $a_{1}, b_{1}, c_{1} \ldots$ Label the polyps of two branches in the sequence of their age as $a_{2}, a_{3}, a_{4} \ldots ., b_{2}$, $\mathrm{b}_{3}, \mathrm{~b}_{4} \ldots$.

2. Examine a small branch under low power (50 diameters). Make a half page drawing showing two hydranths of which at least one should have medusa buds. Label perisarc or membrane covering the stem, cœnosarc or the wall of the stem; on the 
hydranth label mouth, hypostome, oral tentacles, basal tentacles and medusa buds.

3. Examine under high power (400 diameters) a prepared slide of a polyp and make a drawing showing an oral tentacle with the knob of nematocysts at the end. Label supporting endoderm, mesoglœea and ectoderm.

4. Examine on the same slide a basal tentacle and make a drawing of it showing the swellings containing the batteries of nematocysts, supporting endoderm and ectoderm.

5. Examine under high power ( 400 diameters) the prepared slide with a cross-section through a hydranth. Make a drawing showing ectoderm, mesoglœa and endoderm.

6. Examine in the same manner the cross-section through the hydrocaulus; make a drawing and label it.

7. Place a medusa in a syracuse dish with water under the dissecting microscope. Make a quarter page drawing showing the side view of the medusa. Label exumbrella, subumbrella, velum, manubrium, mouth, central gastro-vascular cavity, radial canals, circular canal and rudimentary tentacles, one at base of each radial canal.

8. Additional exercise. Put a live fresh-water hydra on a slide in a drop of water, cover it up with a cover glass and press it with the point of a needle until the animal will break up into small fragments. Examine under high power and find the isolated exploded nematocysts. Make a drawing of one of them showing the structure, and label parts. 


\section{SERTULARIA PUMILA Linnæus}

Material. S. pumila is found growing on fucus and in tide-pools along the Atlantic Coast. The student should receive a colony with gonosomes (it is better to put the whole lot the night before in glycerine), a stained colony, a cross-section through a hydranth, and a longitudinal section through a gonosome.

\section{Descriptive Part}

Sertularia pumila is another common representative of the class Hydrozoa. But unlike Pennaria it has no alternation of generations, there being no medusa stage. It differs from Pennaria also in that it belongs to the group of calyptoblastic polyps in which the perisarc forms a protective covering or theca for the hydranth and for the blastostyle. The method of budding is monopodial with terminal bud, ${ }^{1}$ not with terminal or top polyp as in Pennaria. The stem has as in Pennaria "unlimited" growth, but the terminal bud never develops into a polyp. Instead, it produces at regular intervals two opposite buds which remain sessile and become polyps. The result is similar to that in sympodial budding inasmuch as the oldest polyps are nearest to the hydrorhyza, but every pair of polyps has the same age, the stem is not composite and the polyps take no part whatever in its formation. The creeping hydrorhyza does not present anything particular in its structure. The hydrocaulus or stem is

${ }^{1}$ The sympodial method is more common in calyptoblastic polyps and may be best studied in Obelia. The polyps have limited growth. The polyp nearest the hydrorhyza is the oldest, the end polyp the youngest. The main stem is composite, the stem of every new polyp adding to its length. There are gradations between the sympodial method and the monopodial method with terminal bud. 
straight, divided into regular internodes each with a pair of opposite hydranths. Branches are always opposite, arising at the base of the hydranths. Every internode giving rise to branches has therefore two hydranths and two branches. The ramuli or branches of the second order arise asymmetrically, $i$. e., one ramulus to an internode of a branch. The colony is largely composed of trophosomes, $i$. e., common hydranths whose main function is nutrition, and a few gonosomes or modified polyps which depend for their nutrition on the trophosomes and whose function is sexual reproduction. The gonosomes are asymmetrical, a single gonosome being produced by an internode in front of the trophosomes.

Trophosome. We have already seen that the hydranths of Sertularia pumila are protected by a theca. As there are two hydranths for each internode, there are also two hydrotheca for each internode. They sit on a "shelf" of the internode and the base of each hydrotheca presents a regular diaphragm with a circular opening the diameter of which is considerably smaller than the diameter of the hydrotheca itself. The cœnosarc of the stem is therefore distinctly constricted by the diaphragm, through which it has to pass to form the polyp. The free end of the hydrotheca is provided with an oval opening or aperture. The edge of the aperture is emarginate, produced into two opposite teeth. The aperture may be closed by a two-flapped operculum or lid when the hydranth is entirely withdrawn into the hydrotheca. This operculum is best likened to a double door only that the so-called adcauline flap, $i$. e., the one whose hinge is nearest to the stem, is much smaller than the abcauline flap. The hydranth is provided with a special ectodermal fold which arises considerably below the tentacles and is attached to the edge of the hydrotheca. This fold forms an almost complete contractile sheath and serves as a protractor. ${ }^{1}$ The hydranth has a single circle of usually sixteen filiform tentacles situated at the base of the hypostome. They have the shape of the basal

${ }^{1}$ Nutting mistook the optical section of the sheath for two protractors. 
tentacles of Pennaria with nematocysts grouped in batteries. The microscopic structure of the hydranth is generally speaking the same as in Pennaria.

Gonosome. The reproductive polyp or gonosome is much larger than the trophosome. The gonotheca, usually called gonangium has the shape of a ovoid sac with a truncated end and is attached to the stem by a very thin and short pedicel or collar. An opening is formed later when the so-called acrocyst protrudes through the truncated end to the outside. The blastostyle or modified polyp develops a gonophore which appears as an outgrowth of the ectoderm filled with reproductive cells. The gonophore soon outgrows the blastostyle and almost fills the gonangium. At the distal end of the gonophore a cuticle is produced and the end of the gonophore protrudes now through the gonangium. The cuticle of the gonophore expands forming a globular sac or acrocyst into which the eggs pass. The remains of the gonophore in the gonangium appear as irregular strands called gubernacula. A new acrocyst is formed with the production of a new gonophore. The male gonangia are more slender. The egg develops into a planula which forms a new colony.

\section{Instructions}

I. Put a colony into a syracuse dish with glycerine and examine it under the dissecting microscope. Make a half page drawing showing hydrorhyza, hydrocaulus and branches with trophosomes and gonosomes. Number the polyps I-I, 2-2, 3-3 and so on, beginning with the polyps nearest to the hydrorhyza, to show the monopodial method of branching with terminal bud. Number the branches a, b, c . . . and the polyps of one branch $\mathrm{a}_{1-1}, \mathrm{a}_{2-2}, \mathrm{a}_{3-3} \ldots$... and so on.

2. Cut off a piece of the stem with expanded polyps and put it on a slide in a drop of glycerine. Cover it with a cover glass and examine under low power (50 diameters). Make a half page drawing of two internodes showing the cœnosarc of the stem 
with the shelf to which the polyps are attached, the perisarc, the hydrothecæ with their terminal aperture and two-flapped operculum, the diaphragm at the base of the hydrotheca, the hydranths with the single circle of filiform tentacles, hypostome, mouth and ectodermal fold serving as protractor.

3. Examine in the same manner a gonosome. Make a half page drawing of two internodes of the stem carrying the gonangium, the blastostyle, gonophore and gubernacula or strands representing the remains of the previous gonophore which had been emptied.

4. Examine in the same way the terminal bud (200 diameters) and make a drawing of it.

5. Examine under high power ( 400 diameters) the prepared slide with a stained colony and make a drawing of a tentacle showing its structure.

6. Examine under high power (400 diameters) the cross-section through a hydranth and make a drawing showing hydrotheca, ectodermal fold, ectoderm, mesogloea, endoderm and cœlenteron.

7. Additional exercise. Find among the colonies a gonosome in which an acrocyst has been formed above the gonangium. Cut it off with a piece of the stem, place on a slide in a drop of glycerine, cover with a cover glass and examine under low power (50 diameters). Make a drawing showing details. 


\section{TIMA FORMOSA L. Agassiz}

Material. Tima formosa is not uncommon in the North Atlantic. Along the New England coast the mature medusæ are found in March, April and May and disappear before June. North of Cape Cod they are found in autumn and winter. The specimens should be preserved in formalin. For microscopic study a specimen must be preserved in $\mathrm{r} \%$ osmic acid.

\section{Descriptive Part}

Tima formosa belongs to the class Hydrozoa and has a lifecycle with complete metagenesis. The hydrosome has been bred from a fertilized egg by Agassiz, but is very little known, quite insufficiently in fact, to recognize it in nature. The medusome is one of the largest American hydromedusæ.

The edge of the medusa is a perfect circle and the body, which is called the umbrella may be best likened to a bell. The outer surface of the bell is called the exumbrella, the inner surface the subumbrella. The exumbrella has the shape of a paraboloid and its axis is somewhat longer than the radius of the base. Owing to the thickness of the bell at its apex the axis of the subumbrella is considerably shorter. Moreover, the subumbrella has a peculiar shape inasmuch as its median portion hangs down through the opening of the bell, in the shape of a cone called the peduncle. At the end of the peduncle is a short manubrium with a mouth-opening surrounded by four long lips with transverse folds. The mouth leads into the quadrangular cavity of the manubrium, which is called the stomach. Four radial canals arise from the corners of the stomach and run at even distances from each other in the wall of the peduncle toward its base, bend 
over and continue to the edge of the bell where they open into a circular canal. The stomach with its system of canals represents the colenteron of the medusa. It is usually known under the name of gastro-vascular system. The broad, contorted bands accompanying the radial canals are the gonads. Around the edge of the medusa are thirty-two tentacles; of these four long tentacles are at the points where the radial canals open into the circular canals and four halfway between them, eight medium long ones halfway between the preceding and sixteen short tentacles each halfway between the long and medium ones. The tentacles are hollow and their cavity communicates with the circular canal. Each tentacle is swollen at the base and is therefore subdivided into a bulb and shaft. Between each pair of tentacles are three small protuberances or rudimentary tentacles of which there are therefore 96 all together. There are 128 simple marginal sense organs or statocysts, alternating with the tentacles and protuberances. The entrance to the subumbrella is somewhat constricted by a flat, circular diaphragm or velum. The velum is the organ of locomotion and when it contracts a pressure is produced on the water in the bell-cavity, which forces the medusa to move in the direction of its apex.

It is evident that the medusa is built on the principle of radial symmetry. The axis of the bell, passing through the apex or centre of the exumbrella and the mouth is the longitudinal axis. The bell may be divided into symmetrical octants by four planes intersecting in the longitudinal axis. Two of these planes are called perradial and run through the radial canals; they divide the stomach diagonally. The other two planes, called interradial run halfway between the radial canals; they divide each side of the stomach in two. A plane dividing two opposite octants into two halves is called adradial. There are therefore four adradial planes, but neither of them divides the medusa into two symmetric halves. In accordance with the above terminology the tentacles receive the names of the planes to which they belong. There are four perradial, four interradial and 


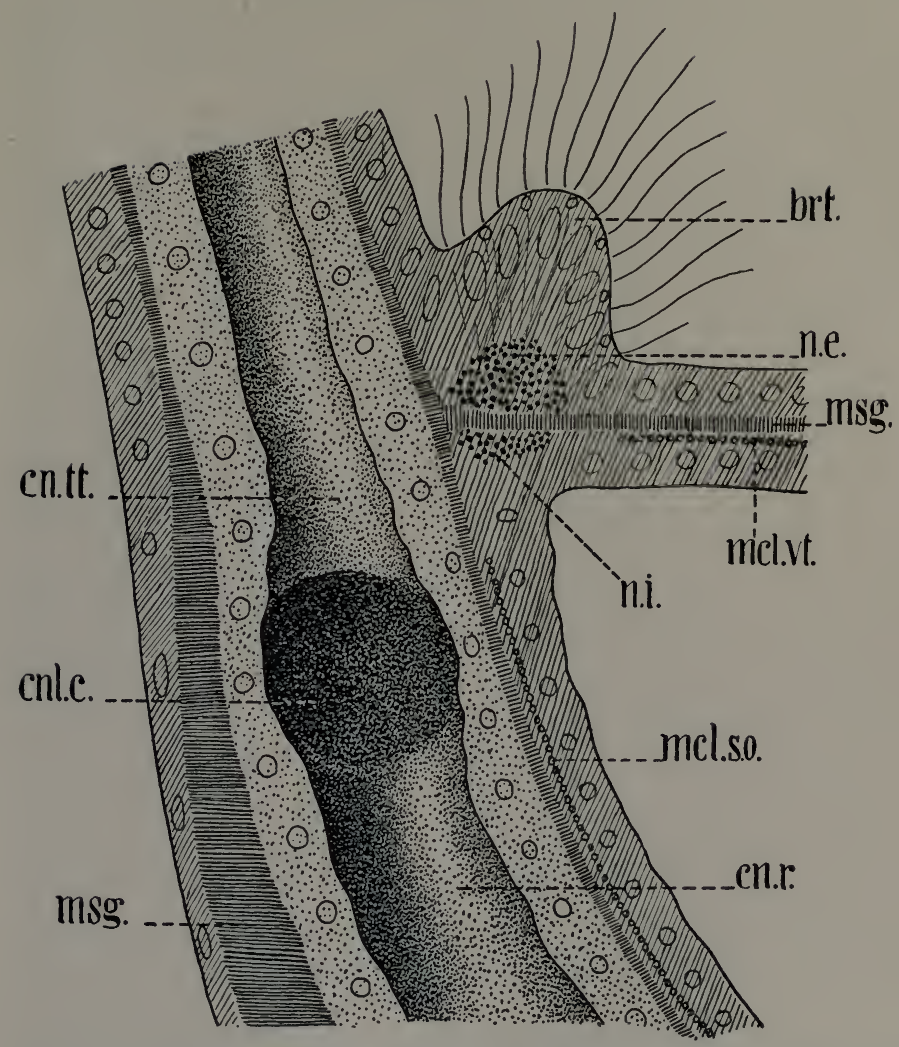

FIG. 6. - Schematic section through a hydromedusa in the region of the velum after Delage and Herouard (Zoölogie Concrète). cnlc, circular canal; $c n t t$, tentacular canal; $m s g$, mesoglœa; $c n r$, radial canal; $m s l s o$, muscular fibres of subumbrella; $m c l v t$, muscular fibres of velum; brt, nettle cell battery; $n e$, external nervous ring; $n i$, internal nervous ring.

eight adradial tentacles. Of the remaining sixteen tentacles, eight are per-adradial (halfway between a per-radial and adradial tentacle) and eight interadradial (halfway between an interradial and an adradial tentacle).

Body layers. The body of the medusa is composed of 
the same three layers as the body of the polyp. These layers are ectoderm, mesogloa and endoderm. The mesoglœa gives the bulk to the body. It is a transparent, gelatinous, structureless substance containing much more water than organic matter. It fills out the space between the ectoderm and the endoderm and is not only found in the umbrella and peduncle, but forms also a thin layer in the velum, manubrium and tentacles. The endoderm forms the lining of the gastro-vascular system and of the tentacles. The ectoderm forms the covering of the exumbrella, subumbrella, peduncle, manubrium, tentacles and velum. To the ectoderm belong further the gonads, the muscular system and the nervous system with the sense organs.

Endoderm. The endoderm of the medusa is composed of the same elements as that of the polyp except that myoepithelial cells are absent. The lining of the stomach is formed by a single layer of digestive endoderm and unicellular glands; the lining of the canals is formed by circulatory endoderm; and the lining of the tentacles by supporting endoderm.

Body covering. The covering of the exumbrella consists of a single layer of ectodermal flat epithelial cells. Near the margin of the exumbrella nematocysts are found also between the flat cells. The ectodermal layer of the subumbrella is more complicated. It consists of two distinct layers, a superficial or epithelial layer and a deeper or subepithelial layer. It must be borne in mind, however, that the subepithelial layer has been differentiated from the epithelial layer. The epithelial layer is composed of indifferent columnal epithelial cells, myo-epithelial cells and sensory cells. The latter, however, are very few in number. The subepithelial layer is composed of ganglionic cells, nerve fibres, striated and unstriated muscle fibres. The same elements are found in the ectoderm of the peduncle and manumbrium. There are, however, many sensory cells on the manubrium and nematocysts on the lips. The ectoderm of the tentacles is composed of indifferent cells, myo-epithelial cells, sensory cells and 
nematocysts. The latter are spindle-shaped and immense in number.

Muscular system. As already stated the muscular system of Tima consists of subepithelial striated and non-striated fibres. To the former belong the circular fibres of the subumbrella, of the peduncle and of the subumbral side of the velum, to the latter the radial fibres of the subumbrella and the longitudinal fibres of the peduncle, manubrium and tentacles. In the tentacles the longitudinal fibres are found only in the shape of one strand in their velar side, while circular fibres are entirely absent. There are no endodermal muscle fibres in Hydromedusæ.

Nervous system. The nervous system consists of a subepithelial network of ganglionic cells and fibres in the subumbrella, peduncle and manubrium, and of two rings in the base of the velum. The rings are usually termed the central nervous system. They too are composed of ganglionic cells and fibres. One ring is subumbral in position, the other exumbral; the rings are concentric and are separated from each other by the mesogloa of the velum. The subumbral ring innervates the circular muscles of the velum. The exumbral ring is the heavier of the two and innervates the tentacles, the marginal sense organs and sensory cells. The two rings are connected with each other by fibres.

Statocysts. Tima formosa has one hundred twenty-eight simple statocysts along its margin, alternating with the protuberances and tentacles. The statocysts are more or less round bodies of very small size. They consist of ectodermal cells and each statocyst contains from fifteen to twenty concretions arranged in a hemisphere. The function of the statocysts is that of controlling the equilibrium of the body.

Reproductive system. The reproductive organs of Tima are simple gonads. They are nothing but specialized ectodermal cells of the subumbrella and peduncle in the region of the radial canals. They appear as four long sinusoid bands. The repro- 
ductive cells are dehisced directly into the bell cavity and through the bell-opening to the outside. The sexes are separate. Fertilization is left to chance and takes place outside of the body, in the water.

\section{Instructions}

I. Examine a specimen of Tima formosa in a finger bowl with water. Make a half page drawing showing the paraboloid exumbrella, velum, bell cavity, peduncle, manubrium with the four lips, the four radial canals, gonads, circular canal, tentacles. Determine the perradial, interradial and adradial planes. Label all structures including the bulb and shaft of a tentacle, and the planes.

2. Cut off a piece of the margin with two tentacles and a portion of the velum. Put it on a slide in glycerine, exumbral side uppermost and examine under low power (50 diameters) without a cover glass. Make a drawing showing the hollow bulbs of the two tentacles, three protuberances and four statocysts.

3. Cut off a piece of the velum and place it on a slide in a drop of glycerine, subumbral side uppermost. Cover it up with a cover glass and examine under high power (400 diameters). Make a drawing showing the circular muscles.

4. Examine in the same manner the shaft of a tentacle. Make a drawing showing muscular strand, nematocysts, endoderm and cavity.

5. Examine under high power the prepared slide with a radial section through the velum and bell edge. Make a drawing showing the circular canal, mesogloea, subumbral and exumbral nervous rings and the two ectodermal layers of the velum with the mesoglœa between them, and the muscular fibres in the subepithelial subumbral layer of the velum. 


\section{GONIONEMUS MURBACHII Mayer}

Material. G. murbachii is common in a certain locality in Woods Hole and may be obtained from the Biological Laboratory. Specimens for microscopic study should be preserved in I\% osmic acid. Every student should study a specimen preserved in formalin and the following prepared slides: a radial section through the velum and bell edge, a cross-section of a tentacle, a cross-section through the manubrium and a crosssection through the peduncle. The general plan of structure is so similar to that in Tima that a separate description is not needed and the specific characters will be pointed out in the instructions.

\section{Instructions}

I. Examine a specimen of Gonionemus in a stender dish with water. To see it best turn it so that it shows more than its profile, enabling you just to see the bell opening. Make a half page drawing of it in this position. The drawing should show: the almost hemispherical exumbrella, the powerful velum, the bell cavity and the subumbrella; hanging down from the centre of the subumbrella the short peduncle with the manubrium and four lips surrounding the mouth; the four radial canals and under them the sigmoid bands which are the gonads; the circular canal near the margin; the tentacles each with a swollen base or bulb and thin shaft. (In a live specimen there is a bright green pigment spot in the endoderm at the base of every tentacle, but the color disappears in formalin.) In making the drawing observe that the peduncle and manubrium have not the shape of a square in a cross-section but that of a cross. The number of tentacles varies in Gonionemus and depends largely upon the 
age of the individual. There are usually from sixty to eighty tentacles.

2. Cut off a piece of the bell-margin between the radial canals, put it on a slide in a drop of glycerine, exumbral side uppermost. Examine through the microscope under low power (roo diameters). Make a drawing showing the circular canal and the margin of the bell with the base of several tentacles and the statocysts with the single concretion in them. There are usually half as many statocysts as tentacles.

3. Cut off a piece of the velum, put it on a slide in a drop of glycerine, subumbral side uppermost, cover up with a cover glass and examine under high power (400 diameters). Make a drawing showing the epithelial cells and circular muscle fibres.

4. Sever a tentacle and examine in the same manner that region of it where it is bent at right angles. Make a drawing showing the rings of nematocysts and the cup-like adhesive pad.

5. Examine under high power (400 diameters) the prepared slide with a cross-section of a tentacle. Make a drawing showing the central cavity, supporting endoderm composed of large cells with small nuclei, mesoglœa and ectoderm with ovoid nematocysts and muscular fibres.

6. Examine the radial section through the edge of the bell and the velum. Make a half page drawing showing the circular canal, mesoglœa, ectoderm of the subumbrella, subumbral ectodermal layer of the velum with the circular muscles, exumbral ectodermal layer, subumbral nervous ring and exumbral nervous ring.

7. Examine a cross section through the manubrium (50 diameters) and make a drawing showing the cross-shaped cavity of the stomach, mesoglœe and endoderm. 


\section{AURELIA AURITA (L.) varietas FLAVIDULA Péron et Lesueur}

Material. Mature individuals of Aurelia flavidula may be collected in summer and preserved in formalin. Scyphostomæ and strobilæ are common on seaweed in October. Ephyræ may be found in March and April. Material for microscopic study should be fixed in $\mathrm{r} \%$ osmic acid. The student should study a mature medusa, a scyphostoma and a strobila preserved in formalin, and the following prepared microscopic slides: a cross-section through an arm of a mature medusa with embryos, an ephyra stained in toto, a cross-section through a scyphostoma, a median longitudinal section through a scyphostoma.

\section{Descriptive Part}

Aurelia aurita is a typical representative of the Class Scyphozoa. It is a cosmopolitan jelly-fish common in European seas and the Atlantic and Pacific Oceans. The American variety is known under the name of Aurelia flavidula. The life cycle of Aurelia flavidula consists in an alternation of generations combined with metamorphosis or development of the adult from a larva. The whole life cycle is completed in one year and the preponderance lies with the sexual stage or medusa, compared with which the polyp is very small. The medusæ begin spawning toward the end of July. The eggs develop in small breeding pouches of the mouth-arms of the female. Here they reach the stage of a ciliated planula. The planulæ leave their mother in October and soon attach themselves to some seaweed or rocks. The mouth appears and tentacles grow out around the peristome. Thus a scyphopolyp or scyphostoma is formed. The scyphostoma begins to grow and produces by a peculiar method of 
transverse fission a column or strobila of about a dozen ephyra. The ephyræ begin to separate in March or April, appear soon as small medusæ, grow rapidly and become mature in summer.

Medusa. The medusa is built on the principle of radial symmetry. It has the shape of a disc or better of a round con-

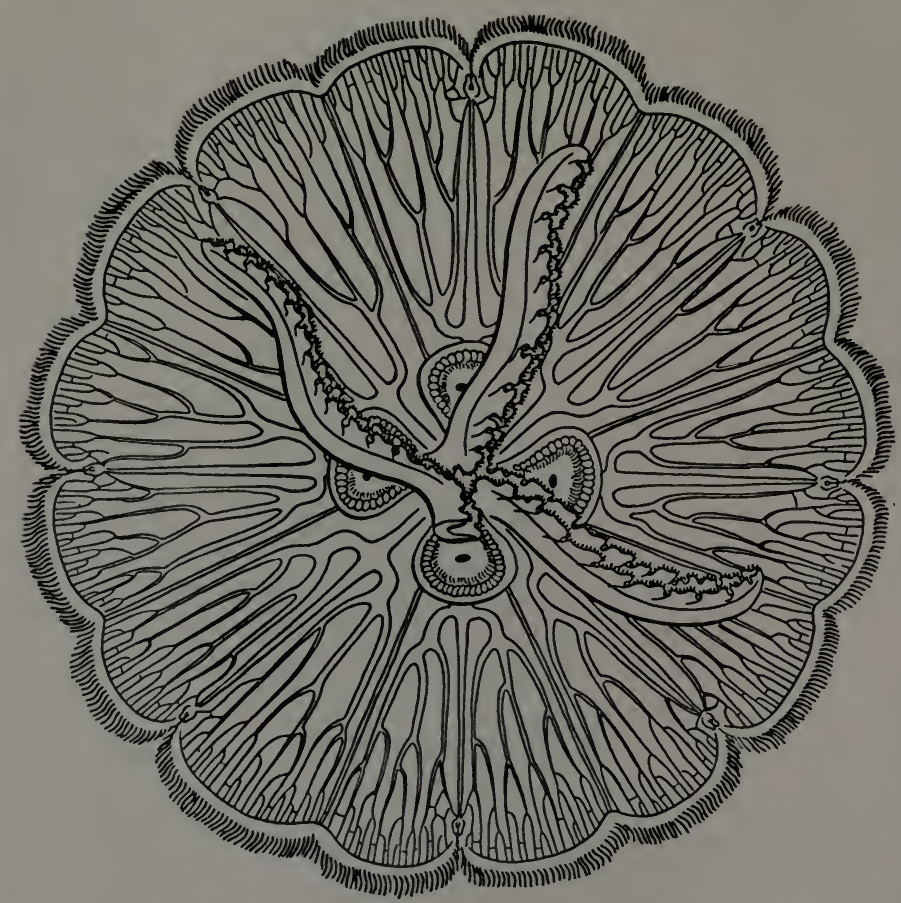

FIg. 7. - Aurelia labiata Ch. \& Eys, from Mayer's Medusæ of the World. One mouth-arm has been cut off to show the structure of the medusa.

vex concave lens. The oral surface or subumbrella is very slightly concave. The aboral surface or exumbrella has almost the shape of a hemisphere when the medusa is fully contracted. The longitudinal axis running from the centre of the subumbrella to the centre of the exumbrella is shorter than the radius of the disc. 
The medusa may be divided into eight symmetric sectors or octants by four planes intersecting each other at $45^{\circ}$ in the longitudinal axis. For the sake of convenience two of the planes intersecting at right angles are called perradial, and the other two interradial. The planes which divide the disc into sixteen sectors are called adradial. Neither of the adradial planes divides the medusa into symmetric halves. The various organs are said to be perradial, interradial or adradial in accordance with the name of the plane which bisects them.

The margin of the medusa is not an unbroken circle. There are eight notches in the margin corresponding to the four planes of symmetry. At the bottom of each notch is a sense organ or rhopalium. Four of them are perradial and four interradial. On each side of a rhopalium is a large marginal lappet. The margin of the medusa is covered with numerous small tentacles. These tentacles arise from the aboral surface at a very short distance from the margin and alternate with small marginal lobules. The tentacles are hollow, distended at their base; their cavity is in direct communication with the circular canal of the gastro-vascular system (cœlenteron) and is lined with endoderm. Each tentacle has on its subumbral side longitudinal muscle fibers in the subepithelial layer of the ectoderm and a row of broken rings of nematocysts on its exumbral side.

Body covering and muscular system. The body covering consists of a single layer of ectoderm. On the exumbrella the cells of the covering belong to the type of very flat epithelial cells with numerous nematocysts arranged in batteries on little protuberances, especially prominent toward the edge of the disc. On the subumbrella the number of nematocysts is small and they are irregularly scattered among the common epithelial cells. The subepithelial layer is a well developed system of circular and radial muscular fibres. The circular fibres are especially numerous toward the edge of the disc. The radial fibres run from the centre toward the tentacles. The contraction of the disc is accomplished by the joint action of the circular and 
radial fibres; the expansion is due to the elasticity of the mesoglœa. There is no velum in Aurelia, as is true for the entire Class of Scyphozoa which therefore are called Acraspeda. What is known as velarium in some Scyphomedusæ is not a fold of the ectoderm but a fold of the subumbrella containing endodermal canals. There is no velarium in Aurelia and the application of this name to the border of the disc between the base of the tentacles and the margin is not correct.

Mesoglœa. The bulk of the medusa is formed by a gelatinous, elastic mesoglœa. The mesoglœa is not structureless as in Hydromedusæ, but contains stellate and bipolar cells.

Gastro-vascular system. We have seen that the cœlenteron of the Hydromedusæ is already considerably more complicated than that of the Hydropolyps. The cœelenteron of the Scyphozoa is still more complicated and appears in the shape of a highly differentiated gastro-vascular system. The mouth is situated at the end of a short manubrium, and has more or less the shape of a square. The angles of the opening are perradial in position. The edge of the manubrium is drawn out to a considerable length and forms four mouth arms which are also perradial. Each of the four angles of the mouth continues as a longitudinal groove to the end of the mouth-arm. Both edges of the groove are fringed with a row of minute labial tentacles. When both edges are in close contact the mouth appears not as a square but as a cross or as a longitudinal fissure. It may be added that the mouth-arms of the female are stouter than those of the male.

The mouth leads into the central cavity or stomach. The stomach is produced into four large interradial gastric pouches, between which the four perradial canals are situated. The openings leading from the stomach into the pouches are called the gastric ostia. On the floor of each gastric pouch is a groove formed by two folds of the lining. These gonadial grooves extend from the ostia to the middle of the pouches where they become 
considerably wider. They serve the purpose of carrying the genital cells from the gonads which are situated in the gastric pouches, to the stomach. On the floor of the pouches, surrounding the gonadial groove is a horseshoe-shaped genital ridge and to the inside of it and closely applied to it a row of gastric filaments. The system of radial canals is quite complicated and subject to great variations although it follows a definite plan. One can always recognize four perradial branching canals, four interradial branching canals and eight adradial straight canals. The perradial canals arise from the corners of the stomach between the gastric pouches and soon give off two opposite branches while the main stem runs straight to the periphery and opens into the circular canal near the base of the perradial rhopalium. The primary branches subdivide several times and spread over the space between the central branch and the adjoining adradial canals. Their terminal branches open into the circular canal. The interradial canals arise from the gastric pouches and branch in the same manner as the perradial canals. But the primary branches are formed so close to the beginning of the canal that they produce the impression of two independent canals. The adradial canals have no branches. They arise from the gastric pouches and run straight to the periphery, opening into the circular canal halfway between the rhopalia. The circular canal follows the edge of the disc between every rhopalium. When it reaches a rhopalium it forms a horseshoe bend around its base. The cavities of all tentacles and rhopalia open also into the circular canal. The entire gastro-vascular system, from the edge of the mouth to the last ramifications of the canals is naturally lined with endoderm. The majority of the cells of which the layer of endoderm is composed are cylindrical ciliated epithelial cells. In the stomach are many glandular cells. In the gastric filaments numerous nematocysts occur. The grooves of the mouth-arms are also lined with endoderm. The labial tentacles are rich in nematocysts.

Subgenital pits. When one examines the subumbrella 
of Aurelia one cannot fail to notice four interradial, oval openings which appear as if they were leading into the gastric pouches. In reality they lead into blind subgenital pits situated under the

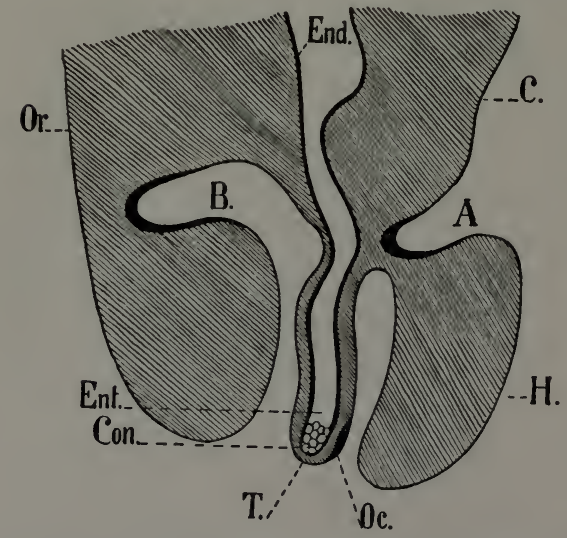

FIg. 8. - Tentaculocyst of Aurelia aurita, longitudinal section. Diagram after Eimer, from E. Ray Lanckester's Treatise on Zoology. $A$, aboral (superior) olfactory pit; $B$, adoral (inferior) olfactory pit; $c$, exumbrella; Con, statocyst; Ent, radial canal continued into tentaculocyst; End, endoderm; Oc, ocellus; $T$, tentaculocyst; $O r$, subumbrella; $H$, bridge between the two marginal lappets (hood). gastric pouches. The pits are lined with ectoderm and have no connection whatever with the gastric pouches. Neither have they anything to do with the reproductive functions of Aurelia. It is probable that the subgenital pits help respiration inasmuch as they increase the surface of the subumbrella and allow the water to come nearer to $\mathrm{th} \mathrm{e}$ reproductive organs.

Nervous system. The nervous system consists of a subepithelial network of ganglionic cells and fibres and of eight nervous centres or ganglia, one at the base of every rhopalium. The subepithelial network is found in the subumbrella between the epithelial layer and the layer of muscular fibres. The function of this network is chiefly that of a motor system.

Sense organs. We have seen that Aurelia has eight marginal sense organs or rhopalia. A rhopalium is a very complicated organ with various functions. It is protected by the two marginal lappets and its cavity stands in direct communication with the circular canal. The rhopalium itself consists of a large dorsal protective fold or hood with the aboral olfactory pit 
at its base and a small club or tentaculocyst under it. An oral olfactory pit is situated at the base of the tentaculocyst. The tentaculocyst is hollow except at its end which is developed as a statocyst or an organ of equilibrium and is filled with statolyths. On the aboral surface of the tentaculocyst, a little in front of the olfactory pit, is a simple pigment spot or aboral ocellus. On the oral surface is a well developed, pigmented, cupped ocellus of the inverted type in which the cones are turned away from the light. The canal which runs from the circular canal into the tentaculocyst, forms two blind canals at its base.

Reproductive system. The sexes are separate and the reproductive organs are simple, ductless gonads. When the gonads are fully developed they appear as four colored rings broken only by the narrow gonadial grooves. They are situated in the gastric pouches and are endodermal in origin. The reproductive cells are simply dehisced into the gastric pouches and reach the stomach through the gonadial grooves. The fertilized eggs are found later in the grooves of the mouth-arms and develop in special pouches there. Here they reach the planula stage and leave then the mother.

Scyphostoma. The structure of the scyphostoma has been often misinterpreted owing to the extreme contractility of its muscle-bands which change the position of the mouth. Thus it happened that investigators have described a manubrium and a gullet where such organs do not exist in reality. The stem is quite short and thin. The tentacles are attached in a circle around a flat peristome from the middle of which arises a conical hypostome. At the extreme end of the hypostome is the square mouth. The tentacles are solid and normally sixteen in number, although as many as twenty-four have been observed. The corners of the mouth mark the two perradial planes. In the interradii of the peristome are four pits which are usually supposed to be homologous with the subgenital pits of the adult medusa. These pits are called septal funnels. They are formed by the invagination of the ectoderm and lead into the wall of the 
tæniolæ. The taniola are longitudinal folds of the endodermal lining of the polyp cavity. The four tæniolæ are interradial in position and subdivide the cavity of the polyp into four perradial chambers. Each tæniola has a strong band of longitudinal muscle fibres which are attached to the blind end of the septal funnel. The ectodermal subepithelial muscle fibres are circular.

Ephyra. We have seen already that the scyphostoma produces about a dozen ephyræ by a process of strobilization. An ephyra which has just detached itself has a flat body divided into eight narrow lobes or rays, four of which are perradial and four interradial. Each lobe has two end lappets (marginal lappets of various authors. According to Schewiakov they become later the sensory lobules of the rhopalia). Between the two lappets is a not yet completely developed rhopalium. The square mouth is situated at the end of a short manubrium. The stomach is subdivided into chambers and gives off eight blind canals, one for each ray. Four interradial gastric filaments are present and their number grows with the growth of the ephyra. The transformation into a medusa is gradual with the more rapid growth of the disc between the lobes, till the star-shaped body assumes the shape of a disc.

\section{Instructions}

I. Put a mature medusa on its back in a dissecting tray filled with water and examine the specimen with naked eye. Determine the perradial planes by the position of the mouth-arms and the interradial ones by that of the gonads. Find the openings of the subgenital pits. Move the mouth-arms carefully apart with two fingers till the mouth is wide open, introduce then a black horse hair through the mouth into one of the perradial canals, pushing the hair gently till it reaches the circular canal. Introduce another hair through a stomach ostium into an interradial canal, and a third hair into an adradial canal. Make a full page drawing showing the following structures: Four mouth-arms 
with the fringe of labial tentacles, longitudinal groove and brood-pouches filled with developing eggs; mouth, four gastric pouches with gastric ostia, gonadial grooves, gonads and gastric filaments; four perradial canals, of which only two running at right angles to each other should be drawn with all branches, of the other two merely their beginning; one interradial canal with all its branches in the quadrant between the two finished perradial canals; two adradial canals of the same quadrant; the circular canal; the eight rhopalia or marginal sense organs; the tentacles all around the edge of the disc; the four openings of the subgenital pits over the centres of the gastric pouches. Label all above structures as well as the perradial, interradial and adradial planes.

2. Cut off with scissors a piece of the margin with a rhopalium. Place it in a syracuse dish in as little water as possible and turn the piece so that its exumbral surface would be uppermost. Examine under low power (50 diameters) the rhopalium and the surrounding structures. Make a half page drawing showing the hollow tentacles with swollen base, the protective fold, in it the tentaculocyst, the two marginal lappets, the pigment spot, and the protuberances with nematocysts on the exumbrella.

3. Turn the piece over and examine it under higher power ( 100 diameters). Make a half page drawing showing the horseshoe bend of the circular canal, the ends of the radial canals, the canals leading from the circular canal into the tentacles, the canal leading into the tentaculocyst with two blind canals at its base, the marginal lappets, the pigmented cupped eye, and the statocyst at the end of the tentaculocyst.

4. Transfer the piece onto a slide, add a drop of glycerine, cover with a cover glass and examine the ectodermal covering of the subumbrella under higher power (200 diameters). Make a drawing showing the circular muscles and the nematocysts scattered over the surface.

5. Cut off another piece of the margin of the medusa with scissors and put it on a slide with its exumbral surface upper- 
most, add a drop of glycerine and cover with a cover glass. Examine the covering of the exumbrella under high power $(400$ diameters). Choose a protuberance with some exploded nematocysts and make a drawing showing an entire protuberance with all nematocysts.

6. Examine a tentacle on the same slide and make a drawing showing the rings of nematocysts.

7. Cut off a piece of a mouth-arm, place it on a slide in a drop of glycerine, cover with a cover glass and examine under high power (200 diameters). Make a drawing showing the tentacles with the nematocysts evenly distributed over them, and the brood-pouches with embryos.

8. Cut off a piece of the floor of a gastric pouch with gastric filaments, put it on a slide in the same manner as in the preceding exercise and examine under high power (200 diameters). Make a drawing of a gastric filament showing the cavity and the walls with nematocysts evenly distributed over them. 


\section{METRIDIUM MARGINATUM Milne-Edwards}

Material. M. marginatum is quite common in larger tide-pools and below the low-water mark along the Atlantic Coast. Specimens must be stupefied by the addition of magnesium sulphate in increasing quantity. When reaction to stimuli has been inhibited the solution may be replaced by weak formalin. Chromic acid is also recommended but has no particular advantage. For microscopic study pieces of stupefied specimens may be preserved in $\mathrm{r} \%$ osmic acid or in any of the reliable fixing fluids. Every student should receive two specimens and a cross-section through an acontium.

\section{Dascriptive Part}

Metridium marginatum is a representative of that group of the class Anthozoa which is known under the common name of sea-anemones. The majority of Anthozoa are colonial forms and possess a calcareous skeleton. Metridium on the other hand is not a colonial animal and does not possess such a skeleton. Yet its structure is nevertheless typical of an Antho-polyp and like all Anthozoa it has no medusa stage, the polyp itself producing reproductive cells.

External features and gastro-vascular system. The body of Metridium marginatum may be divided into a broad foot and a cylindrical column or scapus crowned by a festooned capitulum carrying numerous hollow tentacles. The largest tentacles are nearest the mouth. The oblong mouth is situated at the end of the polyp in the middle of a flat peristome. In the wall of the column are numerous pores or cinclides which leads into the gastro-vascular space. These pores are always closed and 


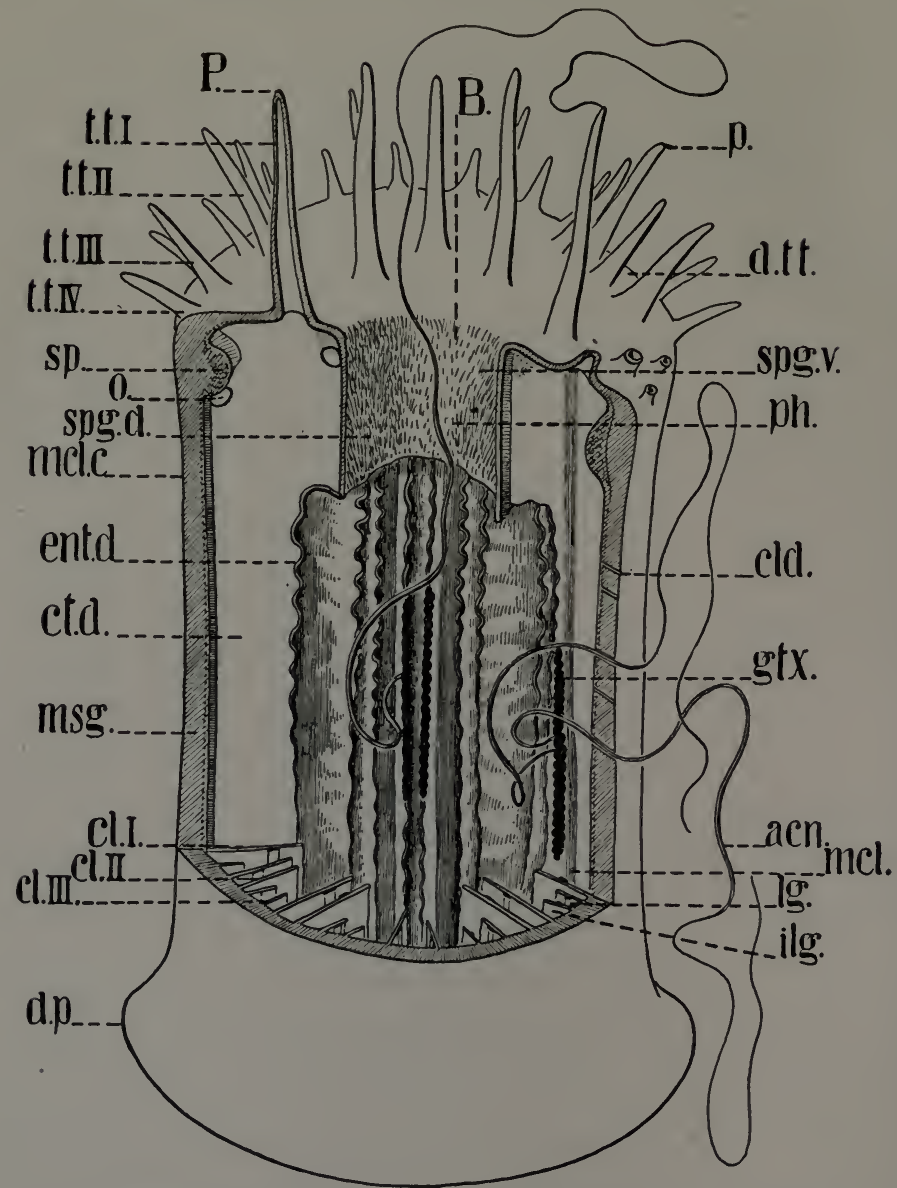

FIG. 9. - Morphologic type of a Hexactinia after Y. Delage \& E. Herouard, Zoölogie Concrète. acn, acontia; $b$, mouth; $c l$ I, primary mesentery; $c l$ II, secondary mesentery; $c l$ III, tertiary mesentery; $c l d$, cinclides; $c t d$, dorsal (directive) mesentery; $d p$, foot; $d t t$, capitulum; entd, mesenteric filament; gtx, gonad; ilg and $l g$, subdivisions of an endocoele; $m c l c$, mesoglœa; $o$, outer septostoma; oi, inner septostoma; $p$, tentacular pore; $p h$, gullet; sph, sphincter capituli; spgd, dorsal siphonoglyphe; spgv, ventral sophonoglyphe; $t$ I I IV, tentacles of the first to fourth verticel. 
therefore invisible. But when a live Metridium is subjected to strong stimuli, long white threads or acontia are suddenly projected through the cinclides to the outside. The transverse folds of the wall are produced by the contraction of longitudinal muscle fibres. The mouth of Metridium leads into a gullet or pharynx which almost reaches the foot and opens into the gastro-vascular space or stomach. We have seen that a gullet had been erroneously ascribed to scyphostoma owing to the temporary invagination of the hypostome under the influence of stimuli. In Metridium the invagination is permanent and the gullet is therefore homologous to the hypostome of scyphostoma. The lining of the gullet is thrown into longitudinal ridges, except in the siphonoglyphes which are ciliated furrows running from the opposite ends of the mouth down the whole length of the gullet. The number of individuals with a single siphonoglyphe is about equal to that with two siphonoglyphes. The gastro-vascular space is subdivided by longitudinal mesenteries or partitions. Of these, six pairs are attached to the wall and to the gullet and are called complete or primary mesenteries. They have in their wall longitudinal muscle bands often called muscle-banners. In diglyphic specimens (with two siphonoglyphs) two pairs of the primary mesenteries are called directive mesenteries. They are attached to the siphonoglyphs and their muscle-banners are directed away from each other. In each of the other four pairs the banners are directed toward each other. In monoglyphic specimens a single pair of directive mesenteries is present and in the remaining five pairs the banners are directed toward each other. The diglyphic type presents therefore two planes of symmetry, intersecting at right angles, while the monoglyphic type is strictly bilateral. The space between the gullet and the body wall is divided by the primary mesenteries into twelve chambers, but the mesenteries being arranged in pairs, the chambers between the pairs are much larger than the chambers formed by the two mesenteries of the same pair. The former are called exocales, the latter endoceles. The endo- 
and exocœles communicate with each other below the gullet, where the inner edge of the primary mesenteries is free and where all chambers open into the central cavity. The chambers communicate with each other also at the anterior end. This communication is established by means of large round or oval openings in the mesenteries. The openings are arranged in two circles; one surrounding the gullet close under the inner surface of the peristome, the other somewhat lower and close to the wall. There are therefore altogether twenty-four openings, two in each mesentery. These openings are called inner and outer mesenteric ostia or septostomata. The free edge of the primary mesenteries forms a thickened and twisted mesenteric filament. Near the base of the mesentery the filament becomes free, changes somewhat its structure and appears in the shape of a long and thin thread or acontium. Each exocœle is subdivided by incomplete mesenteries, which are attached only to the wall of the polyp but not to the gullet and which have only outer septostomata. There are usually one pair of secondary, two pairs of tertiary, and four pairs of quaternary incomplete mesenteries in each exoccele, or altogether forty-two pairs of incomplete mesenteries in the six exocœles. Each incomplete mesentery has a mesenteric filament along its free edge and an acontium at the base. In the wall of the incomplete mesenteries the gonads are situated and appear as a single row of bead-like bodies. When fully developed they fill almost completely the exocœeles. Snall gonads develop also near the free edge of the primary mesenteries, except the directives, below the gullet.

Microscopic anatomy. (a) Ectoderm. The ectoderm forms the covering of the body, of the tentacles, and of the peristome, and the lining of the gullet. Although composed of a single layer of cells it may be divided into an epithelial and a subepithelial layer. The former consists of ciliated columnar cells, mucous glands, albuminous glands, nematocysts, and sensory cells; the latter of nematoblasts, ganglionic cells, nerve fibres, muscle cells and muscle fibres. (b) Endoderm. The endoderm forms the 


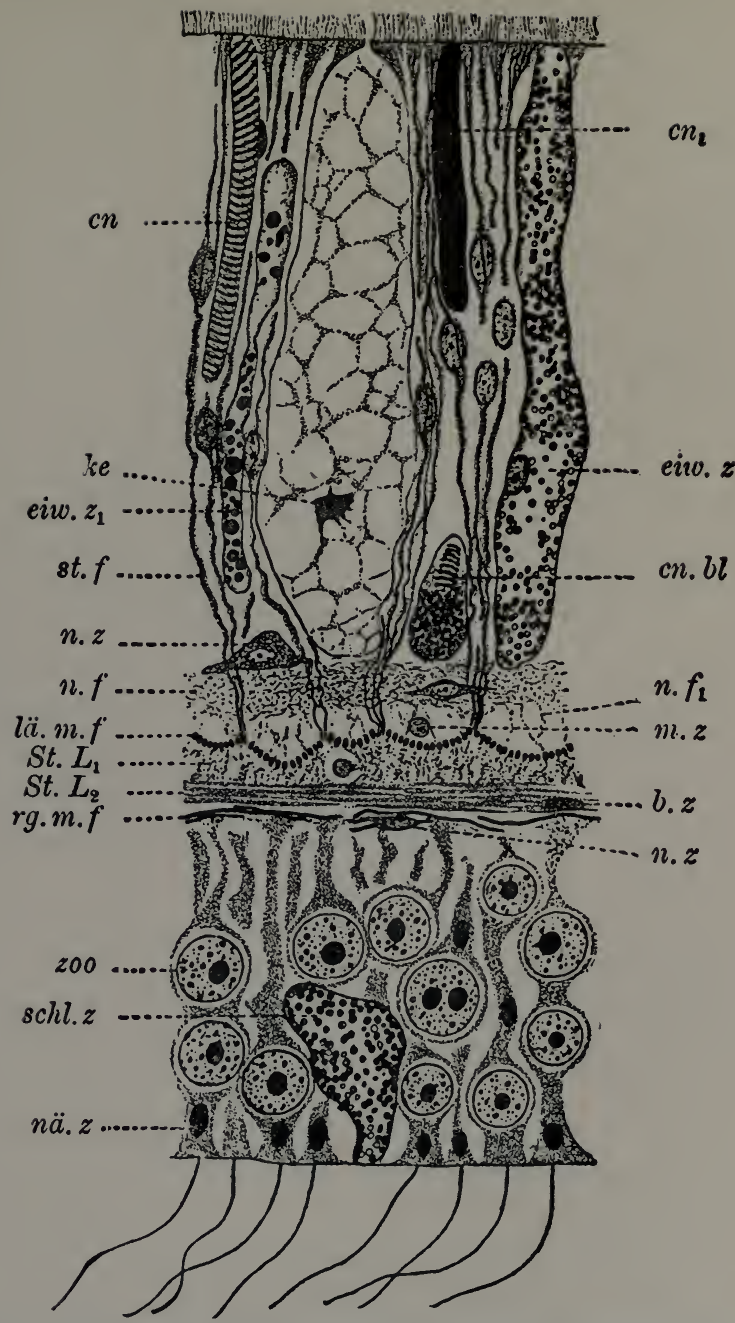

Fig. 10. - Transverse section of a tentacle of Anemonia Sulcata after Schneider. st. $f$, supporting fibre of the indifferent cells (Deckzellen); $c n$, thin-walled nematocyst; $c n 1$, cochleate nematocyst; $k e$, nucleus of a slime cell; ciw. $w$, albumen cell; eiw. $z$, albumen cell with remains of secretions; $n z$, nerve cell; $n f$, nerve fibre layer; $n f \mathbf{1}$, nerve fibre running to the muscles; lii. $m . f$, longitudinal muscle fibres; $S t . L 1$ and $S t$. $L_{2}$, layers of the supporting membrane; $b$. $z$, connective cell; $m z$, muscle cell; rg. $m$. $f$, circular muscle fibre; nü. $z$, nutritive muscle cell (endodermal); schl. $z_{\text {, }}$ endodermal slime cell; zoo, zoöxanthelle; $c n . b l$, cnidoblast. 
lining of the gastro-vascular system, including the mesenteries, the covering of the gullet, and the acontia. The gonads are also endodermal. The epithelial layer of the endoderm consists of columnar flagellated cells and glands as well as numerous long nematocysts in the acontia. The subepithelial layer consists of ganglionic cells, nerve fibres, muscular fibres and nematoblasts in the acontia. (c) Mesoglaa. The mesoglœa is found be-

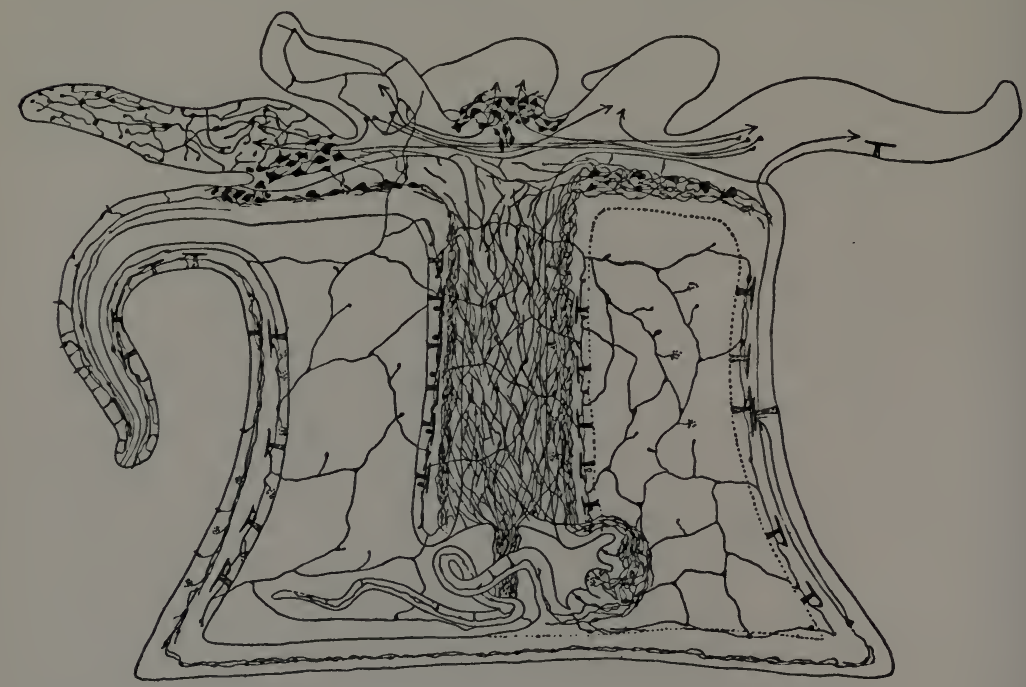

FIG. I I. - Nervous system of an actinia after Wolff.

tween the two preceding layers in the wall, tentacles, peristome, gullet and mesenteries. It is formed by a striated substance in which multipolar connective cells are enclosed.

Muscular system. The muscular system in Metridium is highly developed. Both ecto- and endodermal muscles are formed by myo-epithelial cells, but in many cases the fibre may become independent of its mother cell. All ectodermal fibres are longitudinal in position. The endodermal muscle fibres of the wall and tentacles are circular. At the anterior end of the 
column they form a real sphincter columna. The muscles of the primary mesenteries, all endodermal, are arranged in a definite manner. On one surface of the mesentery is the longitudinal muscle banner and a radial basal muscle. On the other surface are transverse muscle fibres, oblique muscle fibres, and a basal radial muscle.

Nervous system. The nervous system consists of a subepithelial ectodermal and a subepithelial endodermal network of ganglionic cells and fibres. The network is especially rich in the gullet, peristome and tentacles. It is very probable that there is a direct connection between the two networks in the shape of fibres which pass through the mesoglœa. Sense organs are absent but sensory cells with tactile and chemotactile functions are found both in the ecto- and endoderm.

Reproductive system. The reproductive organs have been already described. They are in the shape of ductless gonads situated in the mesenteries. The sexual cells are dehisced into the exocoeles. The sexes are separate. The ciliated planula develops into a polyp.

Asexual reproduction. Reproduction by budding from the base of the column near the foot is not uncommon. Occasionally a longitudinal fission of adult specimens also occurs. If the fission is not completed the result is a specimen with two mouths and gullets.

\section{Instructions}

I. Examine a specimen in a deep finger bowl filled with water. Make a life-size drawing showing the side view. Label foot, column or scapus, capitulum, and tentacles.

2. Make a life-size drawing of Metridium showing the capitulum from above. Label tentacles, peristome, mouth and siphonoglyphs. Label the type to which the specimen belongs, as monoglyphic or diglyphic, depending upon the presence of one or two siphonoglyphs.

3. Take the specimen in your left hand, press it gently with 
your fingers and cut it with large scissors in two a little below the capitulum. The cut must be made at right angles to the axis of the polyp in the same manner as you would cut across rubber tubing. Put the two halves in separate finger bowls. If the cut was not quite neat, trim the edges and mesenteries with scissors, till you obtain a perfect cross-section. This method is vastly superior to a cross-section made by a razor. Examine the cut surface of the upper half. Make a half page drawing showing gullet, siphonoglyphs, primary mesenteries with inner septostomata, incomplete mesenteries, and between them the openings leading into the tentacles, circular muscle. Label also the one or two pairs of primary mesenteries which are the directives.

4. Take the lens from the dissecting microscope and examine the cut surface of the gullet. Make a drawing showing the three layers: ectoderm, mesogloea, and endoderm.

5. Examine the cut surface of the lower half. Make a half page drawing showing primary mesenteries with their musclebanners, incomplete mesenteries, mesenteric filaments, gonads, gullet with siphonoglyphs. Label also the directive mesenteries, exocœles, and endocœles.

6. Cut the lower half in the same manner as before, but this time close to the foot. The cut should be below the gullet, but if it happened to be above the end of the gullet, trim the surface with scissors. Make a half page drawing showing primary mesenteries, incomplete mesenteries, gonads, and acontia.

7. Take another specimen. Introduce the blunt end of the large scissors into the mouth and cut the specimen into two symmetric halves. The cut must be made through the corners of the mouth so that each siphonoglyph will be cut in two. Put both halves in a finger bowl with water and choose the one which has been less damaged. Trim the edge to the primary mesenteries until you have a clean longitudinal section with the gullet in the middle and a complete mesentery on each side of it. Make a half page drawing showing capitulum with tentacles, 
peristome, gullet with longitudinal ridges and siphonoglyphs, both complete mesenteries with their muscles and inner and outer septostomata, mesenteric filaments, acontia, gonads (if present), bases of incomplete mesenteries converging to the centre of the foot, and the sphincter columnæ in the wall under the capitulum.

8. Carefully cut out both primary mesenteries beginning at the centre of the foot and passing one blade of the scissors under the mesentery. When the cut has reached the wall, continue it in the same manner all the way to the capitulum. Then cut in the same manner the gullet, beginning at its lower end, until you reach the mouth. Lift the mesentery carefully with a forceps and cut across the peristome. Place both mesenteries for future examination in a dish with water. The removal of the primary mesenteries exposes the incomplete mesenteries in the exocœles on both sides of the gullet. Make a half-page drawing showing all structures including the mesenteric filaments, gonads, and acontia.

9. Place one of the removed primary mesenteries on a slide and examine against a window. Make a full-size drawing showing the entire mesentery with the strips of the walls to which it is attached. Label foot, column, capitulum, peristome, gullet, mesenteric filament, acontium, gonad (if present), sphincter columnæ, inner septostoma, outer septostoma, longitudinal muscle (banner), oblique muscle, transverse muscles. The two basal muscles are not always discernible. Owing to the transparency of the mesentery, the muscles of both sides are equally well visible. In reality, the longitudinal muscle is on one side, while the transverse and oblique muscles are on the other side.

Io. Put a small piece of an acontium on a slide in a drop of glycerine, cover with a cover glass and press the latter until the acontium is completely mashed. Examine under the microscope at 400 diameters. Make a drawing of a long, spindleshaped nematocyst with the filament in it. 
II. Examine the prepared slide with a cross-section through an acontium. Make a drawing showing the row of nematocysts. I2. Additional exercise. Touch a live Metridium with the end of a pencil until at least one acontium is projected through a cinclide. Make a sketch showing the animal in this condition. 


\section{DENDROCELUM LACTEUM (Müller)}

Material. Live specimens of D. lacteum should be kept in a small aquarium with clean water with a few algæ and several dead leaves at the bottom. They will live a considerable time if fed on daphnids, copepods and small dipterous larvæ. This species is much better for study than Phagocata gracilis, but is rarer and for that reason must be collected considerably beforehand. The best method of fixation for in toto mounts or cross-sections is hot sublimate (saturated aqueous solution) poured suddenly into the dish in which the animal has been allowed to creep on a dead leaf. If after fixation the animal still adheres to the leaf, it can be sectioned with it; but usually it will let go without losing the ciliated epithelium as is invariably the case when it is fixed in a glass beaker without a dead leaf. Specimens with a well-filled alimentary canal should be mounted in toto, without stain of any kind. The differentiation of internal organs in Planarians is impossible even with Alumcarmin which gives such wonderful results in flukes and tapeworms. The internal anatomy, with the single exception of the digestive organs, must therefore be studied on serial sections. If possible, every student should get a complete series of sections and find those among them which are mentioned below.

\section{Descriptive Part}

Dendrocœlum lacteum is a hermaphroditic fresh-water Turbellarian (Planarian), common both in Europe and this country. The body is strongly flattened dorso-ventrally. The mouth opens on the ventral surface considerably behind the middle of the body, and still farther behind lies the joint opening of the 
reproductive organs. At the anterior end which is the seat of the central nervous system, are two lateral projections, the tentacles, and behind them, on the dorsal surface, two eyes. Between the tentacles is a retractile grasping organ.

Integument. The body covering is composed of a single layer

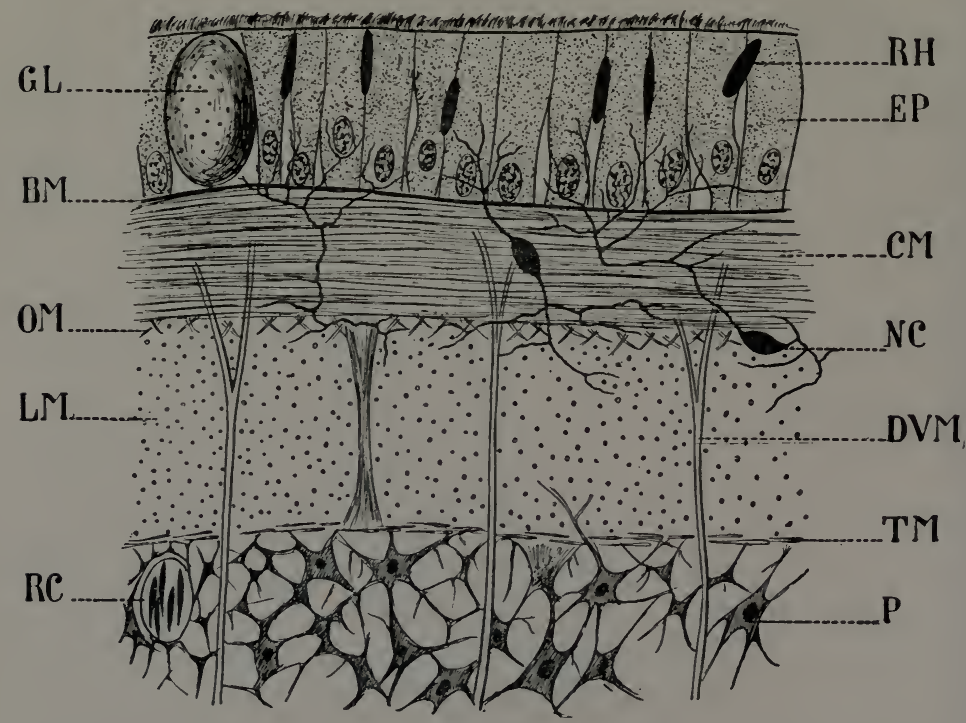

FIG. I 2. - Transverse section through the skin of Dendrocalum lacteum after Hallez, modified. $G L$, gland cell; $B M$, basal membrane; $O M$, oblique muscles; $L M$, longitudinal muscles; $R C$, rhabdite mother cell; $R H$, rhabdites; $E P$, epithelial cells; $C M$, circular muscles; $N C$, nerve cells; $D V M$, dorso-ventral muscles; $T M$, transverse muscles; $P$, parenchyma.

of cilitated epithelial cells lying on a basal membrane. Between the epithelial cells numerous unicellular gland cells are found which secrete slime, together with branches of bipolar nerve cells and little rods or rhabdites which possibly serve as protection and support to the tender epithelium. The rhabdites are produced by special cells in the parenchyma.

Muscular system. The muscular system, which forms a real 
muscular skin bag and is the main organ of locomotion, lies immediately beneath the basal membrane. The movement of the epithelial cilia is of use to the animal only when it glides, ventral surface up, on the surface of the water. A well developed layer of circular muscles situated under the basal membrane is followed inwardly by a much weaker layer of oblique muscles. The well developed layer of longitudinal muscles antagonistic to the circular muscles comes next, and finally a weak layer of transverse muscles, adjoining the mesenchyme or parenchyma. Traversing the whole body of the animal from the dorsal to the ventral surface are the dorso-ventral muscles.

Parenchyma. The space between the dorsal and ventral transverse muscles is occupied by a mesenchyme or parenchyma. In it the cells producing the rhabdites are situated, together with slime glands which open to the outside on the ventral surface of the animal near the edge. The different organs are also imbedded in the parenchyma.

Digestive system. The alimentary canal begins with a mouth situated on the ventral side considerably behind the middle of the body. It leads into a spacious mouth cavity, often called the pharyngeal sheath for the reason that it incloses the protrusible pharynx. The pharynx represents a muscular tube covered with epithelium on the inside as well as on the outside and occupying almost the entire mouth cavity. The opening of the free end of the pharynx is known under the name of pharyngeal mouth, and when the pharynx is protruded to the outside through the mouth proper, the pharyngeal mouth is the organ which grasps the animal used for food. Round the pharyngeal mouth the openings of pharyngeal glands are found, which are situated in the parenchyma. The pharynx leads into a blind stomach consisting of three main tubes with numerous side branches. One of the main tubes is median in position and runs forward almost to the anterior end of the animal, the two others run backward, right and left of the mouth cavity to the posterior end. There is no anus. 
Specialized organs of circulation and respiration are absent.

Excretory system. The excretory system consists of two longitudinal canals, running the whole length of the body and anastomosing anteriorly; they are the so-called collecting canals. The capillary canals, present in great numbers and each closed distally by a flame cell open into the collecting canal. The collecting canals open to the outside on the dorsal surface by means of short tubes. There are altogether four pairs of excretory pores.

Nervous system. The nervous system consists of a brain occupying the anterior end of the animal and of two longitudinal nerves extending to the posterior end of the animal. The brain is composed of two lobes connected with each other by a transverse commissure and supplies with nerves the tentacles and the median lobe as well as the eyes. The longitudinal nerves are connected with each other by numerous commissures and give off numerous branches which innervate the entire body.

Reproductive system. The great majority of Turbellarians including D. lacteum are hermaphrodites. The male and female genital organs open into a genital cloaca communicating with the outside by means of a common genital opening which is situated on the ventral surface at some distance behind the mouth. The male genital organs consist of numerous testes beginning shortly behind the ovaries and extending to or even beyond the region of the common genital opening, of two rather short vasa deferentia which open into a penis pouch, a muscular penis and a group of penis glands (prostata). There seem to be no efferent ducts leading from the testes to the vasa deferentia; the spermatozoa reach the latter through the interstices of the parenchyma. As already stated, the penis opens into the genital cloaca and lies usually invaginated in the penis pouch. During copulation the penis becomes evaginated and protrudes through the common genital opening.

The female genital organs consist of three groups of organs not directly connected with each other, but each with a separate opening leading into the genital cloaca. The first group consists 
of two ovaries situated in the anterior end of the body shortly behind the eyes and two oviducts running more or less parallel to each other and uniting posteriorly of the common genital opening, where they form a common or single oviduct. B oth oviducts receive throughout their length a great number of yolk glands. The second organ which has a separate opening into the genital cloaca is the uterus with its uterine canal. Both are single; the uterus lies in front of the penis pouch, extending to the region of the mouth. The uterine canal is dorsal to the penis pouch.

The third organ with a separate opening into the genital cloaca is the muscular bursa copulatrix which functions as a female organ of copulation.

From the foregoing it is clear that the genital cloaca has five openings: (I) the common genital opening

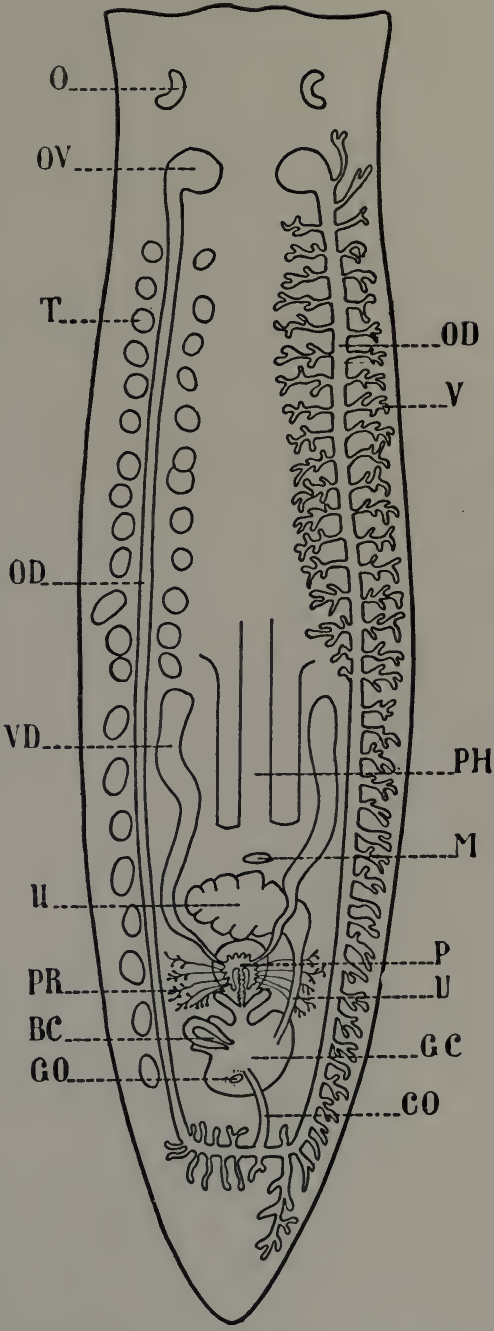

FIG. I3. - Reproductive Organs of Dendrocœlum lacteum after Hallez. $O$, eye; $O V$, ovary; $T$, testis; $O D$, oviduct; $V D$, vas deferens; $U$, uterus; $P R$, prostata; $B C$, bursa copulatrix; $G O$, genital opening; $Y$, yolk glands; $P H$, pharynx; $M$, mouth; $P$, penis; $G C$, genital cloaca; $C O$, common oviduct. 
leading to the outside, (2) the opening of the penis, $(3)$ the opening of the common oviduct, (4) the opening of the uterine canal and $(5)$ the opening of the bursa copulatrix.

The cocoon in which the eggs are inclosed is formed in the case of Dendrocœlum lacteum in the genital cloaca. The development is direct.

\section{Instructions}

I. Make a half page drawing of a live or preserved specimen showing the shape of the body, tentacles, median lobe, eyes, alimentary canal, mouth, genital cloaca and the common genital opening.

2. Place a live specimen on a slide in a drop of water under cover glass and examine the edge of the animal under high power (400 diameters). If the light is adjusted correctly the beating of the cilia of the epithelium will be observed without difficulty.

3. Make a drawing from a prepared slide of a cross-section through the region of the eyes. Label eyes and brain.

4. Make a drawing of a cross-section through the region of the ovaries. Label ovaries and stomach with its branches.

5. Make a drawing of a cross-section through the region somewhere between the ovaries and the pharynx. Label epithelium, muscular system, testes, oviducts, yolk glands, anterior stomach canal with its branches, longitudinal nerves and parenchyma.

6. Make a drawing of a cross-section through the region of the pharynx. Label all organs including the vasa deferentia, mouth cavity, pharynx, and pharyngeal glands.

7. Make a drawing of a cross-section through the region of the uterus and label parts.

8. Make a drawing of a cross-section through the region of the penis pouch and label parts. 
9. Make a drawing of a cross-section through the region of the genital cloaca and label parts.

Iо. Examine section mentioned in No. 5 under high power (400 diameters) and make a drawing of the epithelium showing epithelial cells, gland cells and rhabdites. 


\section{DICROCELIUM LANCEATUM Stiles and Hassall}

\section{$=$ Distomum lanceolatum}

Material. D. lanceatum is by far the best species of Trematodes for class study. Although it does not occur in the United States, at least not as an indigenous species, it is preferable to other Trematodes on account of the clearness with which all the parts of the complicated reproductive organs may be seen even by the inexperienced student. D. lanceatum is so common in Europe, especially in Germany, that there should be no difficulty in procuring any number of specimens. The best results are obtained, when the specimens have been preserved in a weak formalin solution and stained in alum carmin. Prepared slides of Distomum in toto may be bought of $\mathrm{H}$. Böcker in Wetzlar at the listed catalog price of Mark I.5 per slide. The lung flukes of frogs used in this country as representative types of Trematodes are far inferior to D. lanceatum, and possess moreover no Laurer's canal. Each student should receive a prepared slide of $\mathrm{D}$. lanceatum stained and mounted in toto and, if possible, a complete series of cross-sections.

\section{Descriptive Part}

Dicrocœlium lanceatum is a typical representative of the Class Trematodes of the Phylum Platyhelminthes. It is the commonest liver fluke of sheep in Europe, found often in hundreds in the gall ducts. Its body is quite flattened dorsoventrally. The anterior end may be recognized by the mouth sucker and the ventral surface by a similar sucker or acetabulum situated in the median line about one-fifth the animal's length 
DICROCELIUM LANCEATUM STILES AND HASSALL 63

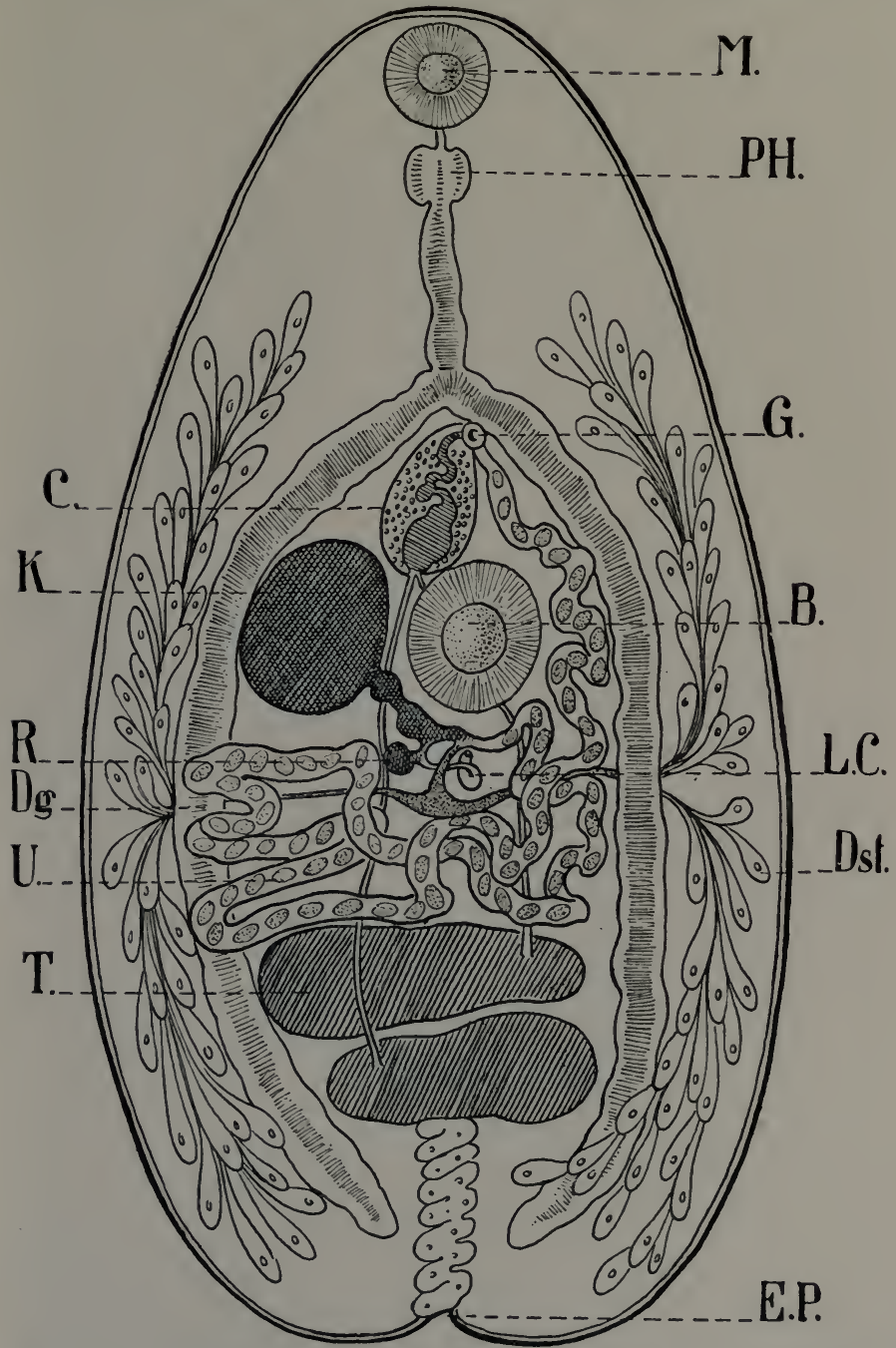

Fig. I4. - Opisthioglyphe endoloba (Duj). After Loos. B, acetabulum; $C$, cirrus pouch; $D g$, branch of intestine; $D s t$, yolk gland; $E P$, excretory pore; $G$, genital pore; $K$, ovary; $L$. $C$, Laurer's canal; $M$, mouth; $P H$, pharynx; $R$, receptaculum seminis; $T$, testis; $U$, uterus. 
from the mouth sucker. Of the five openings to the outside found in the majority of trematodes, three are on the ventral surface (the mouth and the male and female genital openings), one at the posterior end of the body (the excretory opening), and one on the dorsal surface (opening of the Laurer's canal). Än anus is not present. Locomotion is accomplished by the combined action of the muscular system of the body aided by the muscular system of the suckers.

Integument. Unlike Turbellarians, D. lanceatum has no epithelium, a condition due to its mode of development and true to all Trematodes. The body is covered with a cuticle secreted by special cells which are found between the muscles and in the parenchyma.

Muscular system. The muscles underlying the cuticle belong to three distinct layers. First come the circular muscles. Then a thin layer of diagonal muscles. The third or innermost layer is composed of longitudinal muscles. Traversing the body of the animal from one surface to the other and attached to the cuticle on both sides are the dorso-ventral muscles.

The acetabulum or ventral sucker is a shallow cup-shaped muscular organ of attachment composed of radial, equatorial and meridional fibres. Special muscles attached to the acetabulum serve for the locomotion of the entire sucker.

Parenchyma. All the space between the muscular system and the various organs is occupied by a special tissue composed of a homogeneous substance traversed by a network of fibres and containing many nuclei. This tissue is called parenchyma and is a mesenchyme.

Digestive system. The mouth opens ventrally close to the anterior end of the body and leads into the mouth cavity formed by the mouth sucker. The mouth sucker is composed mainly of radial and a network of diagonal muscular fibres. The anterior edge of the sucker forms an upper lip, the posterior edge a lower lip. Both can be moved separately by means of special muscle fibres in the sucker, belonging to the diagonal 
group. The mouth cavity leads into a muscular pharynx which is globular and considerably smaller than the mouth sucker. Its walls are composed mainly of radial muscle fibres. The pharynx protrudes somewhat into the mouth cavity, thus forming an upper and a lower pharyngeal lip. A protractor and a retractor muscle control the forward and backward movement of the pharynx. The last section of the foregut or stomadeum is the cesophagus, a short and thin tube with muscular walls and an inner lining formed by a cuticle with short spines directed backwards. Unicellular salivary glands situated above the œsophagus open by means of long ducts into the pharynx and mouth cavity.

The midgut or intestine into which the œsophagus opens consists of two blind arms running backwards for a considerable distance. It is lined with epithelial cells and has a rather poorly developed muscular layer composed of longitudinal and circular fibres.

Excretory system. The excretory system consists of a pair of canals which begin in the posterior end of the body, run forward as far as the vicinity of the mouthsucker, turn more or less sharply and run backward, finally uniting in a single excretory canal. This canal occupies the median line of the posterior quarter of the body and opens at the posterior end of the animal. A number of smaller canals open into the two excretory canals. Each of these small canals ends in a funnel closed by a so-called "flame cell." The walls of the canals are formed by a thin cuticle and are surrounded by the parenchyma. Inasmuch as their walls have no cellular structure the canals may be regarded as remains of the body cavity. The single median canal is provided with longitudinal muscular fibres and a sphincter controlling the excretory opening.

Nervous system. The central nervous system consists of a pair of cerebral ganglia situated above the pharynx. The right and the left ganglion are connected with each other by a commissure which is dorsal to the pharynx. Each ganglion gives rise to three anterior and three posterior longitudinal 
nerves. Two of these six nerves are ventral, two dorsal and two lateral. Their ramifications supply with nerves the various organs. The six nerves running backward anastomose freely with each other by means of numerous transverse commissures. Ganglionic cells are found throughout the length of the main stems. The mouth sucker and the pharynx receive each a pair of special nerves from the cerebral ganglia. Special sense organs are absent.

No circulatory or respiratory system is present.

Reproductive system. D. lanceatum is a true hermaphrodite like the great majority of the Trematodes, $i$. e., it has a complete set of male and female sexual organs in the same individual. The genital openings are separate, both on the ventral surface in the median ventral line. The female genital opening lies in front of the acetabulum and about on the same level with the two branches of the intestine where they merge in the œsophagus. The male genital opening lies immediately behind the female opening. A common genital cloaca, so common in Trematodes, is wanting in $\mathrm{D}$. lanceatum. The male genital apparatus consists of a pair of testes, their ducts and an organ of copulation. The testes are situated between the two branches of the intestine. They are not symmetrical in their position. The first testis lies immediately behind the acetabulum, while the second testis lies somewhat to the left immediately behind the first one. Accordingly the ducts or vasa deferentia are not of equal length and since both run forward, that of the posterior or second testis is the longer. Both ducts meet in the median line immediately in front of the acetabulum. From here on they continue as a single duct or ductus ejaculatorius. This duct is inclosed in a so-called cirrus pouch and presents three sections, the seminal vesicle, the median or prostatic section and the terminal or cirrus section. The latter may be protruded through the male genital opening by a process of evagination or turning inside-out when it functions as the cirrus or male organ of copulation. The walls of the cirrus have circular and longi- 
tudinal muscle fibres. The cirrus pouch itself has muscular walls and harbors many unicellular glands called the prostata which open by means of separate ducts into the median section of the ejaculatory duct.

The female genital apparatus consists of a single ovary,

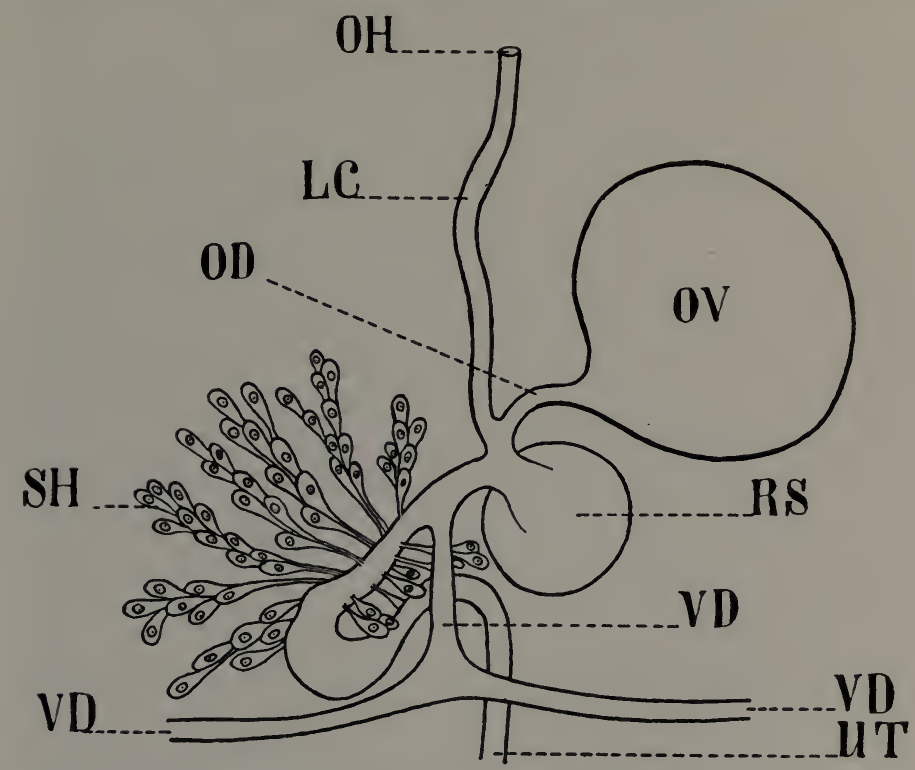

FIG. 15. - Interrelation of various ducts in the female reproductive organs of Dicrocalium lanceatum after Leuckart. OV, ovary; $R S$, receptaculum seminis; $S H$, Mehlis' gland; $V D$, vitello duct; $U T$. uterus; $O D$, oviduct; L. C, Laurer's canal; OH, opening of Laurer's canal.

an oviduct, a receptacle for the sperm, two yolk glands with their ducts, Mehlis' gland, a uterus and a Laurer's canal. The ovary lies immediately behind the second testis, and the considerably smaller receptaculum seminis lies immediately behind the ovary, close to the dorsal surface of the animal. The oviduct is a very short tube and soon receives the Laurer's canal and duct of the receptaculum. The latter is about as long as the ovi- 
duct. The Laurer's canal is several times longer than the oviduct. It runs forward at an angle to the longitudinal axis of the body and opens on the dorsal surface considerably to the left of the plane of symmetry, on the level of the posterior edge of the second testis. Its function is as yet not well understood. The uterus is in direct continuation with the oviduct and from this it is evident that the duct of the receptacle and the Laurer's canal mark the end of the oviduct and the beginning of the uterus. In many Trematodes the space at the juncture of the four canals is considerably widened and is then known under the name of "oötype." But in D. Lanceatum no such oötype is present. The uterus is a very long duct, about twelve times longer than the animal itself and is consequently coiled up. The diameter of the uterus at its beginning is no wider than the diameter of the other three ducts but it becomes very soon considerably wider. The course of the uterus is at first backward, till it reaches close to the posterior end of the body. From here on it runs forward, passes the testes and ends in the female genital opening which has been already mentioned. The coils of the descending (backward) portion of the uterus run parallel with and ventral to those of the ascending portion. This is the reason why in an animal stained in toto the uterus appears as if it were branched. When fully developed the uterus occupies the entire space between the two branches of the intestine and almost all the space to the rear of them. The two yolk glands are situated in the middle third of the body to the outside of the intestinal branches. Each gland is in reality a composite of a number of small glands which open separately into the longitudinal yolk duct (of which therefore there are two, one on each side of the body). The longitudinal yolk ducts are connected with the transverse yolk ducts which run approximately at right angles with the axis of the animal, meet in the middle and form a short common yolk duct which opens into the uterus close to the duct of the receptacle. The transverse yolk ducts are ventral to the intestinal branches. Mehlis' gland consists 
of a number of unicellular glands surrounding the uterus immediately behind the opening of the common yolk duct. Each gland opens into the uterus by means of a separate duct.

Apparently both cross and self-fertilization are possible. In both cases the organ of copulation is the cirrus, but in the case of self-fertilization it is introduced into the female genital opening of the same individual. The sperm travels all the length of the uterus till it reaches the duct of the receptacle and finally the receptacle itself. The eggs produced in the ovary slip down the oviduct and become fertilized by the sperm stored in the receptacle as they pass by the opening of its duct. Yolk from the yolk glands is added to each fertilized egg as it passes by the opening of the common yolk duct. Finally a shell is formed around each egg from material furnished by the yolk ${ }^{1}$ gland and the now completely formed egg travels down the uterus followed by other eggs, until the uterus is completely filled. A well developed uterus may harbor over a million eggs.

Development. The eggs develop in the uterus but the little embryo remains inclosed in the eggshell and does not leave it until the egg has been swallowed by a snail. The eggshell loses its little lid under the influence of the digestive juices and sets free the larva which is called miracidium and is provided with a ciliated ectoderm. This larva finally manages to get into the liver of the snail, but in doing so it strips itself of its ciliated ectoderm. The further development of $\mathrm{D}$. lanceatum has never been observed, but we must assume that it is essentially the same as in its better known near relative, the large liver fluke Fasciola hepatica. Here the larva grows into the new stage known as sporocyst. The sporocyst soon produces by a special kind of internal budding a number of redice or larvæ of the second generation. Each redia produces by a similar process a

${ }^{1}$ The gland formerly known under the name of "shell-gland " and " described here as Mehlis' gland does not produce the shell, but probably secretes a liquid in which the eggs are suspended. See Goldschmidt, Zool. Anz. I909. 
number of cercaria or larvæ of the third generation. The cercaria is already similar to the fluke except that it has a tail and that its reproductive organs are not yet developed. The cercariæ leave the snails, swim for a while in water with the aid of their tail, sooner or later climb up a grass-blade, lose the tail and become encysted. If now swallowed by a sheep, the young fluke becomes liberated from its cyst, travels up the gall duct and soon matures. In the case of Fasciola hepatica a single egg may produce on the average ten rediæ and each redia forty cercariæ. Thus a single egg will produce about four hundred adult flukes and the progeny of a single fluke reach the considerable number of 400,000,000 (four hundred million). This immense productivity counterbalances the loss incurred by the species in the passive transmission to the intermediary and final host.

\section{Instructions}

I. Examine a prepared slide of D. lanceatum under the dissecting microscope to get a general view of the various organs. Place now the slide under the microscope (50 diameters), and make a full page drawing showing all organs. The drawing ought to show the digestive system including mouth sucker, pharynx, œsophagus and intestine; acetabulum or ventral sucker; the common excretory canal with the excretory opening at posterior end of animal; the male reproductive organs including both testes, vasa deferentia, cirrus pouch with ejaculatory duct in which one may sometimes distinguish the vesicula, the prostata portion, the prostata and the cirrus; the female reproductive organs including ovary, receptaculum seminis, oviduct, yolk glands, longitudinal and transverse yolk ducts. (In some cases Laurer's canal, the common yolk duct, the duct of the receptacle and Mehlis' gland will also be visible.) Label all parts including male and female genital openings.

2. Examine under low power (50 diameters) the series of cross-sections through D. lanceatum. Pick out for special study 
the sections through (I) the cerebral ganglia, (2) the acetabulum, (3) the anterior testis, (4) the posterior testis, (5) several successive sections following the end of the testis. Make diagrammatic drawings of each of these sections to show the relative position of the organs and of the various ducts.

3. Additional exercise. Put a snail in a small dish with water, break its shell, make an incision in the liver and collect the escaping rediæ and cercariæ into the water. These larval stages belong to other species of flukes than $\mathrm{D}$. lanceatum and may be readily procured if one has a sufficient number of snails. Examine them while alive. They may be afterwards killed in a sublimate fixing fluid and stained with hæmatoxylin. 


\section{TAENIA SAGINATA Goeze}

Material. Tænia saginata may be obtained at almost any hospital. It should be preserved in $2-4 \%$ formalin (avoid alcoholic specimens as they become intransparent). Stain in Grenacher's Alumcarmin for twenty-four hours. Decolorize for a few seconds in water with hydrochloric acid, wash in water for twenty-four hours. Press the proglottids gently between two slides by tying the slides with a thread and place the slides into $50 \%$ alcohol for twenty-four hours. Transfer slides into $95 \%$ alcohol for twenty-four hours, then into a jar with absolute alcohol with desiccated copper sulphate for twenty-four hours; hence into xylol for twenty-four hours. Cut the thread, separate the slides and lifting the proglottid with a spatula transfer it for twenty-four hours into a thin solution of xylol dammar. Inclose in thick xylol dammar. This method gives remarkably beautiful slides showing all organs. The proglottids with uterus filled with eggs should be treated in the same manner but without any stain. The scolex is too rare to be used for class work. Dipylidium caninum ( = Tænia elliptica sive cucumerina) found in quantities in almost all dogs and cats may be used for this purpose. Material preserved in sublimate is preferable for cross-sections which may be stained in Böhmer's or Delafield's hæmotoxylin. In place of Tænia saginata $\mathrm{T}$. crassicollis, T. serrata or T. marginata may be used.

\section{Descriptive Part}

Tænia saginata is a common human tapeworm. A full grown specimen measures usually about eight metres in length although specimens of only four metres and such of ten metres length are 
not uncommon and cases have been reported where the worm attained the considerable length of thirty-six metres. As the body of the worm is very contractile the length is subject to great variations even if the age and number of proglottids is the same.

The scolex (unfortunately often called "head") is at the foremost end of the body and is followed by a long strobila or chain of upwards of one thousand proglottids which increase gradually in length and width. The oldest proglottids are at the posterior end of the worm. Daily several of these proglottids break off and leave the intestine of the pa$\mathrm{t}$ i e $\mathrm{n} \mathrm{t}$ spontaneously, and daily new proglottids are formed by the scolex by a process of strobilization or segmentation of its "neck." If the entire chain is broken off at the scolex, it takes the latter from ten to twelve weeks to pro-

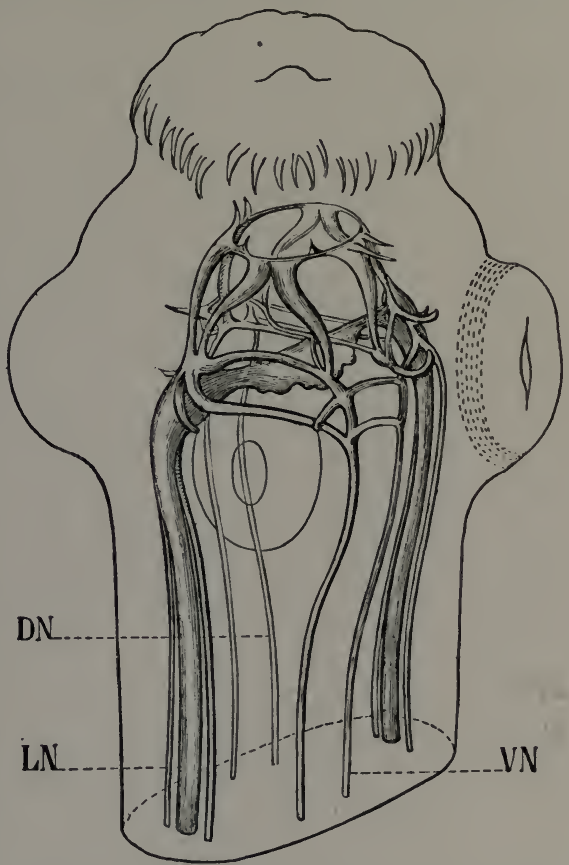

Fig. 16. - Nervous system in the scolex of Tania conurus after Niemiec. $D N$, dorsal nerve; $L N$, lateral nerve; $V N$, ventral nerve. duce a new chain. The internal organization of each proglottid is the same as that of the preceding and following proglottids, but sexual mature proglottids are found only, roughly speaking, in the middle third of the chain. The posterior proglottids show a degeneration of the sexual organs owing to the enormous development of the uterus under pressure of the 
immense quantity of eggs. The entire chain of proglottids is strongly compressed dorso-ventrally, but owing to the lateral position of the genital openings the distinction between the dorsal and ventral surfaces is not so simple as is the case with tapeworms in which the uterus has an opening of its own in the median ventral line. It is customary to call dorsal the surface which is further removed from the ovary.

The scolex is almost square in a transverse section and compared with the chain is very small, for it measures only about I. $5 \mathrm{~mm}$. square. It has four suckers and between them a poorly developed and modified rostellum appearing as a small sucker. Besides a highly developed muscular system it has a central nervous and an excretory system, both of which continue through the entire chain of proglottids.

The mature proglottids are most suitable for the study of the internal organization of the tapeworm for only in them all parts of the reproductive system are found. An examination of a cross-section shows that the outside covering is a cuticle produced by special cells situated in the parenchyma or the tissue which fills out all the spaces between the different organs and muscles. An epithelial epidermis is lacking. The muscular system is highly developed. It consists of a thin sheet of circular muscles followed by a thin sheet of longitudinal muscles beyond which are the cuticle-producing cells. A second set of longitudinal muscles extends all the way to the transverse muscles which run from one side of the proglottis to the other. Dorso-ventral muscles traverse the parenchyma and serve to flatten the body. The central portion inclosed between the dorsal and ventral transverse muscles contains all the organs with exception of the peripheral nerves, four of the longitudinal nerves and the collecting tubules of the excretory system. The parenchyma is a mesenchymatous tissue and its cells produce usually calcareous bodies found in great quantities throughout the parenchyma.

Digestive organs are absent.

The nervous system consists of ten longitudinal nerves, three 
pairs of which are lateral, one pair dorsal and one pair ventral. The dorsal and ventral nerves lie outside the transverse muscles. Of the three lateral nerves of each side the middle one is by far the largest. The longitudinal nerves give off minute branches to the sense cells found in the parenchyma. In the scolex the longitudinal nerves are connected with each other by commissures with ganglionic enlargements forming the central nervous system.

The excretory system consists typically of two pairs of longitudinal canals opening to the outside on the last proglottid. Of these the inner pair is considerably less developed than the outer pair and seems to be missing in older proglottids. Close to the posterior edge of each proglottis is a transverse canal connecting the two longitudinal canals. The collecting tubules which are numerous are very thin tubes opening into the longitudinal canals. The distal end of the tubules is closed by a flame cell.

Reproductive system. Tænia saginata is a hermaphrodite and each proglottid has a complete set of reproductive organs. The genital papilla or the wall of the genital atrium is situated either on the left or on the right side of the proglottis. The male reproductive organs consist of several hundreds of small round testes situated to the inside of the dorsal transverse muscles extending over almost the entire proglottis. The vasa efferentia open near the middle of the proglottis into the vas deferens, a canal which appears under low power as a straight line running to the genital atrium, but which in reality is convoluted throughout its entire length. The end portion of the vas deferens, which is inclosed in a muscular cirrus pouch, may be protruded as a cirrus through the male genital opening into the atrium.

The female reproductive organs are much more complicated. The female genital opening situated in the atrium under the male genital opening, leads into a thin, straight tube running parallel with the vas deferens. This tube is the vagina. Towards the middle of the proglottis the vagina bends downward and forms 


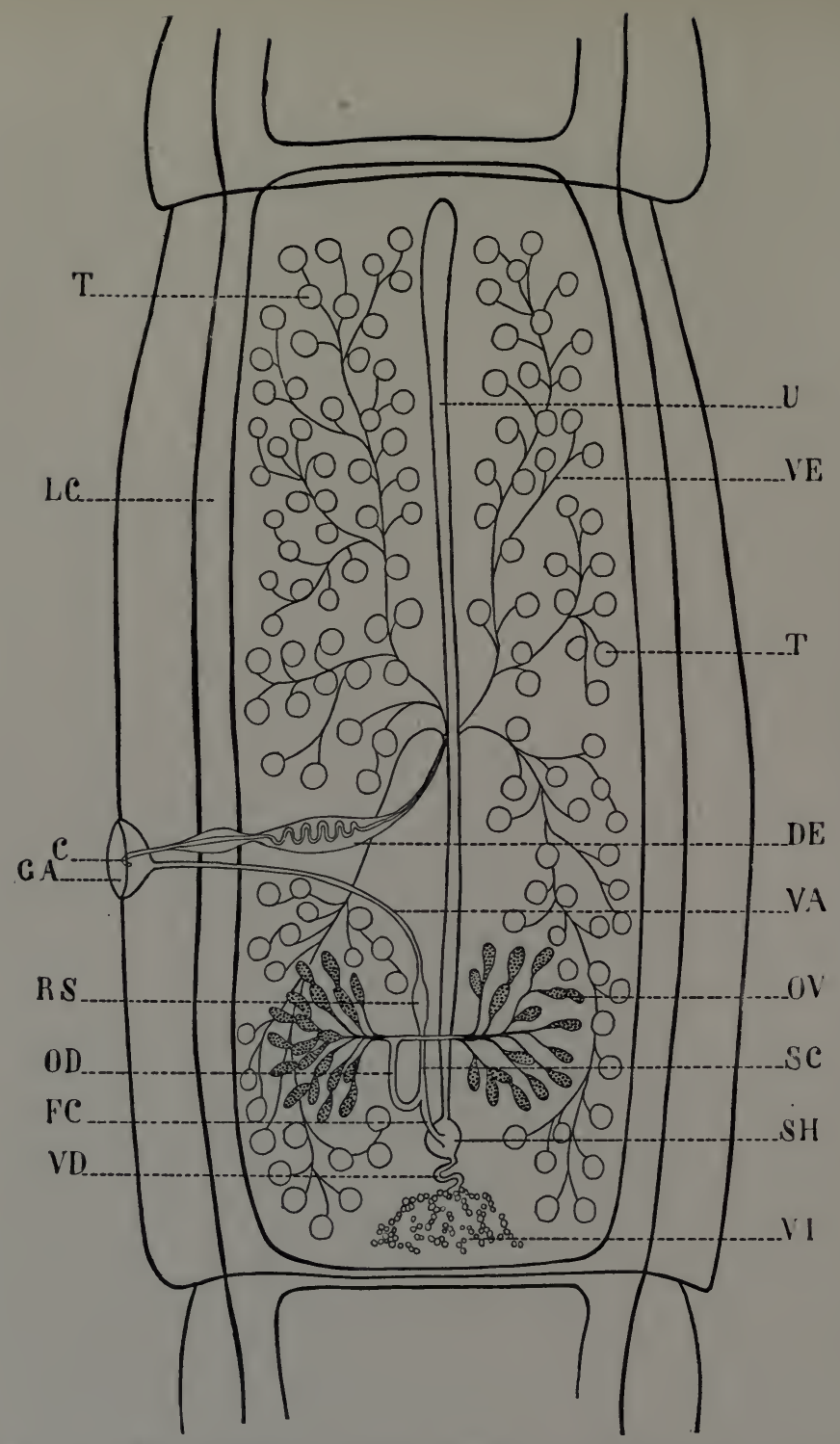

FIG. 17. - Mature Proglottis of Tania Canurus after Leuckart. T, testis; LC, lateral canal; $C$, cirrus; $G A$, genital cloaca; $R S$, receptaculum seminis; $O D$, oviduct; $F C$, fertilization canal; $V D$, vitello duct; $U$, uterus; $V E$, vas efferens; $D E$, ductus ejaculatorius; $V A$, vagina; $O V$, ovary; $S C$, sperm canal; $S H$, Mehlis' gland; $V I$, yolk gland. 
the receptaculum seminis. Immediately beyond this the vagina receives the oviduct and proceeds then as the so-called fertilization canal to the oötype where it unites with the yolk duct and the uterus. The two ovaries although having the appearance of more or less round bodies, are in reality composed of a number of tubular follicles. Their ducts unite in the median line of the proglottis and form a short common oviduct which, as already stated, opens into the vagina behind the receptacle for the sperm. The yolk gland is single, situated close to the posterior end of the proglottis. The yolk duct is short, straight and opens into the fertilization canal in the oötype in the same place with the uterus. The uterus appears as a blind tube of considerable size running forward almost to the anterior edge of the proglottis. In maturing proglottids this tube is simple, but under the pressure of eggs it begins to develop branches and in the rearmost proglottids occupies almost the entire space. There are then from twenty to thirty-five branches on each side of the median canal of the uterus. The Mehlis' gland or oötype has an almost circular shape and consists of numerous glands each opening separately into the fertilization canal at its place of union with the uterus and yolk duct.

Self-fertilization is usual, but cross-fertilization occurs. The sperm is stored in the receptacle. The eggs are fertilized in the fertilization canal, and on being supplied with yolk and surrounded with a shell pass into the uterus. They reach the outside through a disintegration of the tissues or are swallowed with the entire proglottis. The development is combined with a metamorphosis and a change of hosts, the intermediary host being cattle. The first larval stage is known as an oncosphara which on reaching the muscles (or sometimes internal organs) becomes transformed into a cysticercus.

\section{Instructions}

I. Examine under dissecting microscope the prepared slide of a mature proglottis. It shows the longitudinal and transverse 
excretory canals, genital papilla with the atrium and all parts of the reproductive system except the efferent canals and the oviduct. Make a half page drawing and label all parts.

2. Examine under dissecting microscope the prepared slide of a proglottis with a fully developed uterus. Count its lateral branches on each side. Make a half page drawing showing the outline of the proglottis and the uterus.

3. Examine under low power a cross-section through a proglottis. Make a half page drawing and label the cuticle, subcuticular cells, longitudinal, dorso-ventral and transverse muscles, testes and uterus, longitudinal excretory canals and the lateral longitudinal nerves.

4. Examine a prepared slide of a scolex of Dipylidium caninum (a common tapeworm of dogs and cats). Unlike the scolex of $\mathrm{T}$. saginata it has a well developed rostellum with hooks. Make a drawing showing rostellum, hooks, suckers, and neck. 


\section{ASCARIS LUMBRICOIDES Linnæus varietas SUILLA}

Material. A. suilla is so common in pigs that it may be found in great quantities at any slaughterhouse. The specimens should be placed directly into Perenyi's fixing fluid in which they may remain for any length of time. Material thus fixed is good both for dissection and microscopic anatomy. Sections should be stained in hæmatoxylin and eosin. Every student should receive one male, one female, a cross-section showing the nervous ring and a cross-section through the middle of the worm.

\section{Descriptive Part}

Ascaris suilla is a common parasite of the pig and is closely related to the human round worm. It is a typical representative of the Class Nematoda.

External features. Ascaris suilla has the shape of a long cylinder attenuated at both ends. At one end is the mouth surrounded by three finely toothed triangular lips, one of which is dorsal and the other two ventro-lateral in position. Extending practically through the whole length of the animal are four equidistant lines: a median ventral line, a median dorsal line, and two lateral lines. About two millimeters from the anterior end is a small excretory pore in the median ventral line. The posterior end of the female is practically straight and the anus appears as a transverse slit with two anal lips on the ventral side about two millimeters in front of the tail end. The female genital opening is also median and ventral in position and is situated about onethird the entire length from the head. The position of the opening in younger females is nearer the middle of the body. 


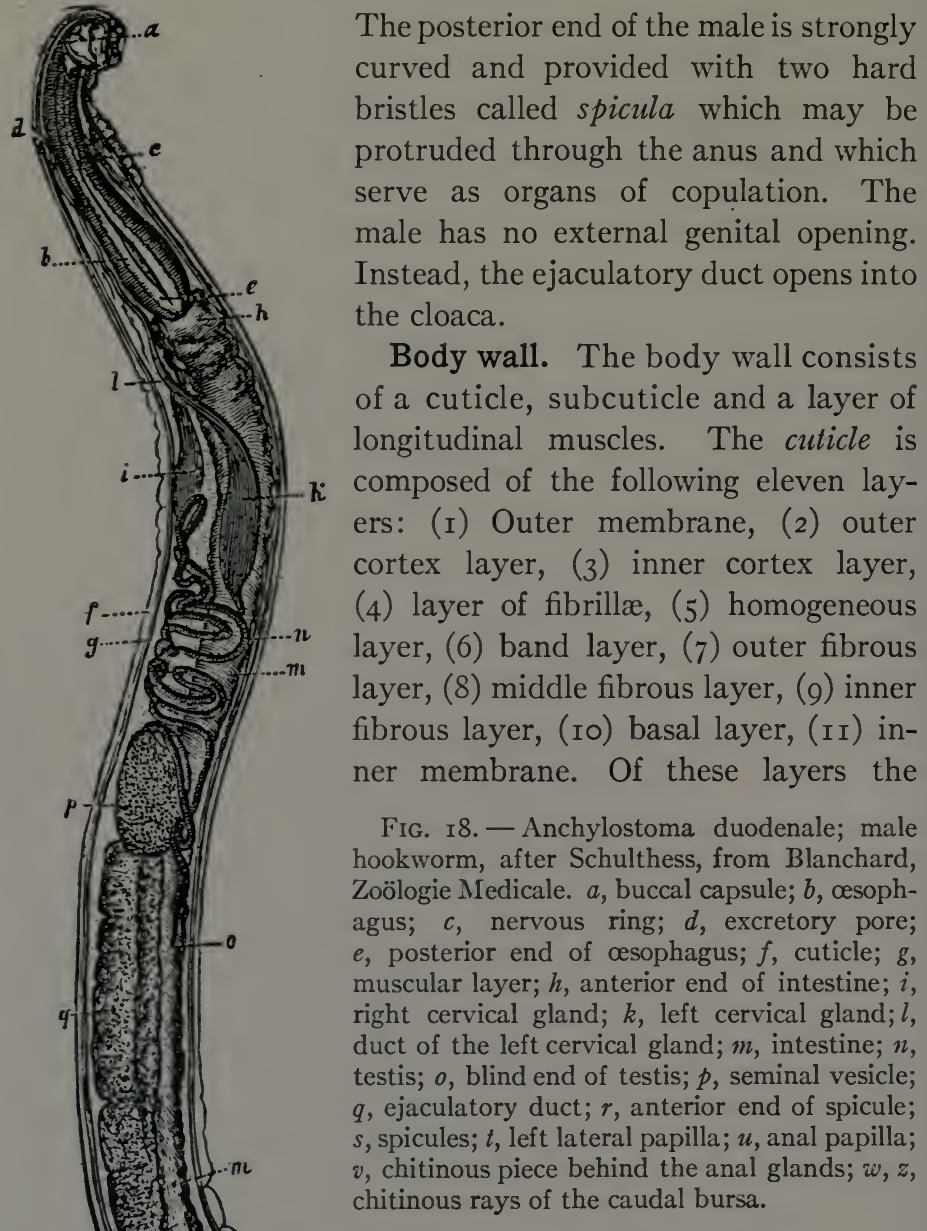

The posterior end of the male is strongly curved and provided with two hard bristles called spicula which may be protruded through the anus and which serve as organs of copulation. The male has no external genital opening. Instead, the ejaculatory duct opens into the cloaca. of a cuticle, subcuticle and a layer of longitudinal muscles. The cuticle is composed of the following eleven layers: (I) Outer membrane, (2) outer cortex layer, (3) inner cortex layer, (4) layer of fibrillæ, (5) homogeneous layer, (6) band layer, (7) outer fibrous layer, (8) mi fibrous layer, (Io) basal layer, (II) inner membrane. Of these layers the FIG. I8. - Anchylostoma duodenale; male hookworm, after Schulthess, from Blanchard, Zoölogie Medicale. $a$, buccal capsule; $b$, œsophagus; $c$, nervous ring; $d$, excretory pore; $e$, posterior end of œesophagus; $f$, cuticle; $g$, muscular layer; $h$, anterior end of intestine; $i$, right cervical gland; $k$, left cervical gland; $l$, duct of the left cervical gland; $m$, intestine; $n$, testis; $o$, blind end of testis; $p$, seminal vesicle; $q$, ejaculatory duct; $r$, anterior end of spicule; $s$, spicules; $t$, left lateral papilla; $u$, anal papilla; $v$, chitinous piece behind the anal glands; $w, z$, 
homogeneous layer is the thickest, equal to or even exceeding in thickness all other layers taken together. The cuticle is nonporous ${ }^{1}$ and transversely plicated. Under the cuticle is a thin syncitial subcuticle containing nuclei. The cuticle is a product of this layer which may be best termed hypodermis. ${ }^{2}$ Under the latter is a single layer of longitudinal muscles. Each muscle cell consists of a protoplasmic core or cell body and a contractile sheath. The protoplasm is highly vacuolated. It contains the nucleus and a system of supporting fibres. The contractile sheath is drawn out on one side of the cell into a flat spindle which is longer than the cell body and is differentiated into longitudinal fibres. In a cross-section the fibres appear therefore arranged in two rows, at first parallel and barely separated from each other, then diverging and partly inclosing the protoplasmic core. The fibres are inserted directly into the cuticle. The protoplasmic core with its supporting fibrillæ sends out processes to the nerves in the longitudinal lines. The layer of longitudinal muscles is divided by these lines into four longitudinal fields or bands. In some Nematodes there are only two muscle cells in a crosssection of a band. But in Ascaris there are several muscle cells to a cross-section of a band and Ascaris belongs therefore to the so-called polymiaria.

Body cavity. Ascaris has no true body cavity. The cavity which one sees in dissecting the worm is in reality a system of intracellular spaces, or large vacuoles in a few enormous cells which fill out the space between the longitudinal muscles and the alimentary canal and reproductive organs. The vacuoles are so large and so many that the walls between them are quite thin and have been overlooked until recently. Ascaris and with it all other Nematodes shows more relation to the

${ }^{1}$ What has been described as a system of minute canals proved to be the fibrillar layer.

${ }^{2}$ The subcuticle is usually called ectoderm. The term hypodermis, first proposed for a similar layer in Arthropods, is less confusing since there are in Ascaris other organs of ectodermal origin. 


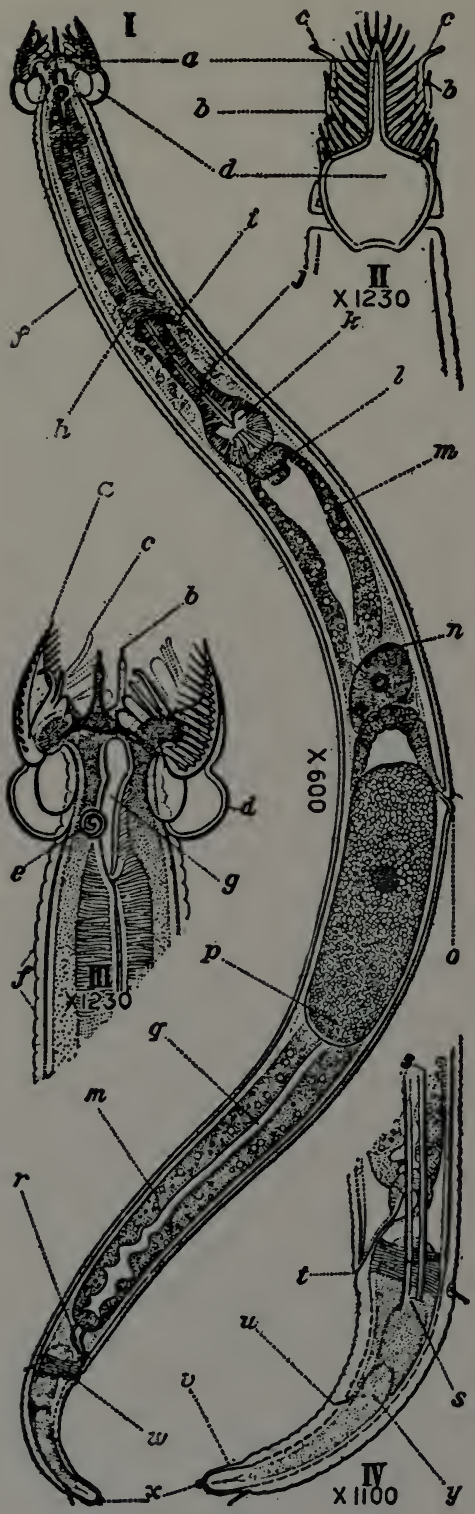

parenchymatous flatworms than to higher invertebrates with a cœlome.

The vacuoles contain a fluid rich in albuminous substances. This fluid has an unpleasant odor and is highly poisonous to some individuals, producing a strong irritation of mucous membranes.

Muscular system. Locomotion in Ascaris is accomplished by the alternating contraction and relaxation of the longitudinal m u sclebands. When all four bands have been contracted simul-

Fig. 19. - Wilsonema, a nematode found in the soil in the United States, after N. A. Cobb, from Yearbook of Dept. Agriculture for IgI4. I, lateral view of female; II, dorso-ventral view of the head of the same individual; III, enlarged lateral view of the tail end; $a$, ventral appendage which, together with the corresponding dorsal appendage, acts as a sieve; $b$, lateral tactile organ associated with the sifting apparatus; $c$, internal elements (supports?) of the sieves; $d$, inflated valvular apparatus; $e$, amphid; $f$, cuticle; $g$, pharynx; $h$, nerve ring; $i$, excretory pore; $j$, œsophagus; $k$, threefold valve of the cardiac bulb; $l$, cardia; $m$, wall of intestine; $n$, flexure of anterior ovary; $o$, vulva; $p$, egg; $q$, lumen of intestine; $r$, rectum; $s$, lateral wings; $t$, anus; $u$, caudal seta; $v$, spinneret; $w$, anal muscles; $x$, apical portion of spinneret; $y$, one of the three caudal glands. 
taneously, expansion is due to the elasticity of the cuticle. Besides the longitudinal muscles there are several special muscles in Ascaris, which will be considered in connection with other organs.

Digestive system. The digestive system of Ascaris is very simple and consists of a straight tube running from the mouth to the anus. It may be divided into three sections: the œsophagus or foregut, the intestine or midgut and the rectum or hindgut. The osophagus is short and shows a triradial lumen in cross-section. Being a stomadeum it is naturally lined with a heavy cuticle. The wall of the œsophagus is formed by myo-epithelial cells of special structure. Their fibres, arranged radially, form real dilatatores cesophagi, $i$. e., they widen the lumen, while the cuticle lining serves as their antagonist. A few gland cells are found in the wall of the osophagus completely inclosed by the myo-epithelial cells. The intestine or midgut is a straight canal which is so much flattened dorsoventrally that it almost has the appearance of a band; its wall is composed of high, columnal epithelium. Two enormous muscle cells form a network of fibres around the hind end of the intestine and act as dilatatores. The same two cells furnish in the male also the muscular fibre-net of the ejaculatory duct. The short rectum is lined with a cuticle and is surrounded by a ring of six large gland cells. The position of the anus has been described above.

Excretory system. The excretory system is inclosed in the side lines. The side line appears as a heavy ridge separating the longitudinal muscles. Already with naked eye one can observe a longitudinal line dividing the side line into two lines, and this division appears still clearer in a cross-section. The structure of a side line is quite complicated and is composed of various elements of which the subcuticle is the least conspicuous, being in the side lines no more developed than in other regions of the body wall. The main tissue of the side line is divided into upper and lower symmetric halves by the cells of the 
interstitial lamella at the end of which is the excretory canal. The entire canal is nothing but a long cylindrical cavity inside of a single enormous cell extending almost from end to end of the worm. The canal bends downward a little behind the nervous ring and unites with the excretory canal of the other side forming a short single duct. We have seen already that this duct opens ventrally in the median line and that this $e x-$ cretory opening is situated about two millimeters from the anterior end. The wall of the common duct is also formed by a single cell. Accompanying the excretory canals throughout their length in the side lines are two pairs of excretory glands, one pair in each side line. In a cross-section they appear as large ovals situated in the main tissue of the line, one above, the other below the interstitial lamella.

Attached to the inner edge of the side lines not far from their anterior end are two pairs of phagocytic organs which have the appearance of small tufts. Their function is to retain and to make substances harmless which cannot be removed by the excretory canals.

Nervous system. The nervous system of Ascaris is composed of several cephalic ganglia or nerve centres situated in the region of the œsophagus, a nerve ring surrounding the latter, eight longitudinal nerves, six anterior sensory nerves and an anal ganglion or nerve centre in the posterior end of the body. The largest and best developed of the anterior ganglia is the so-called ventral cephalic ganglion. It has two lobes and is connected with the other ganglia and the rest of the nervous system through the nerve ring which represents a large cephalic commissure. Connected with the nervous ring and running forwards are six bundles of sensory nerves supplying the sense organs of the lips. Posteriorly the nerve ring gives off six longitudinal motor nerves. One of these is ventral and is the heaviest of all; another is dorsal, two are subdorsal and two sub-ventral. The dorsal nerve is inclosed in the dorsal median line, the ventral in the ventral median line. The other four 
nerves run in the subcuticle. The lateral lines inclose also each a longitudinal lateral nerve which, however, takes its origin from the lateral cephalic ganglion. The longitudinal nerves of each side are connected with the dorsal and ventral nerves by thin commissures which are asymmetric and form right and left semicircles.

The sense organs are represented only by six oral papilla situated on the lips and in the case of the male by from seventy to seventy-five anal papilla. Higher sense organs are absent.

Circulatory and respiratory organs are absent.

Reproductive system. (a) Female. About one-third from the anterior end of the body is a small transverse slit in the midventral line. This is the genital opening or vulva. It leads into a short vagina which soon splits into two very long, convoluted tubes. Each of these tubes is ten times as long as the entire worm and may contain over ten million eggs. The portion of the tube, which is nearest the vagina has a considerable diameter and represents the uterus. The middle portion is the oviduct and the thin end portion is the ovary. The ovary ends blindly. Inclosed in the ovary is a long central rod or rachis round which the young eggs are arranged at first regularly, then more or less in small clusters. The division line between the ovary and the oviduct is not apparent externally, but the oviduct is lacking the rachis and contains free eggs. The end of the oviduct is somewhat distended and functions as a sperm receptacle. Here the eggs are fertilized. The uterus contains therefore only fertilized eggs and its walls secrete an albuminous substance in which the eggs are inclosed.

(b) Male. The male reproductive organs are situated in the posterior third of the body. They consist of a single tube which opens into the cloaca or the short portion of the alimentary tract between the rectum and the anus. The tube is from seven to eight times as long as the entire worm and is clearly divided into three uneven portions. The longest portion is the testis which has the shape of a thin convoluted tube. 
Inclosed in the testis is a rachis similar to that in the ovary and the sperm cells are grouped around it. The rachis is not as long as the entire terminal portion and that part of the thin tube, which is free from the rachis may be termed vas deferens. The central portion is much shorter and thicker. It is the vesicula seminalis. The end portion is again much thinner and quite short, being no more than seven or eight millimeters long. It has a musculature of its own and serves as ductus ejaculatorius.

In the immediate vicinity of the ejaculatory duct are two pouches. They open into the cloaca, dorsal to the intestinal canal, and contain two chitinous bristles or spicula which serve as organs of copulation.

Development. The fertilized eggs develop directly and the shell protects the embryo from desiccation or climatic changes. When swallowed with water or vegetables, the embryo leaves the egg in the stomach of the host and matures in the intestine.

\section{Instructions}

I. Put a female Ascaris into a dissecting tray with water and examine the anterior end with the aid of a lens. Make a drawing showing the ventral view of the anterior end. Label lips, ventral line and excretory pore.

2. Open the specimen by a longitudinal slit which should be made parallel to and halfway between the dorsal and left lateral lines. Pin down the body wall. Make a full page drawing showing œsophagus, intestine, rectum, phagocytic organs if visible, vulva, vagina, uteri and oviducts with ovaries.

3. Open a male specimen in the same manner. Show in the drawing the digestive organs, ductus ejaculatorius, vesicula seminalis and testis with vas deferens; also the spicula.

4. Examine prepared slide with a cross-section through the nervous ring under low power (50 diameters) and make a drawing showing all parts. 
5. Do the same with the cross-section through the middle of the worm.

6. Examine the slide under high power (400 diameters). Make the following drawings:

(a) Cuticle. Label outer membrane, cortex layer, layer of fibrillæ, homogeneous layer.

(b) Side line. Label interstitial lamella, excretory canal.

(c) Muscle cell. Label protoplasmic core, nucleus, contractile sheath.

(d) Intestine.

(e) Uterus.

(f) Oviduct.

(g) Ovary. Label rachis and eggs. 


\section{LUMBRICUS TERRESTRIS, L. Muller}

Material. L. terrestris may be kept alive in moist soil or preserved in Perenyi's fluid for dissection. Specimens for transverse microscopic sections should be fed for several days on milk or olive oil in a jar free from soil and fixed in either Perenyi's or Petrunkevitch's sublimate mixture. Every student should receive one large specimen killed by slow narcotizing in alcohol, and the following transverse sections: through the region of the seventh to tenth segments (œsophagus), through the region between the twentieth to thirtieth segment and through the clitellum.

L. terrestris has been selected on account of its considerable size. The genus Lumbricus should not be confused with either Eisenia (common species Eisenia fotida and rosea) or Helodrilus (common species Helodrilus caliginosus, chloroticus). For distinctive characters see Das Tierreich, Oligochæta by Michælsen.

\section{Descriptive Part}

Lumbricus terrestris is an earthworm equally common in Europe and the United States and a typical representative of the Class Oligochæta. It is a hermaphrodite like the majority of the species belonging to the same class.

External anatomy. The body of Lumbricus is segmented externally. The number of segments varies from one hundred and ten to one hundred and eighty, a condition similar to that in Nereis, showing that in this respect the Oligochæts have not yet attained the degree of fixed segmentation found in leeches. The anterior end of the worm is thicker and almost round in a crosssection. The posterior end is distinctly flattened dorso-ventrally. 
The mouth is situated on the first segment and is surmounted by a prostomium. The anus is terminal on the last segment. About one-quarter or one-third the entire length from the anterior end is found a shiny belt occupying six or seven segments; this is the clitellum. Careful counting of the segments will reveal that the clitellum begins with the thirty-first or thirty-second and ends with the thirty-seventh segment, in other words, it has always a definite position. By passing a finger from the rear end of the worm forward along the ventral surface and on each side, one will feel the stiff bristles situated in each segment and forming two ventral and two lateral lines. Each line consists of two rows and each segment has therefore eight bristles or chete commonly marked as a, b, $c$, and $d$, beginning with the ventral bristles. The first and last segment have no bristles. The ventral bristles of the twenty-sixth segment situated on glandular papilla are often, but not always modified as long genital cheta. There are two openings of seminal receptacles between the ninth and tenth segments and two similar openings between the tenth and eleventh segments in the lateral lines; two female genital pores on the fourteenth segment just above

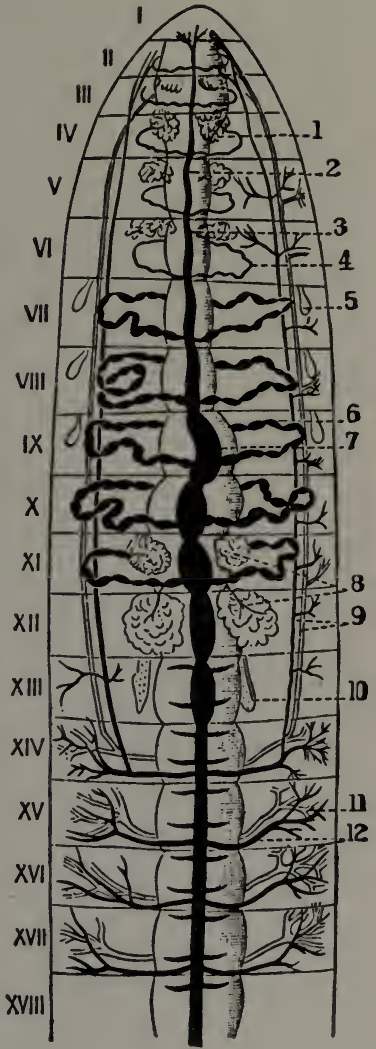

FIG. 20. - Sparganophilus tamesis, general anatomy after Bentam, from Cambridge Natural History. I-XVIII, segments; $1,4,6$, perivisceral vessels ( 6 is one of the hearts); 2 , 3,7 , dorsal vessel; 5 , spermatheca; 8, sperm sacs; 9, intestino-tegumentary vessels; Io, ovary; II, I2, integumentary vessels. 
the $\mathrm{b}$ bristles; two male genital pores on the fifteenth segment between the bristles $\mathrm{b}$ and $\mathrm{c}$; two nephridiopores or excretory openings above the b bristles in every segment, except the anterior three and the last or anal segment; finally a single row of dorsal pores in the mid dorsal line between the segments, beginning with the seven-eight intersegmental line. These openings connect the body cavity with the outside.

Body wall. The body wall is composed of a cuticle, hypodermis, circular muscles, longitudinal muscles and a thin layer of parietal or somatic peritoneum. The cuticle which is a product of the underlying hypodermis, is rather fine and presents when viewed from the surface a system of fine striation. The lines intercross each other more or less at right angles and in many points of intersection there are small pores. The underlying hypodermis consists of a single layer of columnal epithelium. Between the common cells glandular and sensory cells are found. In the clitellum the hypodermis is considerably thickened and richly supplied with minute blood-vessels which run between the cells. This region is, moreover, very rich in large gland cells which become especially active during copulation and the formation of the cocoon. The papillæ of the twenty-sixth segment contain in them capsulogenous glands producing the chief substance of which the cocoon is formed. Immediately under the hypodermis is a heavy layer of circular muscles the function of which is to elongate the body. Between the fibres of these muscles pigment gramules are found. To the inside of the circular muscles lies a still heavier layer of longitudinal muscles. They form four bands, a right and left lateral band situated between the lateral and ventral lines of bristles, a ventral band occupying the space between the ventral lines and a much broader dorsal band. The longitudinal muscles have a very peculiar structure. They consist of a central lamella with a series of parallel lamellæ attached to the former on each side. A transverse section of a longitudinal muscle has therefore the appearance of a plume or feather. The function of the longitu- 
dinal muscles is to shorten the body when all bands contract simultaneously or to curve it in the direction of that band which contracts singly. In this case the opposite bands act as antagonists.

The chetæ or bristles sit in special sacks formed by a depression of the hypodermis. The base of the sack is connected with special muscle fibres. These fibres serve to move the chetæ thus helping in locomotion.

Cœlome or body cavity. The body cavity of Lumbricus, inclosing all organs, is divided into chambers by transverse intersegmental septa. The septa are lacking only in the anterior six segments and the last posterior one where they are replaced by a loose network of muscular and connective fibres. The septa have a muscular structure and the peritoneum which lines the body wall extends over all septa. The body cavity is filled with a liquid containing amobocytes and chloragogue cells which will be mentioned in connection with the digestive system. Each cœlomic chamber communicates with the outside through a pair of nephridia and a dorsal pore. The dorsal pores have been already mentioned. If a worm is subjected to a strong stimulus or irritation a drop of cœlomic fluid appears from every dorsal pore. It is probable that we have herein an arrangement to keep the surface of the worm moist in case of excessive dryness or heat.

Digestive organs. The alimentary canal runs in a straight line from the mouth to the anus. It begins with the mouth cavity. This is followed by a muscular, ovoid pharynx which extends to the end of the sixth segment. The pharynx is provided with numerous muscles attached to the body wall and acting as dilators. The cesophagus is a laterally compressed tube extending as far back as the thirteenth segment. In the eleventh and twelfth segments it receives three pairs of small calciferous glands. These glands secrete calcium carbonate. The œsophagus is surrounded by five pairs of "hearts." The crop has the shape of an ovoid with a diameter several times that of the 
œsophagus. It occupies the fourteenth and fifteenth segments. The gizzard has about the same size as the crop but is provided with powerful musculature. It occupies the sixteenth, seventeenth, and eighteenth segments. The gizzard opens into the intestine which extends all the way to the anus. The absorbing surface of the intestine is considerably increased by the presence of a longitudinal dorsal fold or typholosole. The microscopic structure of the intestine presents some interesting peculiarities. The intestinal cavity is lined with striated cuticle produced or secreted by a layer of high columnal epithelial cells. To the outside of this layer comes the vascular layer containing blood vessels. This is followed by the muscular layer. The outermost layer of the intestine is formed by large chloragogue cells which are supposed to possess an excretory function and which are also found floating in the cœlomic fluid.

Excretory system. The excretory system of Lumbricus consists of paired nephridia or segmental organs. One pair of nephridia is found in every segment except the anterior three and the anal segment. Each nephridium is a coiled tube which opens with a ciliated funnel or nephrostome into the body cavity of the preceding segment and with a nephridiopore to the outside above the $\mathrm{b}$ bristle. The nephridium may be divided into three portions. The first, transparent portion following upon the funnel is a long thin tube with fine blood-vessels between its loops. The median or glandular portion is considerably thicker than the preceding one and is opaque because of the secretion of the glandular cells of its wall. The terminal portion is the shortest and widest and plays the rôle of a collecting bladder.

Circulatory system. The circulatory system of the earthworm is characterized by the presence of five longitudinal bloodvessels extending from end to end of the animal. The segmental character of the system is evidenced by the presence of connecting blood-vessels or loops. The largest longitudinal vessel is the dorsal vessel which runs in the mid-dorsal line above the intestine. This vessel shows swellings in every segment in the 
region of the intestine, but becomes a thinner and perfectly cylindrical tube in the region of the œsophagus and finally bifurcates above the pharynx. The dorsal blood-vessel is contractile and its pulsations push the blood forward, toward the head. In the other four longitudinal blood-vessels the blood runs from the head backwards and neither of them is contractile. The ventral vessel is the largest among them, although considerably smaller than the dorsal vessel. It lies in the mid-ventral line between the intestine and the nervous system and also bifurcates in the region of the pharnyx. The dorsal and ventral blood-vessels are connected with each other by means of five pairs of aortic loops or lateral hearts which are simply pulsating blood-vessels surrounding the œesophagus in the seventh to eleventh segments. The aortic loops push the blood from the dorsal into the ventral vessel. A further connection between the two vessels is established by means of their branches both in the pharyngeal and anal regions of the animal. The subneural blood-vessel runs along the mid-ventral line of the nervous system. The subneural and dorsal blood-vessels are connected with each other in every segment by right and left parietal vessels, the first pair of which belongs to the twelfth segment, $i$. e., follows immediately behind the last aortic loop. In the region of the aortic loops the connection between the subneural and dorsal vessels is established through the intervention of the lateral cesophageal vessels. The blood runs in the parietal vessels from the subneural into the dorsal vessel. The last two of the main five longitudinal blood-vessels are the lateral neural vessels. They run at the sides of the nervous system and are connected with the subneural vessel by short transverse vessels of which there is a pair in every segment. The intestinal canal receives the blood supply from the ventral vessel through small intestinal branches and the blood returns to the dorsal vessel through similar dorsal branches. The body wall receives its blood supply through lateral cutaneous branches of the ventral vessel. Organs of respiration are absent and the blood is oxidized in the body 
wall. Here the branches of the ventral vessel anastomose with branches which return the oxidized blood to the dorsal vessel. The dorsal vessel receives, therefore, mixed blood, the larger part of which has been oxidized while some of it is venous. The blood itself is red, but the color is contained in the plasm and not in the corpuscles.

Nervous system. The nervous system consists of a pair of supraœsophageal ganglia or brain and a ventral chain of paired ganglia. The brain is situated in the third segment and gives off anteriorly two pairs of nerves. Two lateral connectives unite the brain with the subœsophageal or first pair of ventral ganglia. The right and left elements of the nervous chain are so closely connected with each other that their paired origin may be recognized only on sections. The chain appears as a whitish cord with a swelling in every segment, which marks the ganglia. Each swelling gives off two pairs of nerves. There is also a pair of dissepimental nerves given off by the ventral chain halfway between the swellings of the chain. Thus every segment has three pairs of nerves, a condition similar to that in Nereis and Hirudo. Higher sense organs are absent.

Reproductive system. Lumbricus terrestris is a hermaphrodite like all Oligochætes. The male reproductive organs consist of two pairs of testes, two pairs of ciliated funnels, two vasa deferentia, two seminal vesicles and three pairs of spermothecæ. The testes are very small and are situated in the tenth and eleventh segments close to and above the nervous system. They are inclosed in the seminal vesicles. The first seminal vesicle which is situated in the tenth segment has two pairs of spermothecæ or lateral pouches and contains the first pair of testes and the first pair of ciliated funnels. The second seminal vesicle is situated in the eleventh segment, has one pair of large spermothecæ and contains the second pair of testes and the second pair of ciliated funnels. The funnels perforate in both segments the dissepimenta and open into the thin vasa deferentia. These two ducts are rather short, terminating in the two 
genital pores on the fifteenth segment between the b and c bristles. The sperm matures in the vesicles.

The female reproductive organs consist of one pair of ovaries, one pair of oviducts and two pairs of sperm receptacles. The ovaries are situated in the thirteenth segment. The oviducts are extremely short tubes; they begin with a wide opening in the thirteenth segment, perforate the dissepiment and end in the two female genital openings on the fourteenth segment just above the b bristles. The first pair of receptacula seminis are round white bodies situated in the ninth segment and opening to the outside in the lateral lines between the ninth and tenth segments. The second pair of receptacles are similar to the first, situated in the tenth segment and open to the outside in the lateral lines between the tenth and eleventh segments. Self-fertilization is impossible. The sperm is stored in the receptacles during copulation. It passes later into the cocoon which is secreted by the clitellum at the same time as the eggs are deposited into it. Development is direct.

\section{Instructions}

I. Place the specimen in a dissecting tray with water and make a full page drawing showing the side view. Count the segments carefully. Label mouth, anus and clitellum. For the position of the genital openings compare the specimen with what has been stated in the paragraph on external anatomy.

2. Open the specimen by a longitudinal slit parallel to the middorsal line and fasten the sides with pins. Make a full page drawing showing dissepimenta, alimentary canal, dorsal bloodvessel, aortic loops, nephridia and organs of reproduction. Label pharynx with its dilators, œsophagus, calciferous glands, crop, gizzard and intestine; dorsal blood-vessel, five pairs of aortic loops surrounding œsophagus, parietal vessels beginning behind the reproductive glands and connecting the dorsal with the subneural vessel; nephridia and three pairs of large spermothecæ.

3. Remove the alimentary canal by cutting it across in the 
middle of the pharynx, lifting with a forceps and cutting with scissors the aortic loops and parietal vessels. The removal of the alimentary canal will expose all reproductive organs, nervous system, neural blood-vessels and nephridia. Make a full page drawing showing all structures inclosed in segments seven to seventeen. Label first seminal vesicle with first and second pair of spermothecæ, second seminal vesicle with third pair of spermothecæ, the two vasa deferentia; the first pair of receptacula seminis in the ninth segment, and the second pair of receptacula in the tenth segment if not completely hidden by the spermothecæ; the pair of small ovaries in the thirteenth segment, the oviducts; and finally the setigerous glands in the eighth to thirteenth segments.

4. Remove a complete nephridium, place it on a slide in glycerine and examine under low power. Make a drawing showing nephrostome, transparent portion, glandular portion and terminal portion.

5. Remove reproductive organs and lift carefully the nervous system cutting the side nerves. Place the nervous system on a slide and examine under low power. Make a drawing showing supraœsophageal ganglion and at least five ventral ganglia.

6. Examine under low power the prepared section through the region of the aortic loops. Make a drawing showing cuticle, hypodermis, circular muscles, longitudinal muscles, dorsal vessel, ventral vessel, nervous system, œsophagus and such other organs as may be seen.

7. Examine under low power the prepared section through the region of the twentieth to thirtieth segments. Make a drawing showing a, b, c, and d bristles, cuticle, hypodermis, circular muscles, longitudinal muscles, intestine with typhlosole and chloragogue cells, dorsal vessel, ventral vessel, nervous system, median and lateral subneural vessels and nephridia.

8. Examine under high power (400 diameters) the prepared section through the clitellum and make a drawing showing the hypodermis with gland cells. 


\section{NEREIS VIRENS Sars}

Material. N. virens is a common polychæte and may be found in abundance under rocks between tides along the Atlantic Coast. It should be anesthetized in a weak solution of alcohol and preserved either in formalin or alcohol. Small specimens for cross-section are best preserved either in sublimate or in Bouin's picro-aceto-formalin. It is advisable to harden a very large specimen in Müller's liquid for a long time and to cut it into separate segments with a sharp razor taking care not to injure the parapodia. These sections can be preserved indefinitely in alcohol and should be used for the study of the topography of the organs under low power.

\section{Descriptive Part}

Nereis virens is an annulated or segmented marine worm of the Class Polychæta. The number of segments of which its body is composed varies with the size and age of the worm and may be less than a hundred in small specimens and up to about two hundred in old and large ones. This variation is due mainly to the production of new segments in the posterior end of the worm with increasing age. The head represents the first segment of the worm and is sufficiently well distinguishable from the rest of the body. When the proboscis which will be described further on, is completely withdrawn, the mouth appears as a large round opening overhung by appendages of the so-called prostomium. The latter forms a part of the head, situated in front and above the mouth and carries two pairs of eyes, two small tentacles at the end of the median lobe and two large lateral palpi. That part of the head on which the mouth 
opens is called the peristomium and carries four pairs of peristomial tentacles. Among these the two posterior dorsal tentacles are the longest and present a convenient character for the identification of the sex. In males they extend as far back as the ninth segment, while in females they barely reach the middle of the fifth segment.

The segments of the body do not present sufficient differences for separating them into thoracic and abdominal segments as is the case with many other polychæts. On the contrary, with exception of the hindmost or anal segment, they are all more or less alike, each provided with a pair of lateral appendages or parapodia and a pair of nephridiopores or openings of the excretory organs at the base of the parapodia. The parapodia are organs of locomotion and respiration. Each parapodium is composed of two lobes, a dorsal notopodium and a ventral neuropodium. In the notopodium we distinguish a small lower ligula and a large upper ligula with a dorsal cirrus. Between the two ligulæ is an opening through which the chetæ or bristles protrude. Their base is inclosed in the so-called chetigerous sack. One bristle is much stouter than the rest and scarcely projects beyond the opening. It is the aciculum. In the neuropodium we find the same parts with the difference that the ventral cirrus sits at the base of the lower ligula. The parapodia of the first and second segments lack the lower ligula, chetæ and aciculum of the notopodium, the latter being composed only of the upper ligula with the dorsal cirrus. The chetæ of all parapodia consist of two parts: the shaft and the blade. The base of the latter sits in a terminal socket of the former. The last or anal segment has no parapodia. Instead it has two long anal cirri above the anus which is terminal.

Body wall and muscular system. The body wall is composed of a cuticle and of a muscular skin layer. The former is produced by the hypodermis and is perforated in many places by the openings of the unicellular glands. The muscular skin layer consists of circular muscles underlying the hypodermis, longi- 
tudinal muscles forming two dorsal and two ventral longitudinal bands, a nd oblique muscles running from the sides of the dorsal surface to the middle of the ventral surface. The innermost layer of the body wall is formed by the parietal layer of the peritoneal epithelium.

The cœlome or body cavity is the space between $\mathrm{the}$ body wall and the alimentary canal. It is

FIg. 21. - Circulatory system of Nereis virens, side view, after Turnbull. $D B$, dorsal blood vessel; $V$, recurrent blood vessel connecting dorsal blood vessel with $U$ network; $U$, network on pharynx (proboscis); $S G$, salivary gland; $E$, branch to the œsophagus; $D$, dorsal vessel to parapodium; $C$, lateral connecting vessels; $K$, tentacular blood vessel; $G$, network; $S$, branch from ventral vessel to $G$ network; $T$, vessel connecting ventral blood vessel with $U$ network; $F$, ventral vessel to parapodium; $V B$, ventral blood vessel; $L$, anterior portion of ventral blood vessel; $P R$, pharyngeal ring vẹssẹl.

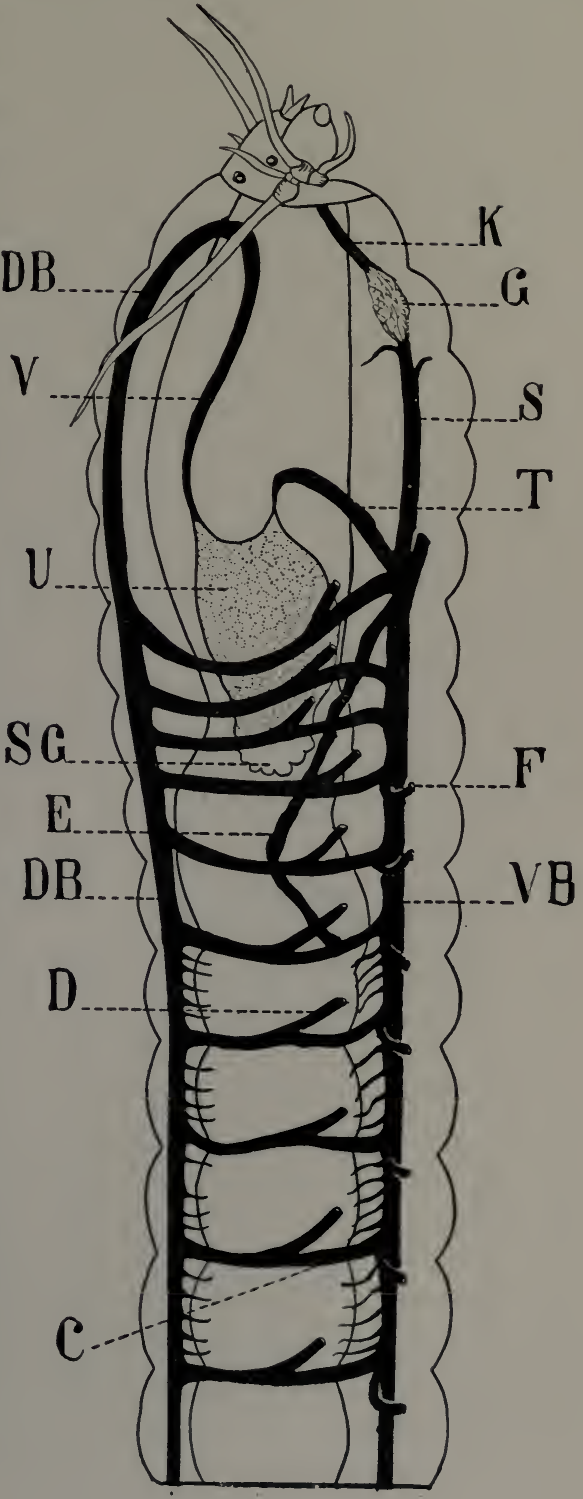


divided by septa or transverse partitions into a series of chambers each corresponding to one segment and connected with the others by openings below the intestine. The Cœlome is lined with peritoneal epithelium.

Digestive system. The mouth leads into a pharynx which is supplied with protractor and retractor muscles and may be protruded in form of a proboscis. On the inner surface of the pharynx, i.e., the one which becomes the outside surface of the proboscis when the latter is protruded, are minute chitinous denticles and two powerful pharyngeal jaws with a serrated edge. The pharynx leads into a short cesophagus. Into the latter open two digestive glands of ten called salivary glands. The œsophagus leads directly into the intestine into which it projects. The intestine is a straight tube running through the entire length of the worm and terminating on the last segment in an amus.

The respiratory organs have been already mentioned. They are the ligula of the parapodia.

The circulatory organs consist of two longitudinal vessels of which one is dorsal and the other ventral. Both are contractile. The dorsal vessel situated above the intestine in the middle line of the body between the two dorsal longitudinal muscular bands propels the blood towards the head. The ventral vessel situated below the intestine propels the blood toward the posterior end of the body. Both vessels are connected in each segment by a right and a left transverse vessel, forming a ring around the intestine. Each ring gives off two dorsal and two ventral branchial vessels to the parapodia. The dorsal vessels form a network in the ligula of the upper ramus, the ventral vessels in that of the lower ramus.

The excretory system consists of paired nephridia, one pair for each segment except head and anal segment. Each nephridium is a coiled tube opening into the body cavity by means of a ciliated funnel and to the outside by means of a nephridiopore situated on the ventral surface at the base of the parapodium. 
The funnel belongs to the segment preceding that of the nephridiopore. Consequently, the canal perforates the septum.

The nervous system consists of a chain of ganglia, one pair of ganglia for each segment. The first pair is dorsal to the alimentary canal and is situated in the head. It is the brain or supracesophageal ganglion. It gives off four optic nerves to the eyes, two palpal nerves to the palpi and two tentacular nerves to the tentacles. The following ganglia are all ventral to the alimentary canal. The first of these, the so-called subcesophageal ganglion is connected with the brain by commissures surrounding the pharynx. Nerves supplying the peristomial tentacles arise from small ganglia connected with the commissures. Each abdominal ganglion sends off three pairs of nerves. Of these the first pair supplies the muscles of the septum, the second passes through the septum to the preceding segment, and the third goes to the parapodia. A visceral nervous system is represented by several dorsal and ventral ganglia on the pharynx; they are connected with each other and with the brain.

Reproductive system. The sexes are separate. The gonads are developed from the peritoneum and the reproductive cells, in the absence of special ducts, reach the outside through the nephridiopores of the posterior region of the body. Fertilization takes place in the water. Development is combined with a metamorphosis. The larval stage is known as a Trochophora.

\section{Instructions}

I. Place a specimen with withdrawn proboscis into a dissecting tray with water. Examine with the aid of the lens the anterior end and make a drawing about three times natural size of the dorsal surface of the first ten segments. Label head and body. Label on the prostomium the eyes, tentacles and palpi, on the peristomium the peristomial tentacles. Observe the length of the two posterior dorsal tentacles and use this character to determine the sex. Label the segments of the body and the parapodia. 


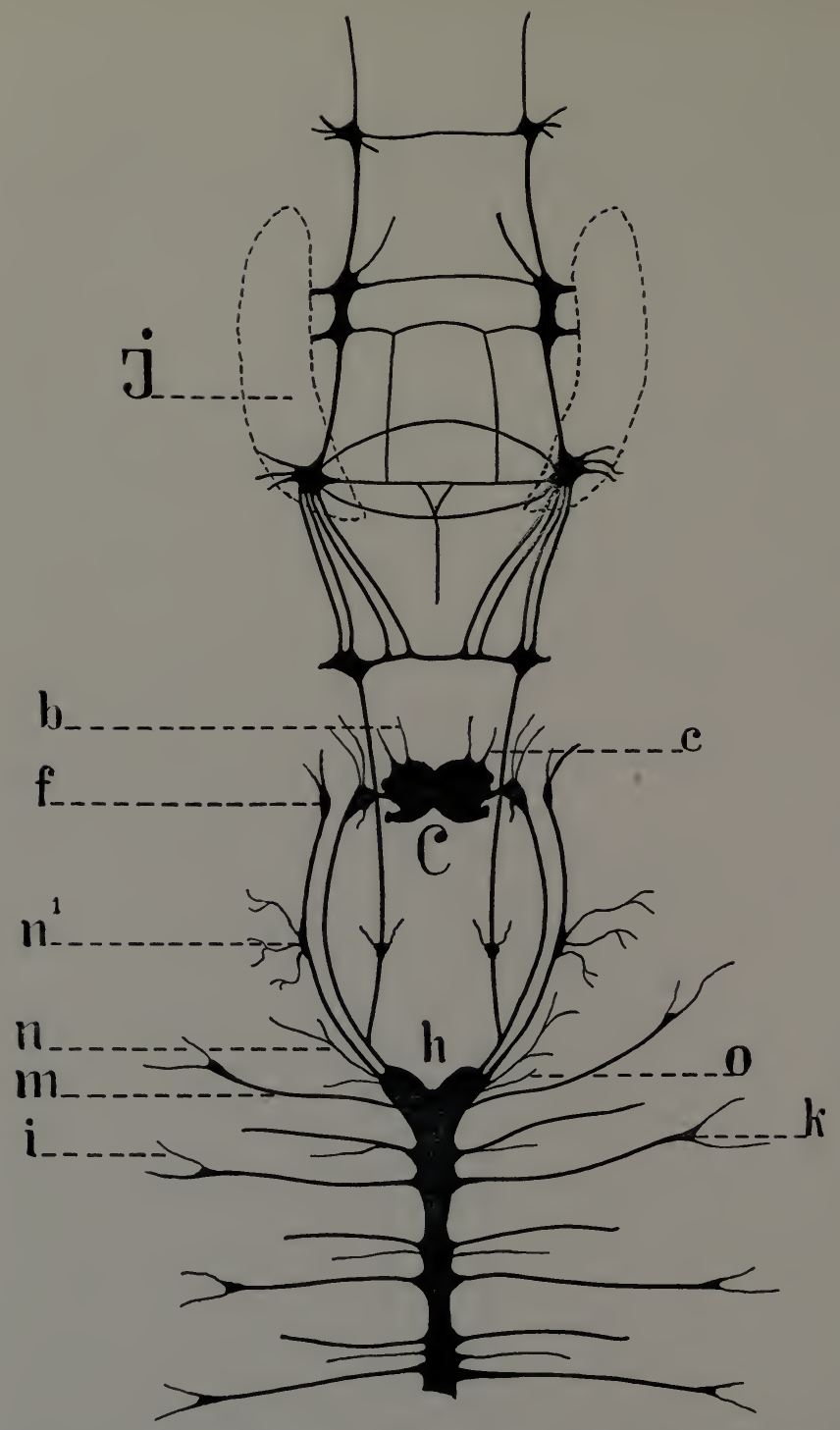

FIG. 22. - Nervous system of Nereis virens after Turnbull, slightly modified. $J$, jaws; $b$, antennal nerves; $c$, palpal nerves; $f$, ganglia for the 
2. Make a drawing showing the side view on the same scale. Label all parts, including mouth.

3. Make a drawing of the ventral surface of the posterior ten segments. Label anus, anal cirri, parapodia and nephridiopores.

4. Place a specimen with a protruded proboscis in the same tray and make a drawing as in No. I. Label proboscis, pharyngeal denticles and jaws.

5. With the aid of a forceps tear out a parapodium from one of the middle segments of the worm. Place it in a syracuse dish with glycerine under the dissecting microscope and make a quarter page drawing of it. Label the notopodium and neuropodium. In the former label the upper ligula with the dorsal cirrus, chetæ, aciculum and lower ligula. In the neuropodium label upper ligula, chetæ, aciculum and lower ligula with the ventral cirrus.

6. Tear out a parapodium from the first segment behind the head, examine in the same manner and make a drawing. Label parts.

7. With the aid of two needles tear the parapodium to free the chetæ. Place a cheta on a slide in a drop of water under a cover glass, examine under microscope and make a drawing showing the shaft and blade.

8. Open the worm along its back in a line parallel to the middorsal line from head to anus and fasten the body wall with pins. Remove ventral longitudinal muscles bit by bit. Make a drawing of the anterior third showing dorsal longitudinal muscles, septa, digestive organs, circulatory organs, nephridia and supraœsophageal ganglion. Label septa, pharnyx, œsophagus, intestine, digestive glands, protractors and retractors of the proboscis, dorsal vessel (on body wall), transverse vessels,

dorsal peristomial cirri; $n^{1}$, ganglion; $n$, nerves for the dissepimenta; $m$, parapodial nerves; $i$, parapodial branch; $h$, ventral chain of ganglia; $C$, cerebral ganglion; $o$, nerve passing through dissepiment to preceding segment; $k$, parapodial ganglion. 
ventral vessel, nervous system visible beneath it, and supraœsophageal ganglion.

9. Remove alimentary canal and ventral blood-vessel and make a drawing showing nervous system and nephridia.

Io. Place the prepared isolated segment of the worm in a syracuse dish with water under dissecting microscope and make a half page drawing showing parapodia, dorsal longitudinal muscles, ventral longitudinal muscles, oblique muscles, dorsal vessel, intestine, ventral vessel, nervous system and nephridia.

II. Examine under microscope a prepared slide with a crosssection through Nereis virens. Make a half page drawing of it and label all parts mentioned in No. ro and also cuticle, circular muscles, dorsal mesentery of the intestine, gonads, parietal and visceral layers of the peritoneum. 


\section{HIRUDO MEDICINALIS Linnæus}

Material. Live leeches may be bought in any pharmacy and can be kept alive in an aquarium, without food, during many months, or they may be allowed to suck the blood of frogs. Two hours before the exercise the leeches should be placed in 10\% alcohol with a few drops of chloroform. The alimentary canal may be injected, though this is not essential. A red gelatine mass gives good results, but carmin suspended in a solution of celloidin is preferable. The mass is allowed to harden by placing the injected leech with the needle in $70 \%$ alcohol. To prepare material for transverse sections the leech must be stretched in a dissecting pan by means of two pins and fixed in a mild fixing fluid such as Perenyi's. The best imbedding medium is celloidin. Transverse sections of imbedded specimens for study under the dissecting microscope should be cut with a common razor to the thickness of one annulus. These sections can be preserved indefinitely in alcohol. Thin sections may be stained in hæmatoxylin and eosin or orange $\mathrm{G}$.

\section{Descriptive Part}

The leech is a hermaphroditic segmented worm inhabiting stagnant fresh-water pools of Europe and imported into this country for medicinal purposes. The development of the leech shows that it is composed of thirty-three ${ }^{1}$ segments, a number characteristic of all segmented worms of the Class Hirudinei.

${ }^{1}$ According to some investigators the head of the leech is composed of six segments and the whole number of segments is therefore 34 and not 33 . In this case the segment with the male genital opening would be the eleventh and the last visible segment the twenty-seventh, and not the twenty-sixth. It is situated between the fourth and fifth pair of nephridiopores. 
The anterior five segments form the head which, however, is not externally distinguishable from the following twenty-one segments which form the trunk. The posterior seven segments are modified in the adult leech into the so-called posterior sucker. Externally the segmentation is shown by the excretory pores, but is otherwise hard of recognition owing to the presence of transverse folds of the skin known as rings or anmuli. The typical number of annuli for each segment in the Hirudinei is three, but in the medicinal leech we find that the first and second segments are composed of a single annulus each, the third and fourth of two annuli each, the fifth and sixth of three annuli each, the seventh of four annuli, the eighth to twenty-third of five annuli each, the twenty-fourth, twenty-fifth and twentysixth of two annuli each, making altogether one hundred and two annuli. The skin of the leech is composed of a cuticle and a single layer of epithelial cells, which we shall call the hypodermis. Inserted between these cells there are many unicellular slime glands the number of which is especially great in the ninth, tenth and eleventh segments where they produce the cocoon covering the eggs during oviposition. These segments represent therefore the clitellum and are equivalent to the clitellum of the earthworm. The skin is the seat of special sense organs in the form of sensory papille especially well developed in the middle annulus of each segment. On the dorsal surface of the animal in the anterior five segments forming the head, are five pairs of eyes, one pair in each segment; the third and fourth pairs are located in the first annulus, the fifth pair in the second annulus of the corresponding segment. The color of the skin is due to special branched pigment cells situated under the hypodermis between the muscles.

The muscular system is highly developed. Immediately under the hypodermis is a layer of circular muscles. The function of these muscles is to extend the animal. The space between the circular muscles and the internal organs is almost completely occupied by a powerful layer of longitudinal muscles. 
Their function is antagonistic to that of the circular muscles. Traversing both layers at right angles are the radial and the dorso-ventral muscles the function of which is to flatten the animal. In the posterior sucker the muscular system is represented by radial and circular fibres. In reality the entire muscular system is still more complicated. Between the muscles we find connective and botryoidal tissue.

Digestive system. The alimentary canal begins with the mouth on the ventral surface of the first segment. The mouth is surrounded by the mouth sucker. In the mouth cavity are three jaws one of which is median and dorsal in its position, while the other two are oblique and ventral. The edge of each jaw is provided with a row of teeth for the perforation of the skin. The jaws are operated by a muscular system of their own. Behind the jaws the mouth cavity leads into a short, muscular pharynx into which the ducts of the salivary glands open. It is the secretion of these glands which prevents the coagulation of the blood of the animal attacked by the leech and causes prolonged bleeding from the wound. Behind the pharynx begins the midgut which is sharply divided into two sections. The anterior section or stomach, called also crop, is by far the most powerfully developed part of the alimentary canal. It possesses eleven pairs of coeca the last of which is the longest. It is a storage place for the food. The resorption of the food takes place in the second section or intestine which is a much shorter and thinner tube connected with the stomach (crop) by what is termed the funnel. The hindgut or rectum terminates in an anus situated on the dorsal surface at the base of the posterior sucker.

The circulatory system consists of two lateral blood-vessels, one dorsal and one ventral sinus and their ramifications. The lateral vessels have muscular walls. Anteriorly and posteriorly they are directly connected with each other, so that the blood can pass from one lateral vessel into the other. A further connection between the lateral vessels is established by the presence 
of seventeen pairs of transverse branches. Some branches split up into numerous capillary tubes between the different organs, the botryoidal tissue and the hypodermis. These capillary tubes communicate with the capillaries of the sinuses. The

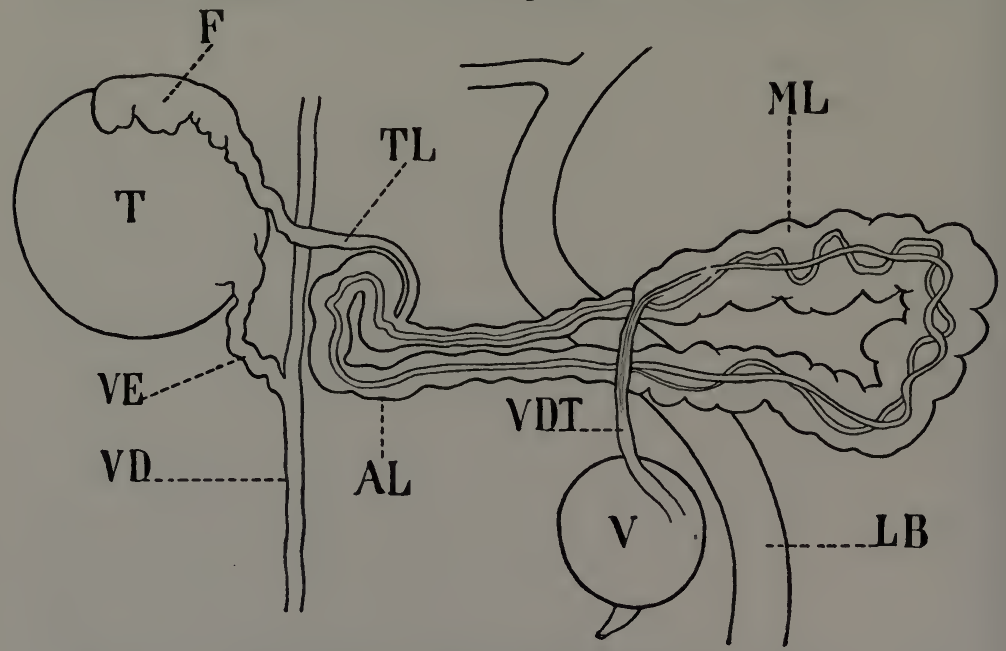

FIG. 23. - A nephridium of Hirudo medicinalis after Leuckart. $T$, testis; $V E$, vas efferens; $V D$, vas deferens; $L B$, lateral blood vessel; $A L$, apical lobe; $T L$, testis lobe; $F$, neptrostome; $M L$, middle lobe; $V D T$, vesicle duct; $V$, vesicle.

dorsal and the ventral sinuses communicate besides with each other in the posterior end of the body. The sinuses with their ramifications represent the cclome. They are lined with epithelial cells but have no muscular walls. There is no regular blood circulation, but the pulsation of the lateral vessels and their branches propels the blood in the one or the other direction.

Organs of respiration are absent, the blood being oxidized in the skin.

The excretory system consists of seventeen pairs of nephridia which open to the outside on the ventral surface through as many nephridiopores. The first pair of nephridiopores is situated on the first annulus of the seventh segment, while 
the following sixteen pairs are situated on the second annulus of the successive segments. The twenty-third segment is therefore the last segment possessing nephridiopores. A nephridium is a coiled tube usually with an open funnel; but in the case of the leech the funnel which lies in a lateral branch of the ventral sinus is closed. The funnel of the sixth to fifteenth nephridia is in close contact with the testes and this is the reason why the first part of the nephridium is called the testis lobe. The largest part of the nephridium is formed by the middle or glandular lobe which forms together with the socalled apical lobe a closed, compressed ring and is connected with the vesicle by a thin vesicle duct. Both the apical and middle as well as the testis lobe are perforated by a complicated, ramified system of canals. The vesicle is the last part of the nephridium and is connected with the nephridiopore by a very short duct.

The nervous system consists of a brain or supraœsophageal ganglion which lies above the pharynx and just behind the jaws, a subcesophageal ganglion underneath the pharynx and connected with the brain by two heavy commissures, and a chain of twentyone pairs of ganglia inclosed in the ventral sinus, one pair of ganglia for each segment except in the case of the last or twentyfirst pair which represents the fused neuromeres of the last seven segments transformed into the posterior sucker. The brain together with the subœsophageal ganglion represents the fused neuromeres of the anterior six segments. The sympathetic nervous system is represented by a median nerve which runs above the nervous chain along the wall of the stomach.

Reproductive system. The leeches are true hermaphrodites. The male reproductive organs in the medicinal leech consist of nine pairs of testes situated beneath the stomach in the thirteenth to twenty-first segments. There are two longitudinal vasa deferentia connected with the testes by short vasa efferentia. Anteriorly each vas deferens forms a convoluted seminal vesicle. The next portion of each duct, connecting 


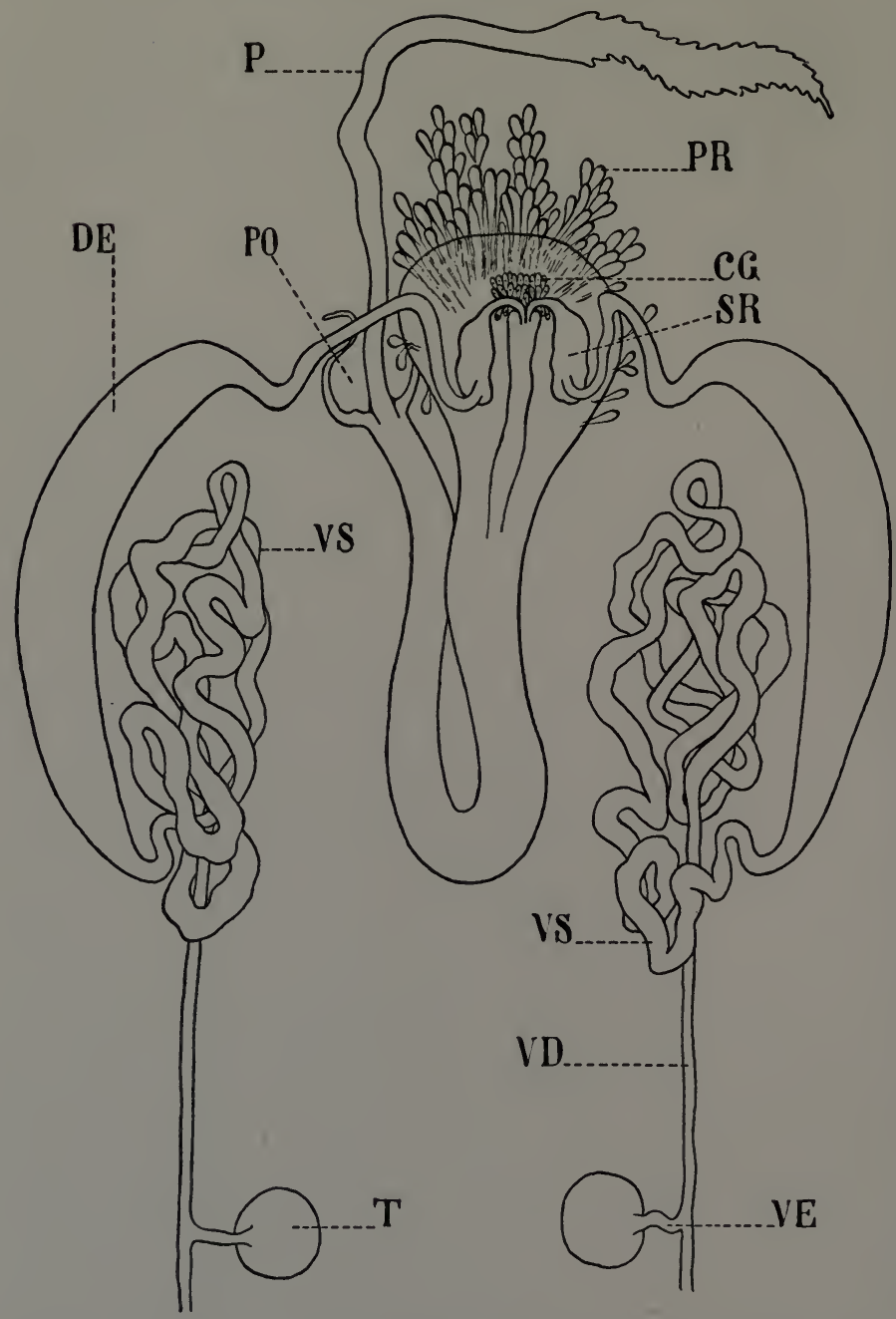

FIG. 24. - Male reproductive organs of Aulostomum after Brandes (combined from two figures and somewhat modified). $P$, penis; $P O$, penis pouch; $P R$, prostata; $C G$, Cowper's gland; $S R$, sperm reservoir; $D E$, ductus ejaculatorius; $V S$, vesicula seminalis; $V D$, vas deferens; $V E$, vas efferens; $T$, testis. 
the seminal vesicle with the penis is a muscular ductus ejaculatorius. The penis is single and may be protruded through the male genital opening which is situated in the median line on the ventral surface between the fourth and fifth annuli of the tenth segment. At the base of the penis is a prostata gland. The female reproductive organs consist of two ovaries, two short oviducts and a single muscular vagina with its female genital opening between the fourth and fifth annuli of the eleventh segment.

\section{Instructions}

I. Place a freshly killed leech on its back in a dissecting tray with water and fasten it by means of two pins stuck through the anterior and posterior suckers, at the same time stretching it as far as possible. Find the genital openings. Make a full page drawing of the ventral surface. Use the male genital opening as a guide to the segmentation. Try to find the nephridiopores and the sensory papillæ.

2. Remove the pins, turn the leech over, dorsal surface up, and fasten it as before. Make a sketch of the anterior five segments showing the eyes.

3. Make a superficial longitudinal median incision with a very sharp scalpel in the middle segments of the body. Stick two pins through the cut edges of the skin and force it apart. Holding the edge of the skin with a forceps continue the incision posteriorly and anteriorly gradually forcing the skin apart and fastening it with pins, until the entire animal has been opened. Make a full page drawing of the alimentary canal and label parts.

4. Remove with the aid of a forceps the entire alimentary canal beginning with the rectum but leaving the jaws. This will expose all the other organs except the dorsal sinus which was destroyed by the longitudinal incision. Try to locate all organs without the aid of the teacher. Make a full page drawing of the male and female reproductive systems, excretory system, 
lateral blood-vessels with some of the branches and the nervous system in the ventral sinus. Label all organs and corresponding segments using the last pair of nephridia for guide.

5. Carefully excise with scissors an entire nephridium, put it in a drop of water on a slide and examine under dissecting microscope. Make a drawing about five times natural size and label parts.

6. Remove a jaw and examine it under microscope in a drop of glycerine. Make a drawing of it about two inches long.

7. Apply a live leech to the hand or arm. When the skin is pierced remove the leech by putting a drop of alcohol on its head. Wipe off the blood and examine the wound. The three incision lines meeting in the centre correspond to the cutting edges of the jaws. Make a sketch of the wound.

8. Study the prepared cross-section of a leech under microscope. Make a half page drawing of it showing the cuticle, hypodermis, circular, longitudinal, radial and dorso-ventral muscles, the botryoidal tissue, stomach, nephridia, lateral vessels, dorsal sinus, ventral sinus with the nervous system, vasa deferentia (and testes if the section contains them). 


\section{DAPHNIA PULEX Müller}

Material. Specimens of Daphnia pulex may be collected at any time of the year, but are more abundant in spring. It is the common large Daphnia of our fresh-water ponds. The animals may be kept well in large aquaria, provided all hydras have been carefully removed. Every student should receive several live specimens.

\section{Descriptive Part}

Daphnia pulex is a common representative of the Suborder Cladocera, Order Entomostraca, Class Crustacea. These little crustaceans inhabit the fresh-water ponds of North America and Europe and may occur in millions in small pools. They swim by the aid of their second antennæ which are developed into powerful organs for a jerkwise method of propulsion. Their food consists mostly of microscopic algæ. Owing to their ability to propagate parthenogenetically, $i$. e., without fertilization, one meets during the spring and summer with scarcely any males.

The body of Daphnia pulex, like that of all arthropods, is segmented or composed of somites. But the somites can be recognized only by their appendages of which there is never more than one pair to a somite, and by the internal metamerization of the organs. We shall see later that the number of somites in higher crustaceans, is definite and that the entire body may be readily divided into a head, thorax and abdomen; the head is composed of six somites, the thorax of eight and the abdomen of seven. But the Entomostraca form a group of crustaceans in which near relatives may have a different number of somites. Only the head is always composed of six somites and, 
in the case of all Cladocera, it is clearly separated from the rest of the body. The somites of which the head in Daphnia pulex is composed are as follows: (I) ocular somite, (2) first antennal somite, (3) second antennal somite, (4) mandibular somite, (5) first maxillary somite, (6) sixth cephalic somite devoid of appendages in the adult but corresponding to the second maxillary somite of all other Crustacea. These six somites are fused together and even in the embryo do not articulate with each other but represent a single unit. The first three somites are preoral, the following postoral in the adult. The remainder of the body is not clearly divided into a definite number of somites and is not well separable into a thorax and abdomen. The five somites following the last cephalic somite are apparent from the five pairs of limbs, whereas the end of the body has no appendages and has lost all evidence of external and internal segmentation. Thus it is impossible to say to how many somites this portion of the body corresponds. The end of it is used as an organ of locomotion when the animal is moving on the bottom of the pool. For this reason it is often called the "scratch foot." It has two tactile bristles, a series of small teeth on the dorsal surface, and ends in two powerful claws which are known under the name of furca. The trunk of the animal is protected by a right and left fold of the integument extending beyond the thoracic appendages. This fold is often spoken of as the "shell" from its analogy to the bivalve shell of the lamellibranch molluscs. The posterodorsal end of the shell is drawn out into a sharp angle which corresponds to the long spine found in other species of Daphnids. The ventral, free edge of the shell carries a series of long bristles at right angles to the surface of the shell and directed inward, $i$. e., toward the plane of symmetry. These bristles afford an excellent protection to the gills of the animal while at the same time freely admitting water into the shell.

Integument and skeleton. The integument of Daphnia consists of a single layer of epithelial cells or hypodermis which secretes a thin supporting membrane on its inner surface and a 


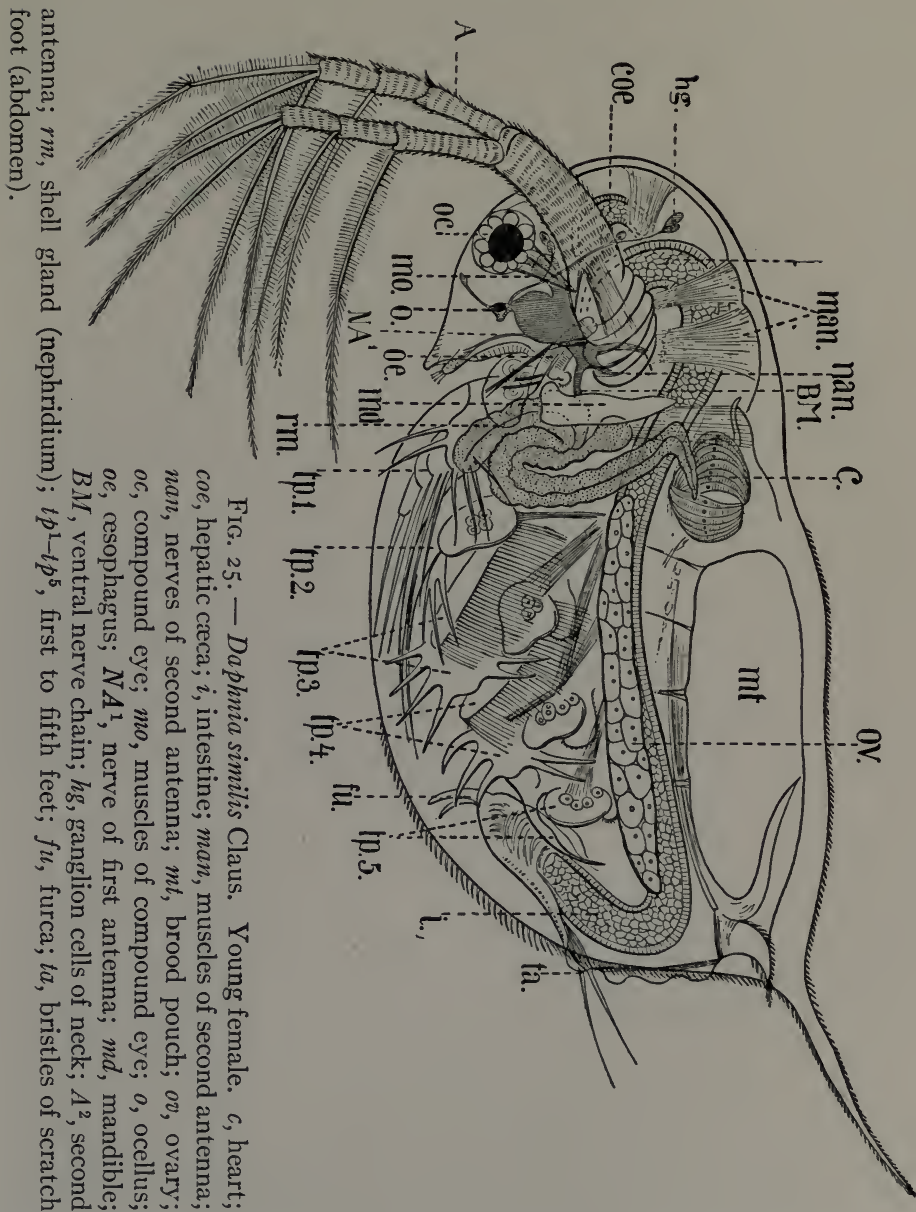

heavy chitinous cuticle on the outer surface. Once produced, the chitinous cuticle is incapable of further growth. It hardens and becomes the skeleton. Increase in the size of the animal can be therefore accomplished only by a process of moulting during which the old skeleton is thrown off. The newly produced 
cuticle stretches rapidly, while soft, and then hardens to take the place of the old skeleton. Another important feature of the external skeleton is that locomotion would be impossible if this were not subdivided into articulating segments connected with each other by thin and pliable cuticle. This is exactly what occurs in all arthropods. In higher forms the articulation is so perfect that locomotion is possible only in strictly circumscribed planes. But in Daphnia articulation is still very primitive, special articulating surfaces are still absent and the joints have more freedom. The cuticle appears often sculptured. Thus for example the shell of Daphnia presents the appearance of a network, due to minute ridges of the cuticle. Two other characteristics of an external skeleton may be mentioned in this place. One is that the muscles are of necessity inside the skeleton, not outside as in the case of an internal skeleton such as in vertebrates. The other is that the skeleton has to be provided with pores to admit of a connection between the nervous system and the sense organs which convey to the former the impressions of the outside world. We shall see later how some of the sense organs are structured.

Appendages. The first pair of appendages are the antennules (often called first pair of antennæ), which belong to the second cephalic somite. They are single-jointed, tiny, cylindrical organs situated near the forward angle of the head. At their ends are several olfactory bristles (æsthetascs). The antennules of the male are considerably longer than those of the female. The second pair of appendages are the antenne (called also second pair of antennæ). They are built on a strictly two-branched or biramous plan and consist of several joints. The joint by which they are attached to the head is called the coxopodite, the one following it, the basopodite. Together these two joints represent the so-called protopodite of a typical biramous appendage. The two branches of the antenna attached to the basopodite are known as endopodite and exopodite. The former is three-jointed, the latter four-jointed. The endopodite 


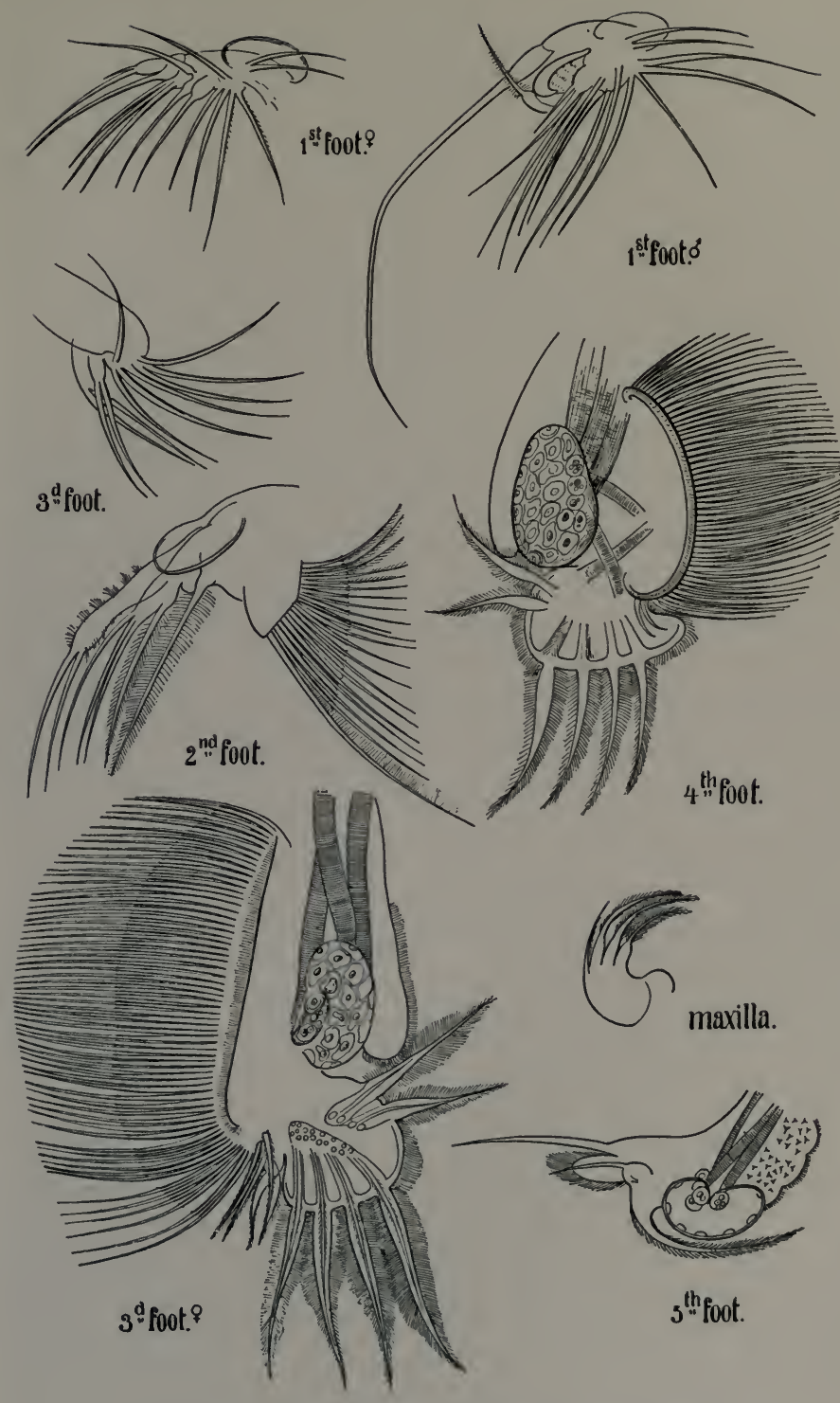

FIg. 26. - Appendages of Daphnia similis Claus. 
carries four long plume-like bristles, one of which sits at the end of the second joint and three at the end of the third joint. The exopodite carries five similar bristles of which three sit at . the end of the last, in this case of the fourth joint. We have seen already that these antennæ are used for swimming. Consequently they possess their own powerful muscles arising from the back of the head and attached to the coxopodite. The third pair of appendages are the mandibles. They are long chitinous plates situated at the sides of the mouth and provided with a masticating edge. The fourth pair of appendages are the maxillce, two weak plates ending in four plume-like bristles. The five pairs of thoracic limbs have a peculiar leaf-like appearance, with many bristles along their edge. The third pair of limbs is the largest, the fourth next in size. The structure as to detail differs in all five pairs, but the plan of structure remains the same and may be best understood from the third or largest limb. It consists of a large leaf-like, single-jointed protopodite, by means of which it is attached to the body and the edge of which is thickly covered with a row of long bristles; a smaller, single-jointed exopodite with six plume-like bristles; and a still smaller oval epipodite which serves as gill. The endopodite is not developed and is represented only by a few bristles situated between the bristles of the protopodite and those of the exopodite.

Digestive system. The mouth is situated on the head in the depth of the depression which separates the head from the trunk. At the sides of the mouth are two mandibles and below it two maxillæ. These two pairs of appendages are the masticating organs of the animal. The alimentary canal is, as usual, composed of three divisions, the foregut, the midgut, and the hindgut. The foregut is represented by a short asophagus which runs slantingly upward and opens into the much wider midgut, slightly projecting into it. The midgut is a cylindrical tube running first upward, then straight backward, and finally downward. Near the anterior end the midgut receives two dorsal 
blind sacs or cæca. There is no differentiation into stomach and intestine, so that the simple midgut performs both functions. The hindgut or rectum is restricted to the last or anal somite. The anus opens at the end of the trunk under the base of the furca, but morphologically it is dorsal to it (almost terminal).

Excretory system. The excretory system consists of a pair of maxillary (or shell) glands. These glands are modified nephridia. They are situated in the wall of the shell in the region below the heart and consist of a coiled tube, one end of which terminates in a little blind sac representing a modified nephrostome, while the other end opens to the outside on the ventral surface of the sixth cephalic somite. The glands are called maxillary because in other Entomostraca the sixth cephalic somite has the second pair of maxillæ for appendages.

Circulatory system and body cavity. The circulatory system of Daphnia is an open one. The heart has the shape of an ovoid and is situated dorsally to the midgut and in front of the brood-pouch. It is composed of a few striated muscular cells and has one pair of ostia or side openings through which the blood returns to the heart. There are no blood-vessels. The pulsation of the heart throws the blood forward and backward into the body cavity where it flows between the various organs until it reaches the branchial lacunæ of the gills. Here it is oxidized and returns to the heart through the ostia. It is therefore probable that the heart receives some "venous" blood besides the "arterial" blood which comes from the gills. The blood is colorless and contains amœbocytes.

Respiratory system. The so-called epipodites of the thoracic appendages are developed as gills. The animal keeps up a constant current of water inside its shell by a continuous beating motion of the thoracic limbs.

Nervous system and sense organs. The nervous system of Daphnia is more or less characteristic of several orders of Entomostraca. The brain or supraœsophageal mass consists 
of an anterior median region from which a nerve runs to the ocellus or simple eye, a pair of lobi optici or protocerebrum with optic nerves for the compound eye, and a pair of ganglia antennularia or deuterocerebrum with nerves for the antennules. The brain is dorsal to the œsophagus and sends out a right and left connective to the subcsophageal mass. This mass consists of a pair of ganglia with nerves for the antennæ, and corresponds therefore to the ganglia antennaria or tritocerebrum of higher crustaceans in which it has become a part of the brain, while the next pair of ganglia moved into its place to form a subœsophageal mass. The subœsophageal mass and the following chain of ganglia are ventral to the alimentary canal. This ventral chain of paired ganglia is characterized by a great concentration of its elements. The last pair of ganglia belongs to the somite carrying the fifth pair of thoracic feet.

Daphnia pulex has a pair of olfactory organs in the antennules, a simple eye, a compound eye and a great number of tactile hairs. A tactile hair is a process of a modified hypodermal cell connected through the intermediation of a terminal ganglionic cell with the central nervous system. The olfactory organs of the antennules may be regarded as modified tactile hairs. The simple eye is of the cup type, reminding of similar structures in lower invertebrates. The compound eye of Daphnia, while originally of paired origin, becomes fused into a single organ early in the embryonic life. It is more primitive than the compound eyes of higher arthropods and cannot be very efficient. To increase its usefulness it is provided with special muscles, the alternate contraction of which keeps the eye in continuous motion to allow shadow-images to stimulate a greater number of nerve endings.

Reproductive system. The sexes are separate. In the male the reproductive system consists of a pair of testes situated one on each side of the midgut. The two vasa deferentia open separately on the ventral surface of the trunk near its posterior end. In the female the system consists of two long ovaries 
situated right and left of the midgut and extending from the heart region to the posterior bend of the body. The oviducts are short and open separately on the dorsal surface of the trunk into the brood-pouch. The latter is a large space under the shell above the trunk and behind the heart. The parthenogenetic eggs develop in this brood-pouch until the young daphnix are able to swim out of the pouch. The so-called winter eggs, i. e., fertilized eggs, are at first enveloped by a special sac called ephippium in the brood-pouch, and the entire ephippium is then deposited into the water. On sinking to the bottom of the pool the ephippium remains there until next spring, when the eggs develop into females.

\section{Instructions}

I. Place a Daphnia in a watch glass with a few drops of water. Add a drop of $10 \%$ ether and examine the animal under low power (50 diameters). Make a full page drawing showing the right side view, but omit from the drawing the left second antenna. Label right second antenna, compound eye, ocellus, first antenna, carapace, heart, furca, abdominal tactile bristles, intestine, hepatic cœca, five thoracic limbs, shell gland, muscles of second antenna, brood-pouch with embryos, ovary, if developed.

2. Etherize the Daphnia still more and turn it on its back. Make a full-page drawing showing ventral view. Label carapace with protective fringe of hair, both pairs of antennæ, both hepatic cœca, compound eye, ocellus, furca, anus, abdominal bristles. 


\section{HOMARUS AMERICANUS Milne-Edwards}

Material. Specimens of the American lobster may be obtained from the Woods Hole Marine Laboratory or from any of the other marine laboratories. Every student should receive a specimen preserved in weak alcohol and another with the circulatory system injected.

\section{Descriptive Part}

Homarus americanus or the common American lobster is a typical representative of the Suborder Decapoda, Order Malacostraca, Class Crustacea. It is an inhabitant of the Atlantic Coast, where it is found in great numbers below the low-tide mark. Unfortunately, owing to its gastronomic qualities, the older and larger specimens become more and more rare. The largest lobster on record is at present in the American Museum of Natural History in New York. It was caught in 1897 at the Atlantic Highlands, N. J., is twenty-three and three-fourths inches in length and weighed when alive thirty-four pounds. Its crushing claw is fifteen inches long. The food of the lobster consists chiefly of fish, live or dead, and to a smaller part of invertebrates. Although much more highly developed than the little Daphnia, the lobster shows much better the segmentation of its body.

External features and segmentation. To avoid repetition, the minute description of the external features of the lobster will be given in the "Instructions" at the end of this chapter. We are here concerned with the general principles of the structure of its body.

The body of the lobster is composed of twenty-one somites 


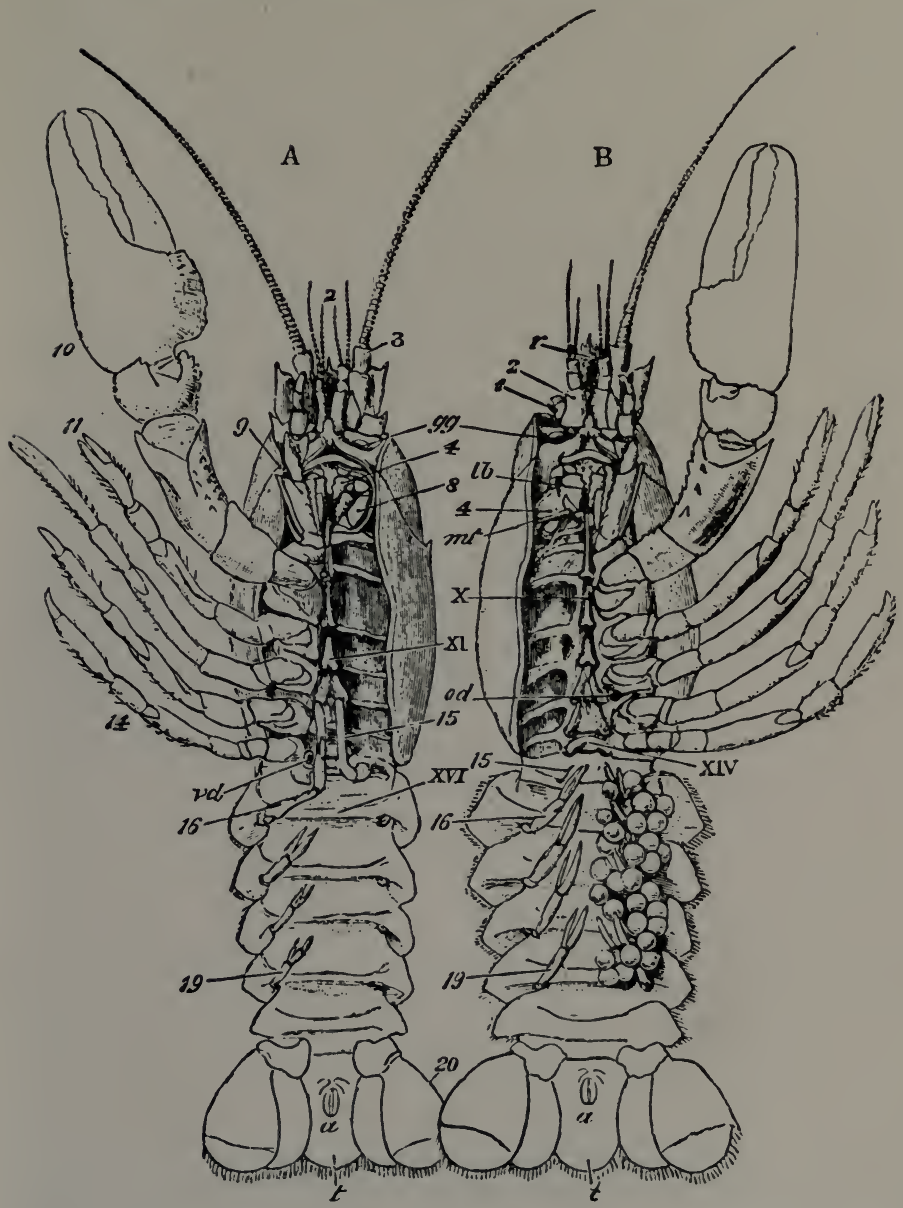

Fig. 27. - Astacus fuviatilis after Huxley. $A$, male; $B$, female; $a$, anus; $g g$, opening of green gland (antennal gland, nephridium); $l b$, upper lip or labrum; $m t$, metastoma or under lip; od, opening of oviduct ( $\$$ gen. op.); $v d$, opening of vas deferens ( $\sigma^{\top}$ gen. op.); $I$, stem of eye; 2 , antennules; 3 , antennæ; 4 , mandibles; 8 , second maxillipeds; 9 , third maxillipeds; IO, first pereiopod; $I I$, second pereiopod; $I 4$, fifth pereiopod; $I_{5}-20$, abdominal appendages; $X, X I, X I V$, sternites of fourth, fifth, and eighth thoracic somites; $X V I$, sternite of second abdominal somite. 
or segments. Externally it may be divided into an anterior fused portion called the cephalothorax and a posterior clearly segmented portion called the abdomen or pleon. The cephalothorax is composed of fourteen segments, the anterior six of which belong to the head or cephalon, the posterior eight to the thorax. The somites of one region of the body have little in common with the somites of the other two regions, since every component of a somite has been modified to meet the requirements of position and function. Thus the somites of the thorax became fused together to give more rigidity to this region, rigidity needed on account of the powerful development of the thoracic legs or pereiopods, especially those of the first pair.

Skeleton. The skeleton of the lobster is of two kinds. One is external, produced as a chitinous secretion by the hypodermis of the integument, and is called the exoskeleton. The other is internal, produced by infoldings of the ectoderm called apodemes. This skeleton is known under the term of endophragmal skeleton or simply endoskeleton. The exoskeleton is thick and calicified. Its color is derived from pigment produced by special cells or chromatoblasts situated below the hypodermis. The exoskeleton of every segment being the product of the integument, naturally has more or less the shape of a ring or cylinder, as, for example, in the case of the abdominal somites. The dorsal surface of such an exoskeletal ring is called the tergum or tergite, the ventral the sternum or sternite, and the sides the pleurce. The calcification of the pleuræ in this case makes the ring thoroughly rigid and the pleuræ themselves little distinct. In many arthropods, however, the pleuræ remain as soft as the intersegmental membrane, and only the tergite and sternite are hard. Such is the case with many arachnids and insects. Where the somites are separated from each other by a thin articulating membrane, there the corresponding sternites and tergites are easily recognized. But when adjoining somites fuse together, it becomes often difficult to recognize them and may even require special comparative 
anatomical and embryological study. Such is the case with the cephalothorax of the lobster. Here, as we have seen, the somites are fused together and the fused tergites form a dorsal shield or carapace. The thoracic tergites have, moreover, produced two lateral folds or branchiostegites for the protection of the gills, these folds forming part of the carapace. Nothing shows the limits of individual tergites and it is not even quite sure, though very probable, that the transverse so-called cervical groove corresponds to the division line between the sixth and seventh somites, $i . e$., between head and thorax. The recognition of the sternites is somewhat easier, owing to the fact that not all of them have fused so completely. The more difficult among them, those of the second and third cephalic somite, are described in the "Instructions." The endoskeleton is restricted to the thorax and abdomen. In the thorax it forms a complicated latticework connected with the sternites of the exoskeleton and forming attachment points for muscles and providing protection for the nervous system. We have already seen that the endoskeleton arises as infoldings or apodemes of the ectoderm between the segments of the body. Consequently the endoskeleton itself is segmented, each segment consisting of a pair of endosternites and a pair of endopleurites. The sternal canal in which the nervous system is inclosed is formed by the endosternites and their dorsal horizontal plates or mesophragmas. The latter thus form the roof of the sternal canal, but this roof is discontinuous, the canal being in reality a passage through several arches. The paraphragmas or outer processes of the endosternites connect the latter with the endopleurites. The endoskeleton forms the peripheral hinges for the articulation of the thoracic appendages in the shape of balls which are situated on the epimeral plates. The median hinges, on the other hand, are cup-shaped and are formed by the sternites.

Appendages. Except for the first cephalic somite which bears the compound eyes and the last abdominal or anal somite called the telson, all the other somites have a pair of appendages. 
We shall consider them in their natural sequence. The appendages of the second (cephalic) somite are called the antennules (or first pair of antennæ). They are typically biramous and consist of a two-jointed shaft or protopodite and two manyjointed flagelli. The inner flagellum is the shorter one, the outer flagellum bears many chemical setæ or æsthetascs supposedly of olfactory function. The first joint of the shaft contains a statocyst with an opening to the outside.

The appendages of the third somite are the antenne (called also second pair of antennæ), characterized by the exceedingly long flagellum. They consist of a two-jointed protopodite, a scale-like exopodite, and an endopodite or many-jointed flagellum. The function of the antennæ is tactile. The first joint of the protopodite bears a papilla with the opening of the antennal or green gland. The antennæ are embryologically postoral appendages, but become soon preoral (prostomial) in position. The appendages of the fourth somite are the powerful mandibles. They consist of a single joint, probably homologous to the coxopodite of a two-jointed shaft, and adapted to the trituration of hard food; and of a three-jointed palpus representing the endopodite. This palpus is protected by a groove in the mandible proper, in which it usually lies concealed. The triturating edge of the mandible is formed by exceedingly hard chitin. When the mandibles are removed from their sockets in the process of dissection, the tendons of their muscles remain adhering to them.

The appendages of the fifth and sixth somite are the first and second maxilla, respectively. Their function is chiefly to pass on the food. They are quite thin, leaf-like structures. The first maxilla consists of a two-jointed protopodite and an endopodite with a short flagellum. In the second maxilla there are present also an exopodite and an epipodite, while the endopodite lacks the flagellum. Comparative study shows that the epipodite is always derived from the exopodite. In the second maxilla the epipodite is still short and wide. It func- 
tions as a scaphognathite or bailer in driving the water out of the branchial cavity.

The following eight, $i$. e., the seventh to fourteenth somites form, as we have seen, the thorax. The first three pairs of thoracic appendages are called maxillipeds, the last five pairs pereiopods. The first and second maxillipeds are used for passing food, the third has mainly a masticatory function. The second and third have besides a respiratory function, inasmuch as they have a gill or podobranchia attached to them. The epipodite is well developed in all three maxillipeds and in the first it is furnished with a fold or trough for the reception of the bailer. The exopodite of all three maxillipeds has a manyjointed flagellum. The endopodite shows a gradual increase in complication. In the first maxilliped it is two-jointed, in the second four-jointed, in the third five-jointed, considerably heavier than the exopodite. In this respect the third maxilliped is especially interesting for it shows clearly how a monoramous appendage such as a pereiopod has developed from a biramous one. If the five joints of the endopodite be counted as a continuation of the two-jointed protopodite, then the limb becomes seven-jointed-and that is the typical number of joints in a pereiopod. Beginning with the proximal end of the limb, the joints receive the names of coxopodite, basopodite, ischiopodite, meropodite, carpopodite, propodite, and dactylopodite. The ischiopodite of the third maxilliped has a comb with a row of about twenty teeth along its inner edge and a brush along its outer edge. Of the five pairs of thoracic legs or pereiopods the anterior three are chelipeds, $i$. e., they have a forceps or chela at their end, whereas the last two pairs end in a simple claw. Each pereiopod consists of seven joints of which the first two represent the protopodite and the remaining five the endopodite. The exopodite has completely disappeared. An epipodite and podobranchia are present in the first four and lacking in the fifth pair. The joints are articulated by means of hinges. The forceps of a cheliped is formed by the propodite and dactylopo- 
dite. The main body of the propodite is called the hand, the dactylopodite the movable finger, while the immovable finger is simply a process of the propodite. The first pair of pereiopods, the so-called great chelipeds, are especially powerful. Their function is to hold and crush the food. It is a common occurrence among crabs and lobsters that the left and right great chelipeds are not alike. In the lobster one claw is heavy, is used for crushing the food, and its fingers for this reason have a row of rounded tubercles. The other claw is more slender, is used for seizing and holding the prey, and its fingers have a row of sharp teeth. All pereiopods are easily broken off by the animal if held fast by an enemy. The breaking plane is always between the baso- and ischiopodite. Anatomically this is due to a special mechanism and it is interesting to remember that the part of the limb remaining intact consists of the two joints of the protopodite. The relation of the pereiopods to the genital openings will be described later.

The following six pairs of appendages belong to the abdomen and are called pleopods. The first pair is uniramous. In the female it is quite small, in the male it is developed as a pair of stylets for copulation. The second, third, fourth and fifth pairs of pleopods are biramous and very much alike in structure. They consist of a single-jointed protopodite and flat exopodite and endopodite, both the latter fringed with tactile hairs. These pleopods are used for forward swimming and, in the female, for holding and aërating the eggs. The last pair of pleopods is at the same time the last pair of all appendages. These pleopods belong therefore to the twentieth somite and form together with the anal somite the tail fan. They are usually called uropods. The exopodite is two-jointed. Both the endopodite and exopodite are in the shape of broad and flat paddles fringed with tactile hairs.

Muscular system. It is clear that a hard, segmented exoskeleton must possess a segmented muscular system of a different type from that of segmented worms in which the in- 


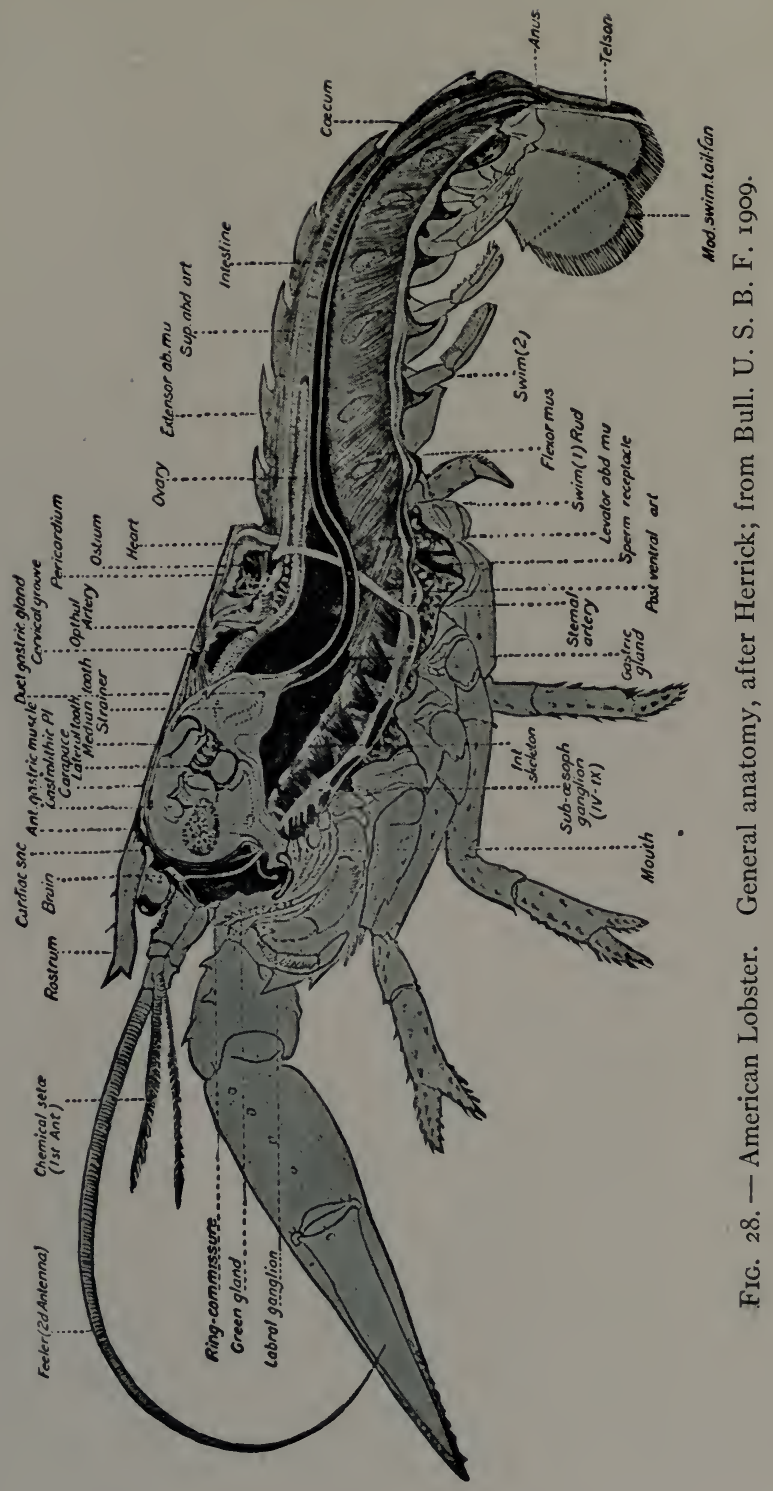


tegument of the body is soft and elastic. On the whole the muscular system is too complicated to be dealt with here, but some of the most important muscles may be mentioned. The extension of the segmented abdomen is accomplished by muscles attached to the tergites, the flexion by more powerful muscles attached to the sternites. The thoracic appendages are moved by muscles arising from the endoskeleton and ending in the coxopodites. A flexor and an extensor is present in every joint of the appendages for the next joint, except of course in the dactylopodite which is the last joint.

Digestive system. The V-shaped mouth is ventral in position and is provided with two lips. The upper lip or labrum has a median keel on both its surfaces, dividing each surface into two concave areas. The lower lip or metastoma is bifurcated. Between the two lips at the sides of the mouth are the powerful mandibles and behind the mouth the maxillæ and maxillipeds described above and used as mouth parts in passing the food. The mouth leads directly into a short asophagus which opens into the stomach. The stomach is a large and complicated organ forming the last section of the foregut. It is divided into three regions, the cardiac sac, the gastric mill and the pyloric sac. On each side of the stomach is a large gastrolithic plate. The gastric mill in which the food is ground into a fine pulp contains a median tooth and lateral teeth. These teeth are the inner projections of special ossicles. The wall of the stomach has a regular framework of articulated ossicles some of which will be mentioned in the instructions. The grinding movement of the gastric teeth is accomplished by the action of special muscles. The anterior gastric muscles are attached to the so-called procephalic lobes of the tergite of the first cephalic somite. The posterior gastric muscle is attached to the carapace at the cervical groove. The food passes from the cardiac sac into the grinding mill separated from the former by a valve. Here it is ground fine and delivered into the pyloric sac. Food that is still too coarse returns to the mill to be reground. Parts that cannot be 
ground sufficiently fine pass again to the cardiac sac and are finally vomited.

The intestine or midgut is a thin straight tube running as far back as the beginning of the sixth abdominal somite. Here it forms a median dorsal blind sac or cœecum. The cœcum marks the end of the midgut. The portion of the alimentary canal behind it is the hindgut or rectum. The anus opens ventrally on the last somite. Connected with the intestine is a large digestive gland, often called liver. It opens into the intestine by

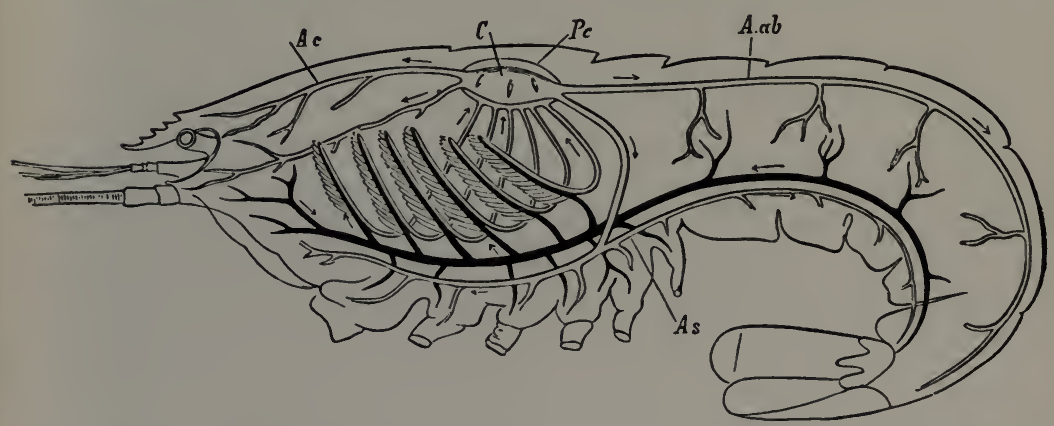

Fig. 29. - Circulatory system of the European Lobster after Gegenbaur. From Claus-Grobben, Lehrbuch der Zoölogie. C, heart; $P c$, pericard; $A c$, aorta cephalica; $A . a b$, aorta abdominalis; $A s$, ventral artery.

means of two short ducts between the pyloric valves. Food is passed into the digestive gland for final digestion.

Excretory system. The excretory system of the lobster consists of two antennal or green glands which are in reality modified nephridia. They are more or less lentil-shaped bodies situated in front of the stomach. Each gland consists of a blind sac which represents a modified nephrostome, a convoluted glandular tube, a bladder and a short duct. The latter opens on a papilla situated on the coxopodite of the second antennæ.

Circulatory system. The circulatory system of the lobster, although highly developed, is an open system, inasmuch as the arteries and veins open into a system of lacunæ and 
sinuses. The heart is inclosed in a pericardium. It is situated immediately under the carapace in the posterior region of the latter. The heart has a peculiar shape, being flattened above, rounded below and somewhat wider in front than behind. It is perforated by three pairs of openings called ostia, through which the blood from the pericard is admitted to the heart and which are provided with valves to prevent the return of the blood to the pericardial sinus. One pair of the ostia is dorsal, one lateral and one ventral. The heart gives off five arteries in front and two behind. The anterior arteries are a single anterior aorta or median cephalic artery which supplies the brain and eyes, two antennal arteries which supply a number of organs, and two hepatic arteries. Posteriorly the heart gives off the posterior aorta or median dorsal abdominal artery which runs backward above the intestine, giving off six pairs of lateral arteries to the pleopods, and the sternal artery which runs down, passes through the nerve cord and divides into two branches. The anterior branch is called the subneural thoracic artery and runs straight forward under the nerve cord. The posterior branch is called the subneural abdominal artery and runs backward under the nervous cord. The arteries split into smaller branches, become finally capillaries and open into lacunæ. From here the blood, which is colorless and contains amœbocytes, passes to the ventral sinus which surrounds the nervous cord, and is driven to the gills by the afferent branchial vessels. Having been oxidized in the capillaries of the gills the blood passes through the efferent branchial vessels into the branchio-cardiac veins. There are altogether five pairs of these veins opening into the pericardial sinus.

Respiratory system. The respiratory system of the lobster consists of twenty pairs of gills. Of these six pairs are podobranchice attached to the appendages of the eighth to thirteenth somites (second maxilliped to fourth pereiopod), ten pairs are arthrobranchice attached to the articulating membrane of the ninth to thirteenth somites, and four pairs pleurobranchice attached to the endopleurites of the eleventh to fourteenth somites. 
The podobranchiæ are protected by the epipodites of the same appendage, while all branchiæ are inclosed in the branchial cavity formed on each side of the cephalothorax by the branchiostegites of the carapace. These two cavities are open to the outside along the lower free edge of the carapace. The water is kept in constant motion and driven out of the cavity by the rhythmic action of the "bailer" which has been described above (epipodite of the second maxilla). The gills consist of a central stem and numerous rows of branchial filaments in which the blood is oxidized.

Nervous system. The nervous system of the lobster is clearly segmented inasmuch as there is typically one pair of ganglia for each somite. The ganglia of each pair are connected with each other by transverse commissures and with the ganglia of the following somite by longitudinal connectives. Thus the nervous system follows the well known "ladder" type of segmented invertebrates. But the high development of the lobster is also demonstrated by the deviations from the ideal type. The anterior three pairs of ganglia form together a more or less compact brain or supraœsophageal mass, situated dorsally to the alimentary canal. The first pair of ganglia supplies nerves to the compound eyes and forms the optic lobes or protocerebrum. The second pair innerves the antennules and forms the deuterocerebrum. The third pair innerves the antennæ and forms the tritocerebrum. The rest of the nervous chain is ventral to the alimentary canal, and the fourth pair of ganglia which form the anterior-most part of the subœsophageal mass are connected with the tritocerebrum of the brain by two long connectives, forming a ring around the œsophagus. The subœsophageal mass is composed of six paired ganglia belonging to the fourth to ninth somites. Next come five thoracic and five abdominal paired ganglia. The ganglia situated in the sixth abdominal somite represent the fused ganglia of the sixth abdominal and anal somites. The connectives between the twelfth and thirteenth somites diverge to allow the passage of the sternal artery 
described above. The lobster possesses also a sympathetic or visceral nervous system consisting of four ganglia and of nerves given off by them. Two of the ganglia, forming a pair, are situated at the sides of the osophagus and are called commissural ganglia. Of the other two ganglia one is called the cesophageal ganglion, is median in position and single; the other is similarly median and single, and is called the gastric ganglion. The sympathetic nervous system supplies nerves to the alimentary canal, heart, and other viscera.

Besides the innumerable sensory hairs which are distributed all over the body and its appendages, the lobster has a pair of balancing organs or statocysts and a pair of compound eyes. A statocyst is a little sac in the coxopodite of the antennules and communicates with the outside by means of an opening. Inside the sac is a horseshoe-shaped sensory ridge composed of some seventy-five plume-like hairs and about three hundred short seta. Scattered among the hairs and setæ are numerous small statolyths. These are simply grains of sand which the lobster introduces into the sac through the opening. This is done during the so-called fourth larval stage. The eyes are situated at the end of movable eye-stalks, and belong to the type of compound eyes, $i$. e., are made up of upward of fourteen thousand ommatidia. Each ommatidium is composed of a corneal lens, a crystal cone formed by four cells, two pigment cells surrounding the cone and shutting out excessively inclined rays of light, seven retimula cells and a rhabdome or rod secreted by the latter.

Reproductive system. The sexes are separate, but the male and female are externally very much alike. The position of the genital openings and the structure of the first (and to some extent of the second) pair of pleopods make, however, the recognition of the sex simple.

Male. The openings of the sperm ducts are on the coxopodites of the fifth pair of pereiopods (I4th somite) and are directed backward and outward. The sternite of the fourteenth somite forms a deep V-shaped grocve for the reception 
of the stylets. These are the first pair of pleopods specially modified for the purpose of copulation. The endopodite of the second pleopod has a short spur and the median spines of the abdominal sternites are fully developed. A pair of testes, sometimes separate, sometimes united by a transverse bridge, are situated behind the heart, partly concealed by the liver. The sperm duct or vas deferens of each testis is a coiled up tube. Its muscular end portion functions as a ductus ejaculatorius. The sperm cells are provided with three stiff rays and are immobile. They are very complicated structures designed to "explode" on touching the egg.

Female. The openings of the oviducts are on the coxopodites of the third pair of pereiopods (I 2 th somite) and are directed backward and inward. The sternite of the fourteenth somite is modified as a sperm receptacle and serves as an organ of copulation and for storage of the sperm. The median spines of the abdominal sternites are poorly developed. The first pleopods are small and filiform, the endopodite of the second pleopods lacks the spur present in the male. A pair of ovaries connected by a traverse bridge occupy in the mature female all the space on each side of the body from the stomach to the fourth or fifth abdominal somites. The oviducts are comparatively short tubes. The number of eggs increases with the age and size of the animal and reaches the total of about one hundred thousand in females of over fifteen inches in length. In spawning the female lies on her back and as the eggs leave the oviducts and pass by the sperm receptacle, they are fertilized; each egg becomes inclosed in a thin capsule; the eggs adhere to each other and the whole batch is carried by the mother attached to the pleopods. Development is indirect, combined with a metamorphosis.

\section{Instructions}

r. Examine the dorsal surface of a lobster and make a full page drawing of it, labeling all parts mentioned below. 
The carapace is produced anteriorly into a sharp median process or rostrum extending far beyond the eyes. A median longitudinal absorption line which has an important relation to the moulting process runs from the end of the rostrum to the posterior edge of the carapace. Halfway between the rostrum and the posterior edge is a transverse cervical groove between two triangular spots. These spots represent the attachment points of muscles the other end of which is attached to the wall of the gill chamber; the cervical groove itself serves for the attachment of the posterior gastric muscles. Beyond the triangular spots the cervical groove continues on each side of the carapace, ending at its anterior edge below the second pair of antennæ. Halfway between the triangular spots and the rostrum are two oval tendon marks of tendons which bind the carapace to the endoskeleton. Two depressions called branchiocardiac lines run from the triangular spots toward the posterior edge of the carapace. The region between these lines is called the areola or cardiac region. The region in front of the cervical groove is called the gastric region since the stomach of the lobster occupies almost all the space under this region of the carapace. The sides of the carapace, limited dorsally by the cervical and branchiocardiac lines, are called the branchial regions. Since the carapace in this region forms merely a protective covering for the gills, the sides of the carapace are called the branchiostegites.

The abdomen is composed of seven distinct segments of which only the tergites and the lateral lobes or pleurce are visible. The appendages of the sixth abdominal segment form together with the seventh abdominal segment a powerful tail-fan used in swimming. A uropod or appendage of the sixth abdominal segment consists of a protopodite or basal joint, a single-jointed endopodite, and a two-jointed exopodite. The seventh abdominal segment is called the telson.

In the position in which the lobster is being examined, several pairs of appendages belonging to the cephalothorax are visible. These are: first and second pair of antenne, third maxillipeds, 
and five pairs of pereiopods. The first three pairs of pereiopods end in a double claw or chela. The chelæ of the first pair are especially powerful. One of them, the cracker claw, is developed more than the other which is called the toothed claw.

2. Examine the ventral surface of the lobster and make a full page drawing of it. Identify the sex by the position of the genital openings and by the structure of the first pair of abdominal appendages. In the male the openings of the vasa deferentia are situated on the inner surface of the basal joint or coxopodite of the fifth pereiopod, and the first pair of abdominal appendages are modified as organs of copulation or stylets. In the female the openings of the oviducts are situated on the inner surface of the coxopodite of the third pair of pereiopods, the fifth sternal plate forms a seminal receptacle, and the first pair of abdominal appendages is poorly developed and more or less filiform. Besides the appendages mentioned in the preceding paragraph, there are visible the abdominal appendages or pleopods. Of the somites only the sternites are visible. The telson shows the amus.

3. Take the specimen into your left hand and looking, so to say, into the mouth of the animal, make a full-size drawing showing the appendages surrounding it in their natural position. The following parts are visible in this position: the first and second pair of antenne, triangular epistome or upper lip, mandibles with mandibular palpi, endopodite of the second pair of maxillipeds, endo- and exopodites of the third pair of maxillipeds. On the basal joint of the second pair of antennæ the openings of the green glands are visible.

4. Remove the carapace by lifting it at the posterior edge and cutting the muscles and tendons. The carapace will come off with eyes and antennæ attached to it. These should be removed not by pulling but by cutting the joint-membrane with sharp scissors. When the inside of the carapace has been cleaned it will be noticed that the skeleton of the three preoral segments remains firmly attached to the carapace. Holding the carapace 
in your left hand and looking into it from the back so that the longitudinal axis of the body coincides with the axis of vision, make a full size drawing showing the skeleton of the three preoral segments. Label the articulation sockets of the eyes, below them a more or less T-shaped sternite of the second segment separating the sockets of the first pair of antennæ, and behind this and forming together with it the epistome, the sternite of the third segment. The lateral projections of this sternite are hinged to the carapace and help to form the sockets for the second pair of antennæ. The two lobes in front of the eye-sockets are the procephalic processes and serve for the attachment of the anterior gastric muscles. The bridge between them is supposedly the tergite of the first or ocular somite, while the two sides of the oval containing the eye-sockets are the epimeral plates of this segment. The thin bars separating the socket of the first antenna from that of the second antenna are the epimeral plates of the second somite. The thickened edge of the carapace is formed by the epimeral plates of the third somite. Attached to the base of the third sternite (and overhanging the mouth) is the upper lip.

5. Remove all appendages beginning with the tail-fan and proceeding gradually forward. In doing so cut the articulation membrane with a sharp scalpel and label every appendage for future use. The label should be tied to the appendage and must show the number of the segment and the side of the body, as for example, left fourteen. This is easily done because the telson is the twenty-first segment. The gill-bearing appendages should be removed with the gill attached to them. There are altogether six pairs of these so-called podobranchiæ, one pair for each somite from the eighth to the thirteenth. When all appendages have been removed, separate the abdominal segments by cutting the membrane between them, clean and label each segment for future study. Put the cephalothorax into a glass beaker half filled with a $5 \%$ solution of potassium hydrate and boil it till all tissues will be dissolved except the endophrag- 
mal skeleton and the stomach. Put the latter aside for future study. Wash the skeleton in water. Place it in its natural position, sternites down, anterior end away from you, and make a natural-size drawing showing the entire endophragmal skeleton viewed from above. It will be noticed that it consists of a meshwork of thin lamellæ or apodemes of which there are two pairs between every pair of adjoining segments. In the position indicated there are visible three rows of meshes. The internodes of the median row are formed each by two horizontal plates or mesophragmata constituting a part of the endosternites. The walls of each mesh of the median row are formed mainly by the endopleurites and partly by the paraphragmata or lateral plates of the endosternites. Each paraphragma articulates with an endopleurite. In the depth below the mesophragmata the sternites of the exoskeleton are visible. The sternites form the floor, the mesophragmata the roof of the sternal canal.

6. Carefully isolate one of these endophragmal segments which have openings for pleurobranchiæ by cutting its connections with the adjoining segments. Make a natural size drawing of it looking into the sternal canal. The sides of the sternal canal are formed by the endosternites, the roof by the mesophragmata of the endosternites, the floor by the sternite of the exoskeleton. The endopleurites will be seen to the outside of the endosternites. Each endopleura has a hard articulation point for the coxopodite of the corresponding appendage.

7. Make a drawing, three-fourths view, of the abdominal segment showing tergite, pleuræ, sternite, epimeron and sockets of pleopods. On the tergite show the portion covered by the preceding segment and clearly separated from the rest by a groove.

8. Make a drawing ${ }^{1}$ of the first antenna showing the threejointed protopodite; the membrane covering the otocyst and the pore leading into the otocyst on the first joint of the protopodite;

${ }^{1}$ Drawings 8 to 16 to represent the ventral aspect of the appendages, i. e., showing the surface normally visible in a lobster turned on its back. 
the inner flagellum and the outer flagellum with chemical setæ (both flagella many-jointed).

9. Make a drawing of the second antenna showing the twojointed protopodite, the scale-like exopodite and the two-jointed endopodite with a many-jointed flagellum; on the first joint of the protopodite show the opening of the green gland.

Io. Make a drawing of the mandible showing the protopodite with the grinding edge, the three-jointed palpus which represents the endopodite, the heavy adductor muscle attached by means of a long tendon to the inner edge of the protopodite and the abductor muscle attached by a small tendon to the outer edge of the joint.

II. Make a drawing of the first maxilla showing the twojointed protopodite, both joints modified as maxillary plates, and the endopodite.

I2. Make a drawing of the second maxilla showing the twojointed protopodite, each joint modified as a maxillary plate and subdivided; the rudimentary endopodite; the scaphognathite or "bailer" which drives the water out of the branchial cavity. The anterior portion of the scaphognathite represents the exopodite, the posterior one the epipodite.

13. Make a drawing of the first maxilliped showing the twojointed protopodite, both joints modified as maxillary plates, endopodite, exopodite with many-jointed flagellum and the large epipodite with the fold or trough at its outer edge for the bailer or fan.

I4. Make a drawing of the second maxilliped showing the twojointed protopodite, the four-jointed endopodite, the exopodite with the many-jointed flagellum, the epipodite and the rudimentary gill or podobranchia. The second joint of the protopodite shows a groove subdividing it into two not yet quite distinct joints. Label first joint of protopodite as coxopodite, second as baso-ischiopodite, first joint of endopodite as meropodite, next as carpopodite, propodite, and dactylopodite.

15. Make a drawing of third maxilliped showing the two- 
jointed protopodite, five-jointed endopodite, exopodite, with flagellum, epipodite and gill or podobranchia. Label coxopodite, basopodite, ischiopodite with comb, meropodite, carpopodite, propodite, and dactylopodite.

r6. Make a drawing of the first pereiopod with the toothed claw showing also epipodite and podobranchia. Label all joints and be careful to represent correctly the interlocking mechanism between the coxo- and ischiopodite and the breaking plane between the baso- and ischiopodite. Indicate by dotted lines the axis of every articulation for comparison with third and fifth pereiopods.

I7. Make a drawing of the third pereiopod showing all structures including epipodite, podobranchia and, if the specimen is a female, opening of the oviduct. Label all joints and indicate by dotted lines the axis of all articulations.

I8. Do the same with the fifth pereiopod, which has an epipodite, but no podobranchia. If the specimen is a male, show the opening of the vas deferens.

19. Injected specimen. Cut away the left branchiostegite by an incision along the branchiocardiac and left cervical line, exposing the left branchial cavity. Make a natural-size drawing showing the gills in situ.' Of the outer gills the anterior six are podobranchice, the hindmost the pleurobranchia of the fourteenth segment. The lamellæ between the gills are the epipodites. Protruding from under the ends of the podobranchiæ the ends of the arthrobranchiæ and pleurobranchiæ are visible.

20. Remove the podobranchiæ and epipodites by cutting them at their base, being careful, however, not to disturb the other gills. This exposes all arthrobranchiæ. Make a drawing of them in situ and label anterior and posterior arthrobranchiæ of every somite.

21. Remove all arthrobranchiæ. This will expose the four pleurobranchiæ, while the attachment places of the removed gills will appear as round holes. Make a drawing and label somites, 
22. Remove left half of endophragmal skeleton by cutting the sternites and endosternites in the median line. Remove left wall of the cephalic portion of the cephalothorax and left half of the abdominal tergites and pleuræ to the pleopods. Gradually remove all muscles of the left half of the body in the thoracic region and abdomen by lifting them and cutting at their attachment places with scissors, and by carefully separating them from the injected blood-vessels. Do not touch any muscles or organs in the cephalic region. When the dissection is accomplished, the cephalic region will show only such structures as lie immediately under the carapace, while the thoracic region and abdomen will show all organs of the left half of the body except the removed muscles. Immediately behind the cervical groove will be seen the heart which gives off anteriorly a median blood-vessel the anterior aorta (or cephalic artery) and posteriorly the posterior aorta (or dorsal abdominal artery); the bloodvessel running parallel with the lateral cervical groove to the second antenna is the left antennal artery. The heavy vessel running behind the heart down to the ventral side is the single sternal artery. It ends in a median longitudinal ventral vessel the forward part of which is called the anterior ventral or thoracic artery and the hind part the posterior or ventral abdominal artery. Immediately behind the left eye will be seen the left procephalic lobe with the anterior gastric muscle attached by the other end to the large stomach. The stomach is partly concealed by a heavy muscle-the adductor of the left mandible-behind which the posterior gastric muscle attached to the stomach and cervical groove is visible. Under the anterior end of the antennal artery is the flexor of the second antenna. Under the antennal artery, occupying all the space between heart and endoskeleton and extending all the way to the abdomen, is the left lobe of the liver. Underneath the latter are the cut edges of the endosternites which form the roof of the sternal canal. Inside that sternal canal is the nervous chain and beneath this the ventral artery which has been already mentioned. Extending longitudinally 
from the liver to the abdomen and lying on the endosternites one sees in the depth the powerful right flexor abdominis. In the abdomen one can see under the posterior aorta the dark intestine clearly separated from the last section of the alimentary canal, the rectum. If the specimen is a male, a tube will be seen running from behind the heart to the base of the fifth leg-this is the left vas deferens; and the testis will be found lying alongside the intestine and partly imbedded in the liver. If the specimen is a female, the ovary occupies, when fully developed, all the space from the stomach to the fourth or fifth abdominal segment.

23. Remove the right wall of the cephalic portion, cut the alimentary canal between œsophagus and stomach, cut the cephalothorax transversely close behind the adductors of the mandibles, remove all organs except the green glands and nervous system and make a drawing showing the rear view of the cut surface. Above the œsophagus you will notice the large brain or supracesophageal mass and running on each side of the œsophagus from the brain to the subœsophageal mass a long connective. Between the muscle of the second antenna and this connective appears one of the large green glands.

24. Open the "hand" of the big claw by removing the entire outer wall. Make a natural-size drawing showing the outline of the claw, the point of articulation between the movable finger and the hand, the large and heavy flexor and the considerably smaller extensor.

25. Boil the stomach in a $10 \%$ solution of potassium hydrate, wash it in water and examine first from above, then from the side. The dorsal pouch leading into the dorsal tooth marks the position of the gastric mill. The soft sac in front of the gastric mill is the cardiac sac, the one behind the gastric mill the pyloric sac. The hard transverse ossicle in front of the pouch is the cardiac ossicle. The hard ossicle forming, as it were, a roof over the pouch is the pyloric ossicle. The floor of the pouch is formed by the urocardiac ossicle. The latter is articulated with 
the cardiac ossicle and with the prepyloric ossicle or median tooth. The cardiac ossicle is at each end (i.e., on the right and left) articulated with the base of the pterocardiac ossicle. Together they form a sharp point. The pterocardiac ossicle is more or less triangular in shape and its apex articulates with the zygocardiac ossicle. The thickened edge of the latter extends to the edge of the pouch. Here it articulates with a small triangular ossicle - the anterior dorsolateral pyloric plate-which thus serves to connect the zygocardiac with the pyloric ossicle. Below the upper edge of the zygocardiac ossicle is a lateral pouch with several dark brown notches. These are the lateral teeth which project into the stomach and form a part of the zygocardiac ossicle. A rod-like ossicle-the posterior intermediate cardiac bar -runs from the lateral pouch of the zygocardiac ossicle obliquely downward. At its lower end it articulates with two closely applied ventrolateral cardiac bars. These bars seem at first sight to form a single ossicle and have the appearance of a curved sabre. At the anterior end the two bars articulate with a single anterior lateral cardiac bar which appears almost as a continuation of the other two. Between the articulation point of the zygocardiac with the pterocardiac ossicle and that of the posterior intermediate cardiac bar with the ventrolateral cardiac bars are two ossicles or intermediate cardiac bars articulating with the small inferolateral tooth. A narrow curved ossicle-the gastrolithic bar-runs forward from the apex of the pterocardiac ossicles. The remaining ossicles (the number of the various ossicles in the stomach is twenty-four and of these several are paired) are more difficult of observation and may be omitted. Make a drawing of a side view of the stomach and label all parts. 26. Open the stomach in the mid-ventral line. Make a drawing of it showing cardiac sac, pyloric sac and gastric mill, consisting of the median tooth, lateral teeth and small inferolateral teeth. 


\section{SCHISTOCERCA AMERICANA Drury}

Material. Schistocerca americana or the common American locust is the largest grasshopper of the United States and for that reason well adapted for dissection. Unfortunately the dissection of the insect comes always at the wrong time of year when live specimens are not available. It should not be dissected at the beginning of the course, not only because of the complexity of the organization, but also and chiefly because of the impossibility of understanding its bearing upon the problem of segmentation without some knowledge of other related forms. The specimens should be preserved in $70 \%$ alcohol and soaked in water for twenty-four hours before dissection. Every student should receive two preserved specimens, one of which must be a male, the other a female, two fresh specimens if available at the time, and, if possible, prepared slides with sections through the chordotonal organ, antennæ, compound eyes, and various internal organs.

\section{Descriptive Part}

Schistocerca americana, or American locust, is a typical representative of the Order Orthoptera, Class Hexapoda or Insects. In its structure it is much more primitive and generalized than many other insects and shows well the metamerism of the body.

Segmentation. The body of the locust is, in all probability, composed of twenty-one somites. The first six somites are fused permanently together. They form the head. The next three somites form the thorax. The abdomen shows only eleven segments, but the eleventh segment is probably composed of two somites.

Head and appendages. Three of the six somites of which the head is composed are preoral in position. The first is the 


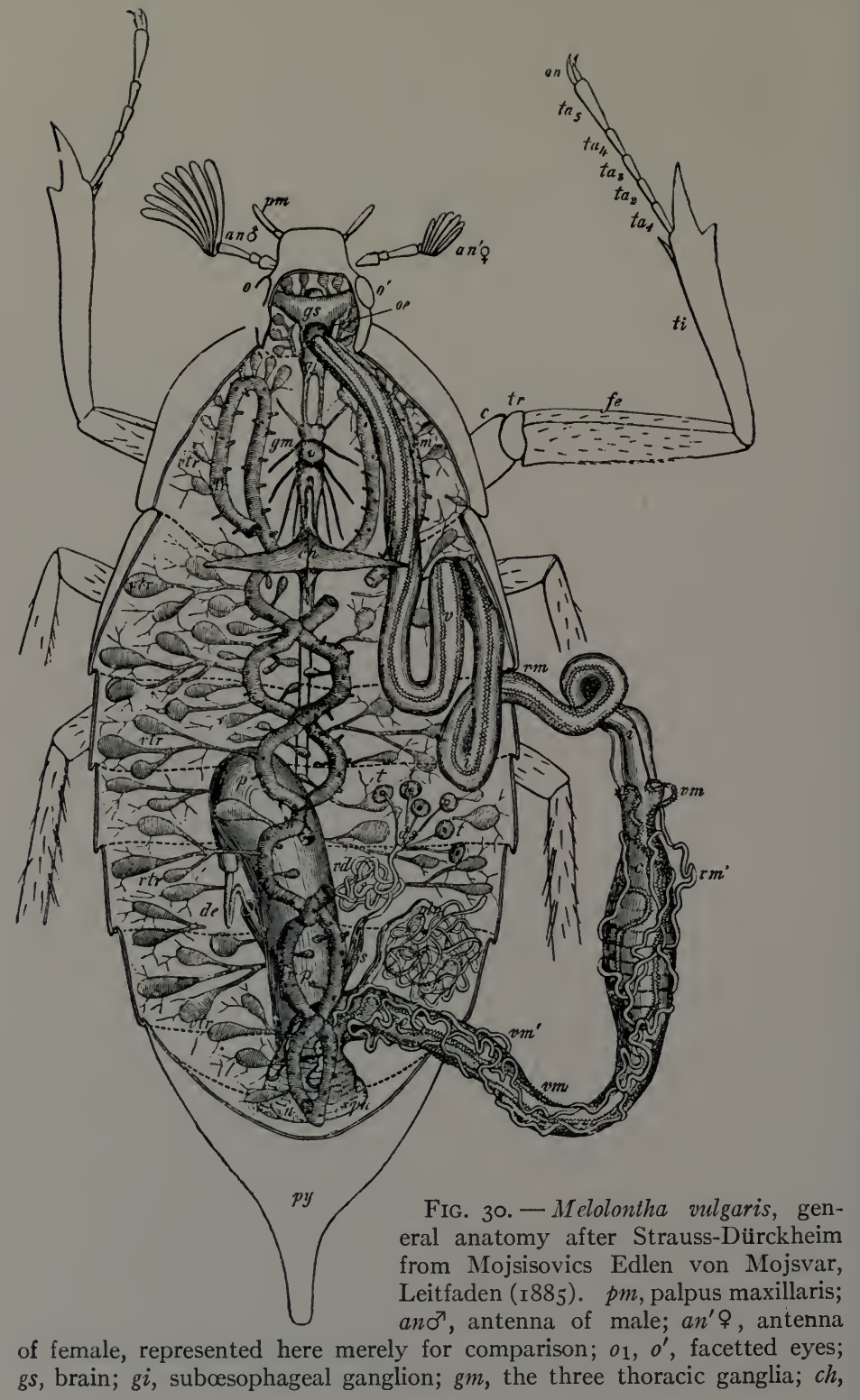


ocular somite and has no appendages. It carries the two facetted eyes and three simple ocelli. The second somite is characterized by the presence of a pair of many-jointed, filiform antennæ. The third somite, corresponding to the so-called intercalary segment of the embryo, has no appendages but is sufficiently apparent from its neuromere, the tritocerebrum, which innerves the upper lip or labrum. The fourth somite carries a pair of powerful toothed mandibles. The fifth somite carries a pair of maxilla. From a comparison of the maxillæ with appendages of crustaceans we conclude that they are composed of a two-jointed protopodite complicated by the presence of two movable plates used in mastication, which must be regarded as a differentiation of the second joint of the protopodite, and an endopodite developed in the form of a palpus, while the exopodite is completely wanting. The first joint of the protopodite is called by entomologists cardo, the second, stipes; the intermaxillary lobe of the protopodite, lacinia, the outer, galea. The maxillary palpus is five-jointed. The sixth somite carries the under lip or labium, which however must be regarded as a pair of second maxillæ fused along their inner edge and slightly modified. The fused first joints of the protopodites are known to entomologists under the name of submentum; the fused second joints under the name of mentum. The two lobes corresponding to the right and left galeæ of the first maxillæ are called ligula, while the laciniæ are wanting. The labial palpi are four-jointed. Projecting into the mouth cavity from the inner surface of the mentum is a small plate called hypopharynx.

Except for the presence of the eyes and appendages the somites of the head could not be recognized externally for the reason that the skeleton of the head forms a single capsule or

chitinous endo-skeleton; oe, œsophagus; $v$, ventriculus; $v m, v m^{\prime}$, malpighian tubes; $i$, intestine; $c$, colon and rectum; $s p h$, sphincter ani; $a$, end of rectum; $t t$, testis; $d s$, vasa efferentia; $v d$, vas deferens; $v s$, vesicula seminalis; $g l m$, mucous gland; $d e$, ductus ejaculatorius; $p p$, penis; vtr, tracheal sacs; $t r$, tracheal tubes; $c$, coxa; $t r$, trochanter; $f e$, femur; $t i$, tibia; $t a_{1}$-tas, tarsus; on, claws; $p y$, pygidium. 
epicranium. The front of this capsule is called frons, the back, occiput, the top, vertex, and the two sides-cheeks or gence. A plate attached to the lower end of the frons and itself serving for the attachment of the upper lip or labrum is called clypeus.

Thorax and its appendages. The thorax is composed of three distinct somites. The first thoracic somite is called the prothorax and carries the first pair of legs. The integument of the prothorax forms a large dorsal sclerite or tergite usually known under the name of pronotum. The corresponding ventral sclerite or prosternum carries a spine. The head is joined movably to the prothorax as the prothorax itself is joined movably to the second thoracic somite or mesothorax. The mesothorax is joined immovably to the third thoracic somite or metathorax. This is due to the presence of a deep incision in the posterior margin of the mesosternum into which a corresponding process of the metathorax fits perfectly. The posterior edge of the latter has a similar incision for the reception of a process of the first abdominal sternite. The mesothorax has a pair of legs and a pair of wings which in this case are modified as covers for the real wings of the following somite. The metathorax has a pair of legs especially adapted to jumping and a pair of wings which are thin and folded under the covers when not in flight. Both meso- and metathoracic wings are simple outgrowths of the integument and the "veins" of the wing are thickened portions having the structure of a tube. The cavity of the veins incloses special nerves and tracheal tubes and communicates directly with the body cavity. The arrangement of the "veins" or the so-called venation of the wings follows a definite plan which is of great importance for a comparative study of insects. The legs consist of five segments, the coxa by which it is attached to the body, the trochanter - a short segment corresponding to the ischiopodite, the femur (or meropodite), the tibia (a fused carpo and propodite) and a three-jointed tarsus or dactylopodite. The ventral surface of the first joint of the tarsus is subdivided by pads giving it the appearance as if it were composed of 
three joints. At the end of the tarsus are two curved claws and between them a movable lobe, the pulvillus.

Abdomen. Generally speaking, the skeleton of an abdominal somite represents a ring composed of two semicircular sclerites connected with each other and with the preceding and following somites by a thin cuticle. The hind edge of each ring overlaps the anterior edge of the following ring. In the case of the first abdominal somite, however, the tergite and the sternite are disjointed. The tergite terminates above the third leg and bears the chordotonal, auditory organs. The sternite has an anterior process which fits into a corresponding incision of the metasternum and forms a rigid juncture. The ninth and tenth tergites of the male are partially fused and are together only as wide as the ninth sternite. The latter has a terminal plate attached to it known under the name of subgenital plate. Attached to the posterior edge of the tenth tergite are two movable plates, the cerci. Beneath the latter are two podical plates which belong to the eleventh somite. The sternites of the tenth and eleventh somites are wanting. In the female the ninth sternite is also wanting. The last or eighth sternite has a long median posterior process. The tenth tergite has also cerci as in the male, but they are considerably smaller, while the triangular podical plates of the eleventh somite are much larger. At the end of the abdomen is an ovipositor composed of three pairs of movable parts representing modified appendages. The median pair is called the egg-guides and is much smaller than and partly concealed by the other two pairs.

Integument. The integument consists of a single layer of epithelial cells or hypodermis which secretes a thin supporting membrane to the inside and a more or less thick cuticle to the outside. The cuticle which is nothing else but the exoskeleton is elastic only where it is very thin, $i$. e., between the joints, whereas the sclerites or thickened portions of the cuticle are more or less rigid. The animal increases in size with each moulting, while the new cuticle is not yet hardened. The increase in size 
of the abdomen in a gravid female is due merely to a stretching of the interarticular cuticle to its full capacity. The grasshopper has an endoskeleton in the shape of the so-called tentorium in the head and of furcule in the thorax. These structures are simply apodemes or infoldings of the integument and serve for the attachment of muscles.

Muscular system. The muscular system shows clearly the segmented nature of the grasshopper in the abdomen. In the rest of the body the muscles are highly differentiated and specialized. Of interest are the heavy muscles of the two pairs of wings in the thorax and the muscles of the ovipositor in the abdomen. Very powerfully developed are also the muscles of the mandibles and those of the third pair of legs which are adapted to jumping.

Digestive system. The alimentary canal of the grasshopper is clearly divided into three portions, the foregut, the midgut, and the hindgut. The foregut begins with the mouth which is provided with mouth parts in the shape of an upper lip, a pair of mandibles, a pair of maxillæ, and a lower lip with the hypopharynx, all except probably the upper lip being true appendages. The pharynx occupies the greater part of the head and leads into the esophagus which runs backward forming a large crop or ingluvies in the meso- and metathoracic somites. The last section of the foregut is the gizzard or proventriculus which in other insects is very well defined, but which in the case - of the American locust is not externally recognizable except as the end portion of the crop. The midgut or ventriculus extends back into the seventh abdominal segment. It receives eight double gastric coca immediately behind the foregut. These cœca are arranged so that one arm of each cœcum is directed forward and the other backward. The end of the midgut is marked by numerous malpighian tubes, beyond which the hindgut begins. The first section of the hindgut is called ileum and is comparatively large. Near the end of the abdomen it is constricted and the much smaller colon rises in a curve. The 
rectum is again much bigger. The amus opens between the podical plates, dorsally to the ovipositor. Morphologically terminal in position in all insects, the anus belongs to the twelf th somite. A pair of salivary glands are situated one on either side of the crop. The salivary ducts open on the ligula of the lower lip into the mouth cavity.

Excretory system. The numerous malpighian tubes which open into the alimentary tract between the mid- and hindgut function as excretory organs.

Circulatory system. The heart is situated under the body wall in the mid-dorsal line. It has the shape of a long tube and consists of a series of ventricles typically one for every somite, inclosed in a pericardial sinus. Each ventricle is separated from the preceding one by a pair of valves and communicates with the pericardial sinus by a pair of ostia. Thus there are a pair of ostia and a pair of valves for every somite. Anteriorly the heart forms a short aorta which opens into the body cavity in the head. There are no blood-vessels and the blood, which contains amœbocytes, circulates freely in the body cavity before it returns to the heart. Metamerically arranged triangular muscles serve to enlarge the pericardial sinus and to draw blood into it. The blood current in the heart is always from the rear end forward.

Respiratory system. The American locust, together with all other air-breathing insects, possesses a complicated system of tracheal tubes communicating with the outside by a series of paired openings. These openings or spiracles (stigmata) are twenty in number. One pair belongs to the mesothorax, one pair to the metathorax, and the rest to the first eight abdominal somites. In the thorax they are situated in the pleura, dorsal to the places of attachment of the legs; in the abdomen on the terga not far from their lateral edge, one on each side. The spiracles lead into short tubes, opening into two longitudinal trunks. Each trunk gives off numerous branches which penetrate between the cells of all organs. The smallest branches end blindly in a terminal cell. The two trunks communicate 
with each other by transverse anastomoses. The microscopic structure of a tracheal tube is very characteristic. It consists of a single layer of cells and a spiral intima or cuticle.

Fat body. All the space between the various organs is occupied by the fat body composed of very large cells. The function of the fat body is not yet quite understood, but it is known that it retains salts of the uric acid and that the quantity of these salts increases with age.

Nervous system. The nervous system of the locust belongs to the ladder or chain type. The brain or supraœsophageal mass is situated in the head above the œsophagus and is composed of three neuromeres (three pairs of ganglia). The first pair or the protocerebron gives off nerves to the eyes and ocelli, the second or deuterocerebron to the antennæ, the third or tritocerebron to the upper lip. The brain sends out two connectives to the subœsophageal mass, thus forming a ring around the œsophagus. The subœsophageal mass is also composed of three neuromeres (three pairs of ganglia) with nerves for the postoral mouth appendages, $i$.e., mandibles, maxillæ and under lip. The following two pairs of ganglia belong to the prothorax and mesothorax. The paired ganglion situated in the metathorax represents the fused ganglia of this and the first abdominal somite. The ganglia of the second and third abdominal somites are also fused into one mass and are situated in the second abdominal somite. The fourth, fifth and sixth somites have a paired ganglion each, but the ganglion situated in the seventh somite undoubtedly represents the result of a fusion of all the remaining ganglia (seven to eleventh neuromeres). There is a highly developed sympathetic or visceral nervous system connected with the brain and supplying nerves to various organs.

Sense organs. Like all insects the locust is a veritable storehouse of sense organs. The olfactory sense is mostly restricted to the antennæ ${ }^{1}$ the auditory sense has for its seat the

${ }^{1}$ McIndoo's observations on what he considers to be the true olfactory organs in insects still need a great deal of additional proof. 


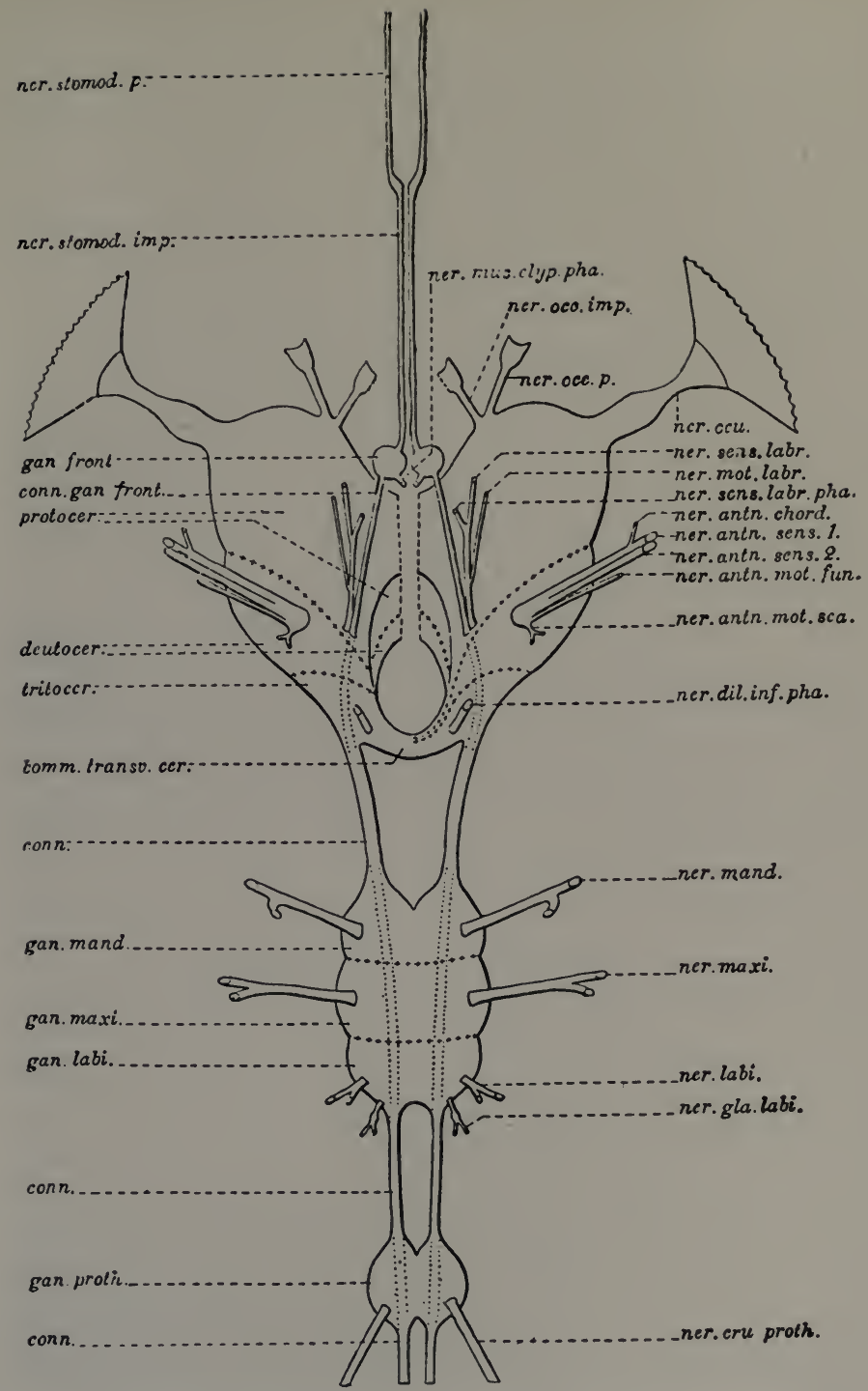

FIG. 3I. - Diagram of the nervous system of an insect after Janet (1905). 
tympanal organs of the first abdominal somite, while the two facetted and three simple eyes are situated on the head. The sense of touch is highly developed in the antennæ, while nerve endings for the perception of taste are found chiefly on the hypopharynx. We shall consider only the eyes and the tympanal or auditory organs. The facetted or compound eyes are composed of a great number of ommatidia. An ommatidium is composed of a chitinous cornea, a crystal cone, pigment cells which isolate one ommatidium from another and prevent reflections of rays forming too great an angle with the axis, and finally the retinula with a central rod or rhabdome. The image formed by each ommatidium correspond to a small portion of the horizon only, and the actual image is a composite of the images formed by all facets. The retina is direct.

The simple eyes or ocelli are composed of a lens formed by the cornea, a vitreous body which is rather poorly developed, and a direct retina. The opinion has been recently advanced that the function of the ocelli is to produce stereoscopic vision in conjunction with the compound eyes, but this opinion is far from being generally accepted.

The tympanal or auditory organs belong to the type of so-called chordotonal organs of which there are many varieties in insects. They are situated on the first abdominal tergite and are rather large. In typical chordotonal organs the swinging or vibrating element is furnished by a tendon, while in a tympanal crgan it is a membrane-tympanum, stretched within an almost circular chitinous wall or rim. The nervous apparatus of the organ is very complicated and apparently allows of a fine perception of various sounds.

Reproductive system. The sexes are separate and easily recognizable owing to the presence of the ovipositor in the female. The female has two ovaries composed of a number of tubes which sit in a row on the corresponding oviduct. The two oviducts unite in a short vagina which opens between the ovipositor on the subgenital plate (eighth sternite). A sperm 
receptacle with a long duct has a separate opening dorsal to the former. The male has two testes with two vasa deferentia uniting in an ejaculatory duct which opens on the dorsal surface of the subgential plate. A number of very fine tubes open into the vasa deferentia near their junction and serve as seminal vesicles.

Development is combined with an incomplete metamorphosis. The immature stage is sometimes called nymph and is in many respects like the adult, but lacks the wings.

\section{Instructions}

I. Place a specimen in a white dish with water on its right side and make a drawing twice natural size showing the left side. In this position the parts enumerated below will be visible and should be labeled. Head: frons, clypeus, labrum, vertex, left gena, below it and limited in front by the clypeus and labrum, the left mandible; behind the mandible the left maxillary palpus; above the gena the left compound eye, in front of the eye the left antenna and above the latter and close to the compound eye left the ocellus or single eye. Thorax: prothorax including pronotum, prosternum, prosternal spine and left prothoracic leg; ${ }^{1}$ mesothorax including mesothoracic wing, left pleuron, left mesothoracic leg and mesosternum (mesonotum and mesothoracic spiracle are not visible); metathorax including pleuron, metasternum, left metathoracic leg, and metathoracic spiracle (metathoracic wing and metanotum not visible). Abdomen: as many segments as are not concealed by the wings, showing tergite, sternite and spiracle of every segment.

2. Place the specimen on its back in a dissecting tray, spread the wings at right angles to the body and pin them down. Make a drawing showing the ventral aspect of the animal. Label antennæ, frons, eyes, clypeus, labrum, mandibles, maxillary palpi, labium, labial palpi, prosternum with spine, prosternal

${ }^{1}$ On the prothoracic leg label coxa, trochanter, femur, tibia and tarsus with claws and pulvillus. 
legs, mesosternum, mesothoracic legs and wings, metasternum, metathoracic legs and wings, first to eighth abdominal sternites. In the male the ninth sternite with the terminal subgenital plate attached to it and the cerci; in the female the ventral division of the ovipositor.

3. Make a drawing showing the left side view of the abdomen of a female from the division line between the seventh and eighth segments backwards. Label eighth, ninth, tenth and eleventh tergites, eighth sternite, cerci, podical plates and the three left divisions of the ovipositor (dorsal, ventral and egg-guide).

4. With the aid of a forceps remove the upper lip or labrum, both mandibles, both maxillæ, under lip or labium and hypopharynx. Place them in their natural sequence and make a drawing showing all parts. Label on the maxillæ cardo or first joint of protopodite, stipes or second joint of protopodite, lacinia or inner maxillary plate, galea or outer maxillary plate and the five-jointed maxillary palpi. On the labium label submentum, mentum, ligula, and four-jointed labial palpi.

5. Make a drawing showing the side view of the metathorax and first and second abdominal somites with wings raised to expose the auditory organ.

6. Cut out with sharp scissors the left auditory organ together with a piece of adjoining integument, remove all adhering tracheal tubes, wash and examine its inner surface in water through the dissecting microscope. Make a drawing showing the thickened edge of the organ, the tympanum or membrane, the auditory nerve, the ganglion.

7. Female. With the aid of fine scissors make an incision along the ventral surface of the animal parallel to and slightly to the left of the mid-ventral line. The incision should extend from the ovipositor to the head. Make a similar incision parallel to and slightly to the left of the mid-dorsal line, and remove the left body wall. Remove in the same way the left side of the head capsule. Make a drawing showing the organs in situ. Label (r) alimentary canal in which the following parts may be recognized: 
crop, salivary glands, cœca, ventriculus, ileum (the rest of the hindgut is covered up by the reproductive organs); (2) malpighian tubes opening into the alimentary canal, marking the end of the midgut; (3) nervous system: brain above the œsophagus in the head and ventral chain below the alimentary canal with three thoracic and five abdominal ganglia; (4) heart, if not destroyed by preserving process, will be seen in the middorsal line of abdomen above all the other organs; (5) ovarial tubes, occupying all the space between the heart and the alimentary canal in abdomen; (6) muscular system: muscles of the fore and hind wings in the thorax and the muscles of the ovipositor in the abdomen; (7) endoskeleton arising from the sternite of the thorax.

Additional exercises.

(a) Take a fresh specimen and remove the dorsal body wall, including wings, by an incision along each side of the body just above the line of the spiracles. Examine the excised wall for the heart and make a drawing of this. Fasten down the ventral body wall with pins in the dissecting tray with water and carefully push the various organs apart allowing the alimentary canal to lie on the left and the reproductive organs on the right. This separation, if carefully performed, will expose the entire alimentary canal, nervous system and reproductive organs. Make a full page drawing and label parts from the text in the general description.

(b) Examine under microscope the sections through the various regions of the alimentary canal and make drawings of them.

(c) Examine under microscope the section through the auditory organ and make a drawing of it.

(d) Examine under microscope a fresh tracheal tube (in water) and make a drawing of it.

(e) Examine under microscope the slide with the stained ovarial tubes and make a drawing of it. 


\section{AGELENA NAEIA Walckenær}

Material. Agelena nævia is the "common grass-spider" and may be collected in great quantities during July and August. Specimens should be preserved in $70 \%$ alcohol. Stronger alcohol is injurious, formalin ruins the specimens completely. Fertilized females will deposit eggs in a cocoon in confinement. The spiderlings should be fixed in my sublimate mixture. Every student should receive a mature female, a mature male, an immature specimen, a series of prepared slides with transverse sections through a spiderling and a prepared slide with median longitudinal section.

\section{Descriptive Part}

Agelena nævia is a very common spider inhabiting the United States. It belongs to the Order Araneæ, Class Arachnida, of which it is a typical representative. Meadows are often covered with the webs of Agelena, which glisten like silver in the morning dew of autumn. They have the shape of a broad sheet extending into a long funnel in the depth of which the spider hides waiting for its prey.

External features and segmentation. The body of Agelena shows a clear separation into an anterior portion or cephalothorax and a posterior portion or abdomen. The latter is joined to the cephalothorax by a very thin stalk or pedicel. With the loss of external and to some extent even of the internal segmentation, the differentiation of the integument into sclerites has been also considerably impaired, if not completely obliterated. The tergites of the cephalothorax are fused together, forming a single shield or carapace. A cephalic groove with sulci 


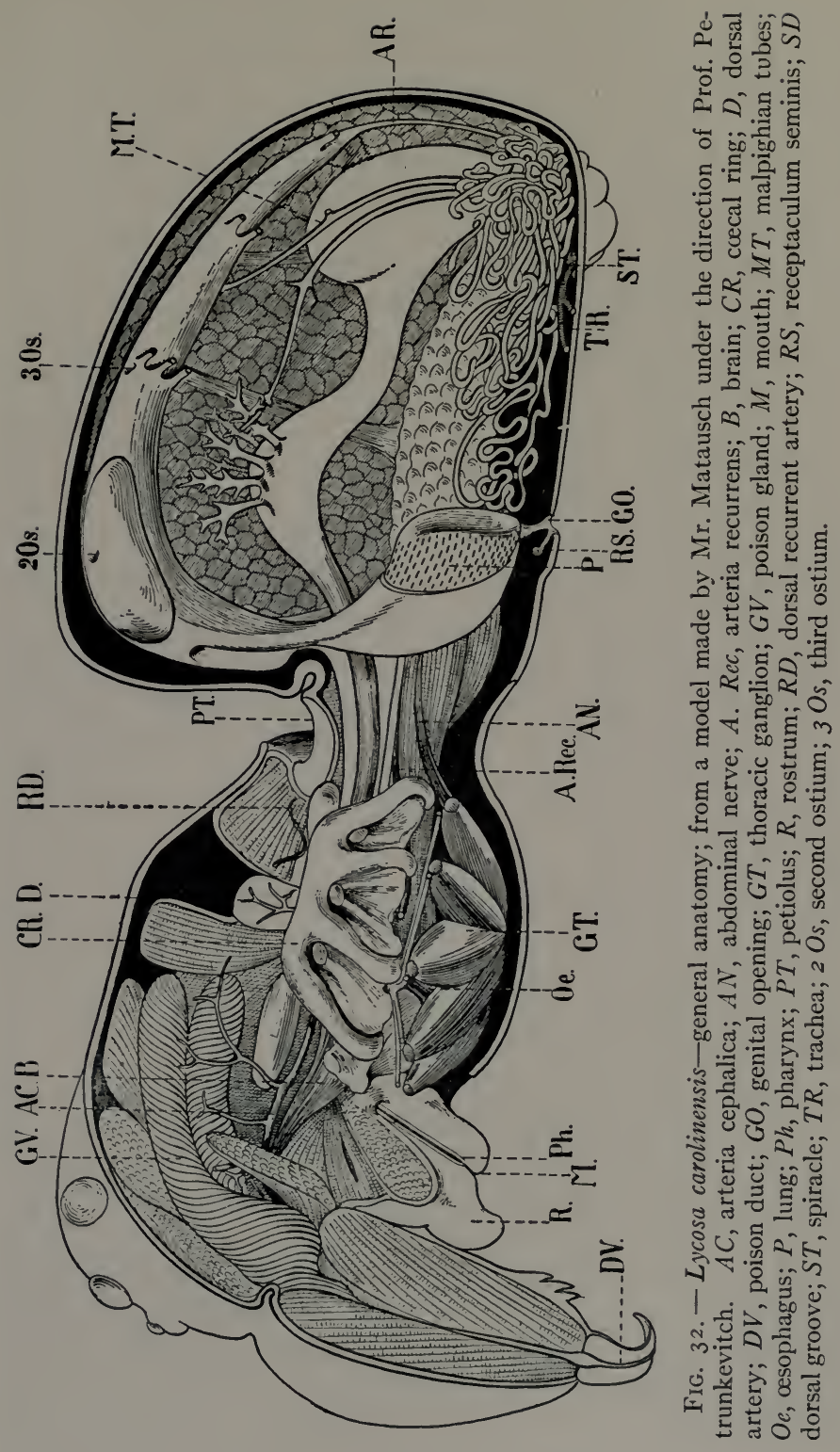


running from it obliquely forward marks the limit between the head or cephalon and thorax. This groove is an infolding of the integument, serving for the attachment of the gastric muscles and corresponds evidently to the cervical groove of the lobster. The thoracic sulci running toward the lateral margins of the carapace still represent the last traces of the external segmentation. At the anterior end of the carapace are eight beadlike eyes. The portion of the carapace between the eyes and chelicera is called clypeus. On the ventral surface of the cephalothorax between the coxæ of the limbs there is a plate called sternum. It represents the fused sternites of the five thoracic somites. Attached to the anterior edge of the sternum is a movable lower lip. The latter protects the mouth from below as the upper lip or rostrum does from above. Between the rostrum and the clypeus edge are two powerful chelicera.

The pedicel which binds the abdomen to the cephalothorax has a dorsal sclerite of peculiar shape. It is called lorum and represents the tergite of the first abdominal somite.

The abdomen has the shape of an elongated egg. It terminates in an anal tubercle in front of which and ventral in position are six spinnerets. Immediately in front of the anterior spinnerets is a small spiracle or opening leading into the tracheal tubes. Not far from the anterior edge of the ventral surface is a transverse genital fold. At the ends of the fold are two lung-slits leading into the book-lungs. The integuments of the abdomen are soft and do not show any traces of segmentation.

It is clear that in order to understand segmentation in Agelena, one must seek other evidence than that afforded by the structure of the exoskeleton. Here the anatomy of internal organs, comparative anatomy and embryology come to our aid. Some Arachnida, such as scorpions and Solifugæ, possess a segmented abdomen. The nervous system retains even in adult spiders its composition of distinct neuromeres, and the embryo shows a transitory external segmentation of the abdomen which is even supplied with appendages. With all that the opinion as to the 
number of somites which enter into the formation of the arachnid body, is still divided. Some maintain that the portion of the head situated in front of the mouth is composed of two somites only. In this case the chelicera would be homologous with the antennules of the lobster. A more generally accepted opinion is based on the assumption that the chelicera are homologous with the antennæ of the lobster, and that the preoral region is composed of three somites. We, for our part, will assume that four somites lie in front of the mouth and that the entire body of an arachnid is composed of twenty-two somites, $i$. e., as many as in the crustacean Nebalia and one more than in the lobster. According to this interpretation the chelicera are homologous with the mandibles of insects and crustaceans. They are postoral in the embryo, but become preoral early in the development. The twenty-two somites are distributed as follows: five belong to the head, four to the thorax, and thirteen to the abdomen. The four preoral somites of the head are (I) the first ocular somite, characterized by the presence of the four lateral and two posterior median eyes; (2) the second ocular somite, characterized by the presence of the two anterior median eyes; (3) an embryonic, evanescent segment with rudimentary appendages which disappear completely; (4) the cheliceral somite with chelicera for appendages. The fifth cephalic somite is the first postoral somite. It has the pedipalpi for appendages. The four thoracic somites have a pair of legs each. The abdomen in the embryo of Agelena is divided into ten segments, the first six of which have a pair of embryonic appendages each. The first to ninth segment represent as many somites, but the tenth segment evidently corresponds to the last four segments of the abdomen in the scorpion and is therefore the result of a fusion of four somites. The embryonic appendages of the first, second, third and sixth abdominal somites disappear, those of the fourth and fifth become spinnerets. The first abdominal somite which disappears completely in the scorpion, forms the pedicel in Agelena. The pair of lungs and the genital opening belong to 
the second abdominal somite. The spiracle belongs to the third somite and is situated at its posterior margin. The six embryonic segments situated behind the spinnerets and representing the sixth to thirteenth somites become quite rudimentary, fuse together and form the small anal tubercle at the end of which the anus is situated.

Appendages. Agelena has two pairs of cephalic, four pairs of thoracic, and two pairs of abdominal appendages. The first pair of cephalic appendages is called the chelicera. They are used for grasping the prey, for holding it during the process of pre-digestion, and, in case of need, for defence. They are two-jointed. The basal joint has more or less the shape of a pyramid, the terminal joint or fang is thin, pointed, and as hard as steel. When "closed" the fangs rest between the two margins of the basal joints. Both joints move in a transverse plane which is characteristic of all the true or two-lunged spiders. Under the tip of the fang is the opening of the poison duct. The second pair of cephalic appendages is called pedipalpi. They are six-jointed. The first joint or coxa has a maxillary lobe or lamina. It does not seem probable that the laminæ serve either for masticating or passing the food to the mouth. The coxa of the pedipalp in tarantulæ which "chew" their food, has no lamina, while all true spiders do not "chew" but "suck" their prey. It is more likely that the laminæ are tactile organs. Their connection with the process of predigestion will be considered later. The remaining five joints of the pedipalp form the feeler or palpus. The terminal joint is simple in the female, resembles the terminal joints of the legs and has a claw. In the male, on the other hand, the terminal joint is modified as an organ of copulation. Its structure is very complicated and may be treated here only in a general way. The dorsal wall has more or less the shape of a trough which serves for the protection of the copulatory apparatus. The latter is the product of the ventral wall of the terminal joint. It consists of a sperm reservoir inclosed in a thin sac called hamatodocha, an embolus or intromittent organ in the 
shape of a spiral tube, a conductor and various hard, chitinous additional structures. The swelling of the hæmatodocha causes the protrusion of the entire apparatus during copulation when the embolus is introduced into the sperm receptacle of the female.

The four pairs of thoracic appendages are seven-jointed legs. Two of them are directed forward and two backward, so that the inner surface of the former corresponds to the outer surface of the latter, and vice versa. The first joint which serves for the attachment of the leg to the cephalothorax is called coxa or coxopodite, the second-trochanter or basopodite, the third-femur or meropodite, the fourth-patella or carpopodite, the fifth-tibia or propodite, the sixth-metatarsus or first dactylopodite, the seventh-tarsus or second dactylopodite. Some of the joints have spines, the number and position of which furnish excellent systematic characters. At the end of the tarsus are two serrated upper claws and a serrated median or lower claw. The first pair of spinnerets called anterior or lower spinnerets are two-jointed appendages of the fourth abdominal somite. It is probable that they are homologous with the exopodite of a pleopod. Their terminal joint is hemispherical and has comparatively few spinning tubes. The appendages of the fifth abdominal somite are the remaining four of the six spinnerets present in the majority of spiders. They are biramous pleopods in which the protopodite disappeared, the exopodite became the two-jointed posterior or upper spinneret, while the endopodite is represented by the much smaller, single-jointed median spinneret. The terminal joint of the posterior spinnerets is long and thin, and this joint as well as the median spinneret are the seat of numerous spinning tubes.

Integument. The integument consists of a chitinous cuticle produced by the hypodermis. The latter is composed of a single layer of epithelial cells. A supporting membrane is produced by the hypodermis on its inner surface. The chitinous cuticle forming the carapace, sternum and segments of the ap- 
pendages is very hard. The articulation membranes are on the other hand quite soft and elastic. The integument of the abdomen is considerably thicker than that of the intersegmental membranes, but is still elastic as is clearly demonstrated by the considerable stretching of the abdomen under the pressure of the growing ovaries. The entire body, excepting the articulation membranes, is covered with hair. This is of at least two types. One is long, serrated, but not branched; the other is shorter, plumose. Every hair is the outgrowth of a single hypodermal cell and is supplied with a nerve fibre. Thus the whole surface of the body is very sensitive to touch or to air-currents and vibrations. The spines as well as the claws and the spinning tubes are also modified hairs. The spines sit in special sockets and may be considerably lifted from their normal position in which they practically lie on the surface of the limb. A new cuticle with all its hair is produced underneath the old one and takes the place of the latter after each moulting.

Endoskeleton. An endoskeleton is present in both cephalothorax and abdomen. In the latter it consists of three rudimentary endosternites serving for the attachment of muscles. The endoskeleton of the cephalothorax is of a very peculiar shape. It consists of a central, saddle-like plate situated between the thoracic ganglionic mass and the ring of intestinal cæca, and of a number of processes. Some of these processes serve for the attachment of muscles which hold the endoskeleton as it were suspended horizontally, others for the attachment of muscles inserted in the coxæ of the limbs.

Muscular system. The muscular system is naturally very complicated and highly specialized. It still retains traces of metamerization in the abdomen and thorax. Of special interest are the muscles of the pumping stomach. The single dorsal one is attached to the fold of the cephalic groove, the two ventral muscles to processes of the endoskeleton. Very powerful are the muscles moving the chelicera. The muscular system of the legs and pedipalpi is characterized by the absence 
of extensors, their function being performed by the elastic interarticular membranes.

Glands. The most important glands are the poison glands and the spinning glands. The poison glands are situated in the head and occupy a large portion of its cavity. There are two of them, one for each chelicer. The glands are sausageshaped, with a spiral muscle in their wall. The duct runs between the flexor and extensor of the fang and terminates in a small opening under the tip of the latter. The action seems to be voluntary, the spider using the poison only in self-defence. The numerous spinning glands are situated in the abdomen. A separate duct leads from each gland to a spinning tube on the spinnerets. The silk is a secretion which hardens from contact with the air. Two coxal glands of uncertain function are situated in the cephalothorax. Their ducts open between the first and second pair of legs. It is probable that all arachnids possessed once a pair of openings at the base of all four pairs of legs. The coxal glands are modified nephridia with a blind end. A group of pedipalpal glands is contained in the maxillary lobe of the pedipalpi. Each gland has a separate opening. The secretion has a peptonizing ferment and is used in predigestion.

Digestive system. The digestive system of Agelena, as that of all spiders, is peculiar in many respects. The mouth opens ventrally so that the upper lip sits really in front of it and the lower lip behind it. The maxillary plates of the pedipalpi are at the sides of the lower lip and not in front of it as is the case with the maxillæ in insects. The foregut is clearly divided into a pharynx, œsophagus and pumping stomach. The pharyn $x$ has two chitinous plates in its intima provided with special muscles. It leads directly upward and its posterior end is considerably thicker than the cesophagus. The latter is a cylindrical curved tube lined with chitin. It opens into the pumping stomach, the wall of which has three chitinous plates and works as a pump. The upper chitinous plate serves for the attachment of the dorsal dilatator, the ventrolateral plates for that of the 
ventral dilatatores. The contraction of these muscles widens the lumen of the stomach. Special circular constricting fibres reduce the volume of the stomach and force its contents into the intestine. This section of the alimentary canal represents the midgut and extends backward through the pedicel into the abdomen as a rather wide and slightly curved tube. The intestine is connected with a so-called coecal ring in the cephalothorax. This ring is formed by two blind processes growing out of the midgut at its juncture place with the pumping stomach. Later the two processes unite in front and give off, besides, blind pouches, one pair of which extends forward from the anterior edge of the ring, a single one-backward from the upper wall of the posterior edge of the ring, and four lateral pairs which end blindly in the coxæ of the legs. Within the abdomen the intestine forms four pairs of highly branched and anastomosing intestinal diverticles which are imbedded in a mass of adipose tissue. For a long time this tissue has been described as "liver," owing to the fact that it binds the diverticles of the intestine firmly together and has the appearance of a large gland. It forms two lobes separated by the heart and extending almost to the mid-ventral line and incloses all the organs. The adipose tissue makes the dissection of spiders very difficult. The hindgut forms a large stercoral pocket into which the malpighian tubes open. The rectum is short and terminates in an anus on the anal tubercle. Salivary glands are absent. The process of feeding in Agelena is very peculiar and characteristic of true spiders. It is combined with predigestion of the food outside of the alimentary canal. When the fangs have pierced the body wall of the victim, a drop appears between the tips of the spider's maxillary lobes. This drop is supposed to be the secretion of the pedipalpal glands, but an admixture of intestinal juice is probable. It peptonizes all organs and tissues of the victim. The fluid is drawn into the alimentary canal by a combined sucking action of the pharynx and pumping stomach. Resorption takes place in all portions of the midgut. 
Excretory system. Two malpighian tubes function as organs of excretion. They are situated in the abdomen, partly imbedded in the adipose tissue, and open into the stercoral pocket of the hindgut. It is probable that the coxal glands, too, have an excretory function.

Circulatory system. Agelena has an open circulatory system in which the arteries open directly into the body cavity. The heart is a long tube with muscular walls, situated in the middorsal line of the abdomen, directly under the body wall, between the two lobes of the adipose tissue. It is inclosed in a pericardium and provided with three pairs of lateral ostia through which the blood enters. Anteriorly the heart becomes constricted and forms the anterior aorta which runs above the intestine, enters the cephalothorax and divides into two arteries in the region of the pumping stomach. These arteries subdivide and supply the appendages and the organs inclosed in the cephalothorax. Posteriorly the heart gives off the posterior aorta which extends almost to the anus. The blood which is colorless and contains amœbocytes, reaches the lungs by way of lacunæ, while a portion of it is oxidized through the tracheal tubes. From the lungs the blood returns to the heart by way of two pulmonary sinuses which open into the pericard at the points nearest to the anterior ostia. The blood oxidized through the tracheal tubes returns to the heart through the four posterior ostia. It is probable that the heart does not contain fully oxidized blood. The rhythmic pulsation of the heart drives part of the blood forward and part backward into the posterior aorta.

Respiratory system. The respiratory system of Agelena consists of a pair of lung-books and of tracheal tubes. The lung-books are modified and infolded appendages of the second abdominal somite. They are situated in front of the genital groove in little pockets of the integument. The opening leading into the pocket is called the stigma or spiracle and is situated at the rear end of the pocket. The lung itself consists of numerous lamella attached to the anterior end of the lining of the pocket 
and comparable to the leaves of a book. The air circulates between the lamellæ, while the blood is oxidized inside of the lamellæ. The system of tracheal tubes is quite separate from the lung-books. The single tracheal spiracle is situated on the ventral surface of the abdomen, in front of the spinnerets. The common stem splits very soon into two branched tubes penetrating among the cells of the various organs.

Nervous system and sense organs. The central nervous system of Agelena is characterized by a great concentration of ganglia. The brain or supracsophageal mass is usually supposed to consist of only two neuromeres, the protocerebron and the deuterocerebron. But it is much more plausible that at least four neuromeres compose the brain. The first neuromere is represented by the first optic ganglia and supplies nerves to the four lateral and the posterior median eyes. The second neuromere is formed by the second optic ganglia and supplies nerves to the anterior median eyes. The third neuromere apparently disappears during development, while the fourth neuromere supplies nerves to the chelicera. The brain is united to the subœsophageal mass by short connectives forming a ring for the passage of the œsophagus. The subœsophageal mass is situated immediately above the sternum and below the endoskeleton, so that a puncture of the sternum involves usually also a puncture of the subœsophageal mass and causes paralysis of the animal. The mass is composed of the last cephalic ganglion, four thoracic ganglia, and at least three abdominal ganglia (four abdominal ganglia in the scorpion). It supplies nerves to the under lip, pedipalpi and legs. Posteriorly the mass is drawn out into a long stem ending in another ganglionic mass in the pedicel. This latter mass is quite small compared with the thoracic mass and represents the fused and greatly reduced remaining ganglia of the abdomen.

The best developed sense in Agelena is that of touch. Every nair, bristle and spine is supplied with a nerve fibre, with the result that the slightest touch or the gentlest vibration of the 
web is at once perceived by the animal. Some of the hair on the appendages is exceptionally fine and erect, sitting in the centre of a small, disc-like or hemispherical membrane. This hair is called trichobothria, and is supposed to convey the impressions of air vibrations or sound. Yet real sense of hearing is wanting in all spiders. An olfactory function has been ascribed to special, so-called lyriform organs appearing as minute slits on the legs near the articulations and elsewhere in the integument. But only strongest odors, such as emitted by essential oils or acetic acid, can be perceived and even these imperfectly. The eyes are fairly well developed. They are situated on the carapace, eight in number, and belong to the type of simple eyes or ocelli. The eyes form two strongly procurved rows and are designated in systematics as anterior middle, anterior lateral, posterior middle, and posterior lateral eyes. But in reality the lateral eyes of the anterior row belong together with the eyes of the posterior row to the first somite, while the anterior median eyes alone belong to the second somite. Moreover, the anterior middle eyes belong to a different type than the other six eyes, inasmuch as they possess a direct retina, while the others have an inverted retina. An ocellus is typically composed of a chitinous corneal lens, a vitreous or glass body and a retina. A ring of pigment under the lens serves as an iris. The retina of the inverted eyes is provided with a tapetum behind the rods. The images formed by the eyes are very sharp, but the acuity is very slight, so that the spider is not able to see much detail.

Reproductive system. The sexes are separate and may be easily recognized. The legs of the male are much longer in proportion to its carapace, while the abdomen of the female is considerably distended by the growing ovaries. At the same time the modified and enlarged terminal joint of the pedipalpi in the male makes the recognition quite simple.

(a) Female. Two ovaries occupy almost all the space below the intestine in the abdomen. Each forms anteriorly a short ovi$d u c t$, the two oviducts uniting in a still shorter uterus. The 
latter terminates in a wide, slit-shaped genital opening situated in the genital groove on the ventral surface of the abdomen. It belongs to the second abdominal somite. Above the genital opening is a chitinous structure called epigynum with two open-

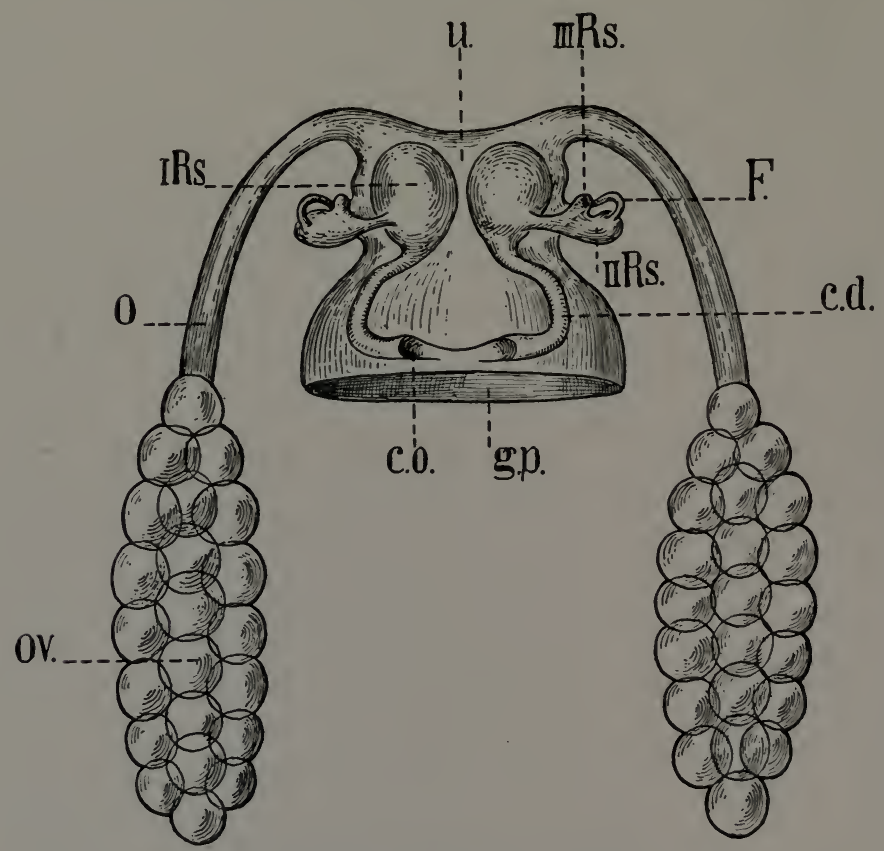

FIG. 33. - Female reproductive organs of a spider, modified from V. v. Engelhardt. $o v$, ovary; $o$, oviduct; $u$, uterus; $c o$, copulation opening; $c d$, copulation duct; $g p$, genital opening; $F$, fertilization canal; I, II, III $R s$, first to third sperm receptacles.

ings leading into as many sperm receptacles. Thus there are altogether three sexual openings. A fertilization canal connects each receptacle with the uterus. Only the two openings leading into the receptacles are used for copulation. The sperm is stored for a considerable time in the receptacles. As the eggs pass the openings of the fertilization canals in the uterus, they are 
fertilized one by one and appear in the median genital opening.

(b) Male. Two testes in the shape of long and thin coiled tubes are situated in the abdomen under the intestine. They continue as vasa deferentia and unite shortly before their joint genital opening. The latter occupies the same position as the corresponding opening of the female-in the genital groove. The copulatory apparatus of the male has no connection whatever with the sexual organs producing the sperm, and is formed by the modified last joint of the pedipalpi, as described above. Thus it happens that Agelena, like all other spiders, has two organs of copulation corresponding to the two openings of the sperm receptacles in the female. When the male becomes mature with the last moult, he weaves a small "sperm" web into which he ejects the sperm through its genital opening and pumps it then into the sperm reservoirs of his palpi. If now the male finds a mature female, he introduces the embolus of one pedipalp into one of the receptacles of the female and fills it with sperm. After a few minutes the other embolus is introduced into the second receptacle and copulation is finished.

Development. The fertilized eggs are laid into a specially prepared sheet which, when filled, is formed into a closed cocoon. Development is direct. The spiderlings resemble their parents. Maturity comes only with the last moult, before which the spiders are unable to reproduce. The life cycle occupies an entire year.

\section{Instructions}

I. Place a mature female in its natural position in a dish with alcohol and examine in reflected light under dissecting microscope. Make a half page drawing of the dorsal surface. Label cephalothorax and abdomen. On the former label carapace, cephalic groove, thoracic sulci and eyes. At the end of the abdomen label the upper spinnerets. The heart is visible 
in some specimens in the mid-dorsal line under the integument in the abdomen.

2. Turn the specimen on its back and make a half page drawing showing the ventral surface. Label chelicera with fangs, pedipalpi with maxillary lobes, lower lip, sternum, legs, pedicel, lung-books, genital fold with genital opening in middle and a stigma at each end, epigynum, anterior or lower spinnerets, posterior or upper spinnerets, and anal tubercle. The tracheal spiracle is difficult of detection, but may be recognized by the direction of the hair surrounding it. The median spinnerets are not visible. Label the somites with the aid of the description given on a previous page. Label all joints of a pedipalp and of a leg.

3. Take the spider with your left hand and examine it through a magnifying lens from in front. Make a drawing showing outline of carapace and chelicera. Label clypeus, anterior and posterior rows of eyes; represent the shape of each row by a dotted line passing through the centres of the eyes. This drawing will represent the relation of characters as used by systematists.

4. Repeat the same drawing omitting the dotted lines. Make a single dotted line between the eyes, dividing them into two groups corresponding with the somites. The second somite has only one pair of eyes. Label somites.

5. Remove two terminal joints of a leg, boil them in $20 \%$ potassium hydrate, wash in water, place on a slide in a drop of glycerine and examine under cover glass through the microscope (200 diameters). Make a drawing showing claws.

6. Examine the joints under high power (400 diameters), find a common hair, a plumose hair, a spine and a trichobothrium. Make drawings of them and label.

7 . Boil the rest of the leg in $20 \%$ potassium hydrate and find the lyriform organs. Make a drawing showing them.

8. Remove the spinnerets together with adjoining tissue and treat in the same manner. Examine under low power and make a drawing showing all six spinnerets. 
9. Examine the terminal joint of an upper spinneret under high power (400 diameters). Make a drawing showing the spinning tubes among the hair.

Io. Remove the epigynum with adjoining tissue, boil it in $20 \%$ potassium hydrate, etc.; and examine it under high power. Make a drawing showing outline of chitinous structures and both receptacles.

II. Remove two terminal joints of an immature spider, treat them in the same manner and examine under high power. Make a drawing showing the old claws and the new claws still inclosed in the tarsus.

I2. Remove one of the pedipalpi of a mature male, treat it in the same manner, and make a drawing showing the terminal joint with the copulatory apparatus. Label the long, spiral embolus and the soft hæmatodocha.

I3. Examine under microscope the series of prepared transverse sections through a spiderling. Make at least four drawings, one through the region of the eyes, one through the pumping stomach, one through the lungs and one through the abdomen in front of the spinnerets. Label all organs.

I4. Examine under microscope the prepared slide with a series of sagittal sections through a spiderling. Choose the section showing both heart and nervous system. Make a drawing showing all organs. Label also all neuromeres in accordance with the somites. 


\section{ASTERIAS FORBESI Desor}

Material. Specimens of Asterias forbesi may be collected among rocks between the tides or in tide-pools. Excellent diry specimens may be obtained by suddenly pouring boiling water into the dish in which the starfish has been allowed to assume the attitude of perfect radial symmetry. For the study of internal organs and especially of the ambulacral system injected specimens are highly recommended. The injection may be accomplished without difficulty through one of the radial canals and should be continued till the ambulacral feet of all radii are injected. The specimens may be then preserved in formalin. Injected specimens are also for sale at most of the marine laboratories. Very small specimens should be fixed for sections in Perenyi's fluid for which purpose each arm is severed with a sharp razor. Decalcifying before imbedding is imperative. Staining in hæmatoxylin with counterstaining in eosin or orange $\mathrm{G}$ is advisable.

\section{Descriptive Part}

Asterias forbesi is a common starfish of the Atlantic Coast. Like all echinoderms it shows radial symmetry inasmuch as each of its five arms contains the same set of organs. But this radial symmetry is not the original plan of structure and a closer examination of the starfish reveals the fact that it is built on the principle of bilateral symmetry. This plan is determined by the position of the so-called madreporic plate which is situated on the dorsal surface of the central disc between two of the arms. The plane of symmetry bisects therefore the madreporic plate, the anus which is situated in the middle of the dorsal surface of the central disc, and the arm or radius opposite to the 
madreporic plate. The two arms between which the madreporic plate is situated form the bivium, the remaining three the trivium. The entire dorsal surface is covered with short spines or tubercles surrounded by groups of pedicellariæ. On the ventral surface, in the middle of the disc, is the mouth surrounded by five pairs of oral spines. Radiating from the mouth are the ambulacral grooves in which the ambulacral feet lie in four rows in each arm. The edges of the grooves are covered with sharp spines. At the end of each arm, imbedded among spines, is the terminal tentacle with a red spot at its base-the eye.

The body wall is very thick and hard owing to the presence of calcified plates or ossicles $^{1}$ in its inner layer. The ossicles of the dorsal surface are more or less irregular in shape and are held together by connective tissue and muscular fibres. The ventral surface is formed by articulated ossicles arranged in four rows in each arm. The two middle rows are formed by the ambulacral ossicles articulated with each other in the median line. Between these are the ambulacral pores through which the ambulacral feet project. The two outer rows of ossicles are called adambulacral and they carry the sharp spines already mentioned. The peristome is surrounded by a pentagon of oral ossicles. The outer layer of the body wall is formed by a ciliated epithelium. Outside of the adambulacral plates on the ventral surface and on the dorsal surface are numerous branchice (or papulæ) protruding through the interstices between the ossicles. They are short, tubelike projections of the cœlome or body cavity, are lined on the inside with colomic epithelium and are capable of being completely retracted. They serve for the purpose of respiration. The pedicellarice are little scissor-like appendages sitting around the tubercles and spines. They are composed of three parts, two blades or jaws and a basal plate with which the blades are articulated. There are two kinds of pedicellariæ, larger ones with straight edges of the blades and

${ }^{1}$ The entire skeleton of ossicles in the starfish is so articulated that it admits an extensive downward and very slight lateral motion. 
smaller ones with curved edges. The blades are provided with special muscles enabling them to open and close. The pedicellariæ are thus enabled to grasp small particles and serve as protection against small enemies and as an apparatus to keep the surface of the starfish clean and to help in forwarding food to the mouth.

The body cavity or cœlome is very large and extends to the end of each arm. It is lined with ciliated cœlomic epithelium, the so-called parietal layer.

Digestive system. The mouth as already mentioned is situated in the middle of the ventral disc and is surrounded by the peristomial membrane and five pairs of movable spines. It leads into a very short cesophagus which is followed by the immense stomach. The cardiac part of the stomach, i.e., the one nearest the œsophagus, forms five broad cardiac pouches and can be everted to the outside through the mouth, when the animal is feeding, for the purpose of predigesting the food. The digestive fluid used in this process comes from five pairs of digestive glands situated in the arms, each gland suspended by two mesenteries from the roof of the arm. These glands are diverticles of the stomach. The retraction of the cardiac portion is accomplished by five pairs of retractors or muscles arising from the sides of the ambulacral ridges. The pyloric portion of the stomach, $i$. e., the one nearest the intestine, is considerably smaller than the cardiac one and has the five pyloric cœeca just mentioned. The intestine is very short and insignificant and bears five intestinal cæca. The anus is situated near the middle of the dorsal surface.

Ambulacral or water-vascular system. From the perforated madreporic plate which is situated on the dorsal disc between the bivium, a stout, somewhat curved hydrophoric or stone canal runs toward the ventral body wall. Here it enters the ring canal in an interradius which is inclosed in the ossicles surrounding the mouth. Into the ring canal open nine Tiedemann's bodies (there being only one T. body in the inter- 


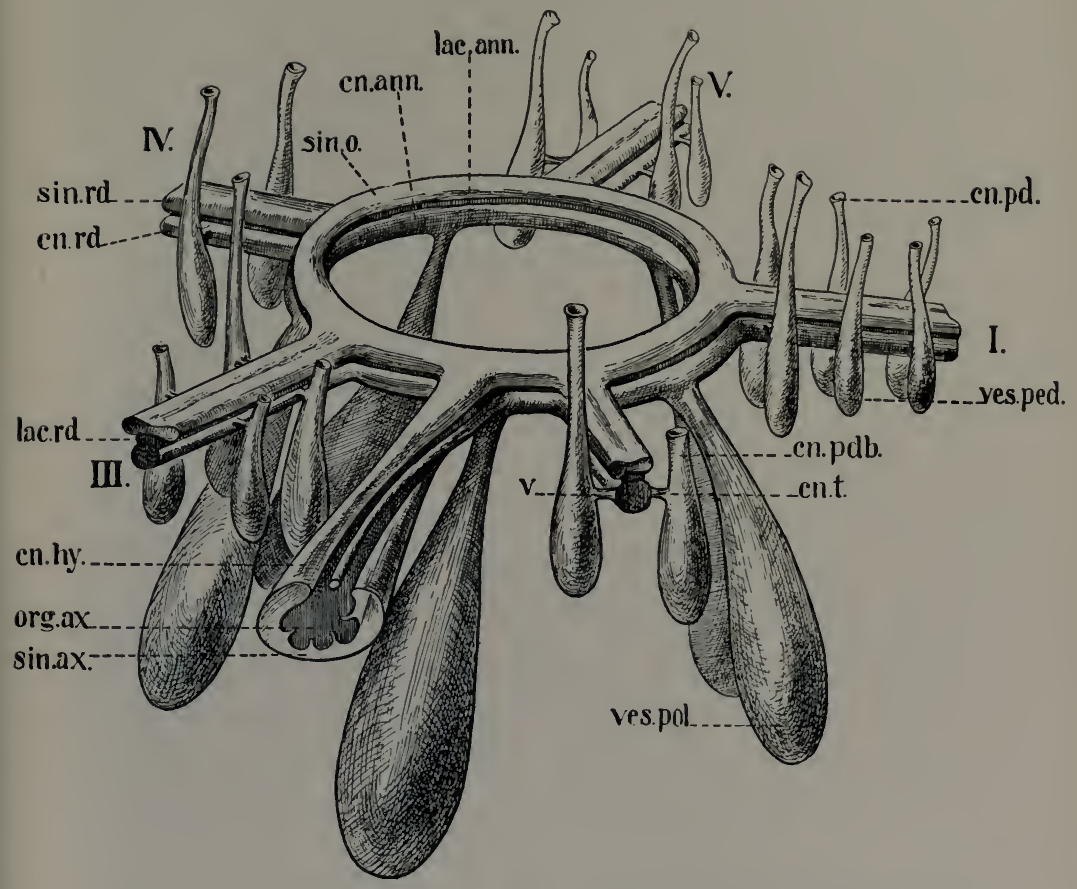

Fig. 34. - Ambulacral system of a starfish after Delage and Herouard. lac. ann, oral lacuna; $c n$. ann, oral (ring) canal (ambulacral); sin. o, oral sinus; $\sin . r d$, radial sinus; $c n . r d$, radial canal (ambulacral); lac. $r d$, radial lacuna; $c n . h y$, hydrophoric (stone) canal; org. ax, axial organ; sin. $a x$, axial sinus; $c n . t$, transverse canal; $v$, valve between transverse canal and ampulla; ves. pol, polian vesicle; $c n$. $p d b$, ambulacral tube; ves. ped, ampulla; $c n$. $p d$, sucker.

radius of the hydrophoric canal) which are minute glands producing amobocytes. The ring canal gives rise to five radial canals each of which runs imbedded in the body wall along the median line on the ventral surface of the arm ending blindly in the terminal tentacle just before the last ossicle. Each radial canal gives off at regular intervals transverse canals. Each pair of transverse canals consists of a short canal on one side and a 
longer canal on the opposite side of the radial canal. The short and long canals of each side are alternating. At the end of each transverse canal is a special muscular hollow organ, consisting of an ambulacral foot with an acetabulum or sucker and an ampulla. The ampullæ are in the body cavity, while the ambulacral feet protrude to the outside through the pores between the ambulacral plates. The first five pairs of ampullæ sitting over the ossicles in which the ring canal is inclosed, are connected with oral tentacles. These tentacles are simply somewhat modified ambulacral tubes. Real polian vesicles opening directly into the ring canal are absent in A. forbesi, but the five pairs of ampullæ just mentioned are sometimes called by this name. The sea water admitted to the system through the madreporic plate mixes with the amobocytes produced by the Tiedemann bodies and is forced by the compression of the ampullæ into the ambulacral feet which become extended and serve the purpose of locomotion. The suckers at the end of each foot allow perfect adhesion to any surface and are made use of also when the starfish intends to open the shells of a mollusc to feed upon the animals. It is probable that the ambulacral system plays also the rôle of an excretory organ.

The circulatory system follows the course of the ambulacral system under which it is situated. It is composed of a system of sinuses and a system of lacunce with the axial organ. Immediately under the ambulacral ring is the oral sinus ring divided by a perforated septum into an external and an internal oral sinus. The external sinus gives rise to five radial sinuses. Each radial sinus is divided longitudinally by a septum inclosing the radial lacuna. The radial sinus runs under the radial canal of the ambulacral system to the end of the arm, the left and right channel uniting in the tentacle. The radial sinuses give off transverse sinuses to the ambulacral feet. The internal oral sinus gives rise to the axial sinus which runs along the hydrophoric canal with which it stands in communication by a distal orifice. Communicating with the dorsal end of the axial sinus 
is the aboral sinus-ring, which gives rise to five genital sinuses. The system of lacunæ is inclosed in the septa of the system of sinuses. It is composed of an oral lacuna ring, five radial lacuna, transverse lacuna, axial lacunce, aboral lacuna ring and five genital lacune.

The axial organ is simply a glandular part of the axial lacuna,

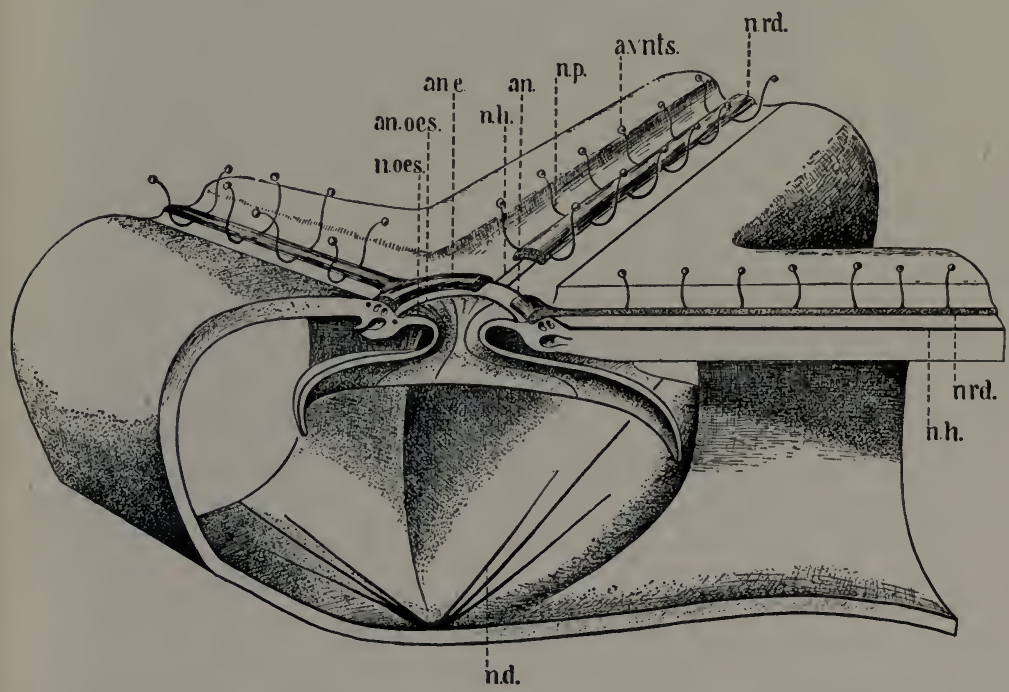

FIG. 35. - Nervous system of a starfish after Delage and Herouard. $n$. ose, œsophageal nerves; an. oes, œsophageal nervous ring; an. c, ectoneural oral ring; $n h$, hyponeural radial nerve; an, hyponeural oral ring; $n p$, transverse (pedal) nerves; avnts, nervous rings of suckers; $n r d$, ectoneural radial nerve; $n d$, deep dorsal nerves.

in which the lacuna forms a plexus. It is connected with the axial sinus by numerous pores.

The axial sinus, axial lacuna with the axial organ and the hydrophoric canal are all together inclosed in a peritoneum and form the axial complex.

The nervous system consists of a superficial or ectoneural, deep ventral or hyponeural, and deep dorsal or entoneural sys- 
tem. The ectoneural nervous system follows the plan of the ambulacral and circulatory systems. It is epidermal in origin, belongs to the ventral surface of the animal and is situated below the system of sinuses covered only by the epithelium of the body wall. Its function is sensory. It consists of a nervous ring surrounding the peristomial membrane, five radial nerves which give off transverse nerves and a peripheral network innervating the feet and the pedicellariæ. The hyponeural or motor system is structured like the ectoneural from which it is separated only by a very thin membrane of connective tissue. The entoneural system belongs to the dorsal colomic epithelium and consists of five nerves radiating from the centre.

Reproductive system. The sexes are separate, but the structure of the reproductive organs is similar in both sexes. Five pairs of ramified adradial gonads open to the outside through as many genital pores which are interradial and dorsal in their position. When fully developed the gonads extend far into the arms, on each side of the digestive cœca.

The eggs are fertilized in the water. The development is a metamorphosis in which the larval stage is represented by the Bipinnaria.

\section{Instructions}

I. (a) Dry specimen. Make a full size drawing of the aboral or dorsal surface of the starfish showing the central disc and all arms, madreporic plates, tubercles and pedicellariæ. Indicate by a dotted line the plane of symmetry and label bivium and trivium. The anus is usually not visible but should be indicated by a dot in the centre of the disc. The details should be drawn only in one arm.

2. Remove with a forceps the ambulacral feet of one arm. Make a full size drawing of the oral or ventral surface, showing mouth, oral spines, ambulacral grooves with four rows of ambulacral pores between the ambulacral ossicles, spines on the 
adambulacral ossicles, ectoneural nervous ring and ectoneural radial nerve. Details should be drawn only in one arm.

3. Examine under low power the madreporic plate and make a drawing about $5 \mathrm{~cm}$. in diameter showing its structure.

4. Remove with a scalpel some of the pedicellariæ, place them in a drop of water on a slide, examine under microscope and make a drawing showing both types of pedicellariæ.

5. (b) Injected specimen. Place the specimen in a dissecting tray with water, examine the oral surface and introduce into drawing No. 2 (in an arm different from the one drawn in detail from the dry specimen) the ambulacral feet, eye and tentacle.

6. Examine the aboral surface and introduce into drawing No. I the branchiæ.

7. With strong scissors make a lateral incision around the whole animal taking care not to ruin the internal organs. Make a circular incision around the madreporic plate. Lift with a forceps the dorsal body wall at the end of each arm and press the digestive glands down, tearing the mesenteries with the handle of a scalpel. Cut the intestine near the anus and remove the entire dorsal body wall. Make a drawing of its inner surface showing the network of ossicles and spaces between them.

8. Make a full page drawing of the digestive system showing cardiac pouches and their retractors, pyloric portion of the stomach with five pyloric cœca or digestive glands, and intestine with its intestinal cœca.

9. Remove with a forceps the entire digestive system taking care not to spoil the peristomial membrane. Make a drawing of the reproductive organs.

Io. Remove the reproductive organs. Make a full size drawing of the ambulacral system showing madreporic plate, hydrophoric canal, Tiedemann's bodies, the five pairs of ampullæ situated over the oral ossicles and belonging to the oral tentacles and the four rows of ampullæ in one of the arms. Show also the peristomial membrane and the axial organ of the circulatory system. 
II. Remove the peristomial membrane, the ampullæ of the oral ossicles and all ampullæ of one arm. Make a full size drawing showing the teeth, ring of oral ossicles with ten pores for the ampullæ and the ossicles of the arm with the ambulacral pores between them.

(c) Cross-section of arm.

I 2. Make a drawing of the prepared slide showing body wall, cœlome, digestive glands with mesenteries, ampullæ, ambulacral feet, radial canal, radial sinuses with the septum containing the radial lacuna and the ectoneural radial nerve. 


\section{OPHIOPHOLIS ACULEATA LinnæuS}

Material. Ophiopholis aculeata is very common in tidepools along the Atlantic Coast north of Cape Cod. Dissection of the internal organs is not satisfactory and the brittle star should be used only for comparison with other classes of Echinodermata. Specimens preserved in alcohol will therefore suffice. The study may be, however, supplemented by an examination of cross-sections through an arm and the disc. For this purpose very small specimens should be preserved in a fixing fluid and decalcified before sectioning.

\section{Descriptive Part}

Ophiopholis aculeata is a representative of the Class Ophiuroidea. While its general plan of structure is similar to that of the starfish, there are many important differences in structure. The radial symmetry is apparent in the whole organization of the brittle star, but the bilateral symmetry is still in evidence from the position of the madreporic plate situated on the oral or ventral surface of the animal. The body, especially on the aboral or dorsal surface of the animal, is sharply differentiated into a central disc and five narrow, long arms. The ossicles of the arms are so articulated as to allow an extensive lateral motion, whereas the up-and-downward motion is very slight. Owing to the fact that the arms are narrow their visible bases do not occupy the entire periphery of the central disc but are separated from each other by those regions of the central disc, which belong to the interradii. The dermal skeleton of the aboral surface of the central disc is composed of a system of distinct plates, while the areas between these plates are covered with short 
spines. One plate is situated in the centre of the disc and is called the central plate. It is surrounded by five radial plates. To the outside of the radial plates are ten radiating rows of

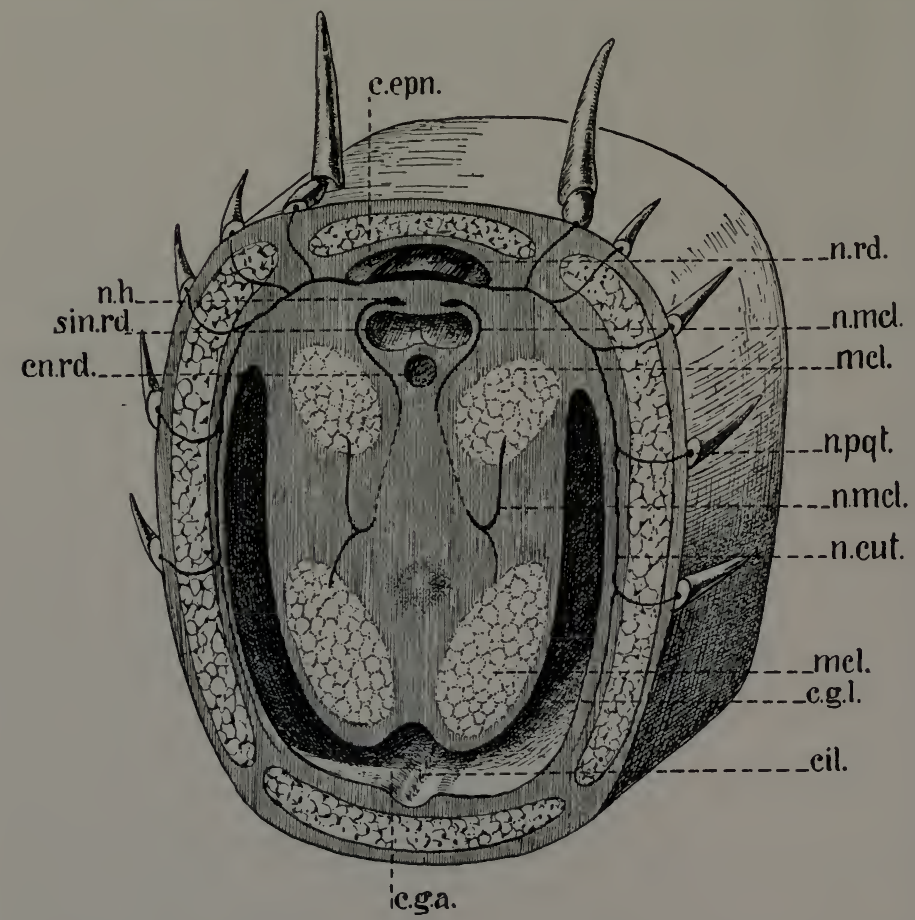

FIG. 36. - Transverse section of an arm of a brittle star after Delage and Herouard. c. $e p n$, epineural cavity; $n . h$, hyponeural oral ring; $\sin . r d$, radial sinus; $c n . r d$, radial canal; $n . r d$, epineural radial nerve; $n . m c l$, nerves of intervertebral muscles; $m c l$, intervertebral muscles; $n$. pgt, spine nerve; $n$. cut, cutaneous nerve; c. g. $l$, lateral portions of the general cavity; cil, ciliated groove or band of the cavity; $c . g$. $a$, axial cavity of the arm.

interradial and secondary radial plates [usually three of the former for each interradius and two of the latter for each radius. At the base of each arm are basal plates (adradial), usually one on each side of the distal secondary radial plate.] On the oral 
surface of the animal the disc is reduced to the interradii appearing as pouches between the arms, which extend to the mouth and enter into the formation of the oral ring or pentagon. On the inner surface of the pentagon are five interradial jaw plates each carrying a series of teeth. The free edge of the pentagon is fringed with scales called oral papilla. Immediately behind this fringe in each interradius are two narrow adoral plates followed by a large oral plate. One of the five oral plates has a minute pore and functions as madreporic plate. On each side of the arms, extending from the oral pentagon almost to the edge of the disc is a narrow genital slit.

The first thing noticeable in the structure of the arms is the absence of the ambulacral groove. Instead, the oral surface of the arm is flat and presents a single row of plates-one plate for each segment of the arm-the so-called ventral or under arm plates. The aboral surface of the arm presents a similar row of plates-the dorsal or upper arm plates. These plates are separated from each other by a row of small scales found also between the dorsal and lateral plates. Each lateral plate has five or six movable spines. The openings for the ambulacral tentacles are situated between the lateral and ventral plates, one opening on each side. The tentacles are protected by a tentacle scale. The dorsal, ventral and two lateral plates are ossifications representing the outer skeleton of the arm. The arm of all brittle stars has also an inner skeleton consisting of a row of articulated vertebre occupying the major part of the cavity of the arm. On removal of the aboral wall of the central disc one can see four vertebræ of each arm between the oral pentagon and the edge of the disc. Between them are the cavities of the interradii for the reception of the genital organs and of the stomach pouches.

The internal anatomy is very similar to that of the starfish and the various systems are built on the same principle. But there are certain differences in structure, which should be emphasized. The digestive system is restricted to the central 


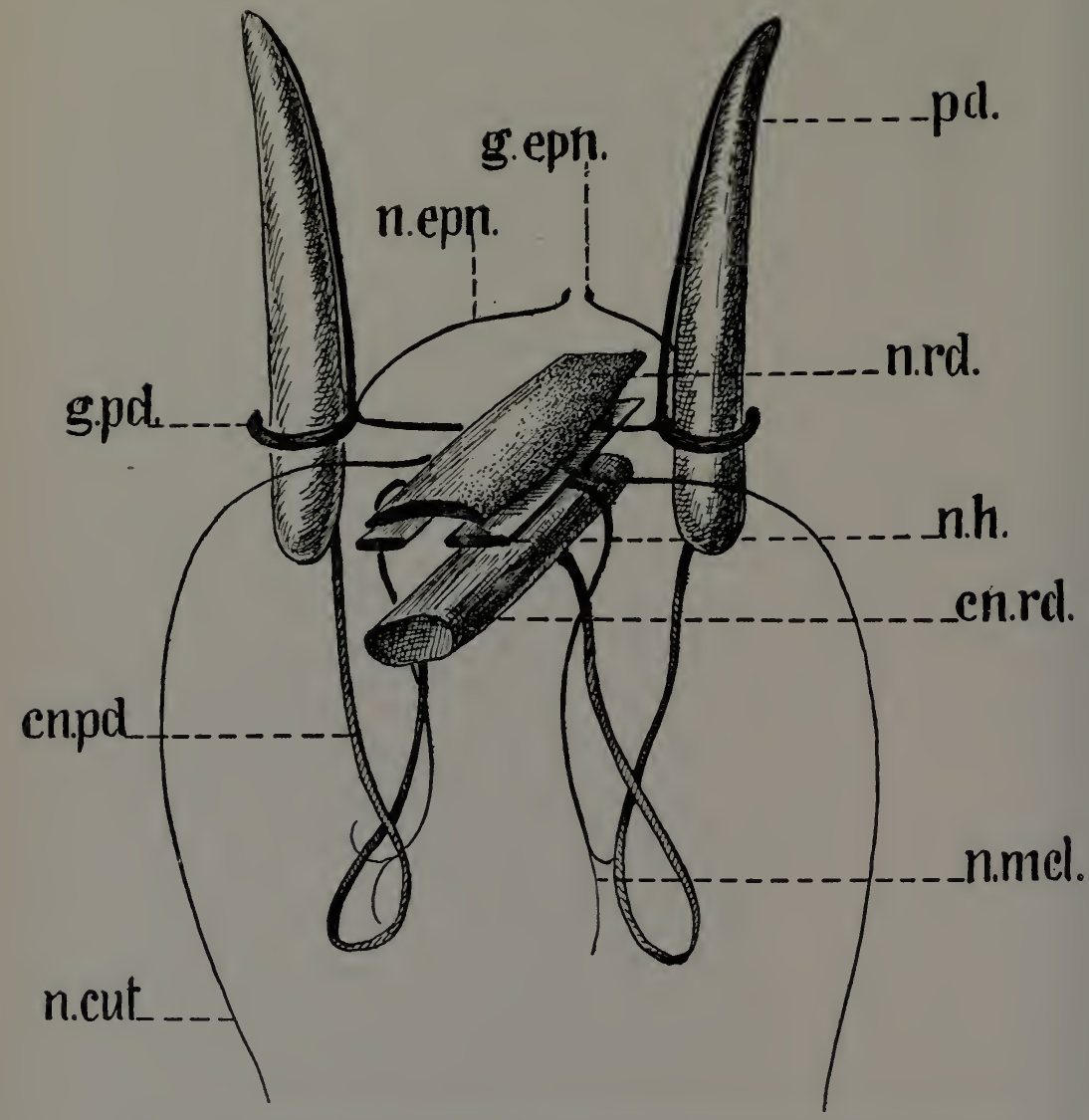

Fig. 37. - Relation between the nervous and ambulacral systems in the arm of a brittle star after Delage and Herouard. n. cut, cutaneous nerve; $c n$. $p d$, pedal canals; $g$. $p d$, pedal ganglia; $n . e p n$, epineural nerve; $g . e p n$, epineural ganglia; $p d$, ambulacral tubes; $n$. $r d$, epineural radial nerve; $n h$, hyponeural radial nerve; $c n . r d$, radial canal; $n$. $m c l$, nerve of intervertebral muscle.

disc. Hepatic glands are absent. The stomach is a blind sac. Intestine and anus are wanting. The ambulacral system presents the following differences: the hydrophoric canal opens on 
the oral surface of the central disc in the madreporic plate already mentioned. There are four Polian vesicles attached to the ring canal. Tiedemann's bodies are absent. In each arm are only two rows of ambulacral tubes and they are developed as tentacles, devoid of a sucker and useless in locomotion. The difference in the number of rows is, however, not of great importance, since we must remember that in the starfish there are alternating longer and shorter transverse canals, while in the brittle star all transverse canals are of the same length. The nervous system is more differentiated than in the starfish. The radial nerves have regular ganglionic enlargements in each segment of the arm; the dermal network of the ectoneural system has disappeared. Eyes are absent, but the terminal tentacle is present in each arm.

Ophiopholis aculeata reproduces with a metamorphosis, in many respects similar to that of the starfish. The sexes are separate and the reproductive cells are discharged into the water. The larva which develops from the fertilized egg is provided with two long and four short arms and is known under the name of Pluteus.

\section{Instructions}

I. Make a half page drawing of the aboral surface showing central disc and arms. Label all plates on the central disc.

2. Make a drawing, on the scale of $5: \mathrm{I}$, under dissecting microscope, of a few segments of an arm, showing dorsal plates, row of scales separating them, lateral scales and the spines on the lateral plates.

3. Make a half page drawing of the oral surface showing oral pentagon with teeth, five arms, genital slits.

4. Make a large drawing of the ventral surface of the disc, examining it under dissecting microscope. Label oral pentagon, fringe of oral papillæ or scales, jaws with teeth, oral tentacles, adoral and oral plates, madreporic plate, genital slits, ventral plates of the arm, ambulacral pores, tentacle scales and tentacles. 
5. Remove with scissors the entire aboral wall of the disc. Remove with a forceps all organs. Make a drawing showing teeth, oral pentagon, vertebræ of the arms, genital pouches of the interradii and genital slits.

6. Break off an arm and examine the exposed cross-section under dissecting microscope. Make a quarter page drawing showing dorsal, ventral, two lateral plates with spines, vertebra, ambulacral tentacles. 


\section{PENTACRINUS ASTERIA (CAPUT MEDUSA) Müller}

Material. This beautiful crinoid is found in the West Indies in depths over eighty fathoms. It is too expensive for class work and the description given here is merely for comparison and completeness.

\section{Descriptive Part}

Pentacrinus Asteria is a representative of the Class Crinoidea. Its body is divided into a long stalk or peduncle and a chalice with arms. The stalk is composed of numerous pentagonal columnal ossicles with toothed anterior and posterior edges and so articulated that the teeth of one columnal ossicle fit into the spaces between the teeth of the next columnal ossicle. In the centre of each ossicle is a canal running through the entire stalk. Situated on the stalk at more or less regular intervals are the cirri. Those nearest the chalice are the shortest. There are always five cirri for each vorticellum. The columnal ossicle bearing the cirri is somewhat larger than the intermediate ossicles and has five articular facets for the reception of the cirri. The cirri are many-jointed and have a central longitudinal canal communicating with the canal of the stalk, and through this with the canals of the arms. The first columnal ossicle of the stalk is star-shaped with the rays of the star situated in the interradii of the animal and appearing on the surface as small rounded plates between the bases of the arms. This star-shaped first columnal ossicle serves as base for the chalice and can be seen on removal of the stalk. The chalice is composed of the arms and the disc. Each arm has three radial joints beyond which begins the splitting up of the arm into branches. Al- 
though the number of branches is definite (our species has forty branches, $i$. e., eight branches for each arm) the method of branching is subject to great variations. Each branch is composed of numerous joints, every other joint carrying on its oral surface two many-jointed pinnula or small branches. Not only the branches of the arms but the pinnulæ too have an ambulacral groove with openings for the ambulacral tentacles devoid of suckers. The ambulacral grooves continue from the two primary branches of each arm onto the oral disc, each pair soon uniting and reaching the mouth in form of a single groove. Radiating from the mouth are therefore only five ambulacral grooves. The anus is also on the oral disc surrounded by ossicles which form a tube-like inclined projection. (Plate III, f. 2 of J. Müller. Abh. Ak. Wiss., Berlin, I84r.) Pedicellariæ absent. In the internal organization should be mentioned the presence of numerous hydrophoric canals opening into the cœlome, absence of Polian vesicles and the position of the gonads in the pinnulæ with genital rhachis running through the whole length of the arm branches. The reproductive cells reach the outside through the rupture of the tissues of the pinnulæ in more or less predetermined places. The development is not known, but is probably similar to that of the European crinoid Antedon. 


\section{ARBACIA PUNCTULATA Lamarck}

Material. Arbacia punctulata is found in shallow water and in tide-pools along the Atlantic Coast. It is advisable to make an incision either in the peristomial membrane or in the equatorial line in those specimens which are to be preserved in formalin or alcohol for dissection.

\section{Descriptive Part}

Arbacia punctulata, or purple sea-urchin, is a common representative of the Class Echinoidea. With exception of a small area on the back and a somewhat larger one on the ventral side, the entire body is covered with spines. In the centre of the dorsal or aboral surface lies the anus protected by four calcareous movable plates of the periproct. In the centre of the ventral or oral surface lies the mouth armed with five sharp white teeth. The mouth can be tightly closed by a circular lip which is a muscular differentiation of the soft peristomial membrane. The edge of this membrane is attached to the test or rigid calcareous skeleton. Around the lip are five pairs of modified ambulacral tubes - the oral papilla or suckers. Scattered over the peristome are long-stemmed pedicellarice. On the edge of the peristome, attached to the peristomial membrane are five pairs of branched organs of respiration - the branchice. Five clusters of ambulacral feet surround the peristome.

When the spines are removed the test appears in the shape of a hemisphere with a rounded edge. It is composed of twenty rows of interlocking calcareous plates extending from the periproct to the peristome. Five pairs of rows consist of perforated ambulacral plates and represent the radii, while the five pairs 
I92 MORPHOLOGY OF INVERTEBRATE TYPES

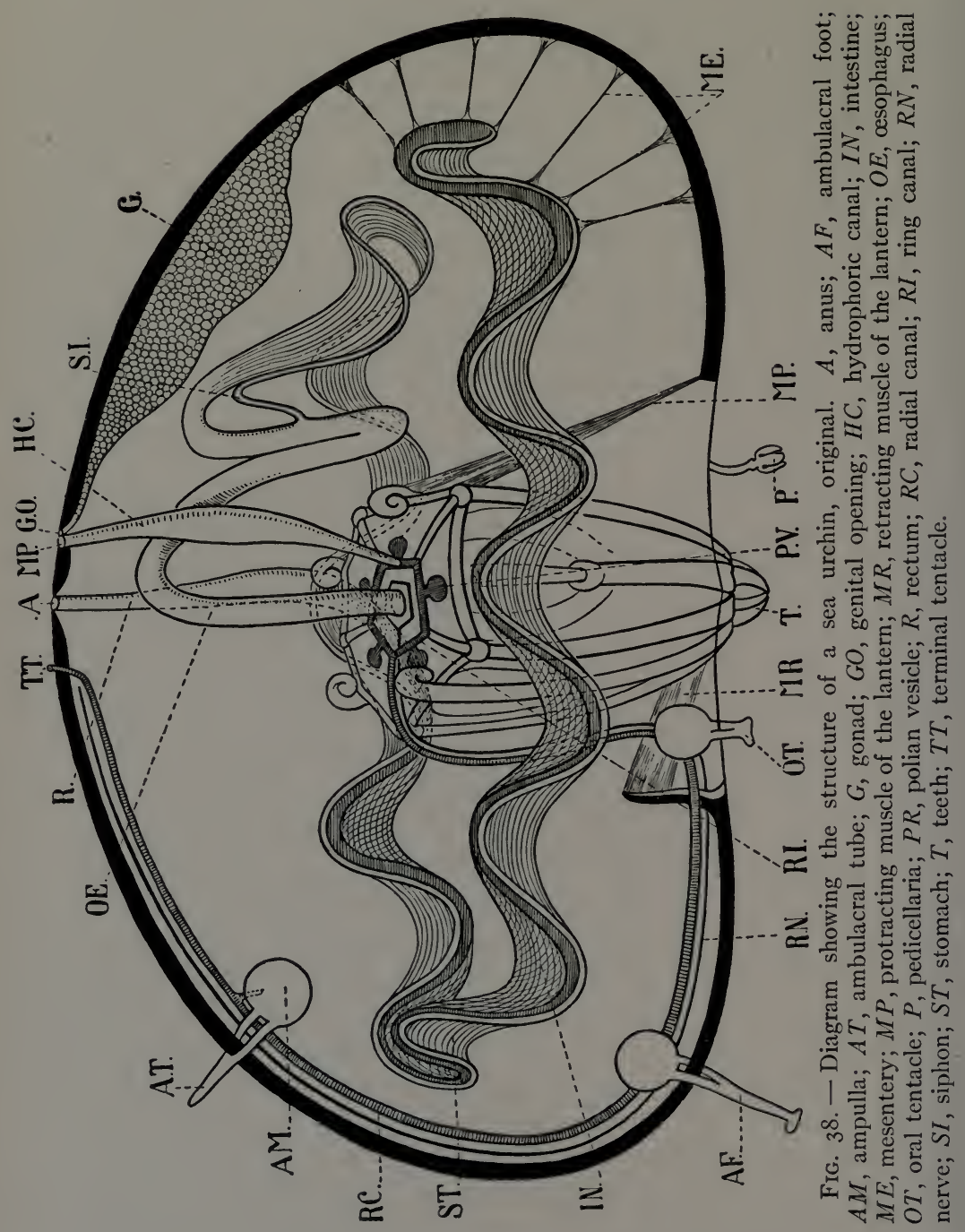


of rows composed of adambulacral plates represent the interradii. Meridional zig-zag lines run in each radius and interradius marking the articulation seams of the interlocking plates. Surrounding the periproct are five large almost triangular genital plates. They represent the terminal plates of the interradii and each shows a large genital pore. One of these plates is somewhat larger than the others and has a rough surface. It is the madreporic plate and marks the plane of bilateral symmetry. Between the genital plates are five small ocular plates. These belong to the radii and each has two pores for the terminal tentacle. The term-ocular-is a misnomer, for the tentacles correspond to the terminal tentacles of other echinoderms and do not have the structure of eyes.

Returning to the meridional rows of plates we observe first of all that the radii are much narrower than the interradii. Moreover, the radial plates increase gradually in size from the ocular plate to the edge of the peristome where the radius is widest. On the other hand, the interradial plates, also gradually increasing in size, are largest at the equator beyond which they again diminish. As a consequence the radial and interradial plates bordering the peristome are about equal in size. Each radius has two median rows of rounded tubercular bases for spines and two lateral double rows of ambulacral pores. An examination of single plates shows that each ambulacral plate has one tubercle and three pairs of ambulacral pores, a pair for each foot. On the oral surface of the test the number of pores increases gradually until near the peristome there are eight pairs of pores for each radius as against two pairs of the aboral surface. The equatorial adambulacral or interradial plates have four tubercles each. This number decreases gradually towards both poles until the last two aboral plates have only one tubercle each, and the plates nearest the peristome only two tubercles each. The radial plates bordering the peristome are in reality the second oral radial plates. The first radial plates are inclosed in the peristomial membrane. There are five pairs of them with 
pores for the five pairs of oral suckers. The first and second adambulacral oral plates are turned over and fused with the third and fourth plates. The edge of the peristome, turned towards the inside of the test is thickened and presents in each radius a pair of calcareous processes or auricles for the attachment of the retractors of the Aristotle's lantern.

The spines of the aboral surface are more or less sharp-pointed and attain their greatest length in the equatorial region. Toward the peristome they begin to change their shape, some become blunt at the end, others widen at the end so that the flat end of the spine appears wider than the base. All spines are fluted and all have a hemispherical socket at their base for the articulation with the hemispherical knob of the tubercles. The spine is held in position by a muscular sheath attached to the base of the spine and the periphery of the tubercle. This sheath is composed of a double set of muscular fibres. The set of external fibres is used for locomotion. The set of inner fibres is used for the fixation of the spine in a given direction. The relaxation of the fibres of the sheath brings the spine in its normal upright position.

The ambulacral tubes are of three kinds. The five pairs surrounding the lip are short, heavy and developed as oral suckers or papilla. The five clusters of tubes surrounding the peristome as well as the tubes of the remaining part of the oral surface are real ambulacral feet with a sucker at the end. In life they are thin and long and may be extended beyond the spines. The tubes of the aboral surface have no suckers and appear as tentacles.

The pedicellarice have a long stem and a head with three jaws. One type of pedicellariæ is found on the peristomial membrane and on the test between the spines. The stem is thick and its calcareous axis extends to the head. The head is large and the jaws are wide. The second type is found only on the test. The stem is thin, the calcareous axis does not reach to the head. The head is small and the jaws are narrow. 
Five minute spharidia are situated on the peristomial edge of the test. They are modified spines and function as sense organs. To be made visible the clusters of ambulacral feet have to be removed when each spheridium appears as a little bean-

3.

N.

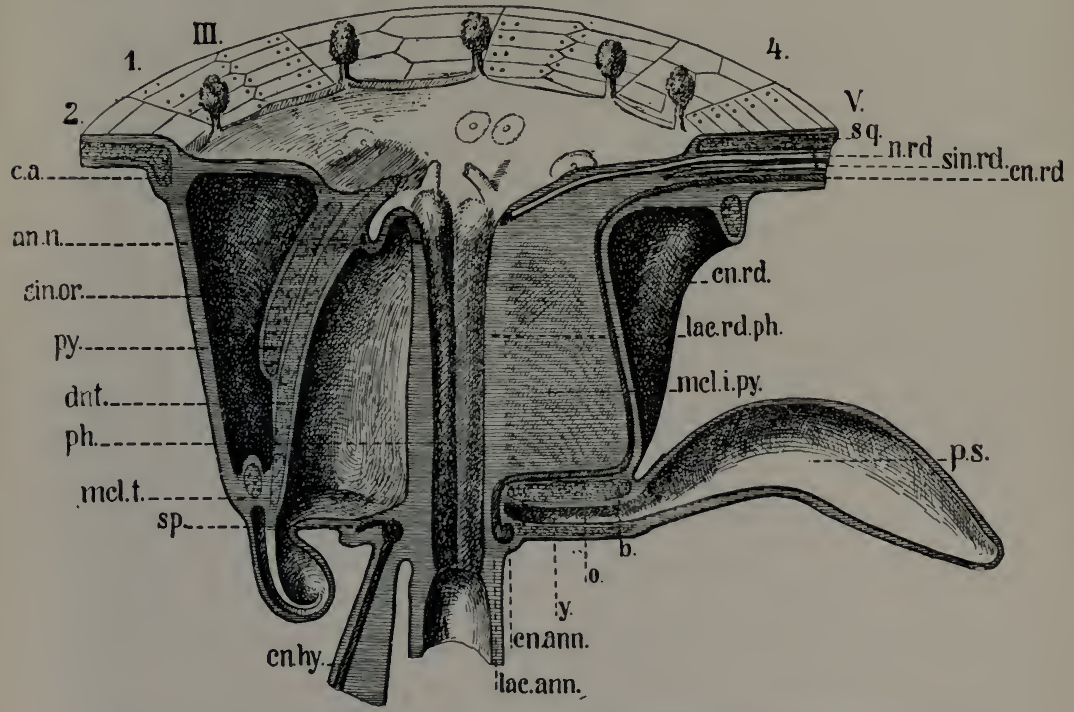

FIG. 39. - Longitudinal section through the lantern of a sea urchin showing the relative position of various organs. After Delage and Herouard. ann, epineural nervous ring; sin. or, oral sinus; $p y$, pyramid (lantern); $d n t$, tooth; $p h$, pharynx; mcl. $t$, transverse muscles; $s p$, sponge-organ; $c n h y$, hydrophoric canal; lac. ann, oral lacuna; $c n$. ann, ring canal; $y$, compas; $o$, opening from oral sinus to Stewart's pouch; $b$, rotula; $p s$, Stewart's pouch; mcl. $i . p y$, interpyramidal muscles; lac. $r d$. ph, pharyngeal radial lacuna; $c n . r d$, radial canal; sin. $r d$, radial sinus; $n$. $r d$, epineural radial nerve; $s q$, ossicles of test.

shaped body in a small depression in the median line of the radius.

The entire test including spines, pedicellaria, sphæridiæ, etc., is covered with a ciliated epidermis. The inside surface of the test forming the wall of the body cavity or calome is lined with a ciliated peritoneal epithelium. 
Digestive system. The mouth, as already mentioned, is situated in the centre of the oral surface. It is surrounded by the circular lip and armed with five teeth placed interradially and belonging to a complicated apparatus known under the name of Aristotle's lantern. The hollow axis of this lantern is formed by the pharynx while the body of the lantern which has the shape of a pyramid with a pentagonal base is composed of five complicated calcareous parts or jaws and as many groups of muscles. When isolated each calcareous jaw appears in the shape of a triangular pyramid. The middle portion of the tooth is inclosed between the two halves of an ossicle called the alveolus. The elastic free upper end of the tooth is curved over the base of the pyramid and inclosed in a pouch of the oral sinus. The hornlike processes of the alveoli serving for the attachment of the protractors are termed the epiphysis and, though fused with the alveoli, are in reality separate ossicles. Radiating from the middle of the lantern at its base are five ossicles articulated to the alveoli and called rotula. Below the rotulæ and also radial in position are five compasses or $Y$-shaped ossicles, called by that name on account of their two diverging ligaments. These long and thin ligaments arise side by side from the head or distal enlargement of the compass and are attached to the peristomial edge of the two adambulacral plates on each side adjoining the radius to which the ossicle belongs. The muscular apparatus of the lantern is very complicated. It consists of seven sets of muscles aggregating no fewer than sixty individual muscles. Of these we will consider the following: (I) Five interpyramidal (or interalveolar) muscles. These short muscles are attached to the adjoining radial surfaces of the alveoli. They hold the alveoli together and close the teeth. (2) Five pairs of protractors. They are attached to the epiphysis and the peristomial edge of the test and run to the inside of and parallel to the compassligaments. (3) Five pairs of retractors attached to the external surface of the alveoli near the teeth and to the auricles. (4) Five muscles binding together the compasses and forming the $d i$ - 
aphragm surrounding the œsophagus. All lantern muscles are composed of smooth fibres.

The entire lantern with its muscles is inclosed in the oral sinus formed by the so-called peripharyngeal membrane which is simply a part of the peritoneum.

The cesophagus is a rather long tube opening into the broad and flat stomach which has numerous folds or pouches. The stomach makes an almost complete circle and leads into the intestine which also forms an almost complete circle, running however above the former in the opposite direction. The short rectum runs directly upward and terminates in an amus in the centre of the aboral surface of the animal. Closely applied to the inner edge of the stomach but not otherwise connected with it runs the siphon. It is a thin tube starting from the osophagus not far from its proximal end and opening into the intestine close to the stomach. The siphon has practically the same histologic structure as the stomach. The entire alimentary canal has a covering of ciliated peritoneum and is suspended by mesenteries.

The ambulacral or water vascular system. We have seen already that one of the genital plates serves at the same time as a madreporic plate. The hydrophoric canal runs down to the diaphragm where it opens into the circular canal surrounding the œsophagus. The circular canal gives off five radial canals. Into the circular canal, between the radial canals, open five small sponge-like organs, erroneously called either Polian or Tiedemann's vesicles, but histologically different from both. The radial canals run between the two auricles of the same radius and terminate in the terminal tentacle. They give off transverse canals connected with the ambulacral tubes and ampulla. The first pair of transverse canals belongs to the oral papillæ. Each ambulacral foot or tentacle, bifurcated at its base, communicates with its ampulla by means of two openings. This is the reason why there are two pores in the ambulacral plates for each ambulacral tentacle or foot. The am- 
bulacral tubes are muscular structures covered externally as well as internally with ciliated epithelial cells.

Respiratory system. The five pairs of branchiæ already mentioned function as organs of respiration as do possibly also the ambulacral tentacles of the aboral surface. The branchiæ are outgrowths of the peristomial membrane and communicate with the oral sinus.

Circulatory system. The circulatory organs are composed of a system of simuses and a system of lacuna. The system of sinuses is characterized by a complete isolation of its component parts. The five radial sinuses end blindly at both ends. The oral sinus has been described above and communicates only with the five pairs of branchiæ. The aboral sinus communicates only with its five prolongations, the genital sinuses. The axial sinus is reduced to the central cavity of the axial organ and communicates with the hydrophoric canal. The system of lacunæ resembles that of the starfish, though somewhat complicated by the presence of stomachal lacunæ. The axial organ which is part of the system of lacunæ, communicates with the aboral as well as the oral circular lacuna. The latter surrounds the œsophagus. Five radial lacunce run from the oral lacuna to the terminal tentacles. The highly branched system of stomachal lacuna extends over the entire stomach and part of the intestine. It consists of two canals with small branches opening into them along their entire extent. One of these canals is the external stomachal lacuna, the other the internal stomachal lacuna. They are closely applied to the stomach and the internal lacuna communicates with the oral lacuna. The aboral lacuna gives rise to five genital lacunæ.

Nervous system. The nervous system includes, as in the starfish, three distinct systems. The ectoneural system consists of an oral ring surrounding the mouth and situated on the inner surface of the lip, five radial nerves with their branches and a subepidermal nervous plexus. The radial nerves are not superficial but run along the inner surface of the test in so-called 
epineural cavities. The hyponeural or motor system is considerably reduced and consists of five very short radial nerves with still shorter five transverse pieces representing the broken up ring. The entoneural system is inclosed in the aboral sinus. It consists of an aboral pentagon or ring with five genital nerves.

Reproductive system. The reproductive organs are similar in both sexes. They consist of five simple, interradial gonads which open on the genital plates. Organs of copulation are absent. The reproductive cells are emptied into the water. The development is characterized by the formation of a larva known as pluteus.

\section{Instructions}

I. Place a sea-urchin in a dissecting pan with water. Examine the spines and remove one of each of the three types of spines: a long, sharp-pointed equatorial spine, a short spine with the broadened flat end and an intermediate spine with blunt end. Study their surface under dissecting microscope. Make a drawing showing the three spines twice their natural size.

2. Remove all spines taking care not to injure the ambulacral tubes. Place the sea-urchin with its oral surface uppermost. Make a drawing twice natural size showing the five teeth, circular lip, peristomial membrane, five pairs of oral papillæ, five pairs of branchiæ, five clusters of ambulacral feet, spine tubercles and the pedicellariæ of the peristomial membrane. Label also radii and interradii.

3. Remove with the aid of a forceps an ambulacral foot and examine it under dissecting microscope. Make a drawing showing the foot and its sucker.

4. Remove an entire cluster of ambulacral feet and examine the place under dissecting microscope. Make a drawing showing the pairs of ambulacral pores and the minute sphæridium.

5. Remove a pedicellaria, place it in glycerine on a slide under a cover glass, examine under microscope and make a drawing 
showing the stem with the calcareous axis and the head with three jaws.

6. Find on the test a similar pedicellaria with jaws open and make a drawing of it.

7. Find on the test the second type of pedicellaria in which the axis does not reach to the head. Make a drawing of it under microscope.

8. Remove an ambulacral tube (tentacle) from the aboral surface of the test, examine it in the same manner and make a drawing of it.

9. Find the five terminal tentacles on the ocular plates.

Io. Carefully clean the entire aboral surface of the test with a toothbrush or examine a dried and cleaned test. Make a large drawing showing the periproct with the four anal plates, five genital plates with the genital openings, five ocular plates with pores for the terminal tentacles, five radii and five interradii with the zigzag suture between the two rows of plates, the tubercles on the interradial or adambulacral plates and the tubercles and pairs of ambulacral pores on the radii. Once more examine carefully the genital plates and find among them the one which serves also as madreporic plate. Show with a dotted line the plane of bilateral symmetry.

II. Make a drawing of the oral surface of a dry specimen in which the spines and the peristomial membrane were removed. Show the arrangement of the spine tubercles, the peristomial edge of the test, the ambulacral pores and the first and second adambulacral plates folded back upon the two following plates.

I2. Holding the test in your hand so as to look into the body cavity under an angle to the dorso-ventral axis, examine with naked eye the peristomial edge of a radius and make a drawing twice the natural size showing the auricles.

I3. Returning to the cleaned alcoholic specimen make an incision around the equator. Strong scissors may be used for this purpose, but a very fine saw is preferable. Carefully open the specimen by cutting the mesenteries of the alimentary canal, 
if necessary, and place both halves side by side in the dissecting tray with water. The oral half will contain the Aristotle's lantern, œsophagus, stomach and siphon, part of the axial complex (hydrophoric canal with the axial organ) and five ambulacral radial canals with ampullæ, as well as the ring canal. The aboral half will contain the intestine with the rectum, five gonads and five radial canals with ampullæ. Make a full page drawing showing both halves side by side with all organs in situ.

I4. Cut the œsophagus and remove the stomach from the oral half. This will expose the Aristotle's lantern inclosed in the oral sinus. Carefully remove with a needle and fine forceps the wall of the sinus, exposing all parts of the lantern. Make a drawing twice natural size showing the base of the lantern as viewed from above. The drawing must show the transverse section of the œsophagus surrounded by the diaphragm, the compass ossicles with their tendons, the curved ends of the teeth and the auricles with the retractors.

I5. Make a drawing showing the side view of the lantern on a large scale. The drawing must show the curved ends of the teeth, the head of the compass ossicles, the compass ligaments, the rotulæ, the epiphyses with the protractors, the alveoli with the interpyramidal muscles, the retractors and the auricles.

I6. Take out the lantern and separate the alveoli. Make a drawing of an isolated alveolus with the tooth.

I7. Separate the two parts of an alveolus, taking care not to break the tooth. Make a drawing of the tooth showing the cutting edge, the central portion and the elastic end. 


\section{THYONE BRIAREUS Lesueur}

Material. Thyone briareus is found along the Atlantic Coast below low water mark on muddy bottom. Like all holothurians they are liable to throw out their viscera when put in a preserving liquid. Various methods have been recommended to overcome this difficulty. Perhaps the simplest is that of seizing the animal below the tentacles with a strong forceps and plunging it into boiling water. After that they may be preserved in alcohol or formalin. For the study of the ambulacral system the specimens should be injected through a Polian vesicle.

\section{Descriptive Part}

Thyone briareus is a common representative of the Class Holothurioidea. Although following the plan of radial symmetry it little resembles the other Echinodermata. Its body is elongated and considerably narrowed towards the anterior end which is provided with branched tentacles surrounding the mouth. Moreover, the animal does not crawl on its oral surface, but uses for this purpose the three radii thickly covered with ambulacral feet. This surface is therefore physiologically the ventral one, while the dorsal one is represented by the remaining two radii. The bilateral symmetry is besides greatly accentuated by the position of the anus at the end of the body and the presence of a single genital opening between the tentacles on the interradius opposite the median radius of the ventral surface. The ten oral tentacles correspond to the ten oral papillæ of the sea-urchin and represent the first five pairs of modified ambulacral tubes. The median ventral pair of tentacles is considerably smaller than the others. It is customary to 


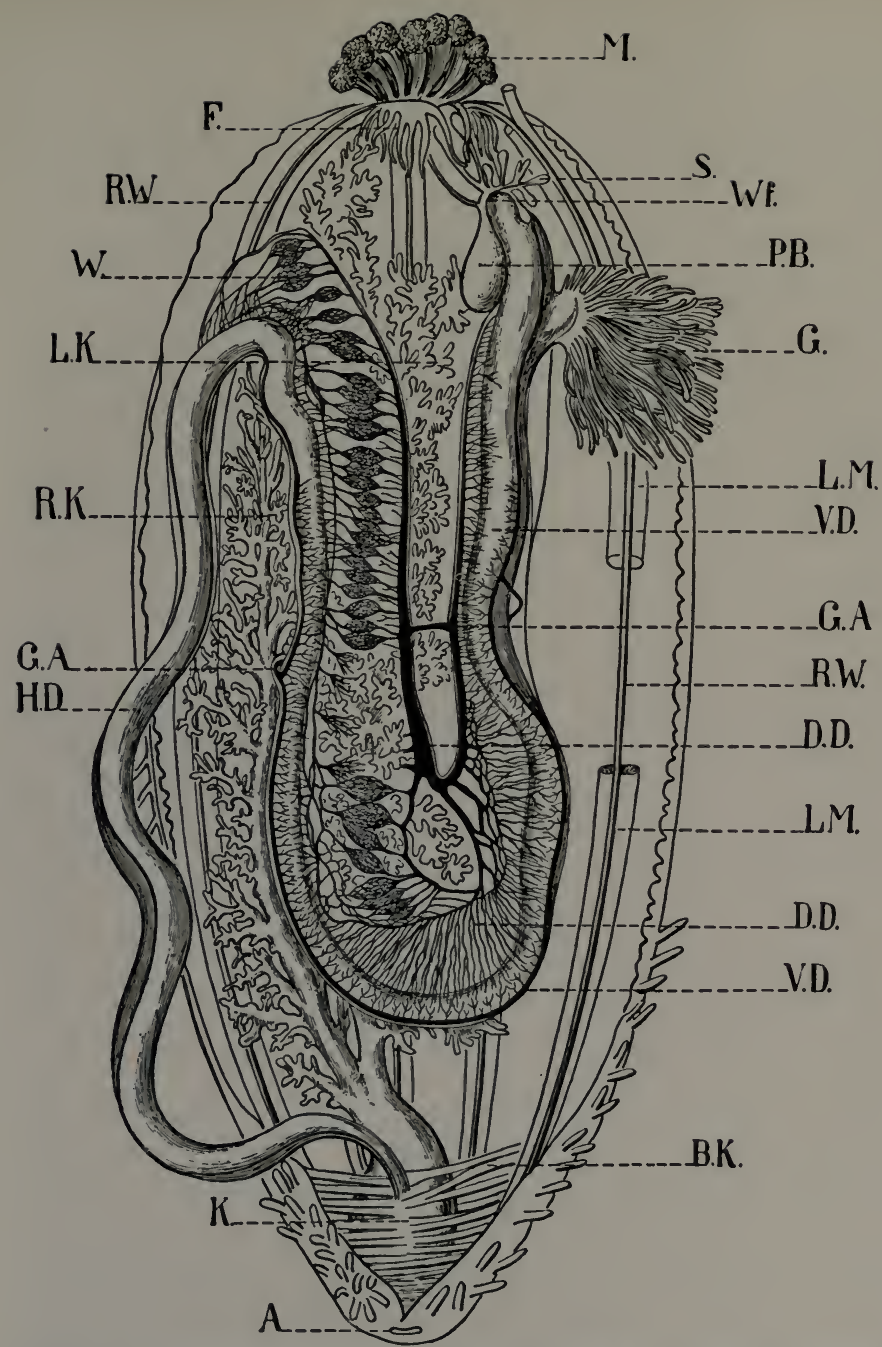

FIG. 40. - Anatomy of Holothuria tubulosa after M. Edwards, somewhat modified. $M$, tentacles; $F$, ampullæ of the tentacles; $R W$, radial ambulacral canal; $W$, rete mirabile; $L$. $K$, left water lung; $R$. $K$, right water lung; $G . A$, anastomosis of the blood vessels; $H D$, posterior section of intestine; $M D$, middle section of intestine; $S$, hydrophoric canal; $W f$, ring canal; $P B$, polian vesicle; $G$, gonad; $L M$, longitudinal muscles; $V D$, ventral blood vessel; $D D$, dorsal blood vessel; $B K$, dilator of the cloaca; $K$, cloaca; $A$, anus. 
consider the radius to which they belong, that is, the median ventral radius of the trivium, as the fifth radius; the adjoining left ventral radius as the fourth radius, and the right ventral radius as the first radius; the right bivial radius as the second and the left bivial radius as the third radius. Behind the tentacles is a short collar strengthened on the inside by a calcareous peripharyngeal ring or corona consisting of five radial and five interradial plates. The ambulacral tubes of the ventral surface are numerous and developed as true ambulacral feet with terminal suckers; those of the bivium or dorsal surface are less numerous and devoid of suckers, $i$. e., they are modified into ambulacral tentacles. Terminal tentacles are absent.

The body wall is devoid of an articulated calcareous skeleton. Instead it is soft and muscular with irregular perforated calcareous plates in its dermal layer, mainly in the anterior and posterior regions of the body. Perforated calcareous plates are found also in the wall of the tentacles and of the suckers of the feet. The external body covering consists of an epidermis which is not ciliated. Under the dermal layer is a heavy sheet of circular muscles. Five longitudinal muscles each consisting of two bundles run the whole length of the radii. The pharynx has five strong retractors, each consisting of two bundles, and the cloaca has numerous dilating muscles-dilatatores cloacc-which run radially in all directions from the cloaca to the body wall. The body cavity is lined with a ciliated peritoneal epithelium.

Digestive system. The mouth situated at the anterior end of the body is surrounded by a circular lip but devoid of teeth or jaws. The pharynx is a cylindrical tube provided with five retractors already mentioned. Between the pharynx and the short cesophagus is a constriction. The stomach is small but muscular. The intestine is thin, very long and convoluted, runs to the posterior end, turns back to the anterior end and turning again runs to the posterior end where it forms a short rectum and opens into the cloaca. The anus or opening of the cloaca to the outside is in the centre of the aboral end of the animal, 
morphologically in the same place as the anus of the sea-urchin. The entire alimentary canal is provided with a muscular sheath of internal longitudinal and external circular muscles.

Respiratory system. Two water-lungs or canals opening into the cloaca and furnished with many lateral branches function as organs of respiration. They are attached to the body wall and to the intestine by mesenteries. The left lung is besides surrounded by a network of lacunæ.

Water-vascular or ambulacral system. The ring canal surrounds the pharynx at its junction with the œsophagus. The hydrophoric canal ends in a madreporic plate. It does not open to the outside, but into the body cavity or colome, since the madreporic plate lies within the latter and not on the body wall, a condition similar to that in Crinoidea. (The Crinoidea have, however, numerous madreporic canals.) There are usually two large Polian vesicles opening into the ring canal. The five radial canals connected with the ring canal run first forward and give off transverse canals to the five pairs of oral tentacles; then turn backward and run between the two bundles of longitudinal muscles to the posterior end where they terminate blindly. The radial canals give off throughout their length transverse canals to the ambulacral feet and tentacles. The ampulla are small and scattered all over the inner surface of the body wall.

The circulatory system is characterized by the greater development of the lacunar system and a reduction of the system of simuses. Both axial sinus and axial lacuna are absent. Five radial sinuses giving off transverse branches to the ambulacral tubes, extend all the way to the cloaca and terminate blindly. At the anterior end they open into the circular oral sinus. The circular oral lacuna gives rise to five radial lacunce and two intestinal lacunce. The ventral intestinal lacuna runs along the intestinal canal. The dorsal intestinal lacuna runs in the mesentery, giving off a series of branches which split into a network-the socalled rete mirabile. This network of lacunæ is connected not 
only with the dorsal lacuna, but also with its collateral lacuna which runs along the intestine in the line of attachment of the mesentery.

The nervous system is composed of an ectoneural and a hyponeural system resembling each other and separated by an extremely fine membrane. The oral nerve ring is situated in the peristome. It gives rise to five radial nerves running to the cloaca. The ectoneural ring gives rise to ten tentacle nerves, the ectoneural radial nerves to a subepithelial plexus. The hyponeural or motor system supplies nerves to all the muscles. An entoneural system has as yet not been described and is probably wanting.

Reproductive system. The sexes are separate, but the anatomical structure of the reproductive organs is similar in both sexes. There is but a single gonad composed of two clusters of numerous tubes. In the case of the male, these tubes constitute the testis and open into a small seminal reservoir. A seminal duct or vas deferens runs forward from this reservoir and terminates in an interradial genital opening at the base of the tentacles in the mid-dorsal line. In the case of the female, the tubes constitute the ovary and open into a common oviduct which terminates in the genital opening. The latter has the same situation as in the male. The sexual cells, copulation being absent, are discharged into the water and fertilization left to chance. Development is characterized by a metamorphosis with a larval stage known as Auricularia.

\section{Instructions}

I. Place the specimen in a dissecting tray with water. Find the smallest pair of tentacles belonging to the middle radius (fifth radius) of the trivium. Turn the specimen so that this radius would be on your right. Make a drawing of the specimen in this position (lateral view) showing tentacles, mouth, ambulacral tubes, and anus. 
2. Holding the specimen in your left hand, spread with your fingers the tentacles and make a drawing (oral view) with the mouth in the centre, the two smallest tentacles directed downward, and the genital opening in the mid-dorsal line.

3. Place the specimen again on its right side and make a longitudinal incision, beginning close to the anus and ending at the base of the tentacles between the smallest and the adjoining larger tentacle (along the edge of the fifth radius). Make a similar incision along the edge of the third radius. Cut the body wall across under the tentacles, and in front of the anus, from one incision to the other and remove the wall, carefully separating it from the viscera. This will expose all organs with exception of those belonging to the radius which has been removed. Pin down the edge of the body wall. Uncoil the alimentary canal by cutting the mesentery close to the body wall. Cut the mesentery holding the gonad with its duct and push the gonad outside of the body cavity, taking care not to tear the duct. Push the water lungs outside of the body cavity. Make a full page drawing showing: outline of the body with tentacles, longitudinal muscles, circular muscles, retractors of the pharynx, cloacal muscles; peripharyngeal calcareous corona, œsophagus, stomach, intestine, intestinal mesentery with the rete mirabile, water lungs, cloaca, gonad with genital duct, ambulacral ring canal, hydrophoric canal with madreporic plate, polian vesicles and ampullæ.

4. Put a piece of the body wall of the trivium in a test tube with a 10-20\% aqueous solution of caustic potash and boil it over a gas flame until all the tissues have been dissolved. Allow the particles to settle to the bottom. Pour off the liquid and wash the sediment in water. Pick up with a fine pipette some of the sediment and put a drop of it on a slide. Find under microscope a calcareous perforated plate of the ambulacral foot. Make a drawing of it.

5. Do the same with a tentacle. 


\section{VENUS MERCENARIA Linnæus}

Material. Live specimens of Venus mercenaria may be bought on the market under the name of hard shell clam. To open them they must be placed for several minutes in water heated to $70^{\circ}$ centigrade. After that they should be preserved in weak formalin. Freshly killed specimens should be injected and preserved in formalin for the study of the digestive organs. The following is the best method. The left valve is removed in the usual manner. The animal in its right valve is placed in a dish with warm water. A hypodermic syringe is introduced into the rectum a little in front of the anus and the injection continued until the mass begins to come out through the mouth. The best mass to be used is a solution of gelatine in water made dark red by the addition of finely powdered carmin. When the injection is finished, the specimen is placed in $4 \%$ formalin which gradually hardens the injection mass and makes it insoluble. Every student should receive one freshly killed and injected specimen. For the additional exercise, transverse sections through hardened specimens should be studied under water.

\section{Descriptive Part}

Venus mercenaria is a common representative of the Class Lamellibranchia which comprises all bivalves. It lives in the mud, between tides, along the Atlantic Coast. In its structure it is strictly bisymmetrical, the valves being right and left and their hinge dorsal in position. The anterior or oral end of the body may be recognized by the fact that it is broader and that the lines of growth of the shell are procurved. The starting points of growth in the two valves are called umbones; the first lines of 
growth form around each umbo and appear in the adult shell as a distinct prominence or shoulder. The valves are held together by a ligament and a lock. The latter is one of the few structures which are not strictly symmetrical in Venus, for the teeth of one shell correspond to notches in the other. The teeth are of two kinds. In front of the ligament are prominent, sardinal teeth,

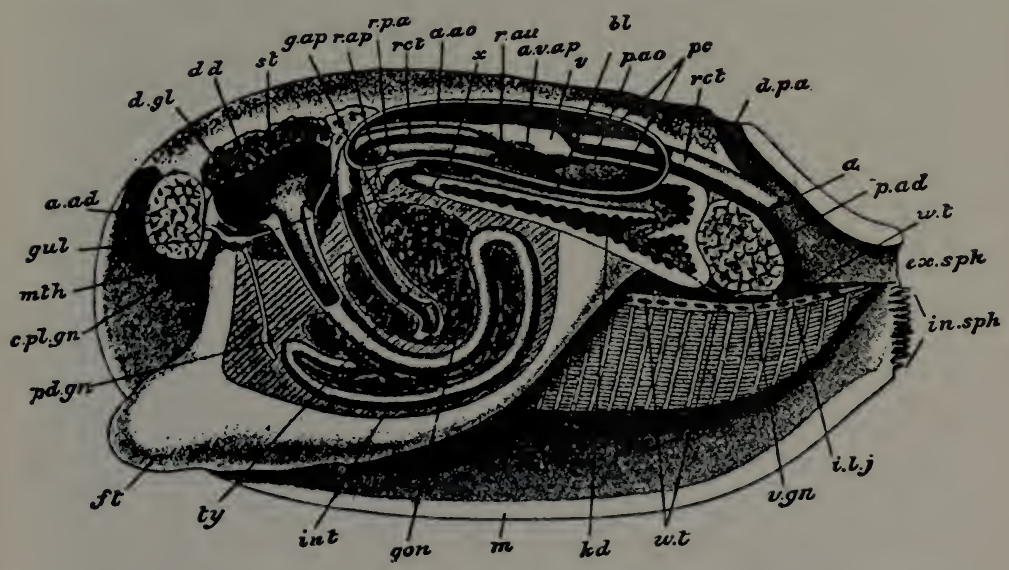

Fig. 4r. - Anodonta cygnea. General Anatomy, from Parker and Haswell's Text-book of Zoölogy. $a$, anus; $c$. $a d$, anterior adductor; $a$. $a o$, anterior aorta; $a$. v. $a p$, auriculo-ventricular aperture; $b l$, urinary bladder; $c$. $p l$. gn, cerebro-pleural ganglion; $d$. $d$, duct of digestive gland; $d . g l$, digestive gland; $d . p$. $a$, dorsal pallial aperture; $e x . s p h$, exhalant siphon; $f t$, foot; g. $a p$, genital aperture; gon, gonad; gul, gullet; $i . l . j$, inter-lamellar junction; in. $s p h$, inhalant siphon; int, intestine; $k d$, kidney; $m$, mantle; $m t h$, mouth; p. $a o$, posterior aorta; p. $a d$, posterior adductor; $p . c$, pericardium; $p d . g n$, pedal ganglion; $r$. $a p$, renal aperture; $r$. an, right auricle; $r c t$, rectum; $r$. p. $s$, reno-pericardial aperture; $s t$, stomach; $t y$, typhlosole; $v$, ventricle; v. $g n$, visceral ganglion; $w$. $t$, water tubes.

while under the ligament are the smaller and more numerous lateral teeth. The free edge of the shell is serrated, this being due to its origin as a secretion of the fringed edge of the mantle and allowing a firmer closing of the two valves. The shell is composed of three layers: the outer layer or periostracum, the middle or prismatic layer, and the inner or mother-of-pearl layer. 
The first two are produced by the edge of the mantle, while the third layer is a secretion of the entire surface of the mantle. In Venus mercenaria the mother-of-pearl layer is very thick but does not possess the aspect of the corresponding layer in other shells. The periostracum is thin and easily worn off by friction against the mud and sand in which the animal lives. The edge of the mantle or pallium leaves a distinct impression on the inside of the shell called the pallial line. At the posterior end of the shell this line shows a distinct triangular pallial sinus marking the position of the retractor of the siphon. Four muscles attached to the shell leave also their impressions on it. These are the two powerful adductors of the valves and the two small retractors of the foot. The impression of the anterior retractor of the foot is always separate from the impression of the much larger one of the anterior adductor of the valves and is situated above it. The posterior retractor of the foot leaves seldom, if ever, an impression of its own, separate from that of the posterior adductor of the valves; usually it merges with the latter, forming a common impression.

As has been stated, the shell is produced by the mantle or pallium, the latter being simply a fold of the body covering. It is not extraordinary, therefore, that both surfaces of the mantle, $i$. e., the one underlying the shell and the other facing the mantle cavity, are lined with eipthelial cells of ectodermal origin. There are naturally numerous glands in the outer epithelial layer of the mantle. Between the two epithelial layers are connective tissue and muscular fibres. The latter form three systems: ( $\mathrm{r}$ ) muscle fibres which run in the free margin of the mantle at right angles to its edge, (2) fibres parallel to the edge, and (3) short fibres traversing the mantle from its outer to its inner surface. The first of these systems forms a regular band visible with the naked eye. Near the posterior end of the body. the right and left mantle folds are grown together in two places, one above the other, thus forming two short tubes or siphons. These may be readily recognized by their dark pigmentation. 
In some lamellibranchs they attain a comparatively enormous length, while in others they are quite absent. The dorsal siphon is called the cloacal or excurrent siphon, the ventral-the branchial or incurrent siphon. These are the only channels through which an exchange of water takes place. By the action of the ciliated epithelium of the gills and of the mantle water is drawn in through the branchial and expelled through the cloacal siphon.

Inclosed in the mantle cavity is the body proper, together with all its organs and the gills. The latter, together with the osphradium, oral papillæ and external openings of various organs, are often united under the name of the pallial organ complex. The lower extremity of the body forms a muscular foot which is laterally so strongly compressed that it has been likened to the keel of a boat. The foot is the chief organ of locomotion. The body cavity or cœlome is reduced to the pericardium.

Digestive system. The mouth is situated at the anterior end of the body above the anterior retractor of the foot. It is provided with an upper and an under lip, each formed by the fusion of two oral lappets or labial palps, of triangular shape. A pharynx is lacking and with it naturally is lacking the grating plate or radula so characteristic of other classes of molluscs. Salivary glands are also absent. The mouth leads directly into the asophagus, which is followed by the stomach. A large liver opens into the stomach near its anterior end. The stomach is a rather thick tube running obliquely backward and downward and has at its pyloric end two openings. The one leads into the intestine, the other into the crystal rod-sheath, a blind diverticle of the stomach secreting a crystal rod of unknown function. The intestine is a coiled tube lying between the pyloric end of the stomach and the liver, under the stomach. The rectum is a very long and thin tube. At first it runs backward to the right of the stomach and at an almost right angle to it. It rises then at more than a right angle until it reaches the pericard. Here it turns again backward, perforates the ventricle of the heart and 
opens behind the posterior adductor of the valves into the cloacal siphon. The stomach, intestine and ascending branch of the rectum are imbedded in the muscular tissues of the body, the pyloric end of the stomach and the beginning of the intestine in the base of the foot.

Excretory system, body cavity and pericardial gland. The majority of the molluscs possess both a primary and secondary body cavity. The former is represented by the system of sinuses and lacunæ by means of which a connection is established between the arterial and venous systems. It always lacks an epithelial covering of its own. The secondary body cavity or colome is reduced to the space within the pericard and the lumen of the gonad. It is always lined with its own endothelium. The cavity of the pericard communicates directly with the mantle cavity through the excretory system. This system consists of one pair of nephridia (called also organs of Bojanus). They are situated on the dorsal side of the animal between the pericard and the posterior adductor of the valves. Each nephridium communicates by means of an open funnel with the pericardial space, and by means of a nephridiopore or external excretory opening, situated on a minute papilla, with the mantle cavity. The nephridium consists of a wide tube or sac bent on itself. The first part, communicating with the pericardial cavity, is glandular (kidney), the second part is non-glandular and plays the rôle of a urinary bladder. The right and left nephridiopores are situated underneath the respective gills immediately behind the right and left reproductive openings.

A pericardial gland (often called Keber's organ), probably with excretory function, lies in front of the pericard. In life it has a dark or reddish color. Its secretion is discharged into the pericardial space.

Circulatory system. The circulatory system of Venus, as that of all other lamellibranchs, is an open system in which the veins communicate with the arteries by means of sinuses 
and lacunæ between the various organs, $i$. e., by means of spaces devoid of a lining of their own. The heart contains arterial blood and is composed of a single ventricle and two auricles. It is inclosed in the pericard on the dorsal surface of the animal. The ventricle has the shape of a pyramid with the apex pointing anteriorly, and is perforated by the rectum. The auricles are quite thin-walled and capable of considerable distension. The ventricle gives rise to two aortas. The anterior aorta runs forward above the alimentary canal a nd soon splits up into several arteries; the posterior aorta r uns backward below the rectum and soon divides into two posterior ma $n$ tl e arteries. The posterior aorta forms a pulsating bulbus arteriosus not far

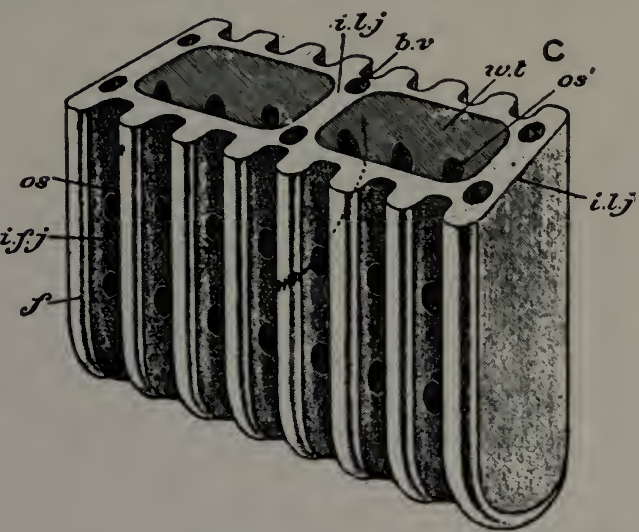
from the ventricle of the heart and Fig. 42. - Diagram of the structure of a gill of Anodonta cygnea after Peck, from Parker and Haswell's Textbook of Zoölogy. $b$. v, blood vessels; $f$, branchial filaments; $i . l . j$, interlamellar junction; $i$. still in the pericar- $f . . j$, interfilamentar junction; os, external ostium; os', dial cavity. The internal ostium; wt, water tubes.

blood passes from the lacunæ between the various organs into a venous longitudinal sinus situated under the pericard, thence through a network of veins in the nephridia into the branchial arteries. After oxidation in the gills the blood enters the branchial veins and returns to the heart through the auricles. A very small quantity of the blood runs in other channels than those referred to above and returns to the heart either venous or partly oxidized in the mantle. The blood itself contains amœbocytes and is rich in albuminous substances. 
Respiratory system. Venus mercenaria has two pairs of gills or ctenidia. However, the two gills of the same side must be regarded morphologically as a single gill. They are outgrowths or folds of the body wall, attached to the body on each side along an almost straight line extending from the anterior end of the liver almost to the lower end of the adductor of the valves. The inner gill is broader than the outer one and both have a striated or ridged appearance. Each gill consists of two lamellæ joined at regular intervals by parallel connections called interfoliary bridges. These bridges correspond to the grooves between the ridges or folia of the gill and divide the space inside the gill into water tubes. These tubes are lined with ciliated epithelium. They open dorsally into the upper branchial chamber of the gill which communicates directly with the cloacal siphon. The folia or ridges of the gill are covered with an immense number of small, ciliated filaments. The gills are naturally rich in blood-vessels, the largest among which run chiefly in the interfoliary bridges. Water is drawn into the mantle cavity through the incurrent or branchial siphon by the combined action of the ciliated epithelium of mantle and gills, passes into the water tubes through the incurrent openings of the gill, oxidizes the blood, collects in the upper branchial chamber and is ejected through the cloacal siphon.

Nervous system. The nervous system of Venus mercenaria is typical not only of all lamellibranchs but in a way also of other molluscs. Although devoid of a head separate from the rest of the body, the lamellibranchs naturally possess a central nervous system corresponding to that in other molluscs. It consists of three paired ganglia. Of these the pair of cerebropleural ganglia is situated above the œsophagus immediately under the anterior retractor of the foot. The pair of pedal ganglia is imbedded in the tissues of the foot close under the place where the stomach opens into the intestine. Finally the pair of visceroparietal ganglia is situated on the anterior surface of the posterior adductor of the valves. The cerebro- 
pleural ganglia are connected with the pedal ganglia by cerebropedal connectives, and with the visceroparietal ganglia by cerebrovisceral connectives. The cerebral ganglia furnish the anterior pallial nerves. The visceroparietal ganglia which, like the other

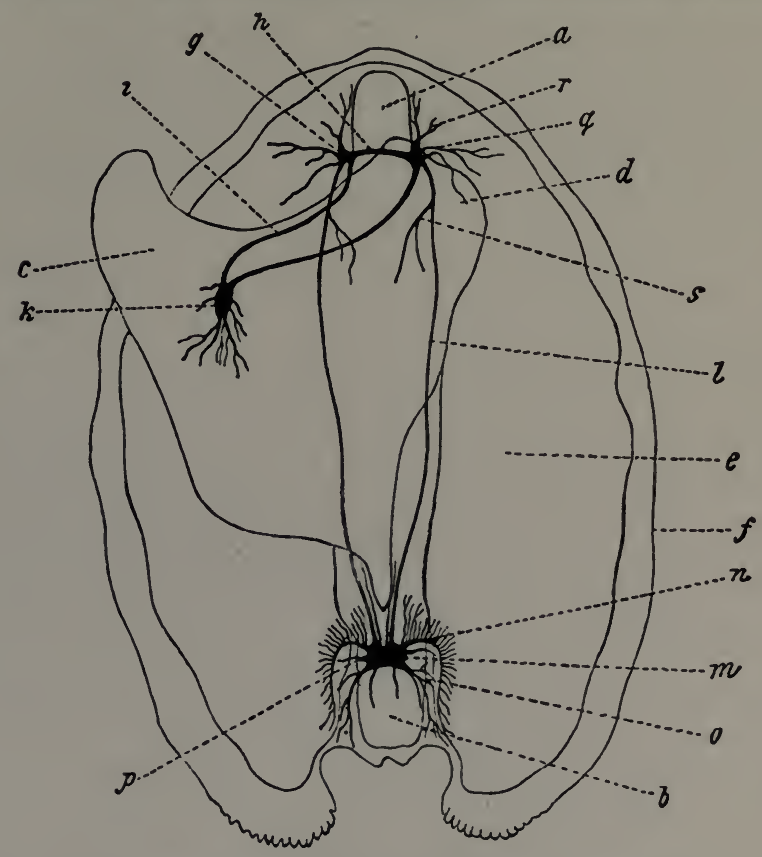

Fig. 43. - Nervous system of Anadonta anatina after Vogt and Yung, Anatomie Comparée. $c$, foot; $k$, pedal ganglion; $i$, cerebro-pedal connective; $g$, cerebral ganglion; $h$, cerebral connective; $a$, anterior adductor muscle; $r, q$, anterior pallial nerves; $d$, liver; $s$, visceral nerve; $l$, cerebro-visceral connective; $e$, gill; $f$, edge of mantle; $n$, branchial nerves; $m$, visceral ganglion; $o$, posterior pallial nerves; $b$, posterior adductor muscle; $p$, lateral pallial nerves.

ganglia in Venus, are of a pink or yellow color, lie so close to each other that they have the appearance of a single ganglion. Behind the cerebrovisceral connectives this ganglionic mass gives off two branchial nerves and two posterior pallial nerves. 
Reproductive system. The sexes are separate and the reproductive organs consist of a pair of simple gonads with a right and left reproductive opening just in front of the corresponding nephridiopore under the gill. The gonads when fully developed fill all the space between the loops of the alimentary canal, extending backward to the posterior end of the body. The reproductive cells are discharged into the mantle cavity and then pass with the water current through the cloacal siphon to the outside. Development is indirect, combined with a larval stage.

\section{Instructions}

I. Place a specimen of Venus mercenaria on edge against the side of a tray, hinge uppermost. Make a full size drawing showing both valves, the umbones and the ligament holding the valves together. Label right and left valve.

2. Make a full size drawing showing the side view of the left valve. Label umbo, lines of growth, anterior and posterior end, dorsal and ventral surface.

3. Cut the ligament longitudinally with a very strong scalpel. Press the ventral edges of the valves somewhat apart, carefully introduce a fine scalpel under the left valve, between it and the mantle, cut the anterior adductor of the valves and retractor of the foot, and the posterior adductor and retractor as close to the valve as possible, press down the mantle with the handle of the scalpel and remove the left valve. Place the right valve with the animal in it into a deep crystallization dish with water for future examination. Examine the inner surface of the left valve and make a full size drawing showing the umbo, ligament, cardinal and lateral teeth of the lock, pallial line showing attachment of the mantle, attachment area of anterior adductor of the valves and above it attachment area of the much smaller anterior retractor of the foot, attachment area of the posterior adductor and, if visible, above it the small area for the posterior retractor of the foot, pallial sinus showing the position 
of the retractor of the siphon, and the serration of the valve edge.

4. Break the shell and examine the broken edge through a lens. Make a drawing showing the outer layer or periostracum, the median or prismatic layer, and the inner or mother-of-pearl layer.

5. Cut off a piece of the left mantle fold near the anterior adductor, examine it under the dissecting microscope and make a drawing showing the fringe of papillæ.

6. Cut off a larger piece of the mantle in the region of the foot. Place it on a slide and examine with the naked eye. Make a drawing showing the free edge of the mantle and the portion normally adhering to the shell. In the former label fringe, thickened portion and muscular portion.

7. Remove the entire left mantle fold by cutting it with scissors around the retractor siphons, adductors and along its dorsal attachment. This exposes that portion of the mantle cavity which is called the branchial chamber. Make a full size drawing showing the outline of the right valve, edge of right mantle fold, anterior adductor, anterior retractor of the foot, posterior adductor, posterior retractor of the foot, the keelshaped foot forming a continuation of the visceral complex, the two triangular labial palps just above the anterior adductor; the two left ctenidia or gills partly covering the visceral complex; the transparent upper branchial chamber limited dorsally by a white line - the attachment place of the gills to the body; above this line in front, dark organs visible through the body wall (dark brown-liver, yellow-gonad, dark-Keber's organ); the large pericard and behind it the dark kidney.

8. Take the right valve with the animal in it into your left hand and hold it so as to obtain a front view of the siphons (left siphonal retractor on your left). Notice the pigmented siphons. The upper one is the cloacal or excurrent siphon. Make an incision in its wall and expose the anus. Make a full size drawing showing left retractor of the siphon, left and right mantle edge, anus, cloacal siphon, branchial siphon. 
9. Hold the specimen, in water, on edge, ventral side up, and press down the outer left gill. Notice between the outer and inner gill a white line. This is the attachment line of the gills to each other and contains the branchial artery. Make a drawing showing the two gills. Label also the gill-filaments and ridges or folia.

ı. Remove both gills. Place a piece of a gill on a slide and cut it with a razor at right angles to the filaments by pressing the razor against it (not by drawing it). Make now in the same manner an incision parallel to and close to the first, thus obtaining a cross-section of the gill-filaments. Examine under microscope ( 50 diameters) in a drop of water without cover glass. Make a drawing showing three ridges or folia of the two lamellæ with their filaments, interfoliary ridges, water tubes and bloodvessels.

I I. Holding the animal on edge, ventral side up, find the yellow visceral ganglion under the posterior retractor of the foot with nerves forming a letter $\mathrm{X}$. The two nerves running backward are the pallial nerves of the siphon. The two anterior arms of the $\mathrm{X}$ are formed by two pairs of nerves. Of these the outer pair soon bends backward and enters the gills. This pair of nerves is called branchial gill nerves. The two inner anterior nerves are the cerebrovisceral connectives.

I2. Remove both labial palps. Split the foot with a razor longitudinally into two symmetrical parts. Cut off the left half by means of an incision parallel to the attachment line of the gill and running backward from the middle of the anterior adductor. Remove the left half of the foot and find on the cut surface of the right half the pedal ganglion-a little yellow or pink body at the base of the foot. Remove the left wall of the pericard and of the urinary bladder. Make a full size drawing showing outline of shell; edge of mantle; both adductors of the valves; both retractors of the foot; left retractor of siphon; left cerebropleural ganglion, which has the appearance of a little yellow or pink body under the anterior retractor; pedal ganglion; 
visceroparietal ganglion; yellowish Keber's or pericardial gland in front of the pericard, wall of pericard; in the pericard-the ventricle of the heart with the rectum passing through it; thin, transparent left auricle and arterial bulb in upper corner of pericardial cavity; urinary bladder between posterior wall of pericard and posterior retractor of the foot; under urinary bladder the opaque, dotted kidney or glandular portion of the organ of Bojanus; under the attachment line of the gill and immediately behind the posterior wall of the pericard, the minute left excretory opening of the kidney; in front of it, the minute left genital opening.

I3. Take the injected specimen. Remove the left mantle fold and the gills in the same manner as before. Remove Keber's gland, left wall of pericard, left wall of urinary bladder and left wall of cloacal chamber. With the aid of forceps and scalpel remove carefully all muscles of the visceral complex and the gonad. In removing the muscles take care never to pull at more than one muscle bundle at a time and never to pull at a deeper muscle until the bundles overlying it have been removed. When the entire alimentary canal is exposed, it will appear as a pink or red coiled tube. Make a full size drawing showing outline of shell, edge of right fold of mantle, left retractor of the siphon, siphons, anterior adductor, anterior retractor of the foot, posterior adductor, posterior retractor of the foot, left labial palps, dark, granulated liver; stomach extending in a curve downward from upper edge of liver; coiled intestine, situated in front of the stomach; thin rectum, situated behind the stomach and rising toward the edge of the pericard, where it passes through the ventricle, runs thence dorsally to the posterior artery over the posterior adductor and terminates in an anus in the cloacal chamber. 


\section{LIMAX MAXIMUS Linnæus}

Material. Limax maximus is a European species which was introduced into this country and is now fairly common. It is found in damp places and may be kept alive for a long time if fed on vegetables or apples. It is by no means a typical gasteropod, nor even a typical pulmonate, since the great majority of gasteropods have a helicoid body. But the size and shape of Limax make it peculiarly adapted for dissection and after all it possesses characteristically gasteropod features. The old method of drowning the animal in a hermetically closed jar filled with water which had been deprived of air by prolonged boiling, is still giving the best results. A few drops of alcohol or chloroform may be added to the water to hasten the relaxation of the muscles. Freshly killed specimens are best for dissection. Specimens preserved in formalin should be soaked in warm water for several hours previous to dissection. Every student should receive one specimen and a prepared slide with a section through the hermaphroditic gland.

\section{Descriptive Part}

Limax maximus or the gray slug belongs to the order of pulmonate gasteropods. It lives on land in damp places, feeding on various plants. Its molluscan nature is at once apparent from its large foot which is its only organ of locomotion, and its dorsal shield which is nothing but the mantle. The foot is quite flat and extends from one end of the animal to the other. Its border is clearly set off from the rest of the body. The head is not distinctly separate, except on the ventral surface. Here the mouth is situated, which, when closed has the appearance of a 
triradial slit. Above the mouth are two pairs of tentacles. The posterior tentacles are the longer ones and carry an eye at their end. As we shall see later, the tentacles are provided with special muscles, are retractile and seldom fully extended even in spec-

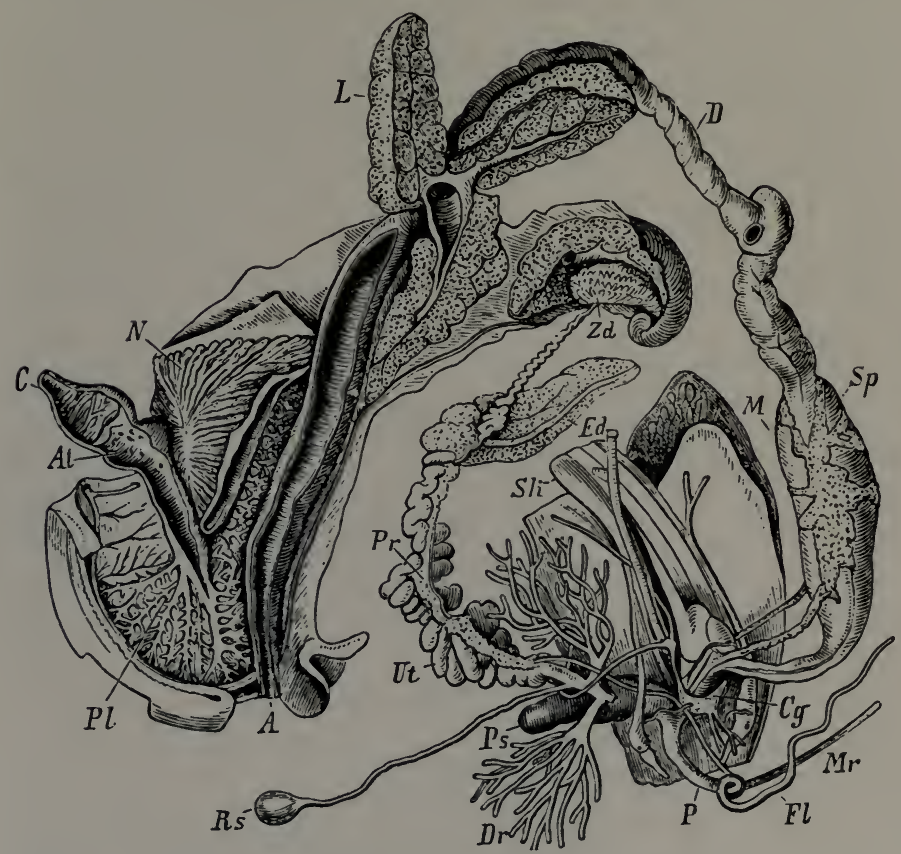

Fig. 44. - Anatomy of Helix pomatia after Cuvier. $A$, anus; $A t$, atrium; $C$, ventricle; $C g$, cerebral ganglion; $D$, intestine; $D r$, mucous glands; $E d$, albuminous gland; $F l$, flagellum; $L$, liver; $M$, stomach; $M r$, retractor penis; $N$, kidney; $P$, penis; $P l$, lung; $P r$, prostata; $P s$, dart sac; $R S$, sperm receptacle; $S K$, columellar muscle; $S p$, salivary gland.

imens which have been killed with great precaution. The shield or mantle is oval and has an oval opening, the pneumostoma, near its right edge, considerably beyond the middle of the entire length of the mantle. This opening leads to the lung, and near it, in the mantle cavity, lie the anus and the excretory opening 
or nephrostoma. The genital opening also is situated on the right side, in front of the mantle, about halfway between the latter and the anterior edge of the animal and about halfway between the right margin of the foot and the mid-dorsal line. Limax is a hermaphrodite, but the reproductive cells do not ripen simultaneously, so that the creature functions either as male or as female at one time. During its female state, the genital opening serves as a vulva; during the male state, the penis is protruded through it and appears as a cylindrical body with a triangular terminal fin. The position of the pneumostoma and of the genital opening is characteristic of the genus.

Integument. The integument of Limax is composed of a single layer of epithelium and of a dermis. The cuticle produced by the epithelial cells is very thin and presents numerous pores. Large gland cells originally belonging to the epithelial layer form a sub-epithelial layer. Between the gland cells under the epithelium are pigment cells which belong already to the dermis. The most important elements of the latter are connective cells and muscle fibres. An especially large caudal gland is located in the integument near the posterior end of the body. The muscular fibres are especially well developed in the foot.

Mantle. The shield of Limax is a true mantle, $i$. e., a fold of the integument, although in this case considerably less developed than in that of the lamellibranch Venus. The epithelial layer secretes a shell which is thin and rudimentary. Moreover, it is internal in position, lying under the epithelium, and is apparently without function, since in other genera it is completely wanting. The pneumostoma, the position of which has been described above, leads into the mantle cavity which is homologous with the mantle cavity of other gasteropods, although Limax is an air-breathing slug.

Muscular system. The system of muscular fibres in the foot serves all purposes of locomotion and there are few individualized muscles in Limax. The muscles belonging to other systems will be described in their proper places. It suffices here to 
mention the retractors of the tentacles. They have a common tendon attached to the body wall in the mid-dorsal line immediately behind the mantle. The muscle runs beneath the loop of the rectum and the coiled penis. On reaching the pharynx it splits into a right and left bundle, the former passing above the penis. Each bundle gives off again a smaller bundle to the anterior tentacle. In the posterior tentacles the retractors split up also into two bundles, one of which is attached to the eye, the other to the wall in the olfactory region.

Digestive system. The mouth is situated on the ventral surface of the head and when closed has the appearance of a triradial slit; two radii are directed obliquely forward, the third backward. This is due to the fact that the mouth is provided with two lips of which the upper one is almost triangular, while the lower one is bilobed. The pharynx is almost globular and the opening from it into the œsophagus is situated in its upper wall. At the sides of this opening, but somewhat lower, there are two small openings of the salivary ducts. The floor of the pharynx is occupied by the radula. This is a chitinous curved band with numerous rows of chitinous teeth. It is produced by the secretion of the lining of the radular sac and may be moved forward and backward on the floor of the pharynx by the action of a protractor and a retractor or tensor. The former is situated in front of the radula, under the epithelial lining of the floor of the pharynx; the latter under the radula itself. The cesophagus is a comparatively thin and short tube leading into a large stomach. Behind the œsophagus is a pair of salivary glands, one of which, the left one, is situated somewhat in front of the other, but both are dorsal to the stomach. Their ducts open into the pharynx. The stomach extends through two-thirds of the animal's length. It leads into a long and coiled intestine. The rectum is somewhat larger but considerably shorter than the intestine and opens through an anus into the mantle cavity near the pneumostoma. The stomach, intestine and part of the reproductive organs are almost completely surrounded by 
the large liver which opens into the stomach near its pyloric end.

Excretory system and body cavity. Limax possesses a primary and a secondary body cavity. The former forms the system of lacunæ and blood sinuses and is devoid of its own epithelial lining. The secondary body cavity or cœlome is reduced to the space within the pericard and the lumen of the hermaphroditic gland. It has its own endothelial lining. The excretory system consists of a single nephridium situated under the shield in contact with the pericard. A ciliated funnel or nephrostoma leads from the pericard into the glandular portion of the nephridium, which is usually known under the name of kidney. The ureter is a long, curved duct beginning at the posterior end of the glandular portion and terminating in a nephridiopore in the mantle cavity near the pneumostoma.

Circulatory and respiratory systems. Limax has an open circulatory system in which the central organ is represented by the heart, while the connection between arteries and veins is established through a system of lacunæ and sinuses. The heart is inclosed in the pericardium. It consists of a single ventricle and a single auricle; the latter condition is due to the fact that the animal has a single lung and consequently a single pulmonary vein. In the normal position the auricle is in front of the ventricle. The latter leads into a large aorta which soon divides into a cephalic artery (called also aorta cephalica) and visceral artery (called also aorta visceralis). The cephalic artery on reaching the region of the pharynx gives off arteries to the tentacles and then divides into a single buccal artery, and a single recurrent pedal artery. The system of veins consists of numerous short branches which open into two longitudinal lateral veins. These form a renal sinus around the nephridium. Pulmonary arteries leading from the sinus to the lung ramify into numerous branches which give rise to equally numerous branches of the pulmonary vein. The latter conveys the oxidized blood to the heart. The blood is practically colorless and contains amobocytes. 
The lung is simply the modified inner surface of the mantle cavity. It is oval, like the external surface of the shield, but the rear third of it is occupied by the pericard with the heart, the nephridium and part of the rectum. The rest of the surface presents a network of fine blood-vessels, some of which are arteries while others are veins. The pneumostoma or opening leading into the pallial cavity may be closed or opened at will by the action of a double sphincter.

Nervous system and sense organs. The nervous system of Limax, while considerably more complicated than that of the lamellibranch Venus, still presents the characteristic paired ganglia. Above the œsophagus is the pair of cerebral ganglia united to each other by a commissura cerebralis. Nine pairs of nerves are given off by these ganglia to the various organs of the head; of these the so-called buccal nerves form a pair of buccal ganglia on the dorsal surface of the pharynx. A tenth nerve is given off by the right cerebral ganglion to supply the penis. The posterior region of each cerebral ganglion forms two lobes, the pedal lobe lying more to the outside, and the visceral lobe more to the inside. The pedal lobe of each side gives rise to a cerebropedal connective. The two pedal ganglia lie under the cephalic artery. Of the four pairs of pedal nerves arising from the two ganglia the last pair is the longest and may be traced without difficulty to the rear end of the foot beyond the visceral complex. The visceral lobes of the cerebral ganglia give rise to a pair of cerebropleural connectives which end in the pleural ganglia of the subesophageal ganglionic mass. This mass, which lies below the asophagus, but above the cephalic artery, consists of five distinct ganglia. The outside pair is formed by the pleural ganglia, then follows the pair of parietal ganglia and the centre is occupied by a single visceral ganglion. The latter, however, must be regarded as the result of an early fusion of a pair of ganglia. The subœesophageal ganglionic mass gives off nerves to the mantle, lung and viscera.

The senses are more or less highly developed. The whole in- 


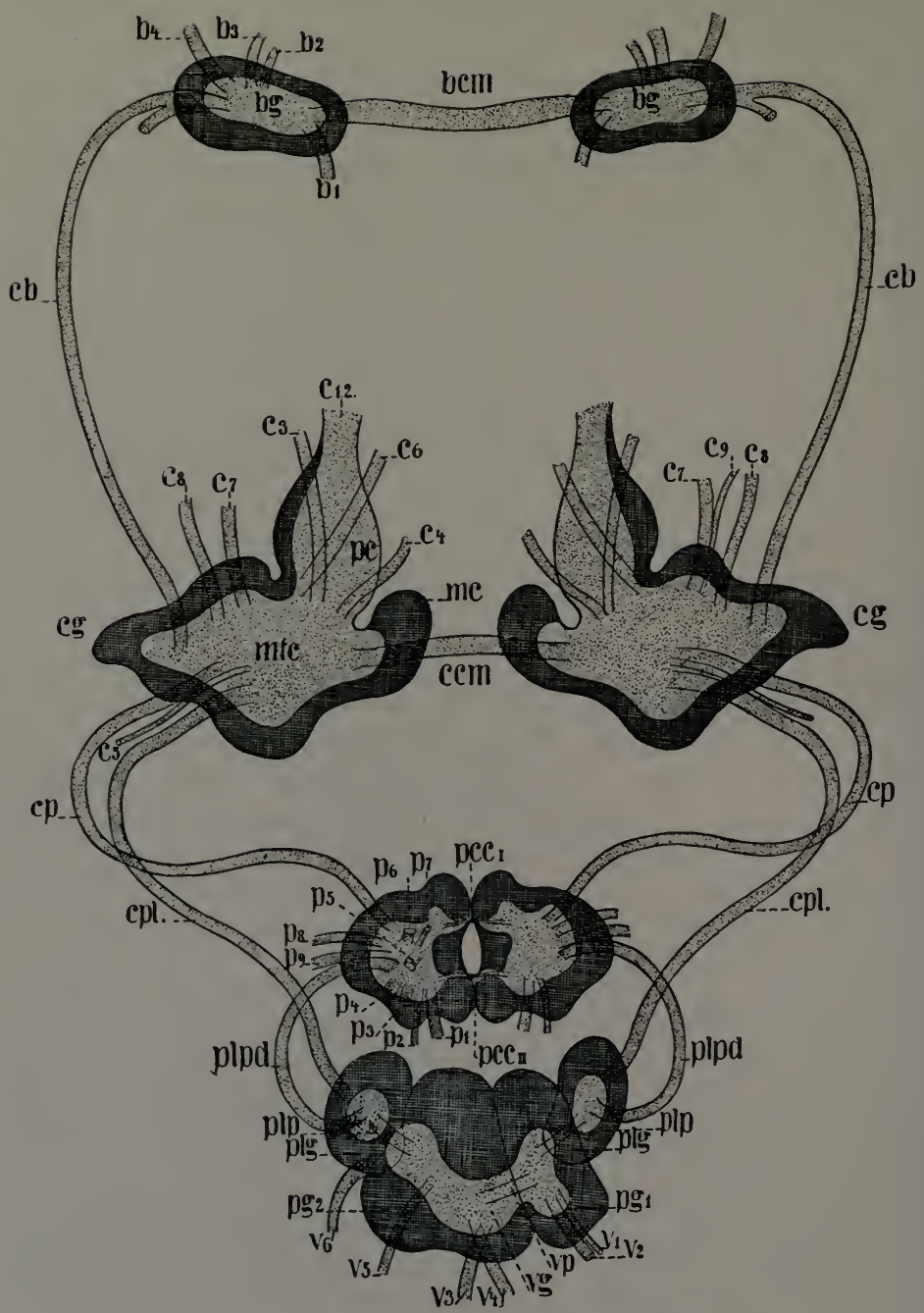

FIg. 45. - The central nervous system of Helix pomalia. Modified after Böhmig and Meisenheimer. $b g$, buccal ganglion; $b c m$, buccal connective; $b_{1}$, pharyngeal nerve; $b_{2}$, nerve to salivary gland; $b_{3}-b_{4}$, nerves to intestine; $c b$, cerebrobuccal connective; $c g$, cerebral ganglion; $m k$, metacerebrum; $m c$, mesocerebrum; $p c$, protocerebrum; $c c m$, cerebral connective; $c l_{2}$, base of 
tegument is rich in sensory cells. Many of these may be safely interpreted as organs of touch although the most sensitive region is on the anterior tentacles and around the mouth. The sense of taste is localized in special cells of the lining of the mouth cavity. The olfactory sense seems to be restricted to the posterior tentacles. These tentacles are also the seat of a pair of well formed eyes. As regards the sense of hearing, the matter is not so simple. There is a pair of otocysts above the pedal ganglia. They receive their nerves from the cerebral ganglia. They serve as organs of equilibrium; but future investigation will have to show to what extent the function of hearing also may be ascribed to them.

Reproductive system. Like all pulmonate gasteropods, Limax is a hermaphrodite and its reproductive system is very complicated. At the rear end of the visceral complex, surrounded by the lobes of the liver, is a hermaphroditic gland with a long and fine hermaphroditic duct. The gland consists of numerous lobes but sperm and eggs never ripen at the same time. The animal is, as we say, proterandric, $i$. e., it functions first as a male and later as a female. The hermaphroditic duct finally divides, giving rise to a rather spacious oviduct and a thin vas deferens. The two ducts run in close contact with each other. The place where the hermaphroditic duct divides is marked by the $a l$ buminous gland which opens into the oviduct and which attains a considerable size when the animal functions as a female. The last portion of the female duct is called the vagina and leads into the vestibule or genital cloaca. The seminal receptacle which functions as a bursa copulatrix and receives the sperm during nervus olfactorius and opticus; $c_{3}$, nervus peritentacularis externus; $c_{4}$, nervus peritentacularis internus; $c_{5}$, nervus acusticus; $c_{6}$, nervus labialis internus; $c_{7}$, nervus labialis medianus; $c_{8}$, nervus labialis externus; $c_{9}$, nervus penis; $c p$, cerebropedal connective; $c p l$, cerebropleural connective; $p c c_{1}$, $p c c_{11}$, connectives of the pedal ganglia; $p_{1}-p_{9}$, pedal nerves; $p l p d$, pleuropedal connective; $p l p$, pleuroparietal connective; $p l g$, pleural ganglion; $p g_{1}, p g_{2}$, parietal ganglion; $r g$, visceral ganglion; $v p$, viscero-parietal connective; $v_{1}$, n. pallialis dexter externus; $v_{2}$, n. pallialis dexter internus; $v_{3}$, n. intestinalis; $v_{4}$, nervus analis; $v_{5}$, nervus cutaneus; $v_{6}$, n. pallialis sinister. 
copulation, opens also into the genital cloaca. The vas deferens separates from the female duct at the point where the vagina begins and soon leads into the coiled penis which opens into the vestibule. The penis is provided with a retractor penis, a powerful muscle which arises from the dorsal body wall somewhat in front and to the left of the common retractor of the tentacles. The penis is situated above the stomach and passes under the retractor of the right posterior tentacle before it reaches the vestibule. We have seen already that the vestibule opens to the outside on the right side of the animal, in front of the shield. This is the common genital opening. When two individuals come together in the act of copulation, the penis of the male is protruded through his common genital opening and is introduced into the bursa copulatrix of the female through her common genital opening. The eggs undergo an abbreviated development in which the characteristic larval stage of gasteropod molluscs is considerably modified and difficult of recognition.

\section{Instructions}

I. Place a specimen in a dissecting tray with water and make a half page drawing of its right side. Label foot, mantle, pneumostoma, genital opening (in front of mantle, behind tentacles), anterior right tentacle, posterior right tentacle with eye (if everted).

2. Make a large drawing showing the front view of Limax. Label the four tentacles, mouth, upper lip and the cleft lower lip.

3. Make an incision with scissors along the left side just above the foot and extending as far as the head. Make another incision along the right side, but extending only to the posterior edge of the shield; remove the dorsal body wall back of the shield by a transverse incision. Pin down the foot. Carefully turn the shield over to the right, cutting the aorta, retractor penis and retractor of the tentacles and freeing the rectum. Make a 
drawing showing all organs in situ: immediately behind the anterior tentacles the ovoid pharynx and above it two thin tentacular nerves; at each side of the pharynx a dark bandthe retractors of the second tentacles; behind these a coiled tube passing to the right under the right retractor-the penis with its retractor the end of which is now free, since it has been cut; on the left side and behind the penis the two white salivary glands and the anterior end of the thin-walled stomach; the brown-lobed liver with two loops of the intestine imbedded in it; three long organs behind the salivary gland and to the right of the liver-the cephalic artery, oviduct and common retractor of the tentacles; the aorta; at the extreme end-the hermaphroditic gland; at each side of the visceral mass running along the foot the right and left pedal nerves; the flat rectum, its end disappearing in the mantle cavity; in front of it, protruding through the wall of the mantle cavity - the cut proximal end of the aorta; to the right of the rectum the cut attachment of the common retractor of the tentacles and in front of this that of the penis.

4. Pull the retractor communis tentaculorum from beneath the intestine. Free the hermaphroditic gland and canal. Cut the liver blood-vessel. Free the intestine from the liver and stomach without tearing any ducts or parts and leave it on your left. Cut the retractor of the right tentacle and free the entire reproductive system, pushing it to the right. Make a full page drawing showing digestive and reproductive organs. In the former, label: pharynx, ducts of salivary glands, œsophagus, salivary glands, stomach, liver, intestine and rectum. In the reproductive system, label: retractor penis, penis, vas deferens, vas efferens, bursa copulatrix, vagina, oviduct, albuminous gland, hermaphroditic duct, and hermaphroditic gland.

5. Remove the digestive and reproductive organs. Open the mantle cavity by carefully removing with a forceps the body wall below it. Make a drawing showing nervous, circulatory ard excretory systems. Label anus, pneumostoma, rectum, 
ureter, kidney, pericardium, auricle, ventricle, pulmonary vein with ramifications. The nephridium is the large spongy body, the ureter runs from its rear edge in a curve to the left (animal's right). The heart is in contact with it.

6. Extract from under the ramifications of the pulmonary vein the shell and make a drawing of it.

7. Remove the radula from the pharynx, place it on a slide in water, examine under microscope (Ioo diameters) and make a drawing of it.

8. Examine under high power (400 diameters) the prepared section through the hermaphroditic gland and make a drawing showing young eggs and spermatozoa or such stages of the male reproductive cells as may be found. 


\section{LOLIGO PEALII Lesueur}

Material. Loligo pealii is found along the Atlantic Coast in depths below low-water mark and down to about fifty fathoms. It should be preserved in formalin. Injection of the circulatory system is not necessary. Each student should receive if possible one specimen of each sex.

\section{Descriptive Part}

Loligo pealii or the common squid is a typical representative of the class Cephalopoda or those molluscs in which part of the modified foot is situated at the end of the head and forms the tentacles and arms surrounding the mouth. At first sight it looks as if the squid were structured on a different plan from other molluscs, but the difference is more of a physiological than of a morphological kind. In order to understand the structure of the squid one should place it head down, hind end up. In this position the ventral surface is formed by the arms, tentacles and funnel, the latter being also part of the modified foot. The mouth is at the anterior end, the funnel at the posterior end of the animal. The dorsal surface is drawn out in the shape of a long cone in which we may recognize an antero-dorsal and a postero-dorsal region or surface. In other words, the squid is an excessively humpbacked animal in which this condition has deeply modified the functions of the various regions of the body. The squid swims forward or backward more or less in the line of its long axis and with the postero-dorsal surface down. This position presents the least resistance to locometion in the water. The postero-dorsal surface functions therefore as the ventral surface, the antero-dorsal as the dorsal surface and the dorso- 


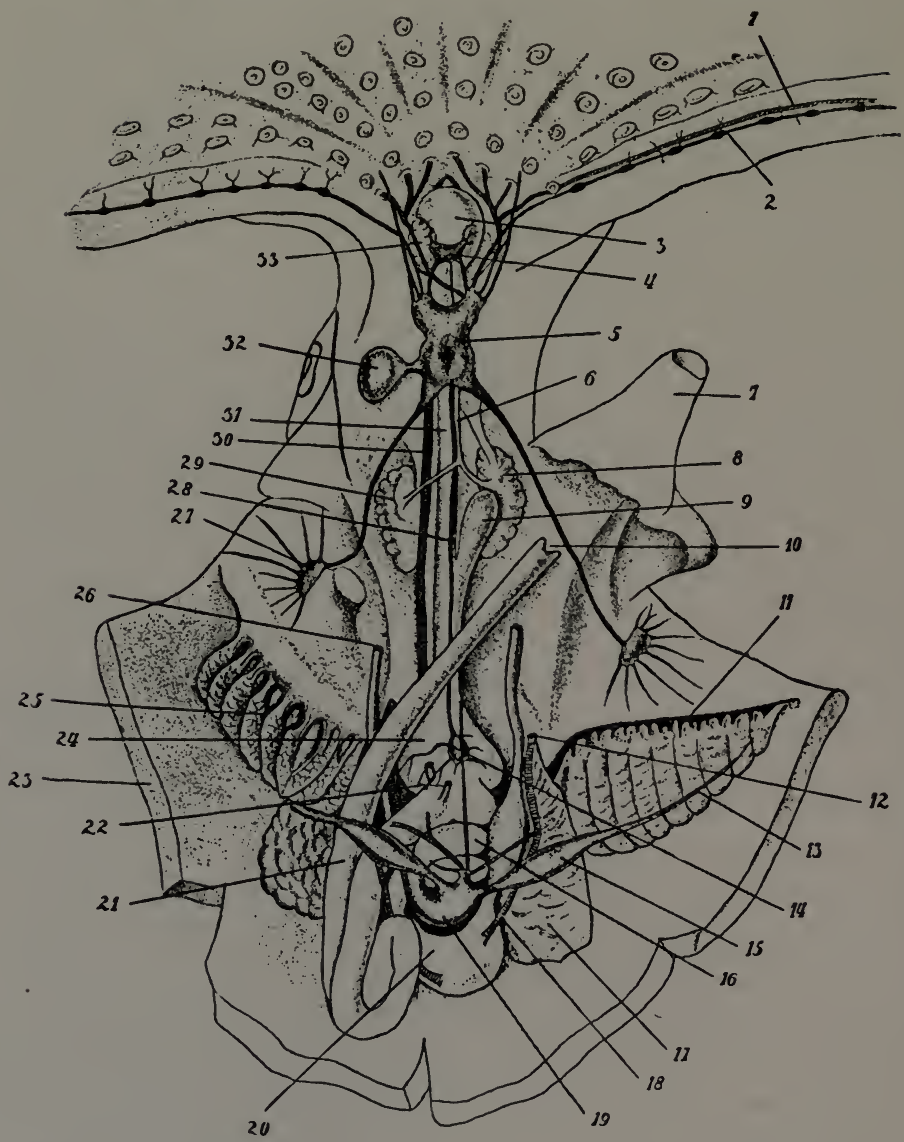

Fig. 46. - Anatomy of Octopus after Leuckart's Wandtafeln. $I$, artery of an arm; 2, nerve of an arm; 3, pharynx; 4, buccal ganglion; 5, cerebral ganglion; 6 , duct of upper salivary glands; 7 , funnel; 8 , posterior salivary glands; 9 , crop; $I O$, anus; $I I$, gill artery; 12 , opening of left nephridium; $I_{3}$, gill vein; $I_{4}$, gastric ganglion; I5, left auricle; 16 , spiral coecum of stomach; 17 , nephridial sac; 18 , water canal; 19 , ventricle; 20 , ovary; 21 , rectum; 22 , hepatic ducts; 23 , mantle; 24 , stomach; 25 , right gill; 26 , opening of the right oviduct; 27 , stellar ganglion; 28, nerve to the gastric ganglion; 29, posterior salivary glands; 30, aorta; $3 I$, œsophagus; 32 , optic ganglion; 33 , anterior salivary gland. 
ventral axis as the longitudinal axis. To avoid confusion the terms anterior and posterior, dorsal and ventral will be restricted to their morphological meaning and will have the same value as in other molluscs. On the other hand, the terms upper and lower, fore and hind, left and right will be applied for the various regions of the body in the natural position of the swimming animal.

External Features. The body of the squid is divided into head, neck and trunk. The mouth is surrounded by ten arms two of which differ from the rest and are called tentacles. It is customary to count the arms beginning at the upper surface of the head. The fourth or last pair of arms is below the mouth and the tentacles are between the third and fourth pair. The third pair of arms is the longest but still considerably shorter than the tentacles. A muscular membrane attached to the base of the arms extends from these to the mouth. Its peripheral portion called the buccal membrane, possesses seven muscular projections each bearing two rows of small suckers on the surface facing the mouth. One of these projections is situated in the plane of symmetry above the mouth, $i$. e., between the first pair of arms. The inner part of the membrane, immediately surrounding the mouth, is called the peristomial membrane. In the female there is a special horseshoe organ on the buccal membrane in the median line below the mouth. This organ serves for the attachment of spermatophores. The four pairs of arms are sessile, gradually tapering toward the end and all but the third pair are trapezoidal at base. They are provided with inner and outer marginal membranes and two rows of suckers. Each sucker is composed of a short pedicel and cup the edge of which is strengthened by a serrated chitinous ring. The central part of the base of the cup is formed by the piston which is the end of the pedicel. The largest suckers are at the base of each arm. The tentacles are retractile. They are composed of a peduncle and a terminal club on which the suckers sit in four rows; the largest suckers are in the middle of the club. The peduncle of the tentacles sits in a sac formed by the outer 
membranes of the third and fourth arm. In the adult male the left fourth arm (the lower left arm often called in text-books the fifth arm when the tentacle is counted as the fourth) is hectocotylized; beginning with about the eighteenth to twentieth suckers from the base of the arm the hectocotylization progresses distally. It consists in an enlargement and swelling of the pedicels and a reduction of the cups. In the thirtieth to thirty-fifth suckers the cups disappear almost completely. The small suckers at the end of the club gradually become normal again.

On each side of the head is a large and well developed eye in which one may easily recognize the transparent cornea, the opaque iridescent iris, the pupil and the lens. In front of the eye, near the edge of the cornea, is a small opening-the aquiferous pore-which may be closed by a sphincter muscle. It leads into a short aquiferous canal which opens by means of a ciliated funnel into the outer chamber of the eye. On each side of the head, beginning just behind the eye, is a fold of the skin called the olfactory crest. Its free edge is covered up by the mantle. On the lower surface of the squid, projecting forward from under the mantle, is the funnel (infundibulum) often called the siphon for the reason that its function is in part analogous to that of the cloacal siphon of lamellibranchs. The two structures are, however, of different origin. The siphon of the lamellibranchs is part of the mantle, while the funnel of the squid is part of the foot. The funnel is a hollow, somewhat flattened conical tube open at both ends and attached to the head and visceral mass. Its tip may be directed forward or backward at will, and in consequence the current of water ejected through the funnel may be forward or backward. The squid swims in the direction opposite to that of the current.

The rest of the body of the squid is completely hidden by the mantle, which has the shape of a long cone with two fins. The free ventral edge of the mantle, called the collar, is drawn out into three more or less equidistant projections. The anterior or upper projection marks the end of the pen, while the two postero- 
lateral or lower projections mark the pallial cartilages. The mantle is attached to the body in the median line on the back. There are other connections, such as ligaments and muscles, which, however, will be considered later.

Integument. The integument of the squid consists of an epidermis and a dermis. The former is a simple layer of epithelial cells, which secretes a thin cuticle and covers the entire body including both the inner and outer surfaces of the mantle. The epidermis, which lines the funnel, forms two pairs of glands of unknown function. These glands are usually known under the name of the organ of Verrill. The pen, which is an internal shell, is also a product of the epidermis inasmuch as it is secreted by the shell gland. Originally nothing but an invagination of the epidermis on the dorsal surface of the embryo, the shell gland becomes later a closed sac inside of which is inclosed the pen. In the adult the pen is a thin and narrow, transparent, chitinous shell extending from the upper projection of the collar to the rear end of the mantle and situated under the latter above the visceral mass. The median ridge of the pen represents the line in which the two free edges of the early shell gland have grown together to form the sac.

The dermis is composed of four layers: outer fibrous layer, chromatophore layer, deep fibrous layer, and iridiocyst layer. The changes in the color of the live squid are due to the second layer and are increased by the reflection of the light from the iridiocysts. Each chromatophore is composed of a pigment cell and of from ten to thirty muscle cells which are attached to the membrane of the pigment cell and receive a supply of nerve fibres from the mantle nerves. A contraction of the muscle cells results in an expansion of the pigment cell. On the under surface of the fins and in all parts where the integument is not exposed to light, both the chromatophores and iridiocysts are lacking.

Skeleton. Besides the pen which serves for the attachment of the mantle the squid possesses several cartilages. These cartilages are usually called the endoskeleton, although they do 
not constitute a connected system. The head contains a cephalic cartilage with several foramina or openings for the various organs such as œsophagus, arteries, nerves, etc., and several smaller cartilages. Other cartilages are situated in the fins, the neck, the siphon, and the mantle. Among them, of special interest are the nuchal cartilage which lies between the liver and the pen, articulating with the latter, and the two infundibular cartilages articulating with the two pallial cartilages.

Muscular system. The muscular system of the squid is highly developed and complex. The foot and the mantle may be regarded as pre-eminently muscular organs, but muscular layers and specialized muscles are also found in connection with various organs. Excepting the three bands of muscular fibres connecting the mantle with the fins, the thick wall of the mantle is composed of a sheet of circular muscle fibres, covered by and lined with integument. Longitudinal, vertical and transverse fibres form the muscular layer of the fins. In the funnel are both circular and longitudinal fibres. The latter are continuous with the heavy (siphonal) retractors of the funnel which arise one on each side of the funnel and terminate in the pen. A pair of short protractors of the funnel arise from the cephalic cartilage and help to attach the funnel to the head. Inside the funnel, close to its external opening and situated on the upper wall, is a muscular valve preventing the entrance of water into the funnel from the outside. On each side of the funnel is a muscular sheet or valve projecting into the mantle cavity and preventing the passage of water from the mantle cavity to the outside by way of the free space between the collar and the head. A pair of heavy cephalic retractors arise from the cephalic cartilage and terminate in the middle of the pen, just behind the so-called nuchal retractors. The muscular system of the arms and tentacles is too complicated to be considered here. Some of the muscles of the various organs will be mentioned in the course of description of the respective systems.

Digestive system. The digestive system of the squid 
consists of the alimentary canal, three salivary glands, liver and pancreas. The buccal membrane surrounding the mouth has been described above. The mouth leads into the mouth cavity. The walls of this cavity are formed by the buccal bulb, a nearly spherical, muscular body inclosed in the buccal sac and provided with a single retractor. Inside the bulb are two powerful chitinous jaws resembling an inverted beak of a parrot, the upper jaw shutting into the lower one. Their action is dependent upon special muscles. Attached to the base of the lower jaw is an organ called the odontophore, projecting into the mouth cavity. The odontophore consists of two parts. The lower portion of the odontophore is a muscular tongue or ligula. At the tip of the ligula is the opening of the salivary duct of the median or abdominal salivary gland which is imbedded in the proximal (ventral) end of the liver. The upper portion of the odontophore is called the radula. The radula bears seven rows of sharp, chitinous teeth and a row of plates on each side. These teeth, as well as the chitinous band connecting and supporting them, are secreted by the cells of the radular sac, into which the radula may be partly withdrawn by the contraction of the retractors of the radula. The opposite movement of the radula is brought about by the protractors of the radula. The exposed portion of the radula is curved. The teeth, which are inclined backward, become more or less erected when the radula is protracted; the triturating action of the radula is therefore possible only during retraction, and this is the reason why the retractors are stronger than the protractors. Partially imbedded in the muscles between the radula and the œsophagus is a pair of buccal salivary glands with short ducts opening into the mouth cavity on the so-called palatine lobes.

The resophagus is a thin and long tube leading from the buccal bulb to the stomach. On leaving the head it passes through a deep groove in the liver to the upper surface of the latter, and continuing in a shallow median groove extends somewhat beyond the middle of the liver. Here the œsophagus dips down- 
ward, perforates the liver, emerges on the lower surface of the latter between the two hepatic ducts and opens into the stomach near the middle of the visceral mass. The liver is embryologically a paired gland, but the two glands grow together during development, and in the adult squid the liver resembles a long cone with its base toward the head and its somewhat drawnout apex toward the rear. The right and left hepatic ducts enter the nephridial sac, pass through the U-shaped pancreas and after receiving the numerous minute ducts of the latter emerge as hepato-pancreatic ducts. These soon unite and open as a common hepato-pancreatic duct into the stomach-pouch. The stomach has thick muscular walls and communicates directly with the stomach-pouch (called also cœeum or spiral stomach) which is a long sac with thin muscular walls. When fully extended the stomach pouch reaches the rear end of the body. Close to the cardiac opening of the stomach connecting it with the œesophagus, is the pyloric opening leading from the stomach into the intestine. The cardiac and pyloric openings are controlled by sphincters. The opening between the stomach and the stomach-pouch is controlled by the gastric valve, that between the pouch and the intestine by the intestinal valve, and the one between the common hepato-pancreatic duct and the pouch by the hepatic valve. The intestine is a short tube running forward and downward between the two lobes of the pancreas. The intestine soon becomes constricted and leads into the rectum which is about half as long as the liver. The rectum ends at the base of the funnel in an anal chamber the entrance to which may be closed by the anal sphincter. The anus is provided with an upper and lower lip and two lateral leaf-like processes-rectal papilla.

Embryologically and histologically the alimentary canal may be divided into three parts. The foregut or stomadeum includes the bulb, œsophagus and stomach, and is lined with a chitinous cuticle. The midgut includes the stomach-pouch and the intestine and is lined with ciliated epithelium rich in unicellular 
glands. The hindgut or proctodeum is represented by the rectum. Connected with the hindgut and embryologically derived from it as an invagination of the distal end of the proctodeum is an organ situated above the rectum and called the ink-sac. It is shaped like an elongated gourd and its duct opens into the anal chamber. The glandular portion of the enlarged end of the inksac produces a black liquid which can be squirted through the anus and out of the siphon, thus hiding the squid from the pursuit of an enemy. The iridescent color of the walls of the ink-sac is due to iridiocysts.

Circulatory system. The circulatory system of the squid is a closed one. There are three central pulsating organs, one of which is arterial and is called the systemic heart, while the other two are venous and are called the branchial hearts. The systemic heart is situated between the two gills at their base, below the stomach. It consists of a single chamber or ventricle. In the European squid, Sæpia officinalis, the branchial veins are dilated at the end, thus forming two auricles. But in the American common squid auricles are absent. The systemic heart receives only oxidized blood through two afferent vesselsthe right and left branchial veins - and distributes it through three efferent vessels - the anterior aorta, the posterior aorta, and the genital artery. The openings of the branchial veins into the systemic heart are protected each by a pair of semilunar valves preventing the return of the blood to the gill. The openings of the anterior and posterior aortas are protected each by a single semilunar valve preventing the return of the blood to the heart. The anterior aorta arises from the anterior projection of the heart and runs forward to the head in close contact with the œsophagus. In the head it gives off branches and communicates through capillaries with the anterior vena cava. The posterior aorta arises from the posterior projection of the heart and soon splits into three pallial or mantle arteries. Of these the median mantle artery runs forward along the median line of the lower surface of the mantle, while the two lateral mantle arteries 


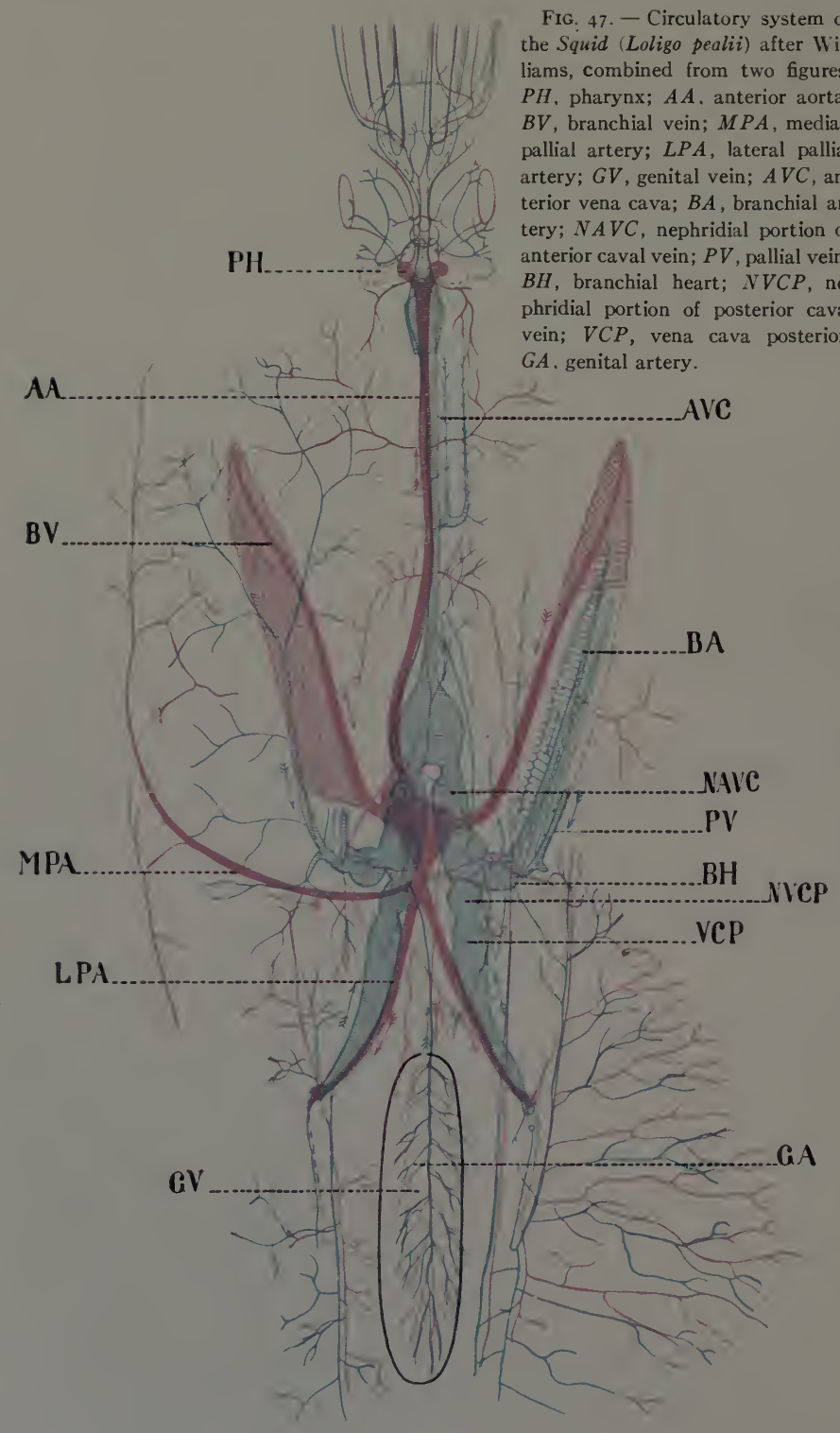


pass obliquely backward to the upper surface giving off branches to the rear half of the mantle and to the fins. The blood from the median mantle artery passes through capillaries into the mantle veins; that from the lateral mantle arteries into the posterior venæ cavæ. The genital artery arises from the middle of the ventral surface of the heart. Its blood passes through capillaries into the genital vein.

The system of veins is characterized by the considerable size of the vessels and by their special relation to the excretory system. The anterior vena cava the branches of which collect the blood from the head is a vessel of considerable size running in the median line below the liver toward the nephridial sac. On entering the latter, it splits into a right and left arm which traverse the nephridial sac and open into the respective branchial hearts. The two arms have been called by Brooks the glandular portion of the anterior vena cava because they are surrounded by the urinary gland. Williams calls them the nephridial sinus because of their wide lumen. The latter term is scarcely more fortunate than the former, since in other cephalopods the two arms are in no wise conspicuously enlarged. They may be best designated as the nephridial arms of the anterior vena cava. Into the right nephridial arm open the right pallial or mantle vein, the right vena cava posterior, and the genital vein; into the left the left pallial vein and the left vena cava posterior. The pallial veins collect the blood from the forward portion of the mantle, blood that was carried there by the median mantle artery. The pallial veins open into the nephridial arms of the anterior vena cava close to the branchial hearts. The right and left posterior venæ cavæ are large vessels collecting the blood from the rear half of the mantle. On entering the nephridial sac, each vein forms a slightly dilated nephridial portion of the (right or left) posterior vena cava (Brooks calls this portion the glandular portion of the posterior vena cava, while Williams considers it to be a part of the nephridial sinus). The nephridial portion is surrounded by the end of the urinary gland. Between the 
nephridial portion of the posterior vena cava and the nephridial arm of the anterior vena cava is a distinct constriction.

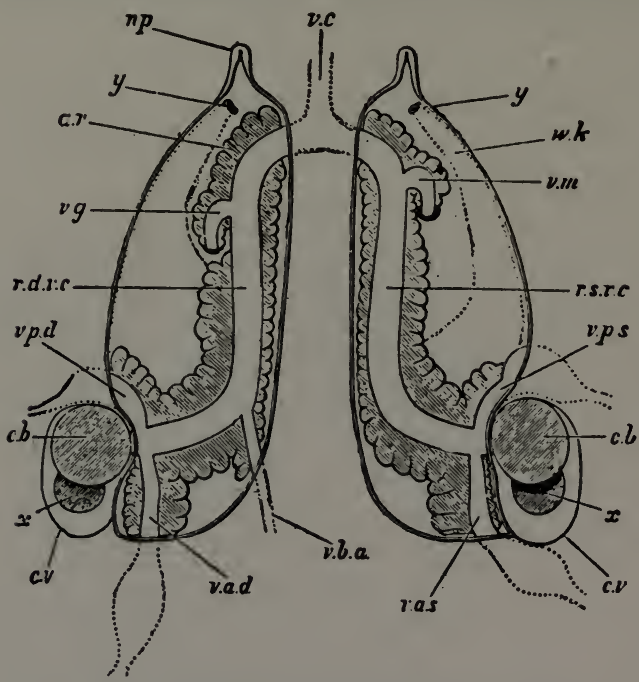

Fig. 48. - Diagram of the excretory system of Sepia officinalis after Vigelius (from Encyclopædia Britannica, Cephalopoda, Fig. 29). The nephridial sacs are supposed to have their upper walls removed. $v . c$, vena cava; $r . d . v . c$, right descending branch of the same; $r . s . v . c$, left descending branch of the same; v. $b$. $a$, vein from the ink-bag; $v$. $m$, mesenteric vein; $v$. $g$, genital vein; v. $a . d$, right abdominal vein; v. a. s, left abdominal vein; v. p. $d$, right pallial vein; v. p. s, left pallial vein; $c . b$, branchial heart; $x$, appendage of the same; $c$. $v$, capsule of the tranchial heart; $n p$, external aperture of the right nephridial sac; $y$, reno-pericardial orifice placing the left renal sac or nephridium in communication with the viscero-pericardial sac, the course of which below the nephridial sac is indicated by dotted lines; $y^{\prime}$, the similar orifice of the right side; $a . r$, glandular renal outgrowths; $w . k$, viscero-pericardial sac (dotted outline). gans are tributaries of the venous system of the anterior vena cava. (They are not shown in Fig. 47.)

The branchial hearts, one at the base of each gill, are inclosed each in its own pericard which is simply a pouch of the cœlome. Each heart has two openings. One opening admits the blood from the nephridial arm of the anterior vena cava and is protected by two semilunar valves. The other opening leads into the branchial artery and has a valve consisting of four tubercles. Attached to each branchial heart is a lymphatic or pericardial gland. The majority of the smaller veins carrying the blood from various or- 
Respiratory system and mantle cavity. It has been already stated that the body of the squid is surrounded by a mantle which has the shape of a hollow, elongated cone. The mantle is attached to the body along the antero-dorsal surface. The free edge of the mantle, called collar, is kept in position by these equidistant cartilages. Of these the right and left infundibular carlilages articulate with the pallial cartilages of the mantle, while the nuchal cartilage articulates with the pen in the upper median line. We have seen besides that inside the funnel is a valve - the infundibular valve-and on the outside of the funnel are two lateral valves. Water is drawn rhythmically into and forced out of the mantle cavity by the expansion and contraction of the mantle. It enters through the free space between the head and the collar and leaves by way of the funnel, a reversal of the current being prevented by the valves. Situated in the mantle cavity and extending from the heart forward to the base of the funnel, are two gills. As the water is drawn into the mantle cavity by the expansion of the mantle, it passes between the so-called pinnæ of the gills and leaves the latter by way of the branchial canals.

Each gill or ctenidium has the shape of a long, trihedral pyramid and consists of a core and the gill proper. The core itself has the shape of a trihedral pyramid and is attached to the mantle by a sheet of integument along the median line of one of its surfaces. The other two surfaces serve as support to the gill proper. The latter may be likened to a plume with triangular barbs or pinnce which are attached to the core by one edge. The branchial vein runs along the free edge of the gill and corresponds to the stem of the plume. An efferent vessel runs along the free edge of every pinna to the vein. The branchial artery runs along the edge of the core, under the vein and parallel to it. It gives off an afferent vessel to each pinna. These vessels run along that edge of the pinna which is attached to the core. The branchial artery is separated from the branchial vein by the branchial canal which runs parallel to them and 
opens into the mantle cavity at the base of the gill. A ductless branchial gland is inclosed in the core of each gill. The function of these glands is not known.

Excretory system and cœlome. The excretory system of the squid stands in close relation to the circulatory system and the cœlome or secondary body cavity. It consists of a bilobed sac-the nephridial sac-and a urinary gland. The sac opens into the mantle cavity by means of two nephridiopores situated on small papillæ, one on each side of the rectum. The intestine passes through the nephridial sac and emerges from it as the rectum. The two nephridial arms of the anterior vena cava and the nephridial portions of the two posterior venæ cavæ are inclosed in the lobes of the nephridial sac. Surrounding these vessels and hiding them from view are the two urinary glands which are therefore likewise inclosed in the nephridial sac. The cœlome connects directly with the nephridial sac by means of two short canals. It is lined with ciliated peritoneum. The systemic heart, the branchial hearts, the stomach, the stomachpouch, and the gonad are contained in the cœlome (visceral $\mathrm{sac})$.

Nervous system and sense organs. The nervous system is characterized by the great concentration of the paired ganglia of the central nervous system and the high development of the sense organs. Four pairs of ganglia enter into the formation of the œsophageal ring. They are inclosed in the cephalic cartilage or skull and are almost completely fused together. Of these four pairs of ganglia the cerebral ganglia lie above the œsophagus, the pleural ganglia form the sides of the ring, while the pedal ganglia and the visceral ganglia are situated below the œsophagus. The pedal ganglia lie in front of the visceral ganglia. Two large optic ganglia are closely connected with the pleural ganglia. Two large stellate ganglia are situated on the inner surface of the mantle just behind the nuchal cartilage. They are connected with the visceral ganglia and supply nerves to the mantle. Several other ganglia are found in the head and 


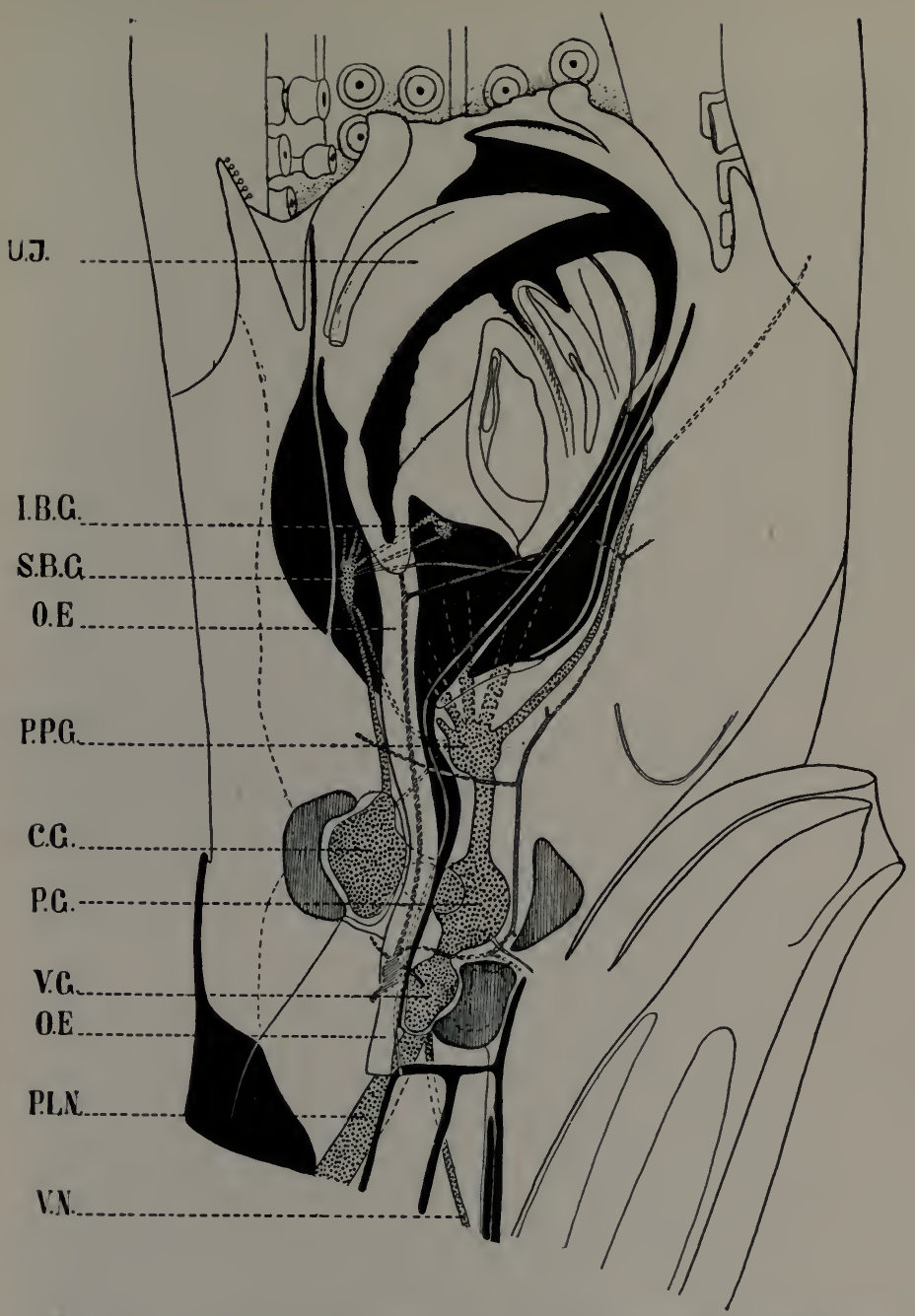

FIg. 49. - Longitudinal section through the head of the Squid showing ganglia and cartilages. After Williams. $U J$, upper jaw; $I B G$, infrabuccal ganglion; $S B G$, suprabuccal ganglion; $O E$, œsophagus; $P P G$, propedal ganglion; $C G$, cerebral ganglion; $P G$, pedal ganglion; $V G$, visceral ganglion; $P L N$, pleural nerve and viscero-stellate connective; $V N$, visceral nerve and viscero-branchial connective. 
foot. Altogether the squid has fifteen paired and one single ganglion. The latter is the splanchnic ganglion. It supplies nerves to the alimentary canal and is connected with the socalled infrabuccal ganglia which are in turn connected with the cerebral and pedal ganglia.

Two large eyes are situated on the head, each in its own capsule. Each is connected with its optic ganglion by a short optic nerve. The structure of the eye is very similar to that of the vertebrate eye. The eyeball is provided with nine eyemuscles. The outer chamber of the eye communicates with the outside by means of the aquiferous pore situated immediately beyond the edge of the cornea. The iris is thick and iridescent. A small contractile fold of it projects, when in the light, so as to give the pupil the shape of a crescent. The spherical lens is attached to the ciliary body by a sheet of connective tissue and is brought nearer to or farther away from the retina by the ciliary muscle. The retina is direct. Wedged in between the eyeball and the optic ganglion, on each side of the head, are two lymphatic glands - the so-called white bodies.

The two olfactory crests harbor in their concavity a special sense organ possibly with olfactory function. They receive their nerves from the pedal ganglion.

Two statocysts are situated in the cephalic cartilage below the visceral ganglia. Each statocyst consists of a cavity lined with epithelium. Twelve papillæ project into the cavity. In one place the epithelium is ciliated and forms the macula statica on which the statolyth rests. A ciliated ridge-crista staticawinds along the walls of the cavity. A ciliated canal-Kölliker's duct-leads from the cavity toward the surface. The duct ends blindly in the adult squid, but communicates with the outside in the embryonic stages. The statocysts receive their nerve supply from the pedal ganglia in the shape of two cristic and two macular nerves.

Organs of taste are found on the tongue or ligula. They receive their nerve supply from the infrabuccal ganglia. 
Organs of touch are represented by numerous nerve endings in the integument, quite especially on the arms.

Reproductive system. The sexes are separate and may be recognized by the presence of the hectocotylized arm in the matuie male and the horseshoe organ on the buccal membrane of the mature female. The male reproductive organs consist of a single testis, vas deferens, vesicula seminalis, prostata, appendix, appendicular gland, spermatophoric duct, spermatophoric sac and penis. The testis is situated in the cœlome and is attached to the cœlomic wall by a mesentery. It has no duct, but opens directly into the cœlome by means of a narrow slit; thus the sperm is first discharged into the cœlome. Near the opening of the testis is a ciliated funnel which leads from the cœlome into the vas deferens. The latter opens into the vesicula seminalis which has the appearance of a convoluted canal. This appearance is due to its origin, but in the adult squid the vesicula is a glandular sac with a very irregular lumen and presents three distinct portions. A ciliated canal (Chun's canal) connects the third portion of the vesicula with the genital sac which surrounds the vesicula, prostata and appendix with its diverticulum and opens into the mantle cavity by means of a short duct. The spermatophoric duct ${ }^{1}$ connects the vesicula with the spermatophoric sac. The latter leads into a muscular penis which opens into the mantle cavity near the anus. The prostata is a large gland, the duct of which opens into the spermatophoric duct close to the so-called appendix with its appendicular gland.

The spermatozoa are discharged in bundles or "ropes" from the slit in the testis directly into the coelome. They reach the vesicula seminalis through the vas deferens and are here inclosed in a special case or spermatophore. The spermatophores are stored in the spermatophoric sac before they are transferred

1 The term "vas efferens" used by Brooks and later by Williams for the designation of this canal is unfortunate, since under this term is usually understood the small duct leading from a testis to its vas deferens in lower invertebrates. 
to the horseshoe organ of the female. The spermatophores have the shape of an elongated tube with double walls and an ejaculatory apparatus at the rear end. The space between the thin inner wall surrounding the sperm rope and the thick, chitinous outer wall is filled with a liquid. At the front end of the sperm rope is a sticky plug. The ejaculatory apparatus consists of a flask-shaped sac prolonged into a long filament which is partly inclosed in the case and partly free. The proximal portion of the filament is somewhat thicker than the rest and is provided with a spiral thickening of its wall, called the spring. The female reproductive organs consist of an ovary, oviduct, a pair of nidamental glands and a pair of accessory nidamental glands. The ovary is a large organ situated in the colome. The eggs drop into the colome and pass into the oviduct through the ciliated funnel of the latter. The oviduct consists of three portions. The first portion is a tube at first running forward, then backward and then again forward. The second portion is considerably thicker and glandular in its structure. It is usually called the oviducal gland and produces spherical capsules of the individual eggs. The last portion is comparatively short and opens into the mantle cavity on the left side of the body near the anus. The nidamental glands are situated on the lower surface of the viscera. They are large, rounded bodies lying side by side in the median line of the trunk and opening into the mantle cavity. The nidamental glands produce the substance of which the capsules of the egg masses are formed. In front of the nidamental glands are the two accessory nidamental glands, smaller in size and oval. Their function is not known.

\section{Instructions}

I. Place a squid on its right side, head towards you, in a large dissecting tray with water. Make a full page drawing of the left side. Label: head, first, second, third and fourth arms, tentacles, eye, aquiferous pore, funnel and mantle. In the eye label: iris, pupil and lens; in the mantle: its free edge or collar, with its 
left lower projection of the pallial cartilage and dorsal median projection marking the forward end of the pen; the left lateral fin and the chromatophores. Label also the antero-dorsal and the postero-dorsal surface. The long axis of the squid is the dorso-ventral axis.

2. Take the squid in your left hand holding the first, second and third pairs of arms between your second and third fingers and pressing down with your thumb the tentacles and the fourth pair of arms; make a drawing showing the front view of the head. Label arms, tentacles, buccal membrane with its seven muscular projections, peristomial membrane, mouth, upper and lower mandible of the beak and, in case the specimen is a female, the horseshoe organ of the buccal membrane.

3. Make a drawing of the right tentacle showing the peduncle and the club with four rows of suckers.

4. Cut with a razor a large sucker longitudinally. Examine the surface under dissecting microscope. Make a drawing showing the cup with the serrated chitinous ring, the piston and the pedicel.

5. Make a drawing of the left fourth arm showing the inner marginal membranes and two rows of suckers. In case the arm belongs to a mature male, it will be found to be hectocotylized, $i . e$. , the cups are well developed only in the proximal eighteen pairs of suckers; from here on they diminish in size and disappear almost completely in the thirtieth to thirty-fifth pair and become gradually normal again toward the end of the arm.

6. Sever one of the muscular projections of the buccal membrane and examine under dissecting microscope. Make a drawing of it showing the two rows of suckers.

7. Make with a sharp scalpel an incision in the mantle along the upper longitudinal median line. Notice that the pen is completely inclosed in a sac. Carefully extract the pen and make a drawing of it.

8. Turn the squid on its back and holding the mantle firmly with your left hand, make in it with a sharp scalpel a deep 
incision a little to the left of and parallel with the median line of the lower surface. This incision should extend throughout the entire length of the mantle and care must be taken not to injure the organs. Place now the squid with its head away from you, press the sides of the mantle apart and fasten them firmly down with pins, thus exposing the mantle cavity. The funnel appears now as a hollow and somewhat flattened muscular cone, open at both ends. The two long, grooved cartilages of the funnel-the infundibular cartilages are now naturally separated from the pallial cartilages of the mantle with which they articulate. The sides of the funnel are provided with muscular valves-one on each side-which have the appearance of flaps. The two heavy muscles arising from the sides of the funnel and running parallel to each other are the retractors of the funnel. The two plume-like organs situated to the outside of the retractors and attached to the mantle by a sheet of integument are the gills or ctenidia. The vessel running along each gill is the branchial vein. The single organ lying in the median line between the retractors of the funnel is the rectum. The amus opens into the funnel and on its sides are the two rectal papilla. From now on the description varies according to the sex of the specimen. In case of a female proceed to instruction No. I6.

Male. In case the specimen is a male it can be recognized as such by the presence of the penis at the left side of the rectum (on your right). Under the rectum the sides of the iridescent $i n k$-sac are visible. The round bodies, one at the base of each gill, are the branchial hearts. A small gill muscle arises from the base of each gill and terminates in the mantle. The vessel running from the mantle to the branchial heart on each side and in its course more or less parallel to the gill, is the mantle vein. The two large, bluish, semitranslucent vessels running obliquely from the branchial hearts backwards, are the posterior vene cave. Three smaller vessels arise from a median point between these veins. They are the mantle arteries. Of these the two lateral mantle arteries accompany the posterior venæ cavæ. The 
median mantle artery running to the median line of the mantle, if not severed during the dissection, will be seen running obliquely to your right and terminating in the mantle where it splits up into finer branches. The two small papillæ at the base of the rectum are provided each with an opening. These openings are the nephridiopores. The thin, bilobed nephridial sac occupies all the space between the base of the rectum and the branchial hearts. Through the wall of the sac the two urinary glands can be clearly discerned. Behind the left branchial heart (on your right) the following organs can be seen through the body wall (visceral sac): the coiled vesicula seminalis, the spermatophoric sac and, more toward the median line,-the large testis extending to the rear end of the sac. Make a full page drawing showing all organs in situ.

9. Cut the lateral valves on each side of the funnel along the infundibular cartilage. Pull the funnel gently with your fingers until you have completely removed it together with its retractors. Open its lower wall along the median line and fasten the sides down with pins. Make a drawing showing the infundibular valve, the four organs of Verrill and the retractors.

ro. The removal of the funnel with its retractors has exposed to view the cephalic retractors with the osophagus and liver between them, and the two large stellate ganglia situated on the mantle under the cephalic retractors on the level of the tips of the gills. The body wall and the nephridial sac should now be removed with the aid of a forceps. When this has been done, pass the end of a curved forceps between the posterior vena cava of each side and the corresponding lateral mantle vein and separate the vessels without tearing them. In a similar manner separate the ink-sac from the rectum leaving intact its attachment to the anal chamber and push the ink-sac to your right. Separate the penis from the underlying tissues; push the stomach pouch to the left exposing the end of the testis with the terminal tendon. Find the single splanchnic ganglion on the rectum near its base. 
Make a full page drawing of all organs as exposed to view.

Ir. Remove the posterior venæ cavæ and the urinary gland together with the nephridial arms of the anterior vena cava passing through them, thus exposing the systemic heart. Cut the sheet of integument which fastens the right gill (on your left) to the mantle and turn the gill so as to bring into view the branchial artery which runs from the branchial heart along the gill. Make a drawing showing the branchial hearts, the left branchial vein, the right branchial artery, the systemic heart, the base of the anterior aorta and the posterior aorta with the three mantle arteries.

I2. Remove the arterial system, branchial hearts and gills. Carefully push to the left the digestive organs, thus exposing to view the male reproductive organs. Make a drawing showing the testis with its mesentery or tendon attached to the wall of a capsule of the cœlome, vas deferens, the convoluted vesicula seminalis, the thin spermatophoric duct with the prostata and appendix connected with it at its beginning, the large spermatophoric sac filled with spermatophores, and the penis.

I3. Open the spermatophoric sac and remove some of the spermatophores into a shallow dish with water. Examine under low power (microscope) showing the double walls with the ejaculatory apparatus at the rear end. In the latter show the flask-shaped sac and the filament with the spring.

I4. With a razor cut into the head in the median line between the eyes both above and below the buccal bulb without injuring the latter. Carefully remove the entire alimentary canal with its glands allowing it to float in water on one side. Make a drawing showing the buccal bulb with the upper and lower jaw, the anterior aorta and the osophagus with the liver through which they pass, the stomach, characterized by its thick muscular walls, the thin and large stomach pouch, the short intestine passing between the two lobes of the pancreas and the rectum with the rectal papilla. Show also the two hepatic ducts connecting the liver with the pancreas and, if possible, the hepato-pancreatic 
ducts; the median salivary gland which appears as a small white body imbedded in the liver on its anterior upper surface.

I5. Open the buccal bulb and remove the radula. Place it in a drop of glycerine on a slide under cover. Examine under low power and make a drawing showing the arrangement and shape of the teeth.

I6. Female. In case the specimen is a female it can be recognized as such by the presence of two long glands situated behind the rectum. These glands are the nidamental glands. They extend backwards between and beyond the branchial hearts which appear as two round bodies at the base of the gills. Two small accessory nidamental glands are partly covered by the forward ends of the nidamental glands. Underneath the nidamental glands and therefore invisible, is the bilobed nephridial sac. The two nephridiopores are situated on small papillæ at the sides of the nidamental glands close to their forward end. The small vessel arising from a median point between the nidamental glands close to their rear ends is the median mantle artery. The two large, bluish, semitranslucent vessels running from under the rear ends of the nidamental glands obliquely toward the mantle are the posterior vence cave. The two small vessels accompanying these veins are the lateral mantle arteries. The mantle veins run from the mantle to the branchial hearts and their course is more or less parallel to that of the gills. A small gill muscle is attached to the base of each gill and terminates in the mantle. Under the rectum and almost completely hidden by it, lies the ink-sac. On the left of the rectum (your right) is the oviduct. The oviducal gland can be seen through the body wall immediately behind the left nidamental gland (on your right). The large ovary, also seen through the body wall (visceral sac) extends backward to the end of the sac. Make a full page drawing showing all organs in situ.

I7. Cut the lateral valves on each side of the funnel along the infundibular cartilage. Pull the funnel gently with your fingers until ycu have completely removed it together with its re- 
tractors. Open its lower wall along the median line and fasten the sides down with pins. Make a drawing showing the infundibular valve, the four organs of Verrill and the retractors.

I8. Remove the nidamental and accessory nidamental glands, the nephridial sac and the body wall. When this has been done, pass the end of a curved forceps between the posterior vena cava of each side and the corresponding lateral mantle vein, and separate the vessels without tearing them. In a similar manner separate the ink-sac from the rectum leaving intact its attachment to the anal chamber and push the ink-sac to your right. Separate the oviduct from the underlying tissues. Push the stomach pouch to the left exposing the ovary and the oviducal gland. Observe the cephalic retractors exposed to view by the previous removal of the funnel, the cesophagus and the liver between the retractors, and the two large stellate ganglia situated on the mantle under the retractors on the level of the tips of the gills. Find the single splanchnic ganglion on the rectum near its base. Make a full page drawing of all organs as exposed to view.

I9. Remove the posterior venæ cavæ and the urinary gland together with the nephridial arms of the anterior vena cava passing through them, thus exposing the systemic heart. Cut the sheet of integument which fastens the right gill (on your left) to the mantle and turn the gill so as to bring into view the branchial artery which runs from the branchial heart along the gill. Make a drawing showing the branchial hearts, the left branchial vein, the right branchial artery, the systemic heart, the base of the anterior aorta and the posterior aorta with the three mantle arteries.

20. Remove the arterial system (except the anterior aorta), branchial hearts and gills. Carefully push to the left the digestive organs, thus exposing to view the female reproductive organs. Make a drawing showing the immense ovary and the oviduct. In the latter show the first portion, the second portion or oviducal gland and the last portion with the genital opening not far from the anus. 
21. With a razor cut into the head in the median line between the eyes both above and below the buccal bulb without injuring the latter. Carefuliy remove the entire alimentary canal with its glands, allowing it to float in water on one side. Make a drawing showing the buccal bulb with the upper and lower jaw, the anterior aorta and the oesophagus with the liver through which they pass; the stomach, characterized by its thick muscular walls; the thin and large stomach pouch; the short intestine passing between the two lobes of the pancreas and the rectum with the rectal papillæ. Show also the two hepatic ducts connecting the liver with the pancreas and, if possible, the hepato-pancreatic ducts; the median salivary gland which appears as a small white body imbedded in the liver on its anterior upper surface.

22. Open the buccal bulb and remove the radula. Place it in a drop of glycerine on a slide under cover. Examine under low power and make a drawing showing the arrangement and shape of the teeth.

23. (This exercise should take the place of the two preceding ones, if the first specimen dissected was a male. In case the first specimen was a female this exercise should take the place of the fourteenth and fifteenth.) Cut off the head. Divide it in two by a quick cut with a sharp razor along the plane of symmetry. Examine the cut surface of the left half. Compare it with the text figure and make a drawing showing the cerebral, pedal, visceral and propedal ganglia; the cephalic cartilage; the buccal bulb with the upper and lower jaw and odontophore (ligula and radula).

24. Additional exercise. Open the mantle cavity of the injected specimen as in paragraph 8. Remove all organs except the gills and genital organs without disturbing or injuring the blood-vessels. The liver has to be removed bit by bit to prevent the breaking of the aorta. When the circulatory system is completely exposed make a drawing of it in color. 


\section{MOLGULA MANHATTENSIS DeKay}

Material. Molgula manhattensis is quite common along the Atlantic Coast and may be preserved by simply putting the specimens into weak formalin. Every student should receive two specimens.

\section{Descriptive Part}

Molgula manhattensis is a common representative of the Order Monascida, Class Urochorda (or Tunicata), Phylum Prochordata. How much the Tunicates have in common with the Cephalochorda and Hemichorda (Enteropneusta), the other two classes referred to the same phylum by modern zoölogists, is a matter for future investigators to decide. I for one do not think that there is much in common between these three classes. Meanwhile Molgula may be studied as a typical representative of the Tunicates.

Molgula has almost the shape of an egg. At the anterior end it is produced into a short tube-the incurrent or buccal siphon, not far from which is another short tube- the excurrent or cloacal siphon. The edge of the former has six lobes, that of the latter four lobes. The semitranslucent external wall of the animal is the tunique. It has the consistency of hard gelatine, is nothing but a very thick cuticle secreted by the hypodermis of the body wall, and is always covered with grains of sand. These sand grains are firmly attached to the tunique owing to the adhesive quality of the radicoid filaments which cover the entire surface of the tunique.

The tunic contains amœboid mesodermic cells, but these cells do not belong to it. They are immigrants from the mesenchyme. Numerous branched vascular diverticles are found in 


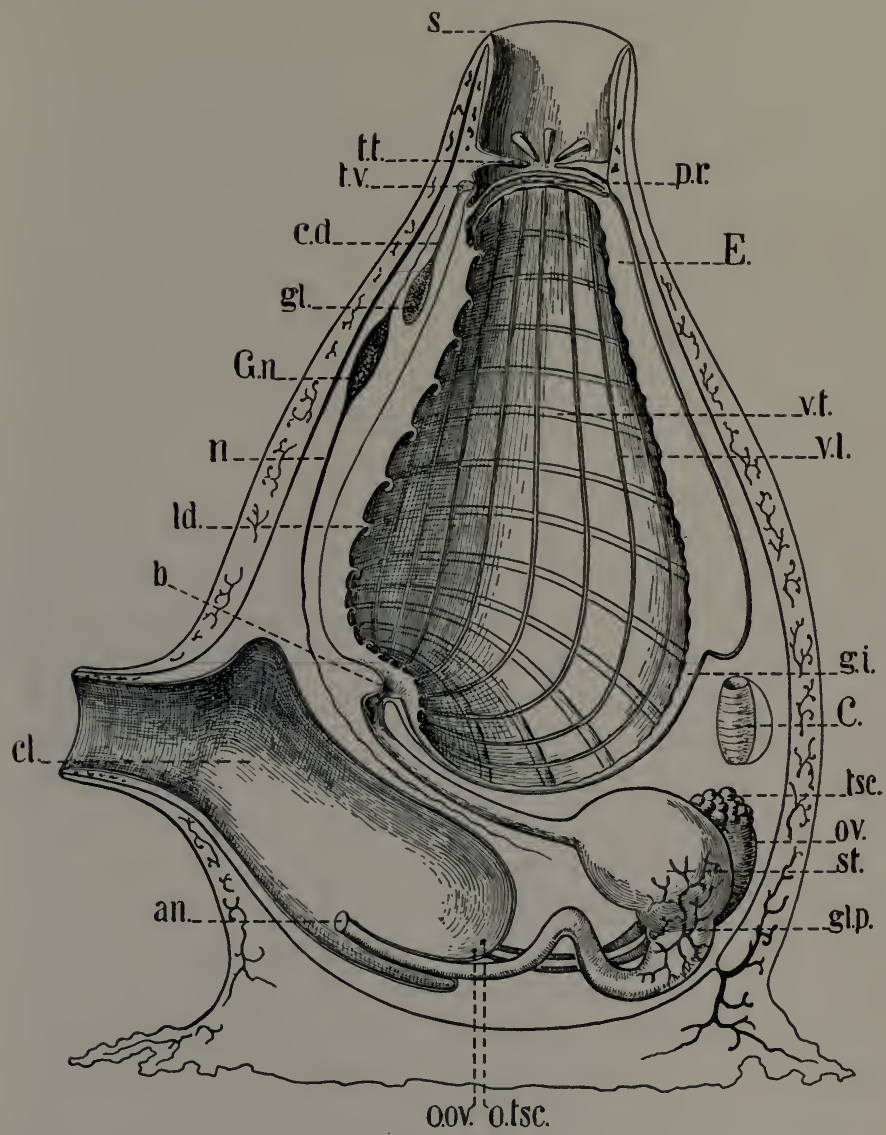

Fig. 50. - Morpholigic type of a Urochord from' ${ }^{\prime} Y$. Delage and Herouard, Zoölogie Concrète. an, anus; $b$, orifice of the osophagus; $C$, heart; $c d$, duct of the neural gland; $c l$, cloaca; $E$, endostyle; $g i$, lower groove; $g l$, neural gland; $g l p$, pyloric gland; $G n$, nervous ganglion; $l d$, dorsal notches; $n$, dorsal nervous trunk; ov, ovary; oov, orifice of the ovary; otsc, orifice of the testis; $p r$, peripharyngeal groove; $s$, buccal siphon; $s t$, stomach; $t s c$, testis; $t$, buccal tentacles; $t v$, vibratile tubercle; $v l$, longitudinal sinus; $v t$, transverse sinus. 
the wall of the tunique. They communicate directly with the schizocœle. The hypodermis (called also epidermis), which secretes the tunique, is formed by a single layer of cylindrical epithelial cells. Under the hypodermis are longitudinal and circular muscle fibres especially well developed in the siphons. The two siphons are formed by an infolding or invagination of the body wall and are lined, therefore, with a cuticle which is an equivalent of the tunic. Inside the incurrent siphon, at its base, is a crown of twelve branched tentacles. Four of these are of the first order and are so situated that two are in the plane of symmetry and two at right angles to it. The remaining eight tentacles are of the second order and much smaller than the former. These tentacles form a transverse sieve at the bottom of the siphon and undoubtedly help to keep larger foreign bodies from entering the pharynx. The excurrent siphon has no tentacles.

The plan of structure of Molgula is a strange mixture of perfect symmetry with asymmetry. The former is the original plan, apparent from the structure of the pharynx, the relative position of the nervous system and endostyle to the siphons and of the gonads to the endostyle. But the immense development of the pharynx and its peculiar function as an organ of respiration has brought about the displacement of the rest of the alimentary canal to the left side of the body and of the heart and kidney to the right side. The plane of symmetry bisects the endostyle and both siphons. The endostyle is ventral, while the nervous system, situated between the siphons, is dorsal in position.

In order to understand the structure of Molgula, one must remember that the pharynx has developed enormously at the expense of all other organs. Disregarding for a moment the siphon and cloaca, one might compare the animal to a rubber ball in which the inner space represents the pharyngeal cavity, while all the organs are in the wall. The difference lies in the fact that in Molgula this wall is not solid. The organs lie, in 
reality, in cavities reduced to mere crevices communicating with each other. These crevices represent the modified body cavity and are called schizocole. The latter should not be confused with the cavity surrounding the pharynx. This cavity, composed of a right and left half separated from each other by the adhesion of its wall along the dorsal lamina and endostyle, is called the peripharyngeal or peribranchial cavity and represents nothing but two blind sacs of the cloacal chamber. Being blind sacs they of course possess an inner and outer wall. The intestinal loop and all other organs pressed to the one or the other side of the pharynx lie in the schizocœele, to the outside of the outer wall of the peripharyngeal cavity.

Digestive system. We have seen already that the incurrent siphon leads into an enormous pharynx and that the passage to the latter is protected by a transverse sieve formed by twelve branched tentacles. The pharynx is a very complicated organ which functions both as pharynx and gill, and it presents many peculiar structures. There is, not far from the tentacular sieve, a circular ciliated peripharyngeal groove formed by two circular ridges. The endostyle, the dorsal lamina and the six pairs of pharyngeal ridges begin at this groove. The dorsal lamina is a straight ridge running in the mid-dorsal line from the peripharyngeal groove to the opening of the œsophagus. The endostyle begins at the opposite pole of the peripharyngeal groove and runs in the mid-ventral line to within a short distance from the opening of the œsophagus. The endostyle is a deep ciliated groove formed, like the peripharyngeal groove by two ridges. Each ridge has three ciliated bands separated from each other by simple epithelial cells. The cells at the bottom of the groove possess extraordinarily long cilia which reach beyond the edges of the ridges. Between the end of the endostyle and the œsophagus is a fine inferior groove. Starting from the peripharyngeal groove and evenly interspaced between the dorsal lamina and the endostyle are six pairs of pharyngeal ridges which end in the inferior groove. They are curved in the same sense as the 
endostyle, but the ventral pair is much more curved than the dorsal pair. The ridges are perforated by openings called stigmata. The stigmata establish a direct communication between the pharynx and the cloacal chamber by way of the peripharyngeal (or peribranchial) cavity into which they open. There is also a ciliated vibratile tubercle, or better, ridge, in shape an incomplete oval with involuted ends, situated between the peripharyngeal groove and the tentacle sieve above the starting point of the dorsal lamina. It surrounds the opening of the adneural gland. As will be shown later, the pharynx is rich in blood-sinuses. As water is drawn into the pharynx through the incurrent siphon, the food particles pass into the œsophagus, driven thither by the action of the endostyle, while the water enters the peribranchial cavity through the stigmata and is again expelled through the cloacal siphon. The opening from the pharynx into the œsophagus is a small oval. It is situated at the lower extremity of the dorsal lamina. The osophagus is quite short and is considerably constricted at the place where it opens into the stomach. A digestive gland composed of several tubular lobes and known under the name of liver opens into the stomach near its cardiac end. The stomach is a curved, U-shaped tube of considerable diameter. It runs first downward and forward and then upward. Here the canal changes its course and structure. It becomes the intestine and runs in an opposite direction to the stomach, dorsal to it, first downward and backward, then upward. The anus opens into the cloacal chamber in the mid-dorsal line.

Excretory system. Molgula has no excretory organs comparable to those of other invertebrates. Waste products are stored in a bean-shaped kidney which is situated on the right side of the animal and is devoid of any duct or opening. There is another organ of unknown function which is supposed to be an organ of excretion. This is the adneural gland, ${ }^{1}$ situated dorsal to the nervous ganglion between the two siphons. The duct of the

${ }^{1}$ Usually called subneural. 
gland opens into the pharynx. The opening is surrounded by the ciliated ridge called the vibratile tubercle.

Circulatory system. The heart is an elongated organ situated in the pericard on the right side of the animal between the right reproductive gland and the kidney. It has no valves and the direction of its peristaltic pulsation alone controls the direction of the blood-current. It is a remarkable fact characteristic of Tunicates that the direction of the pulsation and with it that of the blood-current, changes periodically. The blood flows in both cases out of the heart into the vascular sinuses and returns to the heart by way of the opening opposite to the one by which it left it. Although the sinuses are lacking a wall of their own, so that the blood circulation is an open one, yet they are more or less highly differentiated and almost play the rôle of real bloodvessels. The most important among them are the ventral sinus, the pericoronal sinus, and the branchial sinuses. The blood is colorless and contains amœbocytes.

Nervous system. The nervous system consists of a simple ganglion situated below the adneural gland between the two siphons. Special sense organs are lacking.

Reproductive system. Molgula is a hermaphrodite. It has a pair of ovaries and a pair of testes. The ovary and testis of the same side of the body are so closely applied to each other that they produce the impression of a single gland. Nevertheless each ovary has its own oviduct and each testis its own sperm duct. The latter is a much thinner tube and runs in contact with the corresponding oviduct. The glands themselves are situated on the sides of the animal, those of the left side in the loop of the intestine, those of the right side above the heart. The genital openings are situated in the cloacal chamber somewhat above the anus.

\section{Instructions}

I. Place a Molgula in a dissecting tray with water, with the anterior siphon directed away from you and the posterior siphon 
to your left. Make a drawing showing tunic, anterior or incurrent siphon, posterior or excurrent siphon, dorsal surface between the siphons and attachment area on opposite surface, also external tentacles of siphons if not withdrawn (six incurrent, four excurrent).

2. Remove tunic by making an incision with scissors and tearing it apart with the aid of two strong forceps. Make a drawing of the right side. Label circular and longitudinal muscles on both siphons; the ganglion half way between the siphons; the hermaphroditic gland lying across the body; the more or less bean-shaped and transparent excretory organ under hermaphroditic gland; the heart between them; the endostyle (a white line along right edge of animal, ending in a circular peripharyngeal groove); the brown liver on left, extending to the edge of the animal.

3. Make a drawing of the left side of the same specimen. Label ganglion; endostyle; liver, œsophagus (a short tube between the lobes of the liver); stomach, intestine and left hermaphroditic gland with duct.

4. Support the specimen between two pins stuck into the bottom of the tray and place it so that the incurrent siphon would be directed away from you and the excurrent siphon above it, presenting its sides symmetrically, with the plane of symmetry at right angles to the bottom of the tray. Make a drawing showing all organs which are visible in this position, and label anus, intestine, stomach, liver, œsophagus, both hermaphroditic glands, edge of pharynx, and endostyle.

5. Remove the right body wall, exposing the wall of the pharynx and cloacal chamber. The operation is somewhat delicate and care must be taken not to cut through the wall of the pharynx. The right hermaphroditic gland, the heart and the kidney should be removed together with the body wall. Make a drawing showing peripharyngeal ridges with the stigmata; cloacal chamber with anus and left genital opening in the depth; liver; proximal end of œesophagus and valve separating it from the pharynx; endostyle. 
6. Open the pharyngeal cavity by cutting through the wall of the pharynx. Begin the cut below the liver, continue along the endostyle and finish at the base of the cloacal siphon. Make a drawing showing: endostyle; peripharyngeal groove; dorsal lamina extending to the opening of the œsophagus; crown of inner tentacles at base of the incurrent siphon; opening of pharynx into œsophagus; pharyngeal ridges terminating in the peripharyngeal ridge and converging toward the œsophageal opening; volute-shaped adneural gland and, above it, the ganglion.

7. With sharp scissors cut a specimen from which you have removed the tunic, transversely a little way below the siphons. Make a drawing of the cut surface of the part with the siphons, looking into the pharyngeal cavity. Label body wall; pharynx; peripharyngeal cavity; pharyngeal ridges, peripharyngeal groove; vibratile tubercle; ganglion; endostyle; dorsal lamina; incurrent siphon with four branched tentacles of the first order and eight of the second forming a sieve. 

THE following pages contain advertisements of a 1 few of the Macmillan books on kindred subjects

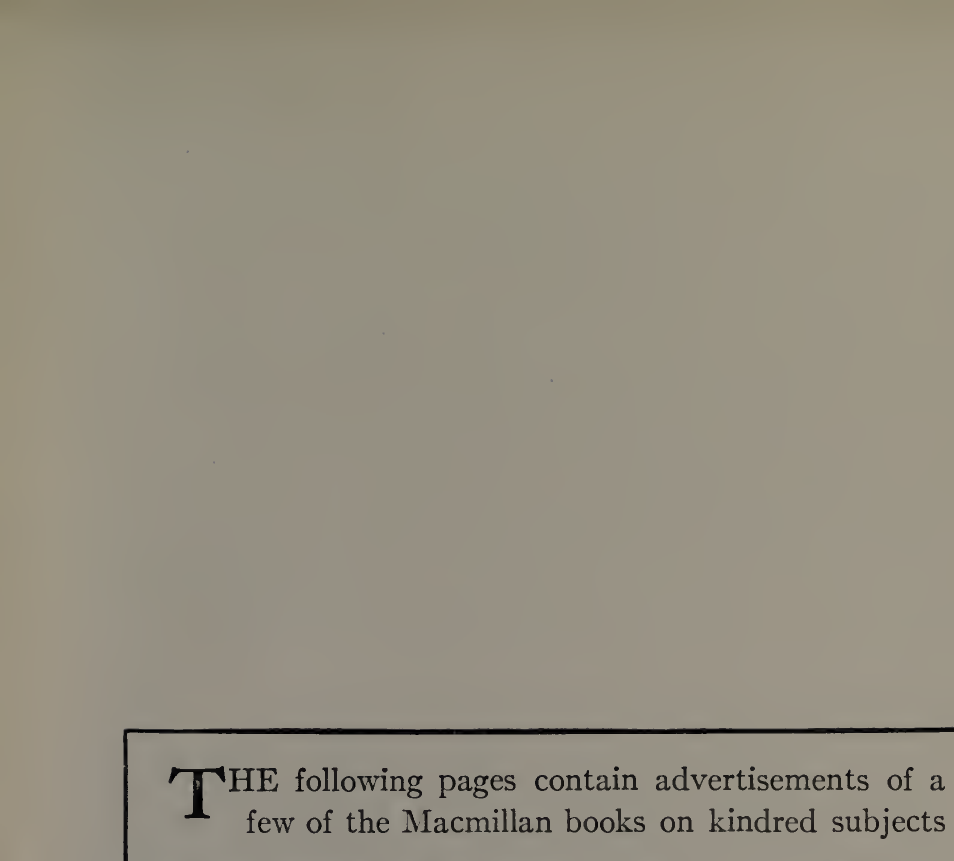





\title{
An Introduction to Zoölogy
}

\author{
By
}

ROBERT W. HEGNER, Ph.D.

Assistant Professor of Zoölogy in the University of Michigan

\section{A TEXT-BOOK INTENDED FOR THE USE OF STUDENTS IN COLLEGES AND UNIVERSITIES}

Ilustrated, $12 \mathrm{mo}, \$ 1.90$

"There are some interesting distinctive features in this new introduction to zoölogy. Only a few types are studied (all of them Invertebrates); they are discussed so as to illustrate the principles of the science; the morphological aspect is not especially emphasized, but is coördinated with the physiological aspect (which, of course, includes the study of interrelations and behavior)."

"The author shows a keen educative instinct; there is a marked freshness and individuality of treatment, and the assistance of a number of experts, who have read particular chapters, has secured an enviable freedom from mistakes. There is a very useful bibliography, and a glossary."

"It is a work which it has been a pleasure to read, and which deserves a career of much usefulness."

- Nature.

"The book is cordially recommended as giving a thorough preparation for advanced courses in the subject."

$$
\text { - American Journal of Science. }
$$

"The attempt is made to present the newer zoölogy to the beginner. Here we find the figures of Jennings, Yerkes, Morgan - in fact, it may be called an American product from cover to cover. Consequently, the student finds himself at home at once among American forms and American names. It is not to be understood, however, that the view is circumscribed and that the data from foreign sources are eliminated."

"It may be said that the result is excellent in the light of the labor set before the author. The book-making is good, the illustrations are carefully selected, and there is a unity in the volume which appeals very strongly to the reviewer."

- Science.

\section{THE MACMILLAN COMPANY

Publishers 64-66 Fifth Avenue New York




\title{
College Zoölogy
}

\author{
By ROBERT W. HEGNER, Ph.D. \\ Assistant Professor of Zoölogy in the University of Michigan
}

Illustrated, Cloth, $12 \mathrm{mo}$, xxiv +733 pp., $\$ 2.60$

A text-book in which physiology is correlated with morphology by describing the most important structural features of the various types of animals and by also pointing out the vital phenomena as expressed in the functions of the organs. Every phylum in the animal kingdom is introduced by an account of the anatomy, physiology, ecology and economic importance of one or more types. Furthermore, the animals in each phylum are compared with those of nearly related phyla so as to afford the student a realization of the unity as well as of the variety in animal life, and the types selected are common native species which can be obtained for direct observation in the laboratory.

The work is progressive and up to date, even such recent topics as the work on the hookworm in the United States being considered.

\section{THE MACMILLAN COMPANY \\ Publishers 64-66 Fifth Avenue New York}




\section{Experimental Morphology}

By CHARLES BENEDICT DAVENPORT, Ph.D., Director of the Biological Laboratory of the Brooklyn Institute of Arts and Sciences

491 pp., I11., 8vo, $\$ 3.50$

Why does an organism develop as it does?

This is the problem with which this book is concerned. The work is intended to serve as an introduction and guide to the study and development of the individual regarded as a complex of processes rather than a mere succession of different forms. The central idea of the work is that ontogeny is a series of reactions to chemical and physical agents.

\section{The Germ-Cell Cycle in Animals}

By ROBERT W. HEGNER

Assistant Professor of Zoology in the University of Michigan, author of "An Introduction to Zoölogy," and "College Zoölogy."

346 pp., Ill., $12 \mathrm{mo}, \$ 1.75$

An excellent survey of a subject which is extremely important to all biologists and a book available for use as a supplementary text in courses on Cellular Biology, Evolution, Heredity, and Genetics. The term "GermCell Cycle" is meant to include all those phenomena concerned with the origin and history of the germ cells from one generation to the next generation. Contrary to the usual custom, the period of the germ-cell cycle which is emphasized in this book is not the maturation of the germ cells, but the segregation of the germ cells in the developing egg and the visible substances (keimbahndeterminants) concerned in this process.

\section{THE MACMILLAN COMPANY \\ Publishers 64-66 Fifth Avenue New York}




\section{A Text-Book of Botany for Colleges}

\section{By WILLIAM FRANCIS GANONG,}

Professor of Botany in Smith College

Part I, The Structures and Functions of Plants. Illustrated

This work embodies the results of the author's well-known interest in educational problems, and his long practical experience in botanical teaching. It is intended for college students in the general or introductory courses in botany. While a clear exposition of the fundamental facts of the science is the first aim, the effort is also made to keep prominent the idea of interpretation or explanation of the principles of botanical phenomena, particularly those which are frequently met with. The economic aspects of botany receive careful consideration in conjunction with the scientific phenomena which respectively underlie them. In order that the professor who is using the book may be enabled to continue the type of laboratory work which he has found adapted to his particular situation, the book is prepared in the form of semi-independent sections, each of which deals with a leading topic. This method of treatment will also make the book desirable for the general reader who is interested in the subject of botany and who finds the prevailing form of text inconvenient for reference.

\section{THE MACMILLAN COMPANY Publishers 64-66 Fifth Avenue New York}







